\title{
Data Mining no Processo \\ de Extração de Conhecimento \\ de Bases de Dados ${ }^{1}$
}

\author{
Luis Carlos Molina Félix
}

Orientação:

Profa. Dra. Solange Oliveira Rezende

Dissertação apresentada ao Instituto de Ciências Matemáticas e de Computação - USP, como parte dos requisitos para a obtenção do título de Mestre em Ciências - Área: Ciências de Computação e Matemática Computacional.

$$
\text { USP - São Carlos }
$$

Agosto de 1998

1 Trabalho realizado com apoio do Instituto Mexicano do Petróleo e do projeto de Redes Cooperativas d Pesquisa / FINEP do Brasil 
Dedicatória

A meus pais, Hortencia e Carlos. 


\section{Agradecimentos}

A minha orientadora Profa. Dra. Solange Oliveira Rezende, pela sua dedicação, apoio e por todo conhecimento transmitido durante estes dois anos, além do empenho no processo de elaboração e revisão desta dissertação.

À Profa. Dra. Maria Carolina Monard pelo apoio recebido neste trabalho, principalmente na seleção do método para classificar os algoritmos de Aprendizado de Máquina e no estudo de caso utilizando uma base de dados petroleira.

Ao Prof. Dr. Carlos André Ponce de Leon Ferreira de Carvalho pela ajuda recebida durante estes dois anos.

A meus amigos Chandler W. Caulkins, Paulo C. S. de Oliveira, Mirla P. Freire, Márcia R. de Carvalho, Ana Elisa T. Piekarski, Ernesto C. Vargas, Juliana de Oliveira, Luis A. C. de Araujo, Luciano J. Senger, Cristina Endo, Adriana M. Centurion, Fabiano Fagundes, Rudinei Goularte, Maristela O. dos Santos, Patrícia T. Leite, Marisa B. Figueiredo, Sissy E. A. Iamasaki, Cláudio A. J. da Rocha, Thereza Padilha, Paulo S. Horst, Aleteia P. F. de Araujo, Robson T. de Oliveira, Marcos R. Geromini, José A. Baranauskas, Marcos S. Kutova, Luciana F. Martimiano, Tatiana Sugeta, Thelma E. Colanzi, Valeria D. Feltrim, Claudia R. Milare, Gustavo Batista e Ricardo Hasegawa pela amizade e disposição em todo momento.

A meus amigos Marcos F. de Paula e Luiz F. Figueiredo pela dedicação ao projeto de iniciação científica que foi incorporado ao projeto de mestrado.

Ao Prof. Dr. Raysildo Lobô e a Antônio do N. Rosa pelas informações referentes ao Programa de Melhoramento da Raça Nelore utilizada nesta dissertação.

A Beth, Laura, Marilia e Andressa pelo apoio administrativo durante este período.

A minha amiga Jaqueline Brigladori Pugliesi pela ajuda na revisão desta dissertação.

A Maria José Romanatto e Ana Dilei Romanatto pela ajuda prestada.

A meus amigos Daniel F. N. de Oliveira e Laércio A. Baldochi Jr. pelos dois anos compartilhando a mesma moradia.

No México, ao Dr. Enrique Bazúa, Dr. Javier Tejeda, Eng. Felipe Beltrán e Alma Corona pelo apoio incondicional neste período.

Ao Instituto Mexicano do Petróleo e ao Conselho Nacional de Pesquisa Nacional de Desenvolvimento Científico e Tecnológico do Brasil pelo financiamento dos estudos que envolveram o projeto de mestrado.

A Naiara e Antonio pelo apoio recebido neste trabalho.

A Sabrine pela sua compreensão e amor.

A todos eles, do fundo do meu coração...

MUITO OBRIGADO. 


\section{Resumo}

Nesta última década, houve um grande crescimento na capacidade de gerar e coletar dados, devido principalmente a três fatores: primeiro, ao constante aumento do poder de processamento dos computadores; segundo, ao armazenamento contínuo de grande quantidade de dados a um baixo custo; e por último, à introdução de novas e melhores tecnologias relacionadas ao processamento e transmissão de dados. Embora os gerenciadores de bases de dados forneçam ferramentas básicas para otimizar o armazenamento e busca em grande quantidade de dados, o fato de como ajudar os humanos a entender $e$ analisar estas grandes estruturas de dados é um problema de difícil solução. Nesse contexto, o Processo de Extração de Conhecimento de Bases de Dados (Knowledge Discovery in Databases - KDD) emerge como uma nova tecnologia orientada à compreensão e busca de conhecimento embutido dentro destas grandes massas de dados, fazendo uso, principalmente, de várias técnicas apoiadas na estatística, bases de dados, ferramentas de visualização e Aprendizado de Máquina.

De um modo geral, o processo KDD é composto de várias etapas, partindo da definição do domínio, um pré-processamento dos dados, uma etapa de Data Mining (Mineração de Dados) e, finalmente, uma análise e interpretação do conhecimento obtido. Este trabalho visa compreender e delimitar as diferentes etapas dentro do processo $\mathrm{KDD}$, analisando o papel da etapa de Data Mining dentro deste processo. Dois estudos de casos (uma base de dados petroleira e uma base de dados do Programa de Melhoramento Genético da Raça Nelore) foram realizados para este fim. Este trabalho aborda importantes aspectos, principalmente quanto à relevância da discretização de dados contínuos na obtenção de melhores regras de classificação, além de mostrar o processo $\mathrm{KDD}$ em uma base de dados real, destacando a problemática encontrada e a importância da presença do especialista do domínio para o êxito deste processo. 


\begin{abstract}
In the last decade, there has been a large growth in the capacity to generate and collect data, mainly due to three factors: first, the constant increase in the processing power of computers; second, the continuing storage of a large quantities of data at low costs; and last, the introduction of new and better technologies related to processing and transmitting data. Although database management systems offer basic tools for optimizing the storing and searching in large quantities of data, it is still difficult to help humans understand and analyze these large data structures. In this context, the process of Knowledge Discovery in Databases - KDD - has emerged as a new technology oriented towards comprehending and searching for knowledge intrinsic to these large masses of data, mostly by using various techniques based on statistics, databases, visualization tools and Machine Learning.
\end{abstract}

Generally speaking, the KDD process is composed of various phases, starting with the definition of the domain, pre-processing the data, a phase of Data Mining and, finally, analyzing and interpreting the knowledge that was obtained. This work tries to comprehend and separate the different phases in the KDD process, analyzing the role of the Data Mining phase in this process. Two case studies (one of a petroleum database and another of a database for the Program of Genetic Improving for the Nelore Breed) were made to emphasize this point. This work also looks at some important aspects, such as the relevance of discretizing continuous data so as to obtain better classification rules, as well as showing the KDD process applied to a real database, indicating the problems that were found and the importance of the presence of a domain expert for this process to be successful. 


\section{ÍNDICE}

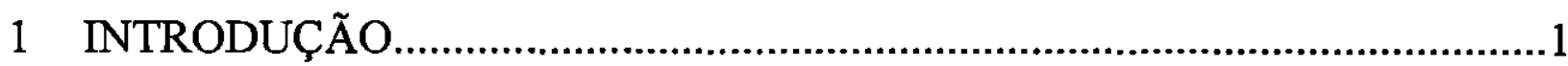

2 EXTRAÇÃO DE CONHECIMENTO DE BASES DE DADOS .......................

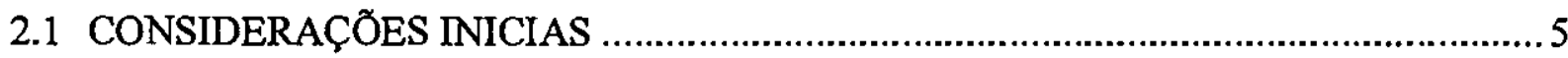

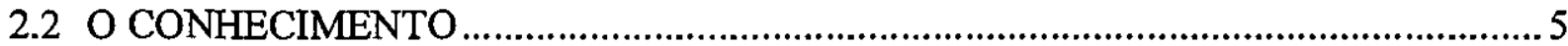

2.3 PROCESSO DE EXTRAÇÃO DE CONHECIMENTO DE BASES DE DADOS...........7

2.4 ETAPAS DO PROCESSO DE EXTRAÇÃO DE CONHECIMENTO DE BASES DE DADOS

2.4.1 Definição e Compreensão do Dominio .............................................................. 8

2.4.2 Seleção e/ou Criação das Bases de Dados........................................................ 9

2.4.3 Compreensão dos Dados ............................................................................. 9

2.4.4 Seleção das Amostras mais Representativas ........................................................ 11

2.4.5 Enriquecimento do Conjunto de Dados .......................................................... 12

2.4.6 Limpeza do Conjunto de Dados................................................................... 12

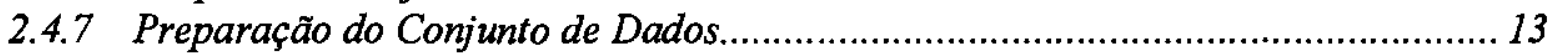

2.4.8 Data Mining....................................................................................... 14

2.4.9 Avaliação do Conhecimento Descoberto …………............................................. 16

2.4.10 Consolidação e Utilização do Conhecimento Extraído ........................................ 16

2.5 ELEMENTOS DE APOIO AO PROCESSO DE EXTRAÇÃO DE CONHECIMENTO

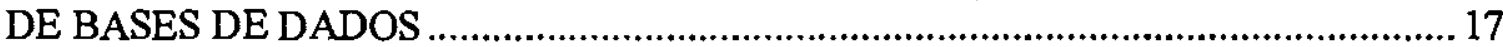

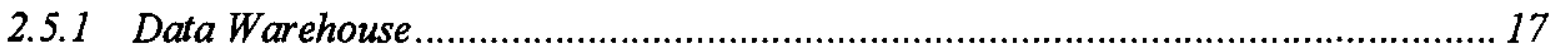

2.5.2 Métodos Estatísticos no Tratamento dos Dados.................................................. 19

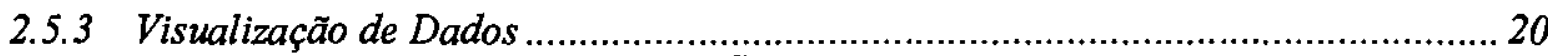

2.6 FLUXO DO PROCESSO DE EXTRAÇÃO DE CONHECIMENTO DE BASES DE

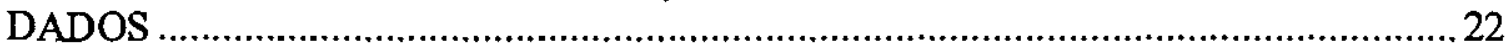

2.7 ALGUNS PROBLEMAS RELACIONADOS COM O PROCESSO DE EXTRAÇÃO

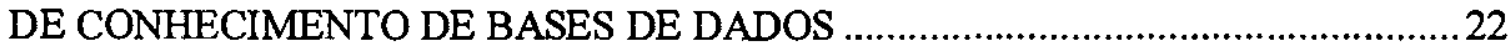

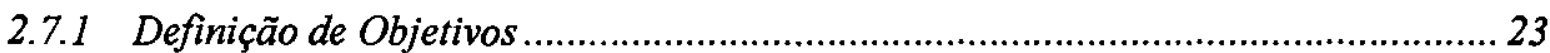

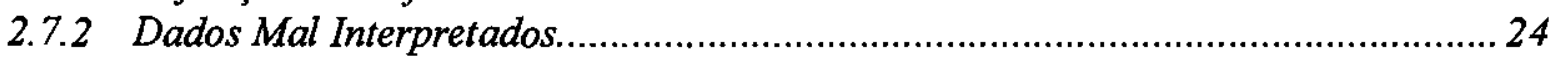

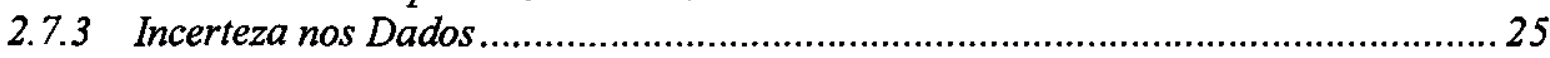

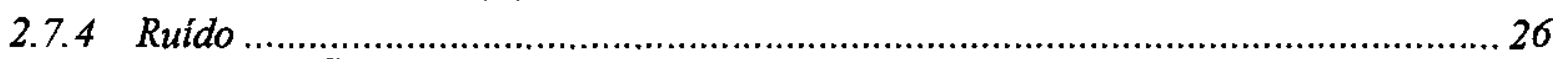

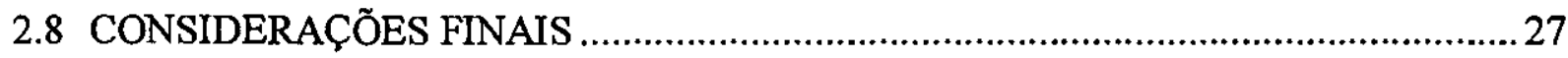

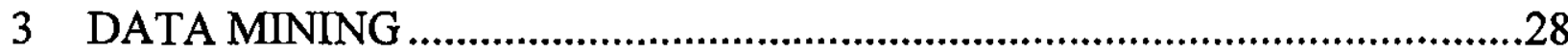

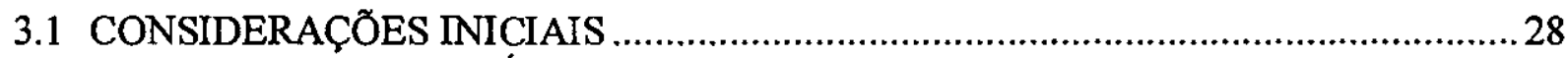

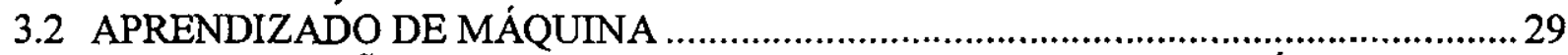

3.3 CLASSIFICAÇÃO DOS ALGORITMOS DE APRENDIZADO DE MÁQUINA …..... 30

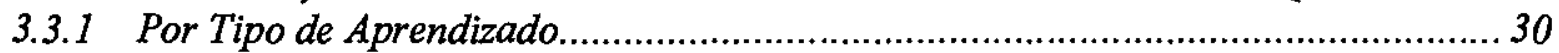

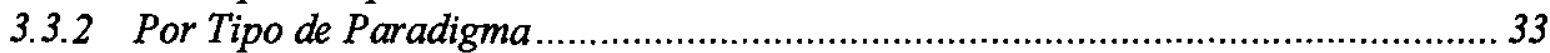

3.3.3 Por Tipo de Linguagens de Descrição .................................................................. 34

3.3.4 Por Tipo de Formalismos para Descrever Casos.............................................. 35

3.3.5 Por Modo de Integrar Novos Exemplos ............................................................. 39

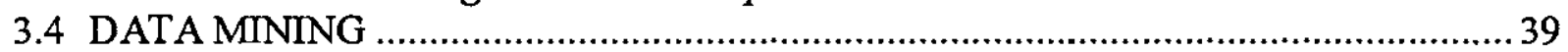

3.4.1 O Conjunto de Treinamento e de Teste ........................................................... 40

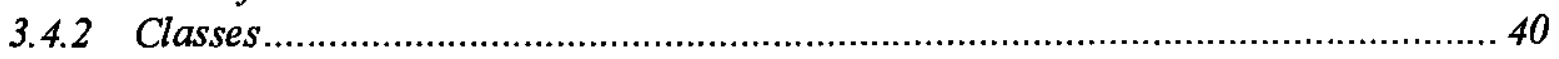

3.4.3 Método de Resampling Cross-Validation........................................................... 42 
3.4.4 Aprendizado de Máquina versus Data Mining ................................................ 42

3.5 ALGUNS PROBLEMAS RELACIONADOS A DATA MINING ..............................44

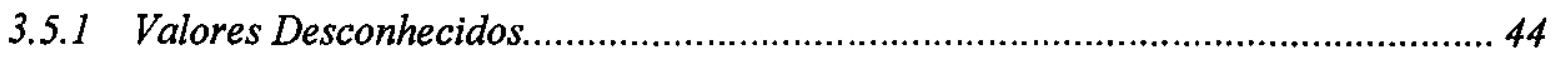

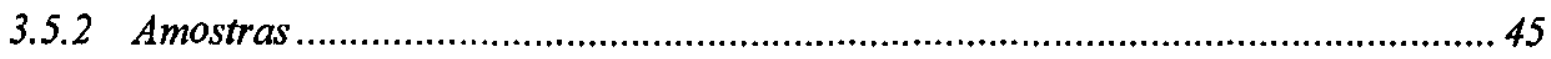

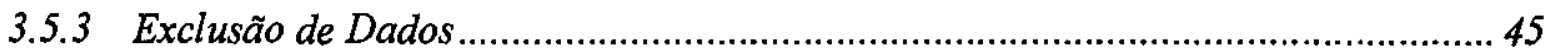

3.5.4 Tamanho das Bases de Dados .......................................................................... 46

3.5.5 Atualizações Constantes das Bases de Dados .................................................... 47

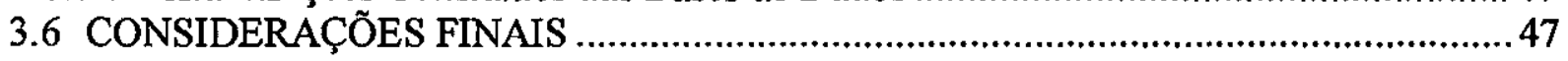

4 FERRAMENTAS UTILIZADAS.....................................................49

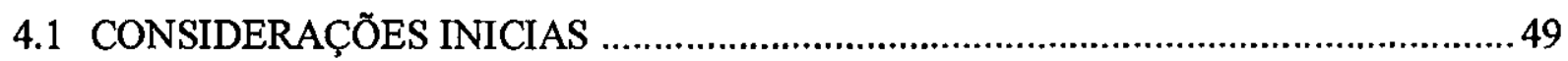

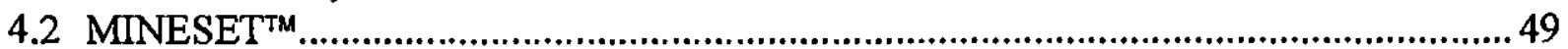

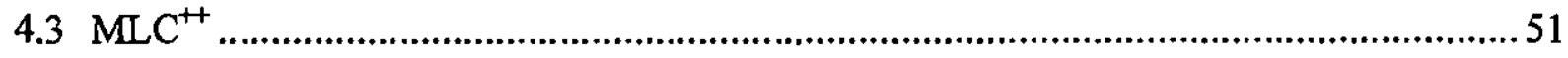

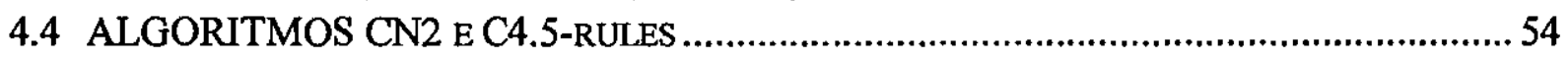

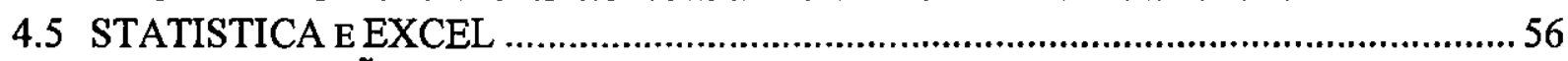

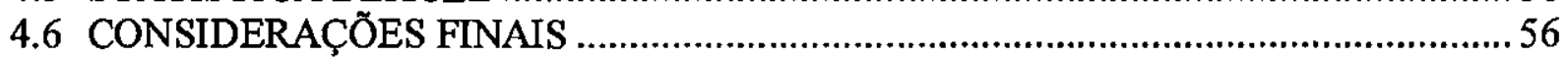

5 ESTUDO DE CASO 1 - BASE DE DADOS PETROLEIRA........................57

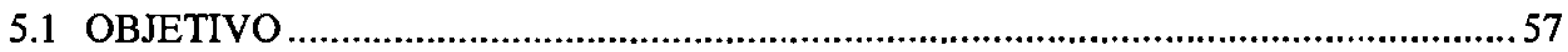

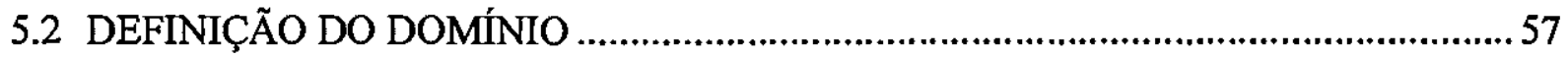

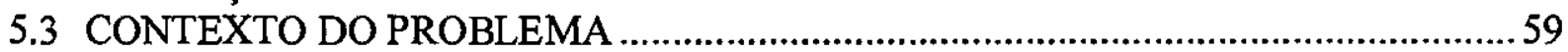

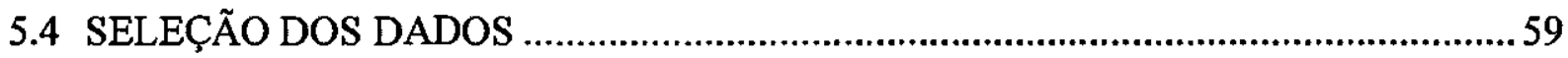

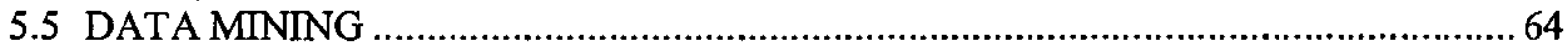

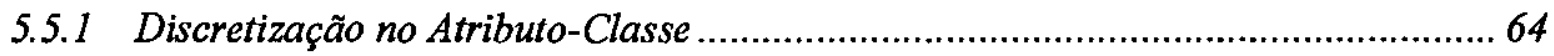

5.5.2 Comparação entre os Métodos de Discretização ................................................ 66

5.5.3 Resultados Usando os Algoritmos Simbólicos de Aprendizado de Máquina ........... 69

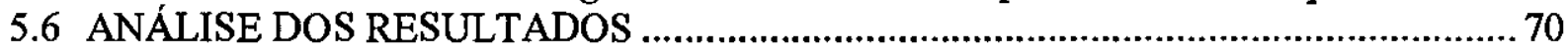

6 ESTUDO DE CASO 2 - BASE DE DADOS DO GADO NELORE .............73

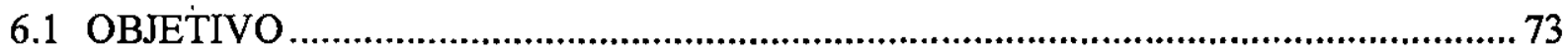

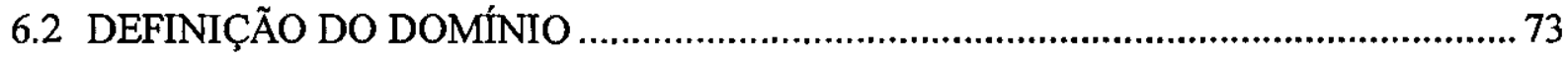

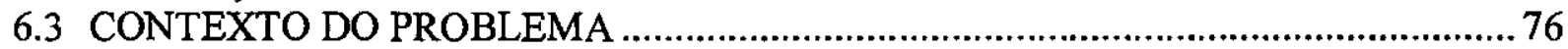

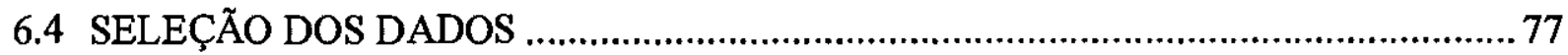

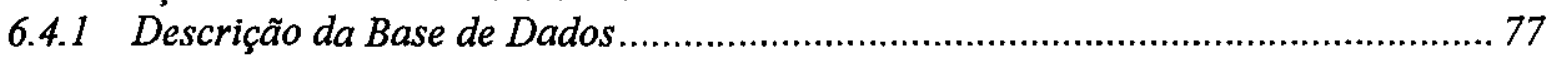

6.4.2 Criação da Base de Dados para Definir o Grupo Contemporâneo ........................ 77

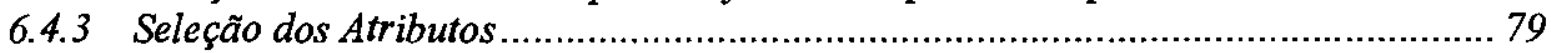

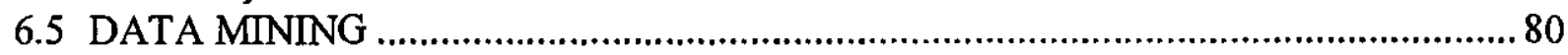

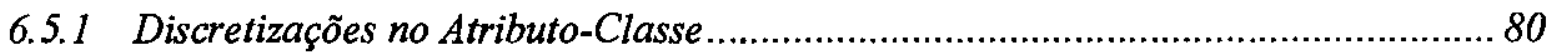

6.5.2 Resultados da Seleção de Atributos Relevantes............................................. 82

6.5.3 Uso da Ferramenta Tree Visualizer.............................................................. 84

6.5.4 Resultados Usando os Algoritmos Simbólicos de Aprendizado de Máquina........... 85

6.6 ANÁLISE DOS RESULTADOS ...................................................................... 87

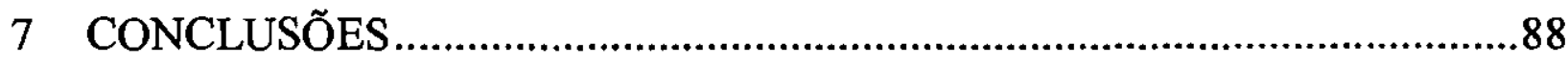

A TAXAS DE ERRO DO ESTUDO DE CASO $1 \ldots \ldots \ldots \ldots \ldots \ldots \ldots \ldots \ldots \ldots \ldots \ldots . . \ldots \ldots 1$

B MATRIZES DE CONFUSÃO DO ESTUDO DE CASO 1 ......................93 
C SAIDA GERADA PELO ALGORITMO C4.5-RULES NO ESTUDO DE

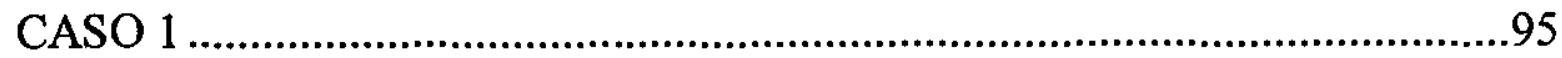

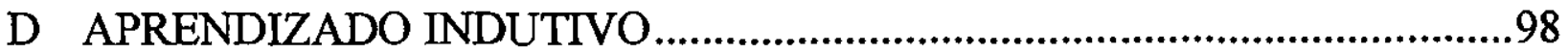

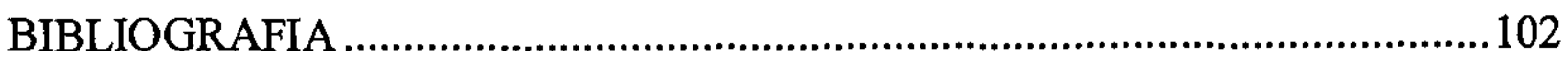




\section{LISTA DE FIGURAS}

Figura 1.1: O Crescimento das Bases de Dados. .1

Figura 2.1: Pirâmide do Processo de Conhecimento...............................................................6

Figura 2.2: Etapas Envolvidas no Processo KDD................................................................ 8

Figura 2.3: Fontes de dados que alimentam as bases de dados............................................... 9

Figura 2.4: Exemplo de compreensão dos dados. .............................................................. 10

Figura 2.5: Gráfico para compreender melhor os dados..................................................... 11

Figura 2.6: Exemplo de enriquecimento do conjunto de dados............................................ 12

Figura 2.7: Exemplo de eliminação de registros duplicados. ............................................... 13

Figura 2.8: Exemplo de preparação de um conjunto de dados. ............................................... 14

Figura 2.9: Exemplo de uma base de dados multidimensional. ............................................... 18

Figura 2.10: Mapa gerado através do MineSet. .................................................................. 21

Figura 2.11: Fluxo de dados em um processo KDD. ........................................................ 23

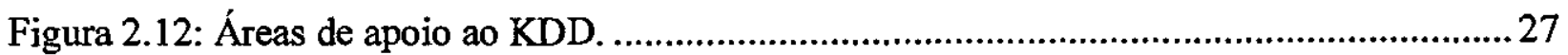

Figura 3.1: Uma forma de classificar os algoritmos de Aprendizado de Máquina..................... 31

Figura 3.2: Descobrindo clusters e descrições em um conjunto de dados. ............................... 32

Figura 3.3: Uma simples árvore de decisão.................................................................... 35

Figura 3.4: Representação de uma rede semântica...........................................................38

Figura 3.5: Representação de um frame. ......................................................................... 38

Figura 3.6: Regras de classificação de aprendizado a partir de um conjunto de dados. ............. 41

Figura 3.7: Diagrama de Aprendizado de Máquina. ...........................................................43

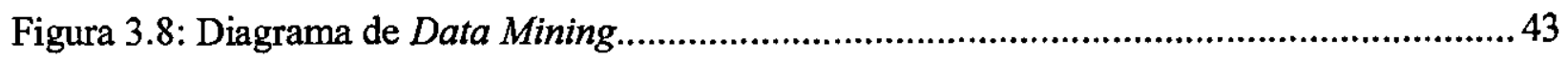

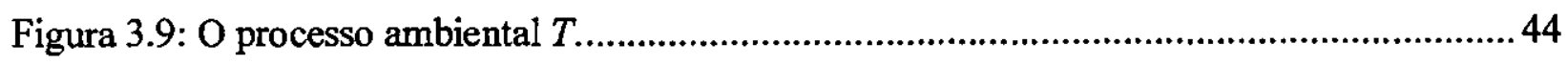

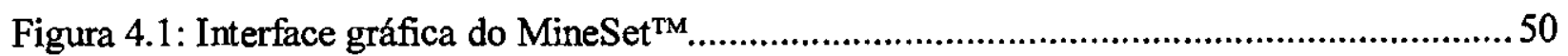

Figura 4.2: Componentes básicos do software MineSet ${ }^{\mathrm{TM}}$.................................................... 51

Figura 4.3: Interação entre indutor, categorizador, a etapa de teste e wrapper. ........................53

Figura 5.1: Interação entre um algoritmo de discretização, um algoritmo de AM e diversos tipos

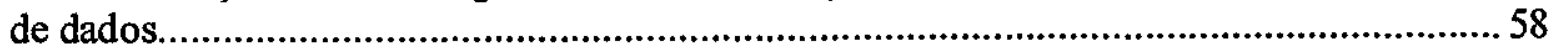

Figura 5.2: Informação dos seis poços (1084 registros em total)........................................60 
Figura 5.3: (a) Visualização da permeabilidade com um erro detectado no poço 1705; (b)

Permeabilidade após ter sido corrigida. 62

Figura 5.4: (a) Visualização da porosidade com um erro detectado no poço 1705; (b) Porosidade após ter sido corrigida.

Figura 5.5: Resultados estatísticos dos seis poços usando Statistics Visualizer (982 casos)........63

Figura 5.6: Informação dos seis poços após limpeza dos dados (982 casos em total)................64

Figura 5.7: (a) Distribuição de 2, 3 e 5 discretizações usando o método stand-alone. (b)

Distribuição de 2, 3 e 5 discretizações baseadas nas considerações do especialista do domínio.

Figura 5.8: Distribuição de freqüência para os valores de "permeabilidade" no poço $1702 . . . . . .668$

Figura 5.9: Taxa de erro apresentada pelos algoritmos CN2 e C4.5-rules fixando o limite

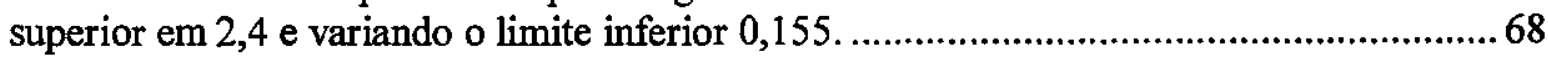

Figura 5.10: Taxa de erro apresentada pelos algoritmos CN2 e C4.5-rules fixando o limite inferior em 0,155 e variando o limite superior 2,4 .

Figura 6.1: Diagrama das interrelações entre o meio ambiente e o animal. ............................. 74

Figura 6.2: Estratégia para criar uma nova base de dados................................................. 79

Figura 6.3: Distribuição dos valores da DDPE550 na (a) discretização 1; (b) discretização 2;

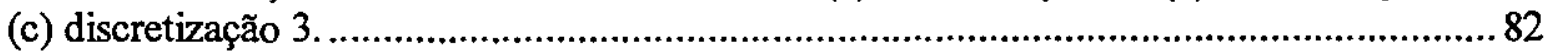

Figura 6.4: Árvore de decisão gerada através de Tree Visualizer........................................ 84

Figura 7.1: Modelo proposto para o processo de Extração de Conhecimento de Bases de Dados.

Figura 7.2: Modelo clássico para o processo de Extração de Conhecimento de Bases de Dados

[Fayyad 96c] 89

Figura D.1: Modelo interno que representa transições no ambiente. ................................... 100

Figura D.2: A busca iterativa para determinar o melhor modelo.................................... 101 


\section{LISTA DE TABELAS}

Tabela 2.1: Notação para indicar um conjunto de dados.................................................... 15

Tabela 2.2: Características de OLTP e OLAP................................................................... 19

Tabela 2.3: Áreas de Trabalho da Estatística. ....................................................................... 20

Tabela 2.4: Número de sobreviventes e mortes ocorridas no hospital. ...................................24

Tabela 2.5: Dados fictícios coerentes com os dados de Wen. ...............................................25

Tabela 2.6: Proporção de mortes dentro do hospital para os dados fictícios da Tabela 2.5. ....... 25

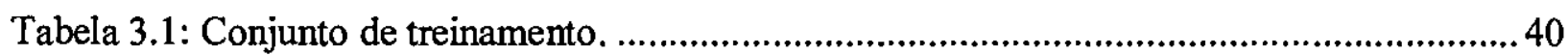

Tabela 5.1: Resultados estatísticos dos seis poços petroleiros..............................................61

Tabela 5.2: Distribuição da permeabilidade de valores zero e $<0,01$..................................... 61

Tabela 5.3: Erro detectado e corrigido através da visualização no poço 1705 ........................... 63

Tabela 5.4: Descrição estatística dos seis poços (982 casos).................................................63

Tabela 5.5: Intervalos obtidos pelos dois primeiros métodos de discretização. .......................... 65

Tabela 5.6: Taxa de Erro para o Cenário 1 ..........................................................................66

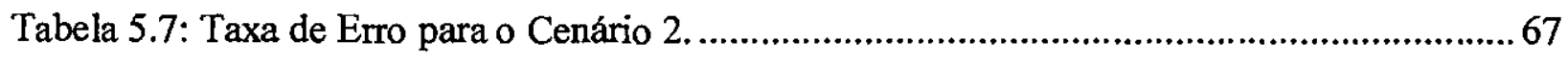

Tabela 5.8: Taxa de Erro para o Cenário 3 ............................................................................6 67

Tabela 5.9: Matriz de confusão para o Cenário 2 usando conjunto de teste A com 3 discretizações baseado no método sugerido pelo especialista de domínio. ........................6 67

Tabela 5.10: Comparação entre a discretização sugerida pelo especialista de domínio e a discretização híbrida.

Tabela 6.1: Descrição da base de dados do PMGRN.......................................................... 77

Tabela 6.2: Descrição dos atributos da base de dados do PMGRN. .......................................... 78

Tabela 6.3: Descrição das informações da nova base de dados............................................ 79

Tabela 6.4: Descrição do arquivo gerado considerando o grupo contemporâneo nascidos em

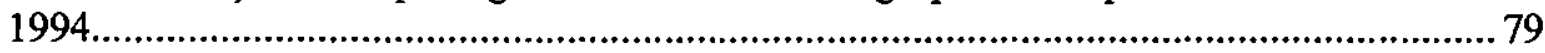

Tabela 6.5: Descrição do conjunto de dados utilizados no MineSet ${ }^{\mathrm{TM}}$. ..................................80

Tabela 6.6: Resumo dos cálculos estatísticos do conjunto de dados selecionado. ......................81

Tabela 6.7: Descrição das Discretizações do atributo-classe DDPE550 ..................................81

Tabela 6.8: Precisão dos algoritmos nas três formas de discretização usando 10-fold crossvalidation.

Tabela 6.9: Resultados obtidos da seleção dos atributos relevantes usando as três formas de discretização. 


\section{Capítulo 1}

"Talento é $1 \%$ de inspiração e $99 \%$ de transpiração."

- Tomas Edison

\section{INTRODUÇÃO}

Nos últimos 10 anos, houve um grande crescimento em nossa capacidade para gerar e coletar dados, devido principalmente a três fatores: primeiro, ao constante aumento no poder de processamento dos computadores; segundo, ao armazenamento contínuo de grande quantidade de dados a um baixo custo e por último, à introdução de novas tecnologias relacionadas ao processamento e transmissão de dados, através de gerenciadores de bases de dados mais poderosos e aumento nas velocidades de transmissão [Karsten 95, Fayyad 96a, Guzmán 96].

O desenvolvimento de novas tecnologias de transmissão de dados, a automação de muitas companhias e entidades do governo, o amplo uso do código de barras nos produtos comerciais e o uso cada vez maior da Internet têm contribuído na geração de grandes massas de dados. Existem estimativas afirmando que a quantidade de dados no mundo duplica-se a cada 20 meses, e da mesma maneira, o número de bases de dados está crescendo consideravelmente. Na Figura 1.1 é apresentada uma previsão feita pela firma de consultoria Red Brick Company, baseada no volume de dados que está sendo gerado e o que se espera na entrada do século XXI [Dilly 95].

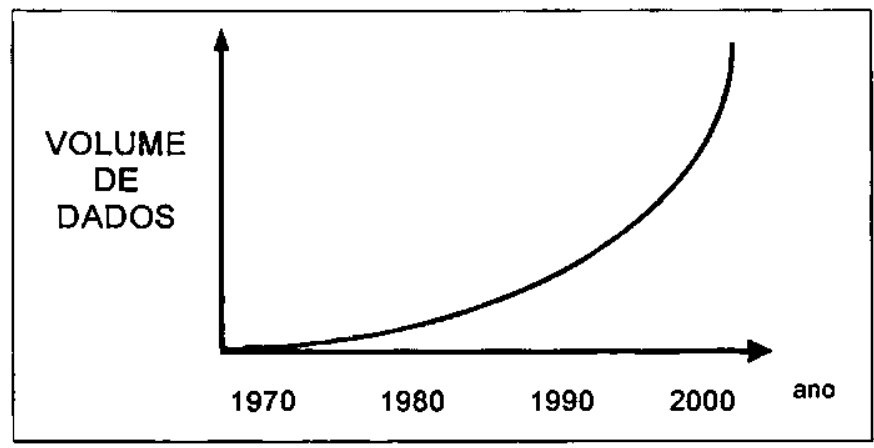

Figura 1.1: O Crescimento das Bases de Dados.

Atualmente, a necessidade de estar informado representa, para os executivos das empresas, um fator importante na tomada de decisões; as empresas estão gerando e armazenando seus dados, visando, entre outros aspectos, um melhor controle da sua estrutura e do seu futuro. 
Esta explosão de dados faz com que hoje em dia as bases de dados sejam medidas em gigabytes e até em terabytes. Vários exemplos ilustram esse crescimento da informação:

- A Mobil Oil Corporation está desenvolvendo um grande repositório de dados capaz de armazenar mais de 100 terabytes de dados relacionados à exploração do petróleo [Harrison 93].

- A Wal-Mart, uma das redes de lojas mais importantes dos Estados Unidos, criou uma base de dados que trabalha com mais de 20 milhões de transações por dia [Babcock 94].

- O sistema EOS (Earth Observing System) da NASA responsável pela órbita de satélites e outros equipamentos espaciais está projetando gerar da ordem de 50 gigabytes de dados de imagens captadas remotamente a cada hora a partir de 1990 até o próximo século [Way 91].

- O projeto SKICAT (Catálogo do Céu), desenvolvido no Centro de Pesquisas do Observatório Palomar, contém uma base de dados da ordem de terabytes com bilhões de imagens do espaço que são classificadas em galáxias, estrelas, planetas, etc. [Fayyad 93].

Métodos tradicionais usados na análise de dados são baseados principalmente na interação humana com o dado, e geralmente não trabalham com grandes arquivos. Embora os gerenciadores de bases de dados forneçam ferramentas básicas para otimizar o armazenamento e busca em grande quantidade de dados, a questão de como ajudar as pessoas a entender e analisar grandes estruturas de dados ainda é de difícil solução. Uma linha de pesquisa emergente chamada "Extração de Conhecimento de Bases de Dados" (Knowledge Discovery in Databases - KDD) promete novas técnicas e ferramentas inteligentes para responder ao desafio da busca de conhecimento embutido nas grandes bases de dados [Fayyad 96a].

O processo $\mathrm{KDD}$ pode ser visto como uma tecnologia que integra principalmente métodos estatísticos, ferramentas de visualização e técnicas de Inteligência Artificial usadas para descobrir conhecimento a partir de dados. $O$ trabalho da estatística neste campo tem sido muito relevante, gerando como resultado um amplo número de métodos para encontrar correlações e dependências entre os dados [Glymour 97]. As ferramentas de visualização desempenham um papel importante no acompanhamento da análise dos dados, visando apresentar de uma maneira mais compreensível a informação ou o conhecimento obtido deles. As técnicas de Inteligência Artificial, principalmente através do uso de Redes Neurais, Lógica Fuzzy e algoritmos de Aprendizado de Máquina, buscam encontrar padrōes, classificações, regularidades ou fazer previsões a partir desses dados.

De um modo geral, o processo KDD é composto de várias etapas iniciando na definição dos objetivos estabelecidos previamente pelos especialistas do domínio, executando um préprocessamento dos dados, uma análise e limpeza dos mesmos, passando-se por uma etapa de Data Mining e, finalmente uma etapa de avaliação e interpretação dos resultados obtidos.

O presente trabalho está focalizado na etapa de Data Mining. Através de um conjunto de algoritmos de Aprendizado de Máquina, tenta-se encontrar situações anômalas e/ou interessantes, relações, previsões, classificações, evoluções e associaçбes entre os elementos de uma base de dados.

Alguns autores, por exemplo, [Cabena 97], tratam o processo KDD e Data Mining de uma maneira indiferente, considerando que Data Mining representa um termo mais comercial entre 
vendedores e imprensa. Por outro lado, Data Mining ${ }^{2}$ pode ser referenciada por meio de outros nomes, tais como: "mineração de dados" [DeJesus 95] ou "garimpo de dados", "descoberta ou extração de conhecimento", "pesca de conhecimento", "análise de padrões de dados", "arqueologia de dados", "coleta de informação" ou "análise de dependência funcional" [Fayyad 96a]. Na Primeira Conferência Internacional sobre Descoberta de Conhecimento e Data Mining, realizada em Montreal, Canadá, em 1995, foram formalizados os termos KDD e Data Mining, sendo o primeiro referente a todo o processo para extrair conhecimento de bases de dados a partir de um conjunto de metas para posteriormente realizar uma análise dos resultados, e o segundo uma etapa dentro do processo $\mathrm{KDD}$, na qual usa-se várias técnicas de Inteligência Artificial. Está é a forma adotada neste trabalho.

Durante a pesquisa bibliográfica realizada observou-se uma falta de concordância entre os pesquisadores da área, ao tentar delimitar as etapas do processo KDD. Este foi uns dos motivos que levaram à realização de uma investigação intitulada: "Data Mining no Processo de Extração de Conhecimento de Base de Dados", visando primeiramente, compreender e delimitar as etapas do processo de Extração de Conhecimento de Base de Dados e, posteriormente, analisar a etapa de Data Mining dentro desse processo. Dois estudos de casos foram realizados para atingir esses objetivos. O primeiro utiliza uma base de dados petroleira fornecida pelo projeto das Redes Cooperativas de Pesquisas do Brasil (RECOPE), e o segundo, uma base de dados do Programa de Melhoramento Genético da Raça Nelore.

O objetivo principal do primeiro estudo de caso é demonstrar como a discretização de valores contínuos é determinante na obtenção de uma melhor precisão nas regras de classificação. Embora não exista uma metodologia única para otimizar a discretização de valores contínuos, visto que cada problema tem sua especificidade, foram exploradas algumas formas de discretização. Este trabalho utiliza uma dessas técnicas e a compara com a discretização sugerida por um especialista do domínio, propondo um método híbrido para obter uma melhor discretização e conseqüentemente melhores regras de classificação. Cabe ressaltar que por não contar com o especialista do domínio responsável pelos dados, não foi possível avaliar o conhecimento obtido. Dessa forma, este estudo de caso é considerado como um problema de Aprendizado de Máquina, mas a mesma problemática ocorre em problemas de Data Mining, como será visto nos Capítulos 3 e 5 . Este caso foi de especial interesse para o autor deste trabalho, que trabalha na área de petróleo, no Instituto Mexicano do Petróleo.

O segundo estudo de caso é também um caso real que visa mostrar todas as etapas do processo KDD. A base de dados usada neste processo faz parte do Programa de Melhoramento Génético da Raça Nelore. A partir da parceria entre criadores e pesquisadores do Departamento de Genética da Faculdade de Medicina, da Universidade de São Paulo - Ribeirão Preto, foram definidas metas para viabilizar o aumento da produtividade do rebanho bovino Nelore de corte nacional. De acordo com a proposta inicial de utilização de tecnologias modernas, está sendo utilizada a metodologia do Modelo Animal para avaliação de touros, matrizes e animais jovens, que permite obter as Diferenças Esperadas nas Progênies (DEPs) entre os pais e os filhos que possuam características, tais como, peso e perímetro escrotal, padronizadas para diferentes idades. Toda informação está armazenada em uma base de dados com mais de 65000 registros e com 35 atributos. Este estudo está focalizado em indicar os melhores acasalamentos entre um reprodutor e uma matriz, para obter touros com as melhores DEPs possíveis. Os resultados já

\footnotetext{
${ }^{2}$ Neste trabalho decidiu-se adotar Data Mining (DM), em inglês, pois tem sido aceito pela comunidade internacional de pesquisadores que trabalham nesta área.
} 
estão propiciando aos especialistas da área mais conhecimento sobre o melhoramento do gado da raça Nelore.

Este trabalho está organizado da seguinte forma:

- No capítulo 2 são explorados os conceitos de "conhecimento" e Aquisição de Conhecimento para, posteriormente, apresentar o estado da arte do processo $\mathrm{KDD}$, mostrando as etapas que o compóem e alguns dos elementos de apoio às diversas etapas, tais como Data Warehouse, ferramentas de visualização e alguns Métodos Estatísticos utilizados na seleção de amostras. Alguns dos problemas encontrados em KDD também são abordados neste capítulo.

- No capítulo 3 são analisados os conceitos de Aprendizado de Máquina (mostrando uma classificação dos algoritmos de Aprendizado de Máquina) e Data Mining, apresentando alguns dos problemas encontrados nessa etapa.

- No capítulo 4 são apresentados, de uma forma geral, o software MineSet ${ }^{\mathrm{TM}}$, a biblioteca MLC $^{++}$, os algoritmos CN2 e C4.5-rules, o software STATISTICS ${ }^{\text {TM }}$ e o Excel 97 que são as ferramentas utilizadas neste trabalho.

- No capítulo 5 é apresentado o estudo de caso utilizando a base de dados petroleira, apresentando alguns dos resultados obtidos através de um método híbrido proposto para 0 processo de discretização.

- No capítulo 6 são apresentados os resultados obtidos do estudo de caso usando a base de dados do Programa de Melhoramento Genético da Raça Nelore, mostrando a etapas do processo $\mathrm{KDD}$, explicadas no capítulo 2, e descrevendo os problemas encontrados e como eles foram solucionados.

- Finalmente, no capítulo 7 são apresentadas as conclusões, as contribuições e algumas sugestões para trabalhos futuros. 


\section{Capítulo 2}

"Nós estamos afogados em informação, mas morrendo de fome por conhecimento."

- John Naisbett

\section{EXTRAÇÃO DE CONHECIMENTO DE BASES DE DADOS}

\subsection{CONSIDERAÇÕES INICIAS}

Dados em estado bruto raramente oferecem benefícios diretos para o processo de tomada de decisão. Tradicionalmente, a análise destes dados está restrita a um processo manual, na qual os analistas devem estar intimamente familiarizados e, com ajuda de técnicas estatísticas, fornecem relatórios e sumários aos responsáveis pelas tomadas de decisões. O maior problema existente neste tipo de análise tradicional é o incremento constante dos dados, tornando essa análise muitas vezes lenta e dificil. Uma comunidade de pesquisadores interessados em fazer uma "análise automática da informação" está trabalhando em uma nova área denominada Extração de Conhecimento de Bases de Dados (Knowledge Discovery in Databases - KDD ${ }^{1}$ ).

Neste capítulo é abordado, primeiramente, o termo "conhecimento", por ser a meta a ser atingida no KDD. Posteriormente, é apresentado o processo de Extração de Conhecimento de Bases de Dados, explicando as etapas que o compõem, os elementos de apoio que o acompanham, para depois representar em um diagrama, o fluxo de dados através das etapas e elementos de apoio relacionados com KDD. Finalmente, serão vistos alguns dos principais problemas encontrados no processo $\mathrm{KDD}$.

\subsection{O CONHECIMENTO}

Durante várias épocas da história do homem, o termo "conhecimento" tem sido um tema filosófico amplamente debatido. Segundo Carbonell, o conhecimento é definido como a informação interpretada, categorizada, aplicada, revisada e possui um certo valor para o usuário [Carbonell 87].

De uma forma geral, no processo de Extração de Conhecimento de Bases de Dados, os dados são a matéria prima bruta. No momento em que o usuário atribui algum significado especial aos dados, estes passam a ser uma informação. Quando os especialistas do domínio do problema elaboram uma norma ou regra, a interpretação de confronto entre esse fato (informação) e essa

\footnotetext{
${ }^{1}$ Neste trabalho, as inicias KDD fazem referencia à Extração de Conhecimento de Bases de Dados.
} 
regra constitui um conhecimento. Uma hierarquia entre os dados, a informação e o conhecimento existente em uma base de dados, observando seu volume e o valor que os responsáveis pelas tomadas de decisões dão a essa hierarquia, pode ser visto na Figura 2.1.

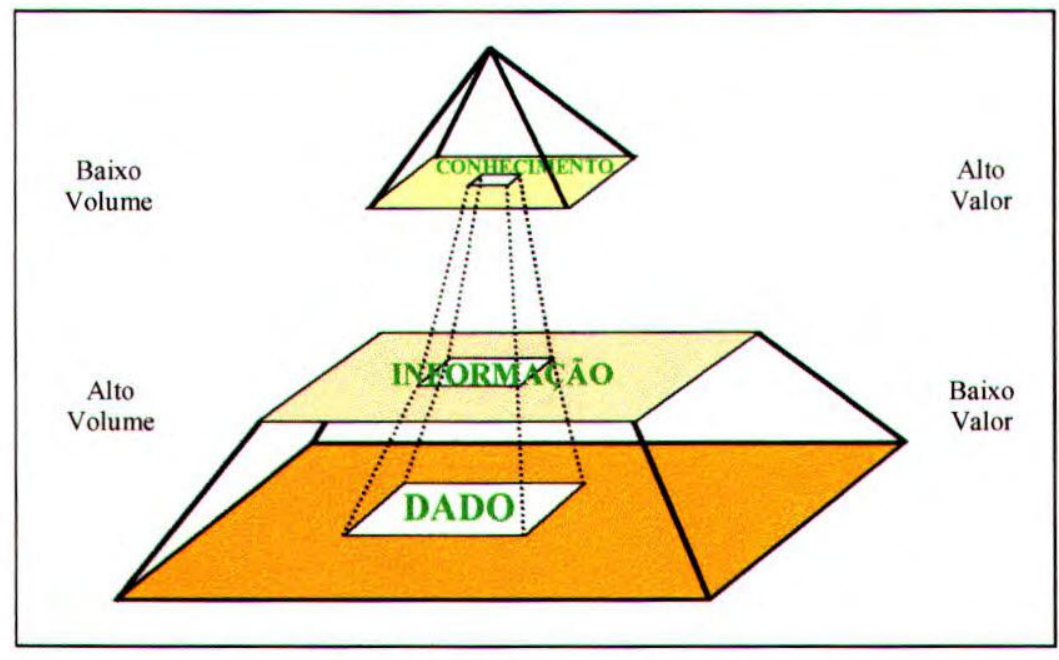

Figura 2.1: Pirâmide do Processo de Conhecimento.

Certamente, o conhecimento pode apresentar diversas e complexas formas de representação, dependendo, na maioria das vezes, da forma como ele é adquirido, sendo isto um dos principais problemas relacionados ao desenvolvimento de Sistemas Inteligentes de um modo geral.

- O processo de Aquisição de Conhecimento (AC) envolve a extração, interpretação e representação do conhecimento de um dado domínio e é considerada como sendo um estágio muito difícil. A AC envolve um consumo de tempo considerável, o que a torna um componente extremamente caro no desenvolvimento de Sistemas Inteligentes.

As dificuldades na $\mathrm{AC}$ se originam, em parte, pela falta de uma boa comunicação com especialistas do domínio, falta de tempo das pessoas envolvidas no processo de AC, falta de habilidade da equipe de engenheiros do conhecimento para entender o especialista do domínio, dificuldades quanto às terminologias empregadas e também falta de habilidade para mapear um domínio de conhecimento para um esquema de representação apropriado para o computador. Com o propósito de solucionar algumas dessas dificuldades, pesquisadores têm sugerido que a delimitação, aquisição e, em alguns casos, a representação do conhecimento se realizem de uma forma mais automática.

Vários esforços estão sendo feitos para automatizar o processo de AC, entre eles destacam-se: editores inteligentes, uso de processamento de linguagem natural para comunicação direta com o sistema e aplicações de aprendizado de máquina para apoiar a aquisição de conhecimento baseada em exemplos passados.

A Extração de Conhecimento de Bases de Dados pode cooperar na solução de alguns dos problemas relacionados a $\mathrm{AC}$, procurando padrões interessantes em bases de dados de uma forma mais automática, obtendo vantagens como o refinamento de tipos específicos de conhecimento, redução de custos (tempo e dinheiro) e de recursos humanos envolvidos no desenvolvimento desses sistemas e ainda podem ajudar na padronização de alguns dos processos de AC. 
Um dos principais objetivos do KDD é apoiar os especialistas do domínio na obtenção de conhecimento de bases de dados, envolvendo diferentes áreas, tais como Estatística, Bases de Dados, Inteligência Artificial e Computação Gráfica. Para poder atingir tais objetivos, o processo KDD é constituído de várias etapas e elementos de apoio que serão apresentados a seguir.

\subsection{PROCESSO DE EXTRAÇÃO DE CONHECIMENTO DE BASES DE DADOS}

Os primeiros grupos de pesquisadores de Extração de Conhecimento de Bases de Dados se encontraram no Primeiro Workshop de Extração de Conhecimento de Bases de Dados em 1989, nos Estados Unidos. Depois seguiram outros em 1991, 1993 e 1994, até chegar em 1995 à Primeira Conferência Internacional sobre Descoberta de Conhecimento e Data Mining realizada em Montreal, Canadá. Um ano depois, houve a Segunda Conferência Internacional em Portland, Estados Unidos, e em 1997 foi organizada a Terceira Conferência Internacional em Newport Beach, Estados Unidos. Atualmente, está sendo organizada a Quarta Conferência Internacional sobre Descoberta de Conhecimento e Data Mining, a ser realizada em agosto deste ano, na cidade de New York, Estados Unidos.

Segundo Fayyad, o processo KDD é definido como um processo não trivial de identificação. válida, recente, potencialmente útil de padrões compreensíveis embutidos nos dados [Fayyad 96a].

Dada a definição anterior de KDD, o "conhecimento" é definido em termos dependentes do domínio relacionados fortemente em medidas de utilidade, originalidade e compreensão. $O$ termo "padrões" denota os conjuntos de modelos ou padrões que representam alguma abstração de um subconjunto dos dados em alguma linguagem. Um outro termo importante na definição anterior é o "processo" que envolve análise, experimentação, iteração, interação com o usuário 2 , normalização, padronização, avaliação e que juntas formam todas as etapas do processo KDD que serão discutidas a seguir [Fayyad 96b, Fayyad 96c].

\subsection{ETAPAS DO PROCESSO DE EXTRAÇÃO DE CONHECIMENTO DE BASES DE DADOS}

O processo KDD é composto por várias etapas, que vai desde a definição e compreensão do domínio, seleção e amostragem dos dados, limpeza, enriquecimento e preparação dos mesmos, Data Mining, até uma etapa na qual os resultados são interpretados e avaliados pelos especialistas do domínio. Essas etapas serão detalhadas nas próximas seções. Na Figura 2.2, baseada nas considerações de [Fayyad 96c], são apresentadas todas as etapas envolvidas no processo KDD.

Baseado na definição de Fayyad [Fayyad 96b], Data Mining pode ser entendido como uma etapa do processo $\mathrm{KDD}$, que envolve a aplicação de ferramentas de busca para encontrar padrões em conjuntos de dados. Este trabalho focaliza-se principalmente na etapa de Data Mining, embora todas as etapas dentro do processo KDD são consideradas de igual importância, destacando-se

${ }^{2} \mathrm{O}$ usuário final ou responsável pela base de dados será chamado de especialista do domínio. 
que uma boa definição e compreensão do domínio, definindo os objetivos a atingir é de fundamental importância para o êxito do KDD.

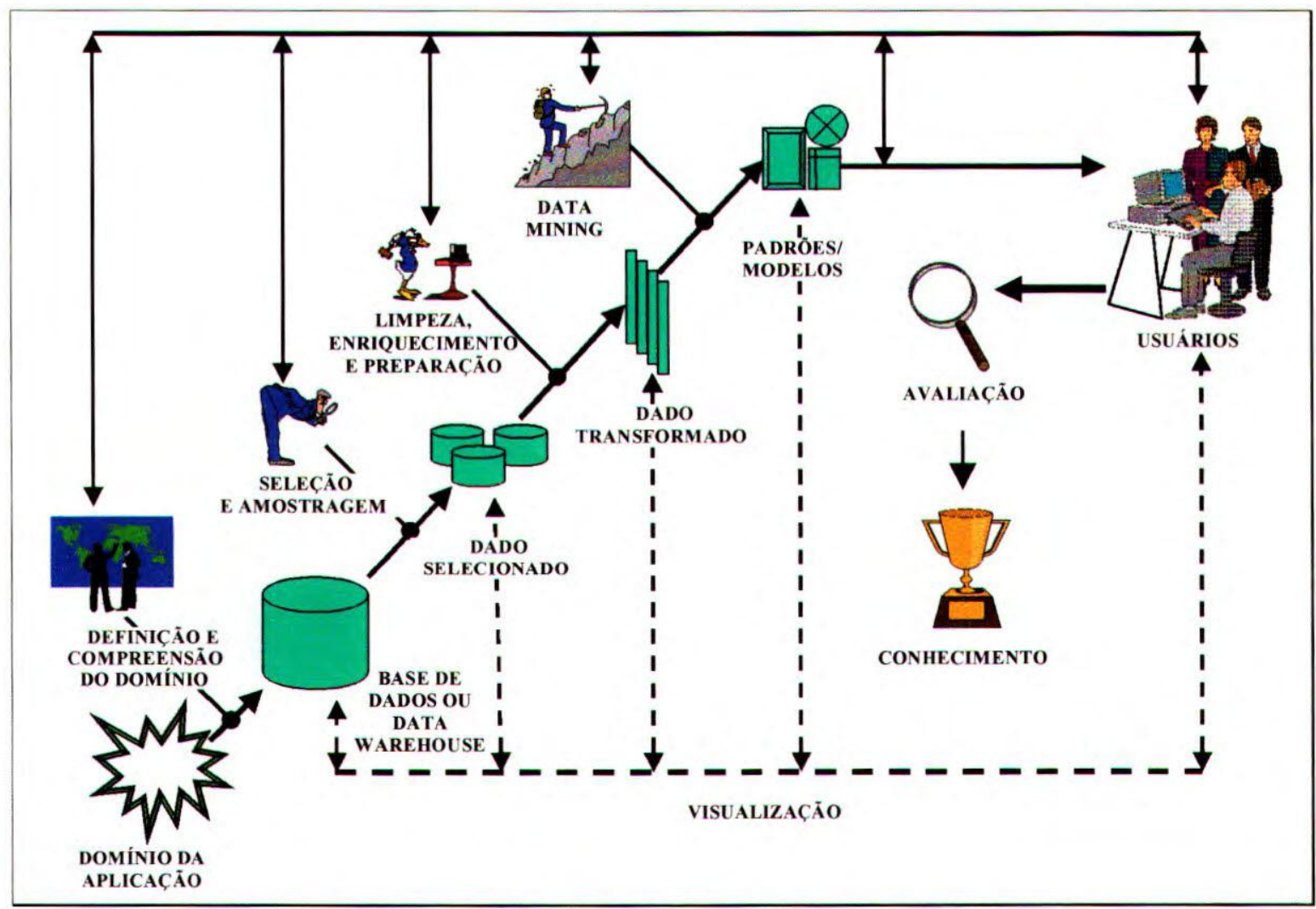

Figura 2.2: Etapas Envolvidas no Processo KDD.

Por outro lado, o fato de existir uma imensa variedade de problemas e diferentes tipos de bases de dados, é praticamente impossível definir uma metodologia única para a Extração de Conhecimento de Bases de Dados. Dependendo do problema, existe em algumas ocasiões, a necessidade de criar "sub-etapas" dentro de cada etapa. A seguir serão discutidas, de uma forma geral, todas as etapas do processo KDD e serão citados algumas dessas sub-etapas para uma melhor delimitação de cada etapa.

\subsubsection{Definição e Compreensão do Domínio}

A definição dos objetivos a atingir é um dos aspectos fundamentais a serem considerados para o êxito do processo de Extração de Conhecimento de Bases de Dados. Essa definição é geralmente realizada pelos especialistas do domínio ou proprietários da base de dados com o apoio do especialista do processo $\mathrm{KDD}^{3}$, a fim de definir o domínio da aplicação (região limitada e definida de uma aplicação), o conhecimento prévio relevante, a viabilidade e custos da aplicação, duração do projeto, resultados esperados, entre outros. Uma análise cuidadosa do problema é requerida nesta etapa para uma melhor compreensão do domínio. Os principais fatores a serem considerados são:

- Quais são as metas? Quais critérios são importantes?

\footnotetext{
${ }^{3} \mathrm{O}$ especialista do processo KDD pode ser visto como o engenheiro de conhecimento do processo de AC.
} 
- Quais são os gargalos do domínio?

- Onde é melhor automatizar o processo e onde é melhor deixar para ser processado manualmente?

- O produto final do processo usará classificação, visualização ou exploração?

- Qual é a relação entre simplicidade e precisão de um conhecimento extraído?

- O que se deseja obter a partir dos resultados finais?

O produto dessa interação deve ser uma documentação completa do domínio, devendo constar a descrição das características da aplicação, definição dos objetivos, agenda de atividades, entre outros.

\subsubsection{Seleção e/ou Criação das Bases de Dados}

Esta etapa consiste em selecionar ou dependendo do caso, criar uma nova base de dados usando conjuntos de elementos de várias fontes de dados. Isto envolve considerações de homogeneidade dos dados e identificação das fontes desses dados, as quais podem ser internas (por exemplo, bases de dados do departamento de produção, de finanças, etc.) ou externas (por exemplo, Internet, livros, etc.), como pode ser observado na Figura 2.3 .

Nesta etapa consegue-se uma melhor identificação dos gargalos do domínio, considerando, entre outros aspectos: viabilidade do projeto, tempo de execução, possíveis resultados esperados, etc.

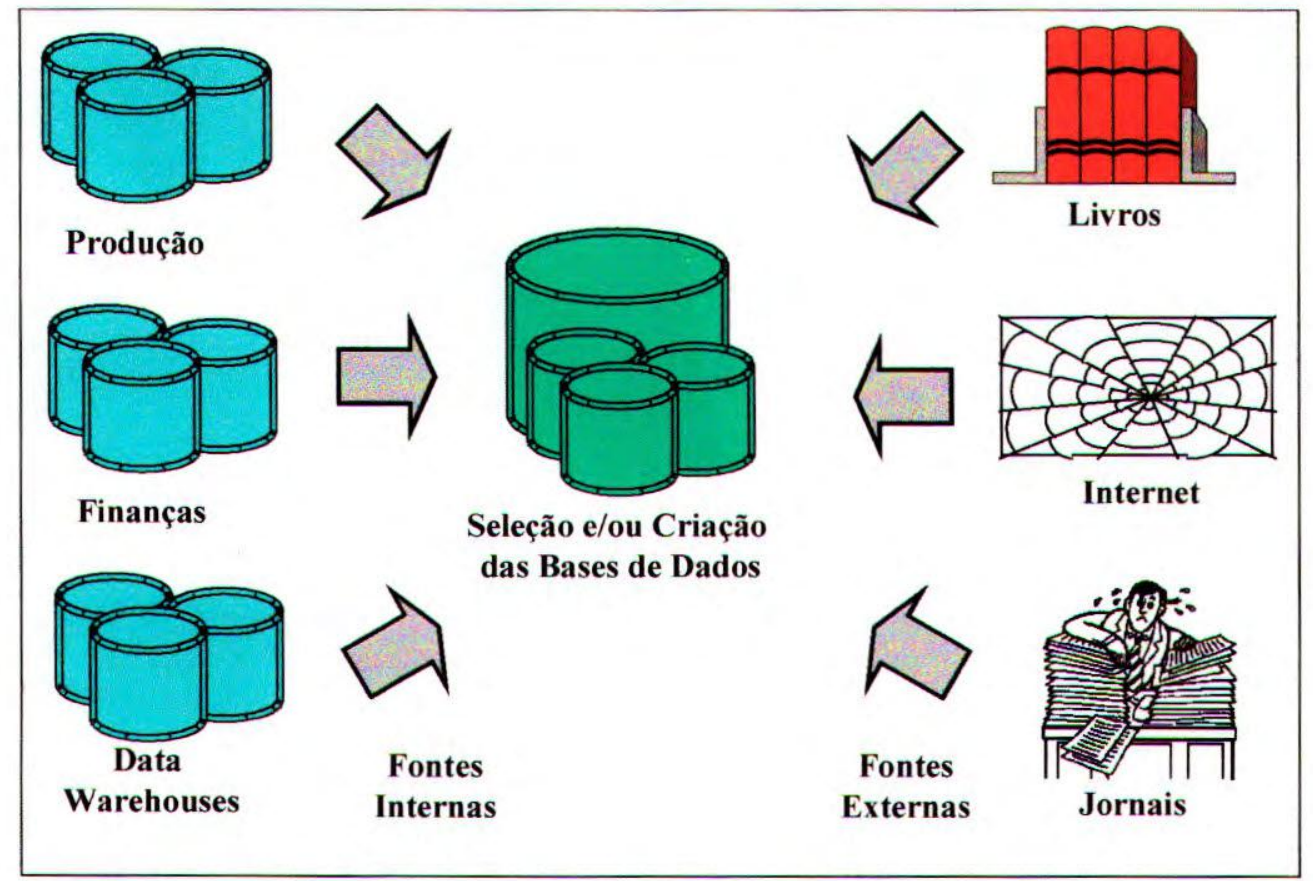

Figura 2.3: Fontes de dados que alimentam as bases de dados.

\subsubsection{Compreensão dos Dados}

Em muitas aplicações é importante interpretar os dados para um melhor entendimento do domínio. Possíveis soluções incluem: consultas usando a linguagem SQL (Structured Query 
Language), ferramentas OLAP (OnLine Analytical Processing) (que serão discutidas na Seção 3.3.1), representações gráficas, visualização dos dados, cálculos estatísticos, etc.

Na Figura 2.4 é apresentado um exemplo de obtenção de informação prévia do domínio usando alguns cálculos estatísticos. A primeira tabela, da Figura 2.4, contém dados dos clientes que compram certos tipos de revistas em um determinado período de tempo. Realizando cálculos estatísticos simples é possível determinar alguns resultados importantes, como é mostrado na última tabela. Uma possível conclusão, a partir desses resultados, é que a média de idade de um leitor de revistas de carros é de 29 anos, o que representa uma média de idade menor que a dos clientes em geral, ou ainda que a média de idade dos leitores de revistas em quadrinhos é a mais baixa de todas. Isto pode ser visualizado através de um gráfico para uma melhor compreensão do exemplo, como pode ser observado na Figura 2.5.

\begin{tabular}{|c|c|c|c|c|c|c|c|c|c|c|c|}
\hline $\begin{array}{c}\text { cliente } \\
\#\end{array}$ & $\begin{array}{l}\text { ida- } \\
\text { de }\end{array}$ & salário & crédito & $\begin{array}{l}\text { carro } \\
\text { pró- } \\
\text { prio }\end{array}$ & $\begin{array}{l}\text { casa } \\
\text { pró- } \\
\text { pria }\end{array}$ & região & $\begin{array}{c}\text { revista de } \\
\text { carros }\end{array}$ & $\begin{array}{c}\text { revista de } \\
\text { casa }\end{array}$ & $\begin{array}{c}\text { revista de } \\
\text { esportes }\end{array}$ & $\begin{array}{l}\text { revista de } \\
\text { música }\end{array}$ & $\begin{array}{l}\text { revista } \\
\text { em qua- } \\
\text { drinhos }\end{array}$ \\
\hline $\mathrm{cl} 2$ & 35 & 50000 & 40000 & 1 & 1 & 1 & 1 & 1 & 1 & 0 & 0 \\
\hline$c 82$ & 22 & 35000 & 28000 & 1 & 1 & 1 & 1 & 0 & 0 & 1 & 1 \\
\hline c55 & 54 & 40000 & 40000 & 1 & 1 & 1 & 0 & 0 & 1 & 0 & 1 \\
\hline $\mathrm{cl} 3$ & 27 & 38000 & 12000 & 0 & 0 & 1 & 0 & 1 & 0 & 0 & 0 \\
\hline c54 & 33 & 41000 & 10000 & 0 & 1 & 0 & 1 & 1 & 1 & 0 & 0 \\
\hline $\mathrm{cl6}$ & 25 & 24000 & 20000 & 1 & 1 & 0 & 1 & 0 & 0 & 0 & 0 \\
\hline c28 & 65 & 32000 & 25000 & 1 & 0 & 0 & 1 & 0 & 1 & 1 & 1 \\
\hline \multirow[t]{7}{*}{$\ldots$} & $\ldots$ & $\ldots$ & $\ldots$ & $\ldots$ & $\ldots$ & $\ldots$ & $\ldots$ & $\ldots$ & $\ldots$ & $\ldots$ & $\ldots$ \\
\hline & \multicolumn{3}{|c|}{$\begin{array}{l}\text { características dos } \\
\text { clientes }\end{array}$} & média & & & \multicolumn{3}{|c|}{ tipo de revistas } & média & \\
\hline & \multicolumn{3}{|c|}{ idade } & 43,9 & & & \multicolumn{3}{|c|}{ revista de carros } & 0,329 & \\
\hline & \multicolumn{3}{|c|}{ salário } & 20500 & & & \multicolumn{3}{|c|}{ revista de esportes } & 0,702 & \\
\hline & \multicolumn{3}{|c|}{ crédito } & 36700 & & & \multicolumn{3}{|c|}{ revista de casa } & 0,447 & \\
\hline & \multicolumn{3}{|c|}{ carro próprio } & 0,59 & & & \multicolumn{3}{|c|}{ revista de música } & 0,146 & \\
\hline & \multicolumn{3}{|c|}{ casa própria } & 0,59 & & & \multicolumn{3}{|c|}{ revista em quadrinhos } & 0,081 & \\
\hline
\end{tabular}

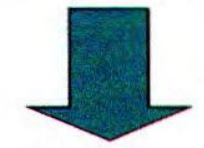

Resultado

\begin{tabular}{|l|c|c|c|c|c|}
\hline & média idade & média salário & média crédito & $\begin{array}{c}\text { média carro } \\
\text { próprio }\end{array}$ & $\begin{array}{c}\text { média casa } \\
\text { própria }\end{array}$ \\
\hline revista de carros & 29,3 & 37100 & 35500 & 0,48 & 0,53 \\
\hline revista de esportes & 48,1 & 21100 & 20000 & 0,58 & 0,76 \\
\hline revista de casa & 42,2 & 24300 & 21400 & 0,70 & 0,60 \\
\hline revista de música & 24,6 & 12800 & 11000 & 0,30 & 0,45 \\
\hline revista em quadrinhos & 21,4 & 11000 & 10300 & 0,32 & 0,26 \\
\hline
\end{tabular}

Figura 2.4: Exemplo de compreensão dos dados.

Vale ressaltar que a visualização dos dados, que será discutido na Seção 2.5.3, tem um papel importante nesta etapa, já que permite que sejam incorporadas diretamente a capacidade de percepção visual e entendimento, as capacidades de cálculo e associações de uma forma mais compreensível. 


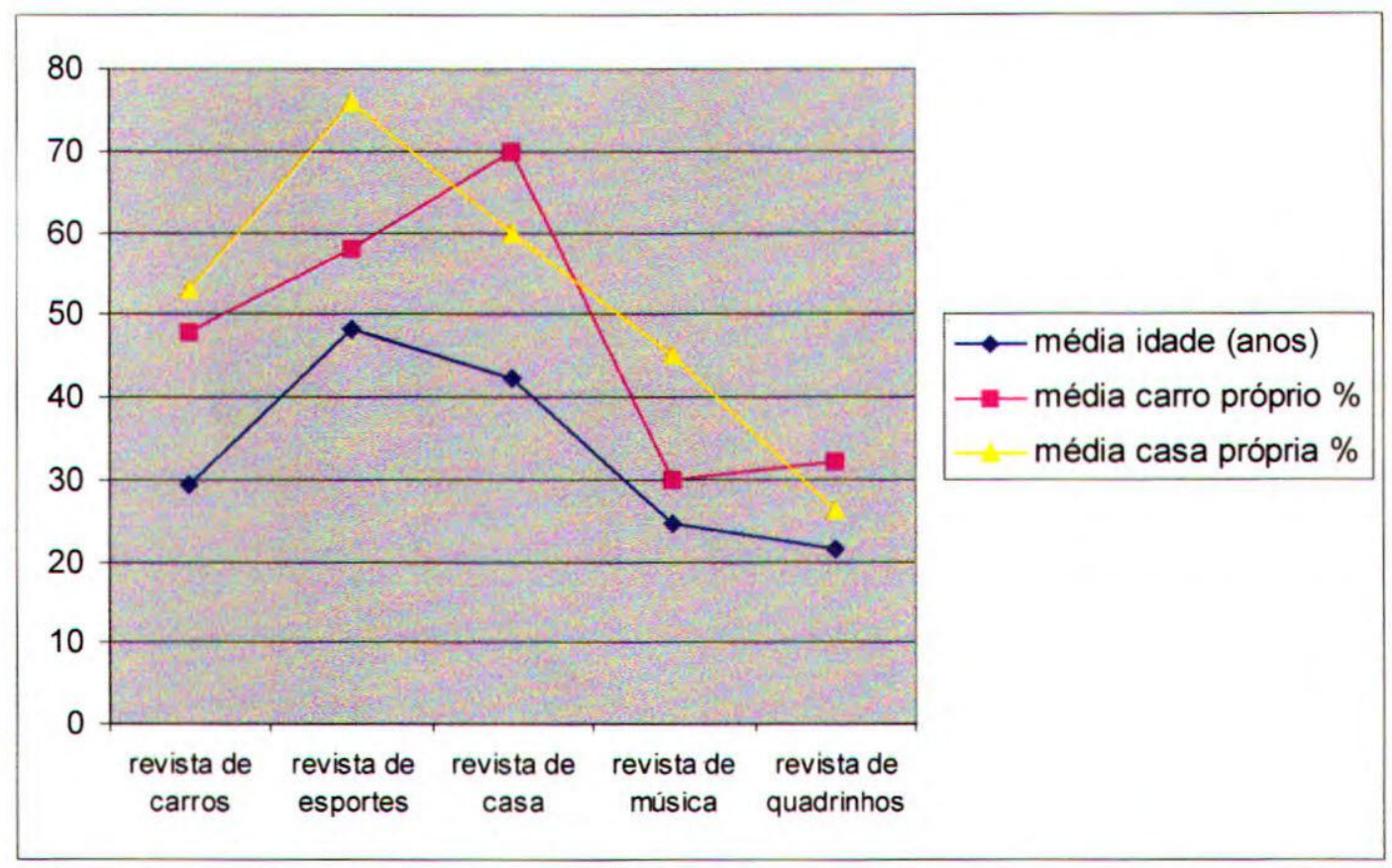

Figura 2.5: Gráfico para compreender melhor os dados.

\subsubsection{Seleção das Amostras mais Representativas}

A extração direta de conhecimento a partir de grandes bases de dados pode se tornar uma tarefa inviável, principalmente pela limitação do número de registros que os algoritmos de Aprendizado de Máquina podem manipular, como será discutido no Capítulo 3. Esse grande volume de dados pode gerar um espaço de busca de padrões combinatorialmente imenso. Além disso, a busca de conhecimento em grandes bases de dados pode ocasionar, na maioria da vezes, um aumento na chance de encontrar padrões pouco significativos e até mesmo espúrios (por exemplo, "as pessoas que ficam grávidas são mulheres" ou "se a cidade é São Carlos então o estado é São Paulo”).

Segundo Mannila [Mannila 97], a seleção das amostras mais representativas consome cerca de $80 \%$ de todo o tempo do processo KDD. Esta etapa é muito importante já que dados em demasia gera um processamento muito lento, mas poucos dados podem gerar conclusões incorretas.

A escolha de uma amostra que reflita com a maior fidelidade possível a base de dados é de suma importância para as demais etapas do processo KDD. Seleções de amostras pouco significativas podem resultar em padrões imprecisos ou sem valia. Portanto, devem ser considerados aspectos como:

- Tamanho da amostra.

- Estratégias para obtenção da amostra (ajuda do especialista do domínio, técnicas estatísticas, etc.).

- Homogeneidade dos dados.

- Dinâmica dos dados (por exemplo, mudança de valores de atributos com o tempo). 
Após esta etapa, a amostra representativa selecionada a partir da base de dados passa a ser chamada, neste trabalho, de conjunto de dados.

\subsubsection{Enriquecimento do Conjunto de Dados}

É necessário, em certas ocasiões, agregar dados externos quando o conjunto de dados selecionados necessita deles para poder atingir as metas determinadas no início do processo. Por exemplo, nas pesquisas de mercado, é importante agregar o CEP ou sexo das pessoas para saber de certa forma o público alvo a atingir ou evitar, como por exemplo, que propaganda de absorventes cheguem pelo correio com o nome de uma pessoa do sexo masculino. Agregar o número de filhos dos clientes, condições de um dia específico, casa própria, carro próprio, são dados que geralmente colaboram.

Na Figura 2.6 é apresentado um exemplo no qual, a partir de um conjunto de dados que mostra várias características de clientes que realizaram compras em uma loja, são acrescentados dados de uma base externa do Registro Geral (RG) do governo para saber o sexo do cliente e a cidade onde ele mora, com o objetivo de identificar melhor qual o tipo de público que mais compra na loja.

\begin{tabular}{|c|c|c|c|c|c|c|}
\hline $\begin{array}{c}\text { transaçäo } \\
\#\end{array}$ & $\begin{array}{c}\text { cliente } \\
\#\end{array}$ & data & tempo & total venda & tipo de pagamento & $\begin{array}{c}\text { número de } \\
\text { produtos }\end{array}$ \\
\hline 3658 & $\mathrm{c} 12$ & $1997 / 08 / 15$ & $16: 45$ & 675 & efetivo & 12 \\
\hline 4088 & $\mathrm{c} 82$ & $1997 / 09 / 22$ & $09: 58$ & 450 & visa & 7 \\
\hline 3456 & $\mathrm{c} 5$ & $1997 / 12 / 05$ & $16: 40$ & 89 & efetivo & 28 \\
\hline 7659 & $\mathrm{c} 13$ & $1997 / 07 / 09$ & $12: 40$ & 825 & master & 20 \\
\hline 2347 & $\mathrm{c} 54$ & $1997 / 06 / 18$ & $11: 10$ & 150 & efetivo & 13 \\
\hline 1347 & $\mathrm{c} 16$ & $1997 / 11 / 11$ & $09: 02$ & 75 & master & 9 \\
\hline 2626 & $\mathrm{c} 28$ & $1997 / 08 / 26$ & $13: 01$ & 908 & visa & 11 \\
\hline 3789 & $\mathrm{c} 36$ & $1997 / 06 / 25$ & $14: 20$ & 203 & master & 34 \\
\hline
\end{tabular}

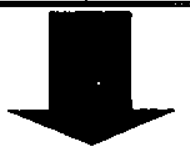

Resultado

\begin{tabular}{|c|c|c|c|c|c|c|c|c|}
\hline $\begin{array}{c}\text { transaçäo } \\
\#\end{array}$ & $\begin{array}{c}\text { cliente } \\
\#\end{array}$ & sexo & \multicolumn{1}{|c|}{ data } & tempo & \multicolumn{1}{c|}{ cidade } & $\begin{array}{c}\text { total } \\
\text { venda }\end{array}$ & $\begin{array}{c}\text { tipo de } \\
\text { pagamento }\end{array}$ & $\begin{array}{c}\text { número de } \\
\text { produtos }\end{array}$ \\
\hline 3658 & $\mathrm{c} 12$ & $\mathrm{~m}$ & $1997 / 08 / 15$ & $16: 45$ & Goiânia & 675 & efetivo & 12 \\
\hline 4088 & $\mathrm{c} 82$ & $\mathrm{~m}$ & $1997 / 09 / 22$ & $09: 58$ & Curitiba & 450 & visa & 7 \\
\hline 3456 & $\mathrm{c} 55$ & $\mathrm{f}$ & $1997 / 12 / 05$ & $16: 40$ & São Carlos & 89 & efetivo & 28 \\
\hline 7659 & $\mathrm{c} 13$ & $\mathrm{~m}$ & $1997 / 07 / 09$ & $12: 40$ & São Paulo & 825 & master & 20 \\
\hline 2347 & $\mathrm{c} 54$ & $\mathrm{f}$ & $1997 / 06 / 18$ & $11: 10$ & São Carlos & 150 & efetivo & 13 \\
\hline 1347 & $\mathrm{c} 16$ & $\mathrm{f}$ & $1997 / 11 / 11$ & $09: 02$ & Cuiabá & 75 & master & 9 \\
\hline 2626 & $\mathrm{c} 28$ & $\mathrm{f}$ & $1997 / 08 / 26$ & $13: 01$ & Rio Preto & 908 & visa & 11 \\
\hline 3789 & $\mathrm{c} 36$ & $\mathrm{~m}$ & $1997 / 06 / 25$ & $14: 20$ & São Paulo & 203 & master & 34 \\
\hline
\end{tabular}

Figura 2.6: Exemplo de enriquecimento do conjunto de dados.

\subsubsection{Limpeza do Conjunto de Dados}

Esta etapa inclui, principalmente, a padronização e eliminação de ruídos gerados de diversas formas nos conjuntos de dados. A geração de ruídos é devida a migrações de um sistema para 
outro, quedas de tensão na hora do processamento, desligamento do computador tendo arquivos abertos, etc. Entre os vários aspectos a serem levados em consideração, destacam-se:

- Padronização do conteúdo dos registros. Por exemplo, no caso do sexo das pessoas, é comum que seja especificada através de valores $\mathrm{M}$ ou F, 0 ou 1, Mas ou Fem. É recomendável transformar, sempre que for possível, em valores numéricos, no caso do exemplo anterior é recomendável padronizar para 0 e 1 .

- Análise de valores desconhecidos para determinar se é melhor eliminar os registros que os contêm ou se é possível utilizar alguma técnica para tratar esses dados ausentes (missing values).

- Eliminação de registros duplicados, produzidos geralmente pela captura de dados de diferentes fontes.

- Tratamento de ruídos nos dados, produzidos principalmente pelas migrações de um sistema para outro.

- Cuidado com dados fora dos limites estabelecidos. Por exemplo, a idade de um funcionário com 350 anos ou a velocidade de um carro ser de $1800 \mathrm{~km} / \mathrm{h}$.

O exemplo apresentado na Figura 2.7 mostra que os clientes c12, c14 e c15 são a mesma pessoa, mas o cliente c16 é outra pessoa. Também os clientes c24 e c38 são a mesma pessoa, mas o cliente c36 é outra. Estes cuidados, entre outros, devem ser levados em conta nesta etapa do processo KDD.

\begin{tabular}{|l|l|l|l|l|l|c|}
\hline cliente \# & \multicolumn{1}{|c|}{ sobrenome } & iniciais & \multicolumn{1}{c|}{ cidade } & \multicolumn{1}{c|}{ rua } & \multicolumn{1}{c|}{ cep } & idade \\
\hline c12 & Molina Félix & L.C. & São Carlos & Carlos Botelho & $13564-350$ & 29 \\
\hline c14 & Molina Felix & L. C. & São carlos & carlos Botelho & $13564-350$ & 29 \\
\hline c15 & Molina télix & L. & São Carlos & Carlos Botelho & $13564-350$ & $?$ \\
\hline c16 & Molina & C. & São Paulo & $?$ & $11900-120$ & 22 \\
\hline c24 & Lopes Clima & E. S. & Goiânia & R-17 & $74125-170$ & $?$ \\
\hline c36 & Lopes Lima & W. & Curitiba & c-17 & $15780-120$ & 35 \\
\hline c38 & Lopes Lima & E. & Goiânia & r-17 & $74125-170$ & 22 \\
\hline
\end{tabular}

Figura 2.7: Exemplo de eliminação de registros duplicados.

\subsubsection{Preparação do Conjunto de Dados}

Em algumas ocasiões, é necessário fazer certas adequações no conjunto de dados de acordo com a técnica de Data Mining a ser usada. Alguns aspectos a serem considerados na preparação do conjunto de dados são:

- Simplificação dos valores, por exemplo, dividir os salários anuais dos funcionários por 1000 para eliminar zeros.

- Agrupamento de valores contínuos, por exemplo, todas as transações entre 8:00 e 11:00 formam o grupo 1, das 11:01 às 14:00 formam o grupo 2 e assim por diante.

- Normalização dos dados, por exemplo, muitas redes neurais só aceitam dados numéricos em um intervalo de 0.0 a 1.0 ou -1.0 a 1.0 , então deve ser feita uma escala para levar os valores dos elementos para dentro desse intervalo.

- Transformação de colunas, por exemplo, dividir uma coluna em X colunas, dependendo dos $\mathrm{X}$ conjuntos de valores qual a compõe, para posteriormente serem preenchidas com valores 0 ou 1. 
- Colocação do atributo-classe utilizado nos algoritmos simbólicos de Aprendizado de Máquiina na última coluna, porque a grande maioria desses algoritmos o requerem.

- Redistribuição dos atributos, por exemplo, no estudo de caso 2, discutido no Capítulo 6, foram realizados vários experimentos utilizando Redes Bayesianas [Heckerman 97], os quais mostraram, entre outros resultados, que a distribuição dos atributos do conjunto de dados usado, afetava diretamente o tempo de execução da rede.

Na Figura 2.8 é apresentado um exemplo de transformação de colunas para a coluna "tipo de pagamento", onde posteriormente é levado a uma representação de 0's e l's. Junto com isso a coluna "números de produtos" foi agrupada em valores contínuos, de forma que para produtos em um intervalo de 0 a 10 , o valor passa a ser 10 , de 11 a 20 o valor passa a ser 20 e assim por diante.

\begin{tabular}{|c|c|c|c|c|l|c|c|c|}
\hline $\begin{array}{c}\text { Transação } \\
\#\end{array}$ & $\begin{array}{c}\text { cliente } \\
\#\end{array}$ & sexo & data & tempo & \multicolumn{1}{|c|}{ cidade } & $\begin{array}{c}\text { total } \\
\text { venda }\end{array}$ & $\begin{array}{c}\text { tipo de } \\
\text { pagamento }\end{array}$ & $\begin{array}{c}\text { número de } \\
\text { produtos }\end{array}$ \\
\hline 3658 & $\mathrm{c} 12$ & $\mathrm{~m}$ & $1997 / 08 / 15$ & $16: 45$ & Goiânia & 675 & efetivo & 12 \\
\hline 4088 & $\mathrm{c} 22$ & $\mathrm{~m}$ & $1997 / 09 / 22$ & $09: 58$ & Curitiba & 450 & visa & 7 \\
\hline 3456 & $\mathrm{c55}$ & $\mathrm{f}$ & $1997 / 12 / 05$ & $16: 40$ & São Carlos & 89 & efetivo & 28 \\
\hline 7659 & $\mathrm{c} 13$ & $\mathrm{~m}$ & $1997 / 07 / 09$ & $12: 40$ & São Paulo & 825 & master & 20 \\
\hline 2347 & $\mathrm{c} 54$ & $\mathrm{f}$ & $1997 / 06 / 18$ & $11: 10$ & São Carlos & 150 & efetivo & 13 \\
\hline 1347 & $\mathrm{c} 16$ & $\mathrm{f}$ & $1997 / 11 / 11$ & $09: 02$ & Cuiabá & 75 & master & 9 \\
\hline 2626 & $\mathrm{c} 28$ & $\mathrm{f}$ & $1997 / 08 / 26$ & $13: 01$ & Rio Preto & 908 & visa & 11 \\
\hline 3789 & $\mathrm{c} 36$ & $\mathrm{~m}$ & $1997 / 06 / 25$ & $14: 20$ & São Paulo & 203 & master & 34 \\
\hline
\end{tabular}

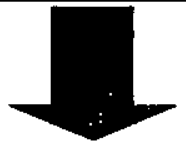

Resultado

\begin{tabular}{|c|c|c|c|c|c|c|c|c|c|c|}
\hline $\begin{array}{c}\text { Transaçäo } \\
\#\end{array}$ & $\begin{array}{c}\text { cliente } \\
\#\end{array}$ & sexo & data & tempo & cidade & $\begin{array}{c}\text { total } \\
\text { venda }\end{array}$ & $\begin{array}{c}\text { efeti- } \\
\text { vo }\end{array}$ & $\begin{array}{c}\text { visa } \\
\text { mas- } \\
\text { ter }\end{array}$ & $\begin{array}{c}\text { número de } \\
\text { produtos }\end{array}$ \\
\hline 3658 & $\mathrm{c} 12$ & $\mathrm{~m}$ & $1997 / 08 / 15$ & $16: 45$ & Goiânia & 675 & 1 & 0 & 0 & 20 \\
\hline 4088 & $\mathrm{c} 82$ & $\mathrm{~m}$ & $1997 / 09 / 22$ & $09: 58$ & Curitiba & 450 & 0 & 1 & 0 & 10 \\
\hline 3456 & $\mathrm{c55}$ & $\mathrm{f}$ & $1997 / 12 / 05$ & $16: 40$ & São Carlos & 89 & 1 & 0 & 0 & 30 \\
\hline 7659 & $\mathrm{c} 13$ & $\mathrm{~m}$ & $1997 / 07 / 09$ & $12: 40$ & São Paulo & 825 & 0 & 0 & 1 & 20 \\
\hline 2347 & $\mathrm{c54}$ & $\mathrm{f}$ & $1997 / 06 / 18$ & $11: 10$ & São Carlos & 150 & 1 & 0 & 0 & 20 \\
\hline 1347 & $\mathrm{c} 16$ & $\mathrm{f}$ & $1997 / 11 / 11$ & $09: 02$ & Cuiabá & 75 & 0 & 0 & 1 & 10 \\
\hline 2626 & $\mathrm{c} 28$ & $\mathrm{f}$ & $1997 / 08 / 26$ & $13: 01$ & Rio Preto & 908 & 0 & 1 & 0 & 20 \\
\hline 3789 & $\mathrm{c36}$ & $\mathrm{m}$ & $1997 / 06 / 25$ & $14: 20$ & São Paulo & 203 & 0 & 0 & 1 & 40 \\
\hline
\end{tabular}

Figura 2.8: Exemplo de preparação de um conjunto de dados.

\subsubsection{Data Mining}

É importante considerar previamente que os algoritmos de Aprendizado de Máquina usados por Data Mining necessitam que os conjuntos de dados estejam em um determinado formato para poderem trabalhar. Uma notação padrão para indicar um conjunto de dados com duas classes é mostrada na Tabela 2.1 . 
Devido a sua complexidade e importância, a etapa de Data Mining pode ser dividida em três subetapas: redução de instâncias ${ }^{4}$ e/ou atributos (features), descoberta de padrões e pré-avaliação do conhecimento obtido por parte do especialista do KDD.

Tabela 2.1: Notação para indicar um conjunto de dados.

\begin{tabular}{|c|c|c|c|}
\cline { 2 - 3 } \multicolumn{1}{c|}{} & \multicolumn{2}{c|}{ Atributos } & \multicolumn{1}{c|}{ Classe } \\
\hline Instâncias & Atributo $_{1}$ & Atributo $_{2}$ & Valor $_{12}$ \\
\hline Instância $_{1}$ & Valor $_{11}$ & Valor $_{22}$ & $\mathrm{C}_{1}$ \\
\hline Instância $_{2}$ & Valor $_{21}$ & Valor $_{22}$ & $\mathrm{C}_{2}$ \\
\hline Instância $_{3}$ & Valor $_{31}$ & Valor $_{32}$ & \\
\hline
\end{tabular}

A primeira sub-etapa dentro do processo de Data Mining refere-se a que não necessariamente devem ser enviadas todas as instâncias ou atributos do conjunto de dados aos algoritmos de Aprendizado de Máquina, a não ser que o especialista do domínio determine o contrário. Reduzir atributos ou instâncias representa, na maioria das vezes, e depois de uma análise cuidadosa, a obtenção de poucas regras ou árvores sem muita complexidade que conseguem descrever o modelo, significando, entre outros, um melhor entendimento dos padrões encontrados. Podem ser consideradas 4 tipos de reduções:

- Redução de exemplos ou instâncias: algumas vezes, trabalhar só com instâncias positivas ou negativas do conjunto de dados pode ser útil para determinar os melhores ou os piores casos, respectivamente.

- Redução de atributos: existem atributos no conjunto de dados fortemente dependentes entre si, mas por outro lado podem existir outros que não representam nenhuma relação. Então, os atributos podem ser reduzidos já que algumas vezes os algoritmos de Aprendizado de Máquina ficam confusos com muitos atributos, construindo classificadores com pouca utilidade.

- Redução através da combinação de atributos (Aprendizado de Máquina Construtivo): consiste na criação de um ou vários atributos a partir da combinação de outros atributos já existentes.

- Redução de valores discretizando atributos contínuos: os algoritmos simbólicos de Aprendizado de Máquina usados em Data Mining requerem de valores discretos no seu atributo-classe, mas a maioria das bases de dados reais contêm só valores contínuos. Devido a isso, é feita uma discretização que gera uma redução dos valores contínuos do atributoclasse das instâncias selecionadas. Embora alguns pesquisadores considerem a discretização como uma etapa fora de Data Mining, neste trabalho é considerada como uma sub-etapa dentro desta etapa, devido a que os métodos de discretização "híbridos" (reunindo técnicas estatísticas, especialista de domínio e métodos de discretização que interajam diretamente com os algoritmos de Aprendizado de Máquina) visam ter um melhor desempenho na procura de melhores precisões nos algoritmos de Aprendizado de Máquina, como será discutido no Capítulo 5.

A segunda sub-etapa de Data Mining visa, geralmente através de técnicas de Aprendizado de Máquina, encontrar padrões, modelos ou classificações dentro do conjunto de dados. $O$ processo é bastante complexo, consistindo de uma tecnologia composta de um conjunto de modelos

\footnotetext{
${ }^{4}$ Uma vez que os registros foram selecionados então passam a ser chamados de instâncias, casos ou exemplos.
} 
matemáticos e diversos algoritmos de Aprendizado de Máquina, em geral, suportados por poderosas ferramentas de visualização.

A terceira sub-etapa, denominada de pré-avaliação do conhecimento por parte do especialista do processo KDD, objetiva fazer uma filtragem, eliminando o conhecimento obtido que não representa valor nenhum e situações b́bvias guiadas pelo senso comum. Nesta sub-etapa, a precisão dos algoritmos de Aprendizado Simbólico, a representação do modelo, a complexidade das regras ou árvores de decisão geradas são de grande importância para representar conhecimento de uma forma mais simples.

Uma vez definidas as três sub-etapas, este trabalho aborda a redução de valores do atributoclasse e a descoberta de padrões usando algoritmos de Aprendizado de Máquina. Para isso, no Capítulo 5 será apresentado um estudo de caso, discutindo a importância da discretização na obtenção de uma melhor precisão das regras geradas pelos algoritmos de Aprendizado de Máquina. A parte de descoberta de padrões é analisada no Capítulo 3. Esta parte é de suma importância já que descreve o conceito de Aprendizado de Máquina, realizando uma classificação dos algoritmos existentes de Aprendizado de Máquina, bem como algumas considerações referentes a Data Mining.

\subsubsection{Avaliação do Conhecimento Descoberto}

$\mathrm{O}$ processo KDD não termina quando os padrões nos dados de entrada são descobertos. É preciso que o especialista do domínio entenda e possa julgar a utilidade do conhecimento extraído.

A avaliação do modelo é uma tarefa bastante difícil que envolve, entre outras, a utilização de técnicas de visualização para auxiliar o especialista de domínio a decidir a importância e utilidade do conhecimento extraído, bem como na remoção de padrões redundantes e irrelevantes.

Para verificar o produto final do processo KDD - o conhecimento - a interatividade do especialista do KDD com o especialista do domínio é bastante acentuada nesta etapa. Portanto, os resultados obtidos podem acarretar mudanças a quaisquer das fases anteriores ou, ainda, o recomeço de todo o processo $\mathrm{KDD}$.

\subsubsection{Consolidação e Utilização do Conhecimento Extraído}

A consolidação do conhecimento extraído pressupõe a verificação e solução de potenciais conflitos com o conhecimento existente antes do processo KDD ser iniciado. O conhecimento pode ser organizado pelo especialista do KDD dentro de um modelo existente na aplicação ou simplesmente documentado e informado ao especialista do domínio, uma vez que é considerado útil nas tomadas de decisões.

É importante destacar que as bases de dados são dinâmicas, sofrendo mudanças constantes ao longo do tempo, e consequentemente alternado também o conhecimento. Deste modo, o processo KDD é também dinâmico, sendo convenientemente executá-lo periodicamente. 


\subsection{ELEMENTOS DE APOIO AO PROCESSO DE EXTRAÇÃO DE CONHECIMENTO DE BASES DE DADOS}

Nesta seção serão abordados três dos principais elementos de apoio ao processo KDD: Data Warehouse, Técnicas Estatísticas e Visualização de Dados. Esses elementos podem ser considerados como ferramentas de auxílio neste processo devido ao fato de que, em muitas ocasiões, seu uso faz com que o especialista do KDD encontre menos dificuldade no decorrer do processo.

Embora não seja estritamente necessário usar Data Warehouse dentro do processo KDD, na prática, é conveniente seu uso, principalmente em bases de dados de grande porte que necessitam de rápido acesso aos dados, e sobretudo de uma normalização dos mesmos, facilitando o trabalho do especialista do processo KDD. Por outro lado, as técnicas estatísticas têm um papel importante de apoio às etapas do processo $\mathrm{KDD}$, principalmente na compreensão do domínio, seleção de amostras e redução de atributos (procurando correlaçães entre eles). $O$ terceiro elemento que será abordado é a visualização dos dados que praticamente dá apoio a todas as etapas do processo KDD, mostrando de maneiras mais compreensíveis os resultados gerados em cada uma das etapas do processo. Uma melhor explicação desses três elementos será vista a seguir.

\subsubsection{Data Warehouse}

O conceito original de Data Warehouse (Repositórios de Dados) foi apresentado por William H. Inmon [Inmon 96] e popularizado pela IBM com o termo Information Warehousing. Seu uso como modelo de infra-estrutura para o suporte à tomada de decisão tem quatro objetivos fundamentais:

1. Proteger os sistemas de produção de dados e informação do acesso indiscriminado de usuários, que poderiam afetar o desempenho desses sistemas.

2. Prover um ambiente de informação protegido e bèm administrado para auxiliar o processo de tomada de decisões, já que representam um ativo importante para a empresa.

3. Construir um modelo de dados corporativo que permita uma padronização na manipulação da informação, tanto nos sistemas de produção, como nos sistemas para o suporte à tomada de decisão.

4. Manter independência entre os processo dos usuários e os da administração da informação, definindo-os como problemas independentes.

Estes objetivos marcaram o ponto de partida para que se desenvolvessem, de uma maneira prática e comercial, as diversas estratégias de implantação desse tipo de ambientes.

Data Warehouse (DW) é uma base de dados voltada ao suporte na tomada de decisão de usuários finais, derivado de outras diversas bases de dados operacionais, segregado de um ambiente transacional (On-Line Transaction Processing - OLTP) [Amaral 97]. Um DW pode ser visto como um conjunto de diversas tecnologias, tais como, plataformas de hardware, ferramentas de extração e conversão de dados, bases de dados voltadas para consultas complexas, ferramentas inteligentes de prospecção e análise de dados e ferramentas de administração e gerenciamento de bases de dados. Embora, as tecnologias incorporadas em um ambiente DW não sejam novas, as que mais evoluíram na última década foram: 
- Sistemas gerenciadores de bases de dados distribuídas que suportam processamento paralelo.

- Produtos de conversão de dados operacionais.

- Tecnologias cliente/servidor que permitem acesso a dados distribuídos em múltiplas plataformas.

- Integração de ferramentas de análise e relatório em ambiente de escritório (desktop).

Criar um DW não é uma simples questão de tecnologia de bases de dados ou processadores paralelos, envolve planejamento e modelagem (aspectos muitas vezes deixados em segundo plano, mas que garantem a qualidade dos dados que é um fator crítico para o sucesso), integração de diferentes produtos de software e uma contínua atualização e refinamento.

Uma solução bem projetada de DW objetiva satisfazer as necessidades de análise de informaç̃̃es dos usuários, como monitorar e comparar as operações atuais com as passadas, além de prever situações futuras. Ao transformar, consolidar e racionalizar as informações dispersas em diferentes bases de dados e plataformas, um DW permite que sejam realizadas análises estratégicas bastante eficazes em informaçð̃es antes inacessfveis ou subaproveitadas.

Os processos de DW estão baseados em grandes volumes de dados, principalmente históricos (5 a 10 anos) que manipulam dados em níveis analíticos e/ou sintéticos, relacionais ou "multidimensionais", entrelaçados ou não, através de consultas não previsíveis.Na Figura 2.9 é apresentado um exemplo de uma base de dados multidimensional relacionando as vendas de produtos de uma loja nessa base de dados existem várias dimensões, podendo ser feitas diferentes tipos de consultas.

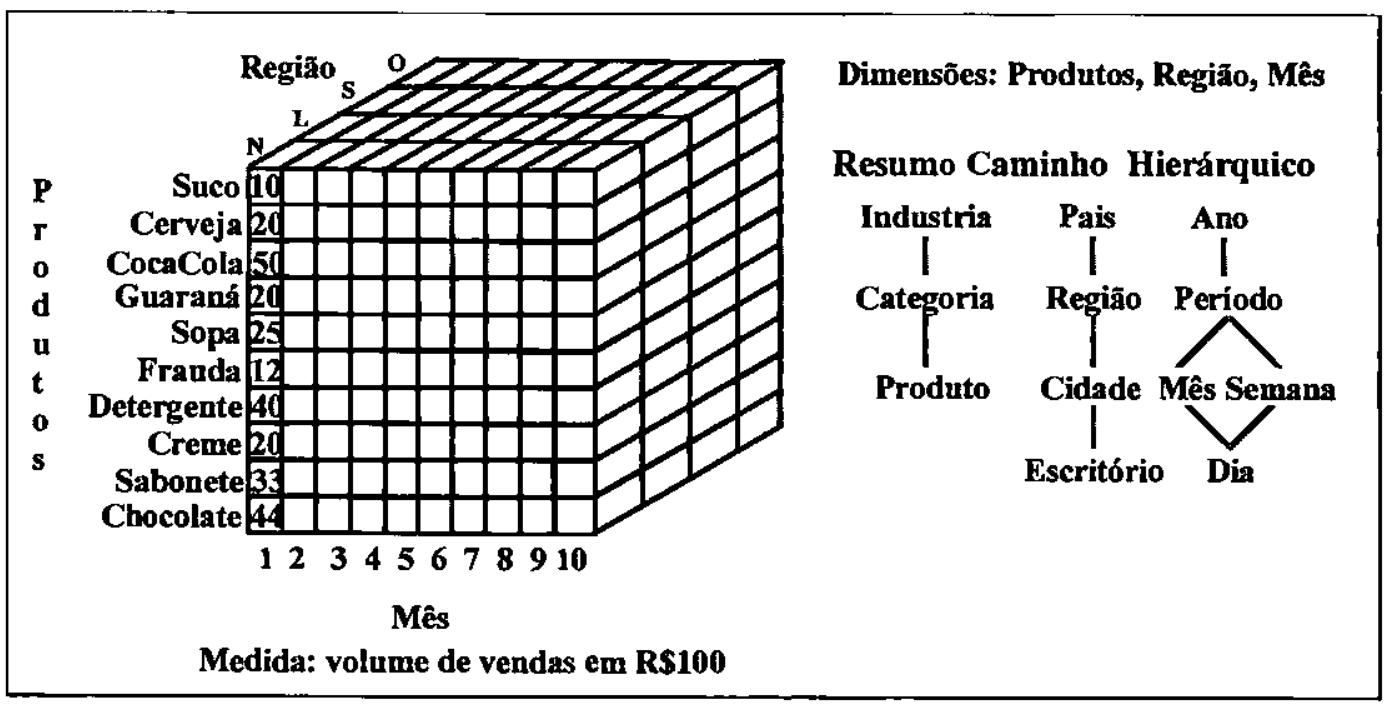

Figura 2.9: Exemplo de uma base de dados multidimensional.

A comunidade de bases de dados desenvolveu ferramentas para a análise de DW, chamadas de Processamento Analítico em Linha (On-Line Analytical Processing - OLAP), para obter informações destinadas à tomada de decisões táticas diárias da orgartização. As ferramentas OLAP enfocam análise multidimensional de dados de modo superior aos mecanismos de "resumo" (summary) e "lotes encaixantes" (quebra ou break-down) entre dimensões oferecidas pelas ferramentas tradicionais. A partir de todos estes elementos envolvidos no DW, o especialista do processo KDD aproveita essas bases de dados normalizadas, sem ruídos e feitos 
diversos tipos de consultas nelas, e pode selecionar só os atributos necessários baseados nas considerações do especialista do domínio. Os termos OLTP e OLAP são detalhados a seguir.

- OLTP (On-Line Transaction Processing): o OLTP tem como objetivo guardar a integridade da informação necessária para administrar uma organização de maneira eficiente. Esse modelo não corresponde à forma como o usuário percebe a operação de uma organização, sendo que a estrutura relacional consiste de tabelas e relações, porém a visão do usuário consiste de hierarquias e dimensões, que the permite observar os dados em diferentes perspectivas.

Os sistemas transacionais são dinâmicos no sentido que estão constantemente atualizando dados. Analisar esses dados pode apresentar resultados distintos em questão de minutos; 'e as "fotografias" desses sistemas devem-se extrair e armazenar esses resultados com um consumo adicional de recursos de armazenamento. Realizar uma análise complexa sob um sistema transacional pode resultar na degradação do sistema, com o subseqüente impacto na operação da organização.

- OLAP (On-Line Analytical Processing): OLAP surgiu como um processo para ser usado na análise de vendas e marketing, para elaborar relatórios administrativos e consolidaçóes, para orçamentos e planejamentos, para análise de rentabilidade, relatórios da qualidade e outros aplicativos que requerem uma visão flexível, partindo do topo até os níveis mais baixos da organização. OLAP se alimenta principalmente dos sistemas transacionais, e como tais, deve considerar uma eficiente administração da base de dados e prever um nível adequado de segurança.

Na Tabela 2.2 é apresentado um resumo das principais características de OLTP e OLAP (Fonte: IBM Consulting Group).

Tabela 2.2: Características de OLTP e OLAP.

\begin{tabular}{|r|c|c|}
\hline \multicolumn{1}{|c|}{ Caracteristicas do Sistema } & OLTP & OLAP \\
\hline Alcance de interação com o usuário & Transacional & Base de dados completa \\
\hline $\begin{array}{r}\text { Volume de dados efetuado por cada } \\
\text { interação com o usuário }\end{array}$ & Registros individuais & Grupos de registros \\
\hline Tempo de resposta & Segundos & Menos de um minuto \\
\hline Utilização da máquina & Estática & Dinâmica \\
\hline Tipo de dado & Primitivo (dados mais detalhados) & Derivado (cálculos e consolidaç̃̃es) \\
\hline Tipo de acesso à base de dados & $\begin{array}{c}\text { Acesso estático predefinido entre } \\
\text { as rotas e relações entre dados }\end{array}$ & $\begin{array}{c}\text { Não está definido o acesso dinâmico } \\
\text { entre as rotas e relações entre dados }\end{array}$ \\
\hline Volatilidade dos dados & $\begin{array}{c}\text { Alto (os dados mudam em cada } \\
\text { transação). Alto desempenho }\end{array}$ & $\begin{array}{c}\text { Baixo (os dados não mudam muito } \\
\text { na duração da consulta) }\end{array}$ \\
\hline
\end{tabular}

\subsubsection{Métodos Estatísticos no Tratamento dos Dados}

A Estatística é a área da matemática que estuda a coleta, organização e interpretação de dados numéricos, especialmente a análise de características da população por inferências a partir de amostras [Glymour 97].

As ferramentas estatísticas de hoje trabalham com um rico conteúdo de pesquisas teóricas e metodológicas, onde alguns são mostradas na Tabela 2.3 [Glymour 97]. Os estatísticos têm desenvolvido uma grande infra-estrutura teórica para suportar seus métodos, e linguagens para 
descrever uma aproximação dos modelos, quantificando a incerteza associada às inferências a partir dos dados. Estes métodos permitem, entre outras funções, descrever relações entre variáveis para previsão ou quantificar efeitos entre elas.

Tanto KDD quanto estatística referem-se à "aprendizado a partir dos dados" ou a "conversão dos dados em informação", mas o contexto KDD tem uma ênfase um pouco diferente. Em particular, KDD envolve análises "retrospectivas" de dados: assim, tópicos como desenho de experimentos estão fora do âmbito de $\mathrm{KDD}$, mas dentro da estatística formal. Existe um enfoque em modelos interpretáveis relativamente simples envolvendo regras, árvores de decisão, grafos, etc. Aplicações que envolvem um número muito grande de variáveis e números vastos de medidas também são comuns em KDD. Assim, a eficiência computacional e escalabilidade são extremamente importantes e assuntos de consistência estatística podem ser uma consideração secundária. Além disso, a prática atual de KDD é freqüentemente focada a padrões em vez de modelos, por exemplo, uma vez que se constrói um modelo global coerente que inclui todas as variáveis de interesse, os algoritmos utilizados por Data Mining produzem conjuntos de declarações sobre dependências locais entre variáveis (em forma de regra).

Tabela 2.3: Áreas de Trabalho da Estatistica.

\begin{tabular}{|l|l|}
\hline \multicolumn{1}{|c|}{ Área de estatística } & \multicolumn{1}{c|}{ Descrição de atividades } \\
\hline Desenho de experimentos e amostragem. & Como selecionar casos si se tem a liberdade de \\
& escolha. \\
Análise exploratório de dados. & Geração de hipótese antes do teste de hipótese. \\
Estatística gráfica. & Visualização de dados. \\
Modelagem estatística. & Técnicas de classificação e regressão. \\
Inferência estatística. & Técnicas de estimativa e previsão. \\
\hline
\end{tabular}

Mais detalhes podem ser encontrados em [Glymour 97].

\subsubsection{Visualização de Dados}

As ferramentas de visualização de dados estão se tornando cada vez mais importantes no processo $\mathrm{KDD}$, pois permitem aumento na capacidade de análise e de interpretação dos resultados obtidos [Rezende 98b]. Existem certas abordagens que tentam unir visualização com a etapa de Data Mining, como a de Peter Brooks [Brooks 97], que diz: "a visualização dos dados por si só pode ser uma forma completa de aplicação de Data Mining". Este trabalho trata estas duas áreas como interligadas, mas independentes, Data Mining é mais que uma visualização de dados.

Por outro lado, na maioria dos casos a visualização de dados pode ser usada como uma ferramenta exploratória na análise de dados. Um especialista em visualização pode construir diferentes exibições de dados para determinar os gráficos mais significativos. O número e tipo de exibições de dados que estão sendo geradas depende da capacidade ou discernimento do especialista em visualização. Por exemplo, na Figura 2.10 é apresentado um mapa dinâmico dos estados do Brasil, no qual é possível observar a evolução das vendas de várias lojas classificadas por estados, em um período de 8 anos, que pode, por exemplo, auxiliar na determinação de um critério de investimento. 
A visualização dos dados permite que sejam incorporadas informações diretamente à capacidade de percepção do especialista do domínio. Existem algumas restrições de visualização: muitas pessoas não têm orientação espacial, principalmente em gráficos $3 \mathrm{D}$ ou 4D; pessoas daltônicas que não conseguem distinguir as partes que compõem um gráfico quando são diferenciadas por cores; aspectos de hardware como resolução dos monitores, suporte de cores, e desempenho do computador são levados em consideração quando se refere a visualização.

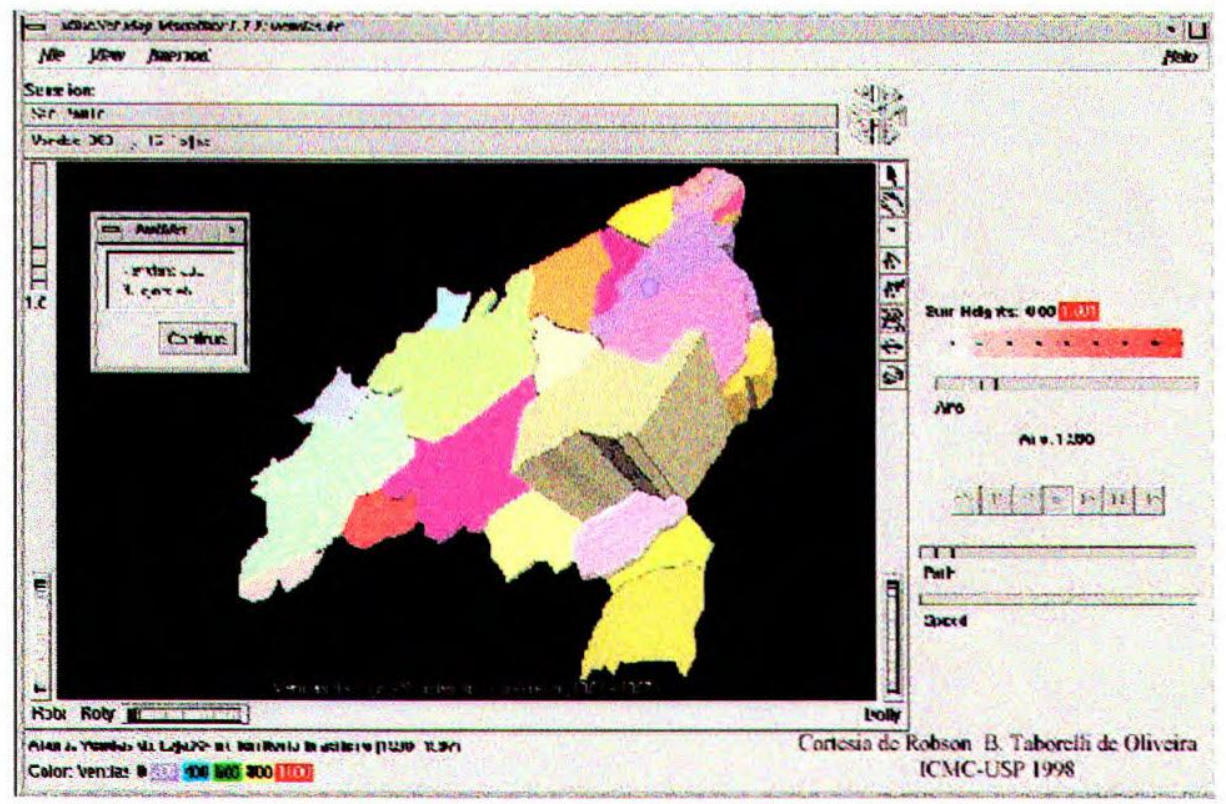

Figura 2.10: Mapa gerado através do MineSet.

Dois tipos primários de ferramentas são usadas para realizar aplicações para visualização dos dados: as linguagens de programação especializadas e as ferramentas Graphic User Interface (GUI). O desenvolvimento das linguagens de programação de visualização dos dados, que às vezes trabalha junto com uma ferramenta GUI, é executado com as seguintes etapas [Brooks 97]:

1. Extração de todos os dados ou de um subconjunto de dados, a partir de sua origem para o ambiente da ferramenta de visualização de dados.

2. Exploração dos dados com a ferramenta de visualização dos dados.

3. Identificação das principais necessidades de visualização e das interações com o usuário.

4. Uso da linguagem de programação para desenvolver gráficos personalizados e diálogos com o usuário.

5. Inserção das aplicações desenvolvidas ao menu de ferramentas da GUI ou à biblioteca de gráficos.

A maioria das ferramentas GUI permitem que os desenvolvedores acessem e analisem os dados, selecionem os gráficos de visualização a partir de um conjunto predefinido de modelos, personalizem os gráficos e depois os adicionem a uma biblioteca para que os usuários finais possam acessá-los. O desenvolvimento da visualização dos dados com essas ferramentas, geralmente, é realizado de forma iterativa através das seguintes etapas:

1. Extração de todos os dados a partir de sua origem para o ambiente da ferramenta de visualização de dados. Geralmente, depois que os dados são carregados, todos os gráficos estão disponíveis para pesquisa e exploração.

2. Personalização dos modelos gráficos que interessem. 
3. Exploração dos dados através do exame de gráficos, da alteração do esquema de cores, da rotação dos gráficos e/ou isolamento das áreas de interesse para investigação mais detalhada.

4. Acréscimo dos gráficos selecionados ao menu de ferramentas da GUI ou à biblioteca acessivel.

As linguagens de programação de visualização de dados são apropriadas nos casos que se exigem gráficos especializados além dos disponíveis no mercado. Também se devem ter habilidades de programação necessárias na criação de gráfico, por exemplo, em $\mathrm{C}$ ou $\mathrm{C}++$. As ferramentas da GUI são apropriadas quando a visualização dos dados não precisa exceder suas capacidades gráficas.

Para os usuários das ferramentas avançadas de visualização de dados, geralmente é necessário treinamento em análise estatística e deve ter uma compreensão profunda dos dados que estão sendo analisados, ao contrário das ferramentas que têm capacidade de visualização mais simples e que são facilmente entendidas por um usuário esporádico.

\subsection{FLUXO DO PROCESSO DE EXTRAÇÃO DE CONHECIMENTO DE BASES DE DADOS}

$\mathrm{O}$ controle de fluxos no processo KDD é geralmente um processo iterativo de consultas, análises de tarefas, coleção de dados das bases de dados, padrões de busca e apresentação das decisões. $\mathrm{Na}$ Figura 2.11 são mostradas todas as etapas e os elementos de apoio do processo KDD visando uma aproximação do fluxo de dados dentro do processo [Fayyad 97].

Pode ser visto nessa figura, que a depuração do conhecimento é altamente recursiva devido ao fato de que o conhecimento obtido é avaliado, tanto pelo especialista do KDD como pelo especialista do domínio, e são eles que determinam o passo que deve ser verificado novamente, se for o caso.

Nem todas as etapas e elementos de apoio no processo KDD podem ser aplicados, mas vale ressaltar que todos esses passos são importantes; uma análise mal realizada, uma seleção de amostras ou uma normalização errada podem prejudicar muito o resultado final desse processo.

Neste fluxo de dados, embora não tenha sido colocado, a visualização dos dados pode acompanhar todas as etapas e elementos dentro do processo $\mathrm{KDD}$, apoiando tanto o especialista do processo $\mathrm{KDD}$, como o especialista do domínio.

\subsection{ALGUNS PROBLEMAS RELACIONADOS COM O PROCESSO DE EXTRAÇÃO DE CONHECIMENTO DE BASES DE DADOS}

Nesta seção serão tratados alguns dos principais problemas relacionados ao processo KDD e algumas das medidas que podem ser tomadas para evitá-los. Os problemas existentes dentro da etapa de Data Mining serão tratados na Seção 5 do Capítulo 3 referente a Data Mining. 


\subsubsection{Definição de Objetivos}

Claridade sobre metas a serem atingidas influencia diretamente o êxito ou fracasso do KDD. Alguma vezes, uma análise cuidadosa dos dados ajuda a encontrar uma representação computável conveniente e fácil. Faz-se necessário ter um conhecimento aprofundado da base de dados, para assim determinar as possíveis metas a serem alcançadas. Em outras situações, a análise de dados ajuda a prever características de novos casos, ou novas amostras, desenvolvendo um modelo para prevê-los provindo um plano de políticas ou procedimentos. Cada uma destas formas de análise apresenta problemas distintos, sendo provável chegar a conclusões que indiquem que não é possível obter nenhum conhecimento da base de dados, devido entre outros, ao fato de que os algoritmos podem não conseguir classificar corretamente todos os conjuntos de exemplos.

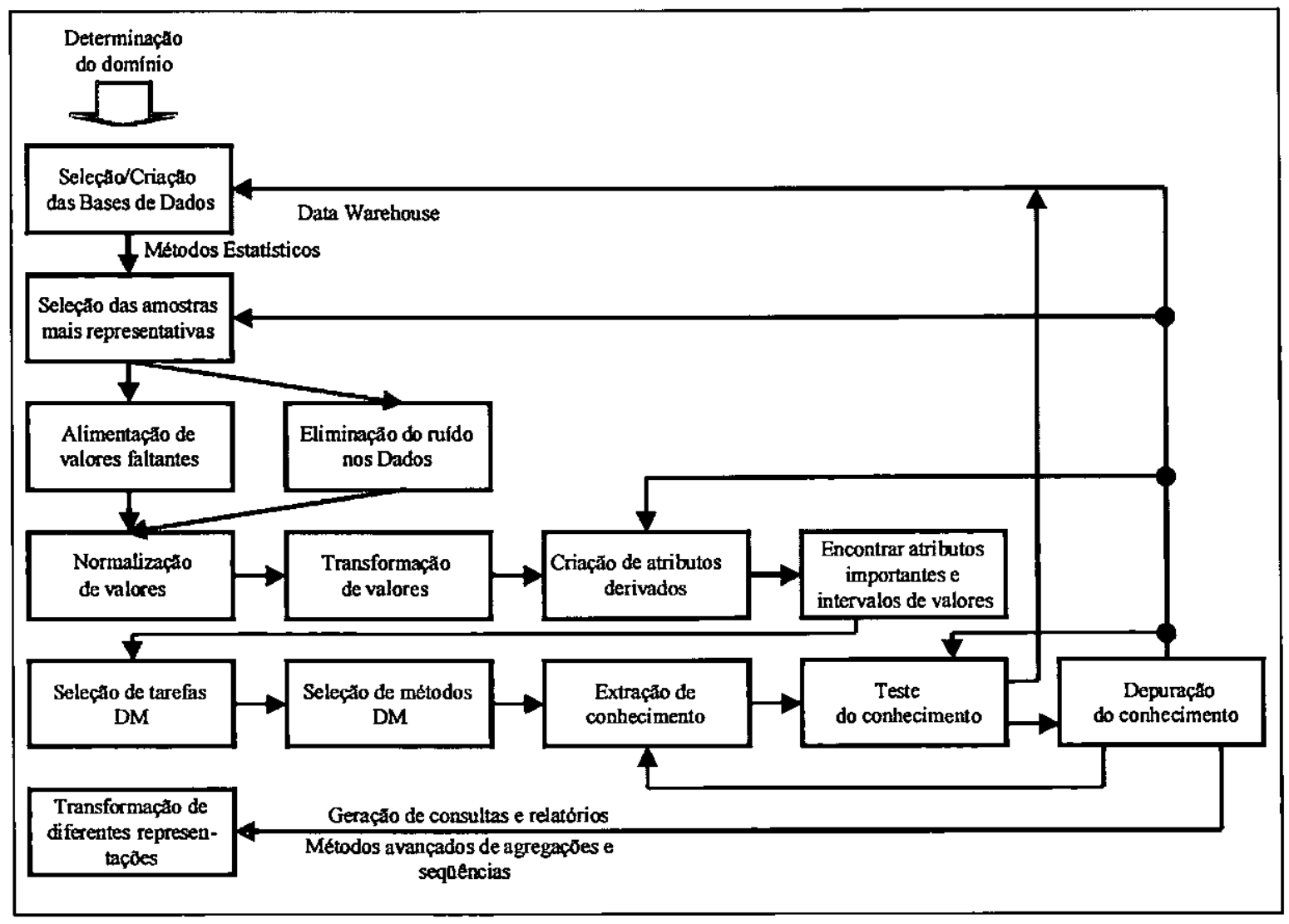

Figura 2.11: Fluxo de dados em um processo KDD.

Foi observado, por outro lado, que a resposta à pergunta: "o que se quer obter a partir dos resultados finais?" representa um ponto crucial para trabalhos futuros. Em experimentos realizados neste trabalho, notou-se que uma vez que foi mostrado o provável conhecimento ao especialista do domínio, ele começou a solicitar uma grande quantidade de permutações nos conjuntos de dados, tentando descobrir novos conhecimentos. Com todas essas permutações, ele acabou-se perdendo por não definir bem as suas metas.

É necessário contar com uma capacidade de orientação por parte do especialista do KDD, para poder controlar a "ansiedade" do especialista do domínio. Uma solução útil é mostrar os resultados obtidos de uma forma controlada, através de um "planejamento do fornecimento do 
conhecimento" para que o especialista do domínio possa analisar e assimilar todo o conhecimento.

\subsubsection{Dados Mal Interpretados}

Tipicamente, as aplicações de KDD confiam em dados observados (em oposição aos experimentais). Interpretar as associações observadas em tais dados é um desafio; inferências relevantes exigem análises cuidadosas e considerações detalhadas dos fatores subiacentes. F́. apresentado aqui um exemplo detalhado que sustenta esta posição.

Wen [Wen 95] analisou registros administrativos de todas as divisõés do hospital público de Ontário (altas, transferências, ou mortes dentro do hospital) de 1981 até 1990, concentrando-se especificamente em pacientes que haviam feito uma colecistotomia aberta primária. Alguns desses pacientes também haviam feito uma apendicectomia incidental (ou "discricionário") durante o procedimento de colecistotomia.

Na Tabela 2.4 são exibidos os resultados das mortes ocorridas no hospital, bem como os sobreviventes que passaram pelo tratamento de colecistotomia aberta primária com e sem apendicectomia incidental. Um teste chi-quadrado comparando os resultados para os dois grupos de pacientes mostra uma diferença "estatisticamente significante". Esta "descoberta" é surpreendente, visto que a prevenção em longo prazo de apendicite é a única base racional para o processo de apendicectomia incidental - nenhuma melhora em curto prazo nos resultados é esperada. Esta "descoberta" pode fazer com que um diretor de hospital ingênuo conclua que todos os pacientes de colecistotomia devem fazer uma apendicectomia incidental para melhorar suas chances de ter um bom resultado. Fica bem claro que algo está errado - como uma apendicectomia incidental poderia melhorar os resultados?

Tabela 2.4: Número de sobreviventes e mortes ocomidas no hospital.

\begin{tabular}{|l|c|c|}
\hline & $\begin{array}{c}\text { Com } \\
\text { Apendicectomia }\end{array}$ & $\begin{array}{c}\text { Sem } \\
\text { Apendicectomia }\end{array}$ \\
\hline No. de mortes ocorridas no hospital, \% & $21,(0,27 \%)$ & $1394,(0,73 \%)$ \\
\hline No. de sobreviventes no hospital, \% & $7825,(99,73 \%)$ & $190205,(99,27 \%)$ \\
\hline
\end{tabular}

Wen considerou separadamente um subgrupo de pacientes de baixo risco. Para estes pacientes (usando dez definições diferentes de "baixo risco"), a apendicectomia casual de fato teve resultados muito insatisfatórios. Paradoxalmente, poderia ser até o caso de que apendicectomia adversamente afete os resultados tanto para pacientes de alto, quanto para os de baixo risco, porém surge para afetar positivamente os resultados quando os pacientes de alto e baixo risco estão agrupados. Wen não fornece dados suficientes para verificar se este chamado "Paradoxo de Simpson" [Simpson 51] ocorreu neste exemplo. Contudo, a Tabela 2.5 apresenta dados que são plausíveis e coerentes com os dados de Wen.

A Tabela 2.6 exibe as proporções correspondentes de mortes dentro do hospital classificadas por apendicectomia incidental e grupos de pacientes de risco para estes dados fictícios. Evidentemente as categorias de risco e morte estão diretamente correlacionadas. Além disso, apendicectomias são mais prováveis de serem colocadas em prática nos pacientes de baixo risco do que naqueles de alto risco. Assim, se não é conhecida a categoria de risco (idade) de um 
paciente, sabendo que ele passou por uma apendicectomia, permite deduzir que é mais provável para o paciente fazer parte do grupo de baixo risco (jovens). Porém, isto não implica, de modo algum, que passar por uma apendicectomia irá diminuir o risco de alguns pacientes. Entretanto, quando o risco é omitido da tabela, uma conclusão ilusória exatamente igual aparece justificada a partir dos dados.

Tabela 2.5: Dados fictícios coerentes com os dados de Wen.

\begin{tabular}{|l|c|c|r|r|}
\hline & \multicolumn{2}{|c|}{$\begin{array}{c}\text { Com } \\
\text { Apendicectomia }\end{array}$} & \multicolumn{2}{c|}{$\begin{array}{c}\text { Apem } \\
\text { Apendicectomia }\end{array}$} \\
\hline & Baixo risco & Alto risco & Baixo risco & Alto risco \\
\hline Mortes & 7 & 14 & 100 & 1294 \\
\hline Sobreviventes & 7700 & 125 & 164009 & 26196 \\
\hline
\end{tabular}

Tabela 2.6: Proporção de mortes dentro do hospital para os dados fictícios da Tabela 2.5.

\begin{tabular}{|l|c|c|}
\hline & $\begin{array}{c}\text { Com } \\
\text { Apendicectomia }\end{array}$ & $\begin{array}{c}\text { Sem } \\
\text { Apendicectomia }\end{array}$ \\
\hline Baixo risco & 0,0009 & 0,0006 \\
\hline Alto risco & 0,1000 & 0,0500 \\
\hline Combinado & 0,0030 & 0,0070 \\
\hline
\end{tabular}

Retornando aos dados originais, Wen fornece uma análise de regressão mais sofisticada, ajustado para muitas variáveis que podem confundir a análise (por exemplo, idade, sexo, status da entrada no hospital). Eles concluem que "não há base, de forma alguma, para uma melhora em curto prazo nos resultados devido à apendicectomia incidental". Estas análises cuidadosas condizem com o senso comum neste caso.

Em geral, uma análise de dados demanda um cuidado especial no momento de ser interpretada.

\subsubsection{Incerteza nos Dados}

A abordagem estatística afirma que expor uma única variável a uma estimativa de parâmetro ou a uma única previsão é quase sempre inadequado. A quantificação da "incerteza" associada a uma única variável, embora freqüente desafio, é decisiva para uma tomada de decisão subsequiente. Como um exemplo, D. Draper [Draper 95], considerou o caso do Energy Modeling Forum (EMF) de 1980 na Universidade de Stanford, onde um grupo de trabalho de 43 pessoas, entre economistas e especialistas em energia, reuniram-se para prognosticar os preços do petróleo mundial (a única variável) de 1981 até 2020. O grupo gerou as previsões com base em vários modelos e cenários econométricos, incorporando um variedade de suposições sobre abastecimento, demanda, e taxas de crescimento de quantidades relevantes. Um modelo e cenário de referência plausível foi selecionado como representativo, mas o resumo do relatório [EMF 82] advertiu contra previsões no ponto da interpretação, baseados no cenário de referência como “ 'o prognóstico' (do grupo de trabalho) sobre o futuro do petróleo, visto que existem muitas incógnitas para admitir qualquer projeção como um prognóstico". O resumo do relatório concluiu, entretanto, que a maior parte da incerteza sobre os futuros preços de petróleo "não se preocupa se esses preços irão aumentar, mas sim quão rapidamente eles aumentarão". 
Em 1980, o preço médio do petróleo bruto estava em torno de $\$ 32$ o barril. Apesar da advertência sobre a incerteza potencial associada às estimativas de ponto, os governos e companhias privadas de todo o mundo concentraram-se na última sentença da citação acima e passaram a investir uma estimativa de 500 bilhões de dólares, com base no fato de que o preço provavelmente estaria perto de $\$ 40$ o barril, na metade dos anos 80 . Na verdade, o preço médio real do petróleo no mundo em 1986 estava em torno de $\$ 13$ o barril.

Usando apenas a informação disponível para o EMF em 1980, com métodos estatísticos ponderados, porém elementares, D. Draper [Draper 95] mostra que um intervalo previsto de $90 \%$ para o preço de 1986 variaria cerca de $\$ 20$ até mais de $\$ 90$. Observa-se que este intervalo realmente não contém o preço real de 1986. Porém, os responsáveis pela decisão tomada teriam (e deveriam ter) agido mais cautelosamente em 1980, se tivessem entendido suas incertezas por inteiro.

Certamente os cálculos das diferentes fontes de incerteza apresentam desafios significativos. Até recentemente, a literatura sobre estatística concentrou-se primeiramente em medir a quantidade de incerteza prevista e parametrizadas "no contexto de um modelo particular". Duas abordagens distintas são usadas em comum. Em geral, estatísticos concentram-se na casualidade de dados de amostras e resumem a casualidade induzida em parâmetros e previsões pela comumente denominada "distribuição de amostras". Os estatísticos Bayesianos usam o "Teorema de Bayes" para transformar a opinião anterior sobre quantidades de interesse (sempre representadas por uma distribuição de probabilidade) em uma chamada "distribuição posterior", que abrange toda informação disponível. Os grandes conflitos entre as gerações anteriores de estatísticos gerais e Bayesianos tem amplamente dado lugar, em anos recentes, a uma abordagem mais pragmática, sendo que muitos dos estatísticos irão basear sua escolha de ferramentas por conveniência e adequação científica.

\subsubsection{Ruido}

Assumindo também que a informação provida no conjunto de dados está totalmente correta, infelizmente, é muito improvável que os Sistemas de Aprendizado de Máquina que usam dados do mundo real achem que esta suposição possa ser sustentável. Os exemplos podem incluir atributos baseados nas medidas subjetivas e de juízo, ambas podem dar lugar a erros. Alguns dos exemplos podem estar até mesmo não classificados. Os erros não sistemáticos deste tipo em cada um dos valores dos atributos ou informação da classe normalmente são chamados de "ruído".

O ruído causa dois problemas: em primeiro lugar, quando as descrições geradoras usam um conjunto de treinamento ruidoso e em segundo lugar, quando os casos com ruído são classificados usando estas descrições.

Construindo descriçôes: se o sistema tem que construir descrições em um ambiente com ruído, este deveria ser impedido de construir descrições que tentam cobrir exemplos corrompidos. Então, deve ser capaz de decidir que um exemplo em particular - ou um atributo neste exemplo - está corrompido e assim deveria ser ignorado.

J. R. Quinlan [Quinlan 86a] usa técnicas estatísticas para decidir se um atributo deverá ser adicionado a uma árvore de classificação. A idéia básica é que uma pequena quantia de dados excepcionais é considerada por ser causada por ruído e então pode ser desprezada. 
O ruído também pode afetar a informação da classe de um exemplo que tem um impacto dramático na precisão da classificação das regras geradas. Então, uma tentativa deveria ser feita para eliminar rú́do que afeta a informação da classe dos casos no conjunto de treinamento.

Classificando exemplos: uma vez que foram construídas descrições do conjunto de treinamento, elas podem ser usadas em regras de classificação para determinar a classe de exemplos previamente não vistos. Em experiências com alguns sistemas, adicionando ruído para os dados resultaram em uma "degradação atrativa": adicionando ruído significativo resulta em baixos níveis de desclassificação de exemplos não vistos.

Um fenômeno interessante, discutido em [Quinlan 86a, Quinlan 86b], é que as regras, aprendidas de um conjunto de treinamento corrompido, desempenham-se de uma forma superior sobre a classificação de dados com ruído quando são comparadas com as regras que são aprendidas sobre o mesmo conjunto de treinamento, mas livre de ruído. Quinlan [Quinlan 86a] conclui que "não vale a pena gastar esforço para eliminar ruídos nos valores dos atributos dos casos no conjunto de treinamento se vai existir uma quantidade significante de ruído quando a regra de classificação induzida seja usada na prática".

\subsection{CONSIDERAÇÕES FINAIS}

Neste capítulo foi apresentada uma visão geral do processo KDD. Este processo é composto por várias etapas, nas quais cada uma delas é extremamente importante para obter um conhecimento com alto grau de confiança. Além disso, é importante ressaltar que dentro de cada etapa do processo podem existir outras sub-etapas.

Como foi citado anteriormente, existe uma confusão entre os pesquisadores acerca do significado exato dos termos Data Mining e KDD devido a que alguns deles os consideram como sinônimos. $\mathrm{Na}$ Primeira Conferência Internacional sobre Descoberta de Conhecimento e Data Mining realizada em Montreal, Canadá, em 1995, foi proposto que o termo KDD seja usado para descrever o processo total de extração de conhecimento a partir dos dados. Por outro lado, o termo Data Mining deve ser usado exclusivamente para o estado de descoberta de padrões dentro deste processo.

Vale ressaltar que KDD não é uma nova tecnologia, é um campo multidisciplinar de pesquisa no qual Aprendizado de Máquina, Estatística, Tecnologias de Bases de Dados, Sistemas Inteligentes e Ferramentas de Visualização contribuem no seu processo, como é apresentado na Figura 2.12.

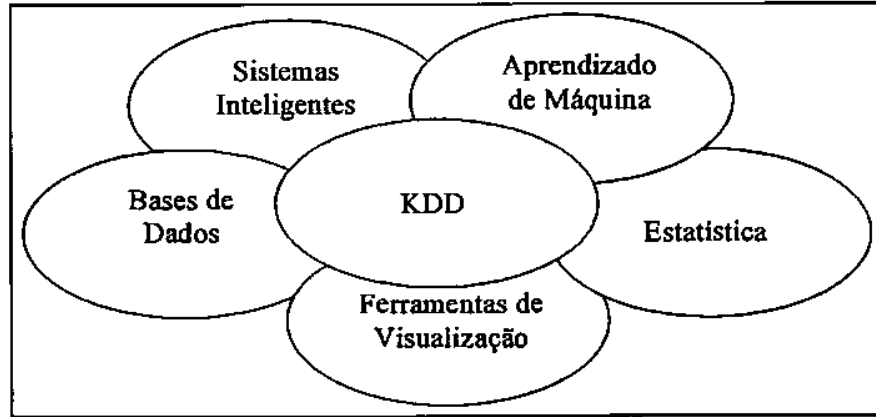

Figura 2.12: Áreas de apoio ao KDD.

No próximo capítulo será discutida com mais detalhes a etapa de Data Mining por ser o tema central deste trabalho. 


\section{Capítulo 3}

Fatos descobertos a partir de uma pesquisa feita nos restaurantes dos Estados Unidos:

Cidades com prefeito republicano servem em torno de $15 \%$ mais pratos com carne vermelha que com um democrata.

Cidades com prefeito democrata tendem a servir mais comida frita, queijo de cabra e creme pesto.

- The Belly Barometer Survey Results

\section{DATA MINING}

\subsection{CONSIDERAÇÕES INICIAIS}

Uma base de dados pode ser um repositório de dados seguro, quase sempre fidedigno, visando entre seus principais propósitos, a recuperação eficiente dos dados, para serem transformados em informação. Esta recuperação nem sempre é uma cópia fiel dos dados armazenados na base de dados, porque muitas vezes pode ser inferida a partir da base de dados [Holsheimer 94]. De uma perspectiva lógica, podem ser distinguidas duas técnicas de inferência: a dedução e a indução.

A dedução é uma técnica que infere informação como uma "conseqüência lógica" dos dados. A maioria dos sistemas de gerenciamento de bases de dados (Database Manager Systems DBMS), como um DBMS relacional, oferece operadores simples, usando a linguagem SQL (Structured Query Language) para a dedução de informação.

A indução é uma técnica para inferir informação que é "generalizada" a partir dos dados, sendo então uma informação de "alto-nível": declarações gerais sobre as propriedades dos casos.

A diferença principal entre dedução e indução é que na primeira os resultados estão formulados em declarações provavelmente corretas sobre o mundo real, considerando que os dados estejam corretos, enquanto que na segunda, só resulta em declarações gerais que são apoiadas pelos dados, mas não necessariamente verdadeiras no mundo real. Um dos aspectos mais importantes do processo de indução é, então, a seleção de regras mais plausíveis e de regularidades suportadas pelos dados.

A inferência da informação de uma base de dados normalmente está acima da capacidade humana, simplesmente por causa do grande tamanho das bases de dados, assim, o processo de inferência deveria ser suportado pelo DBMS. Alem disso, todos os DBMSs suportam dedução da informação, mas nenhum suporta indução. Porém, existe um interesse crescente em KDD e Data Mining, tanto em pesquisa como em aplicações, para que estes venham a suportar indução.

Um dos objetivos da inferência por indução é prever situações em um ambiente através da criação de um modelo. Uma discussão de aprendizado indutivo através de modelos é tratada no Apêndice D. 
Neste capítulo será abordada uma forma de aprendizado indutivo através dos computadores chamada Aprendizado de Máquina, que usando algoritmos tentam encontrar padrões a partir de um conjunto de dados. Posteriormente serão tratados alguns dos aspectos mais relevantes relacionados à etapa de Data Mining, visto que, geralmente, baseado nesses algoritmos de Aprendizado de Máquina, esta etapa tem como principal objetivo encontrar padrões a partir de um conjunto representativo da base de dados.

\subsection{APRENDIZADO DE MÁQUINA}

O estudo e modelagem dos processos de aprendizado indutivo através de computadores são assuntos da área de "Aprendizado de Máquina" (Machine Learning) [Carbonell 87]. Um sistema de Aprendizado de Máquina (AM) não interage diretamente com o seu ambiente, mas usa observações codificadas, freqüentemente armazenadas em um "conjunto de dados".

Um sistema de AM utiliza um pequeno conjunto de dados de laboratório cuidadosamente selecionados, tentando classificá-los através um sistema de alto nível chamado "classificador". A forma mais simples para representar um classificador seria uma "caixa preta", que aceita um conjunto de treinamento como entrada e produz uma regra como saída para que uma tomada de decisão seja feita a partir dela. O objetivo dos sistemas de AM é moldar a estrutura do classificador para um problema específico, encontrando uma forma genérica de relatar qualquer padrão particular de observações em uma das classes especificadas nesse classificador.

Dado um conjunto de dados, e possivelmente algumas classes definidas por um especialista do domínio, um sistema de Aprendizado de Máquina pode construir várias descriçães. Algumas dessas são mais corretas do que outras, ou seja, algumas descrições são mais prováveis que classifiquem corretamente exemplos não vistos. A construção de uma descrição é nada mais do que um "problema de busca": encontrar a melhor descrição no conjunto a partir de todas as descrições construídas $D$ [Holsheimer 94].

Quando existe um conjunto de treinamento muito grande, é preciso contar com um "algoritmo de busca eficiente". A maioria dos sistemas de Aprendizado de Máquina escolhem uma descrição inicial e, iterativamente, a modificam até melhorar a sua qualidade. Estas modificações são operaç̃̃es feitas na descrição. $O$ conjunto de descrições, junto com essas operações e a função de qualidade, são chamados de "espaço de busca" [Nilsson 92]. O espaço de busca $\langle D, O, f\rangle$ consiste de: um conjunto de descrições $D$, um conjunto de operações sobre essas descrições $O$ e uma função de qualidade $f$.

O "conjunto de todas as descrições" construidas dada uma representação em particular é chamado de "espaço de descrição" $D$. Para cada descrição $D$ em $D$ corresponde um subconjunto do conjunto de dados $S$, chamado de "cobertura" $\sigma_{D}(S)$.

Pode-se dividir o "conjunto de todas as operações $O$ " em operações de "generalização", que "enfraquecem" a descrição, por exemplo, fazendo a cobertura de mais casos, e operações de "especialização" que "fortalecem" a descrição reduzindo sua cobertura: Os termos generalização e especialização são definido a seguir:

- Generalização: aplicando uma operação de generalização a uma descrição $D$, resulta em uma nova descrição $D^{\prime}$ que cobre mais casos, por exemplo, $\sigma_{D}(S) \subseteq \sigma_{D}(S)$. 
Conseqüentemente, se um caso é coberto pela descrição $D$, também é coberto pela descrição $D^{\prime}$, mas a operação contrária não é garantida. Assim sendo a operação de generalização não preserva a verdade, por exemplo, se uma regra classifica os casos corretamente, então uma generalização dessa regra não necessariamente será correta. Porém, as regras de generalização preservam as falsidades: se um caso é classificado incorretamente pela regra (por exemplo, um caso é coberto por $D$, mas não é um exemplo da classe $C$, assim o caso falsifica a regra), então também falsificará quaisquer das generalizações dessa regra.

- Especialização: a operação de especialização é a inversa da operação de generalização, o que significa que o conjunto $S_{i}$ será substituído por $S_{i}^{\prime}$ e $S_{i} \supset S_{i}^{\prime}$. As técnicas de especialização buscam induzir novos conceitos partindo de uma descrição o mais geral possível e aplicando restrições a está descrição. A princípio, tal descrição é capaz de cobrir exemplos negativos e positivos, e as sucessivas restrições à descrição buscam torná-la consistente, ou seja, incapaz de cobrir exemplos negativos.

A "função de qualidade" atribui um valor, por exemplo, no domínio de 0 a 1, para cada descrição, indicando sua qualidade. Existem dois aspectos para a qualidade de uma descrição. Uma déscrição deve ser em geral "válida", ou seja, deve classificar corretamente qualquer caso não visto. Além disso, a descrição deve ser "correta" a respeito das classes definidas pelo especialista do domínio. Pode-se combinar este critério, atribuindo um valor para cada critério e usando uma função para calcular a qualidade global.

Alguns pesquisadores tem desenvolvido vários algoritmos de Aprendizado de Máquina para gerar, entre outras, regras de produção ou árvores de decisão, apresentando cada um dos algoritmos suas vantagens e desvantagens. Embora, não seja preciso conhecer profundamente seu funcionamento, é importante conhecer de um modo geral como os algoritmos trabalham e que tipo de saídas geram. Perante uma grande quantidade de algoritmos desenvolvidos, é importante fazer uma classificação para um melhor entendimento do seu domínio de aplicação. A seguir será discutida uma forma para classificar esses algoritmos.

\subsection{CLASSIFICAÇÃO DOS ALGORITMOS DE APRENDIZADO DE MÁQUINA}

Classificar os algoritmos de Aprendizado de Máquina não é uma tarefa fácil, pois existem uma infinidade de métodos para agrupá-los. Neste trabalho foi feito uma síntese dos métodos de classificação a partir da forma de como um algoritmo de Aprendizado de Máquina aprende, para depois ser dividido de acordo com seu paradigma, e então partir para uma classificação considerando a linguagem utilizada para descrever o aprendizado, e finalmente, classificá-los pelo modo em que podem ser integrados novos exemplos. Na Figura 3.1 é mostrada esta classificação e posteriormente será explicada cada parte dela.

\subsubsection{Por Tipo de Aprendizado}

A forma básica de classificar os algoritmos de Aprendizado de Máquina, de acordo como eles aprendem é: aprendizado supervisionado e aprendizado não supervisionado.

Aprendizado supervisionado: no aprendizado supervisionado ou aprendizado dirigido, o especialista do domínio apoia o sistema na construção do modelo, definindo as classes e 
alimentado-a com exemplos de cada classe, por exemplo, casos pré-classificados. O sistema deve encontrar regras capazes de classificar novas observações a partir das classes já existentes. $\mathrm{O}$ especialista do domínio pode definir uma única classe ou múltiplas classes [Dietterich 83]:

\begin{tabular}{|c|c|c|c|}
\hline TIPO DE APRENDIZADO & $\begin{array}{l}\text { PARADIGMAS DE } \\
\text { APRENDIZADO }\end{array}$ & $\begin{array}{l}\text { LINGUAGENS DE } \\
\text { DESCRIÇÃO }\end{array}$ & \begin{tabular}{|l|} 
MODO EM QUE NOVOS \\
EXEMPLOS SÃO \\
INTEGRADOS
\end{tabular} \\
\hline $\begin{array}{l}\text { - } \quad \text { SUPERVISIONADO } \\
\text { - NÃO SUPERVISIONADO }\end{array}$ & 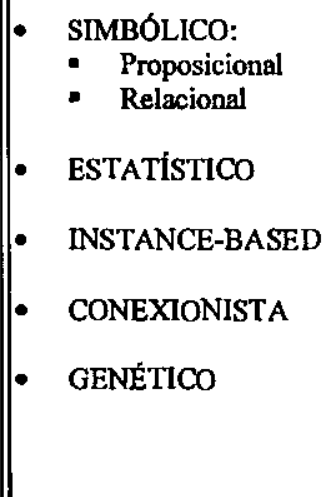 & \begin{tabular}{||l} 
DE EXEMPLOS OU \\
INSTÂNCIAS \\
DE HIPÓTESES OU \\
CONCEITOS \\
APRENDIDOS \\
- Regras de Produção \\
- Árvores de Decisão \\
Dedes Semânticas \\
DE TEORIA DE \\
DOMfNIO OU \\
CONHECIMENTO DE \\
FUNDO
\end{tabular} & $\begin{array}{l}\text { - INCREMENTAL } \\
\text { - NÃO INCREMENTAL }\end{array}$ \\
\hline
\end{tabular}

Figura 3.1: Uma forma de classificar os algoritmos de Aprendizado de Máquina.

- Aprendizado por uma única classe: o especialista do domínio define uma única classe $C$ para que uma chamada "descrição de características" possa ser construída: uma descrição que separa as instâncias de $C$ de qualquer outro exemplo que não seja uma instância de $C$. Dois casos podem ser distinguidos: primeiramente, todos os exemplos, fornecidos pelo especialista do domínio, são os membros dessa classe (denominados de exemplos "positivos") e o sistema tem que construir uma descrição para estes exemplos. O outro caso alternativo refere-se a quando são fornecidos exemplos positivos e negativos; os exemplos negativos podem ser vistos como membros de outras classes. São úteis os exemplos "não cobertos", que estão fora da classe e provêm informação interessante sobre os limites de classe. Por exemplo, em um ambiente de animais, pode-se definir a classe "pássaro" e procurar por uma descrição de características, na qual todos os pássaros servem como exemplos positivos e todos os outros animais (por exemplo, "peixes") como exemplos negativos. Um exemplo interessante para analisar é o pingüim que permite assim induzir que a propriedade característica dele é asas, mas não tem habilidade para voar.

- Aprendizado por múltiplas classes: o especialista do domínio define um número finito de classes $C_{1}, C_{2}, \ldots C_{m}$, para as descrições que devem ser encontradas. $O$ sistema pode também procurar pelas "descrições de características", que são as descrições que distinguem as instâncias de $C_{i}$ de qualquer outro exemplo, como no aprendizado por uma única classe. As instâncias de $C_{i}$ formam os exemplos positivos e todos os casos que não estão em $C_{i}$ são os exemplos negativos.

Alternativamente, se cada exemplo pertence a pelo menos uma classe, o sistema pode procurar "descrições discriminantes": descrições que juntas cobrem todos os casos e separam uma instância de uma classe das instâncias de todas as outras classes. Por exemplo, no ambiente animal, pode-se construir descrições discriminantes assumindo que todos os animais pertencem à classe "peixe" ou "pássaro". Algumas possíveis descrições são que os pássaros têm asas e os peixes não tem asas. Estas descrições são suficientes para distinguir os peixes dos pássaros. Porém, se o conjunto de exemplos contém outros animais, pertencendo a 
classes desconhecidas, novas descrições características devem ser construídas, como peixes têm barbatanas e pássaros têm asas, para distinguir pássaros e peixes de outros animais.

Aprendizado não supervisionado: no aprendizado não supervisionado ou aprendizado por observação e descoberta, o sistema tenta encontrar suas próprias classes em um conjunto de estados $S$, sem ajuda de um especialista do domínio. Praticamente, o sistema tem que formar "grupos de características" (clusters) do conjunto de estados $S$. Os casos são fornecidos ao sistema, como no aprendizado supervisionado, mas agora, nenhuma das classes estão definidas. O sistema tem que observar os exemplos e reconhecer padrões (por exemplo, descrições de classe) por ele mesmo [Michalski 83a]. O resultado de um processo de aprendizado não supervisionado é um conjunto de descrições da classe, por exemplo, $D_{1}, D_{2}$, e $D_{3}$, uma para cada classe descoberta, que juntas cobrem todos os casos do ambiente, como pode ser observado na Figura 3.2. Estas descrições formam um resumo de alto nível dos casos do ambiente. Por exemplo, no exemplo do ambiente de animais, pode-se encontrar uma descrição que declara que os dados consistem de três classes: animais voadores com asas, animais aquáticos com barbatanas e uma classe para as exceções, por exemplo, um pingüim aquático com asas. Esta descrição é correta se, por exemplo, cobre todos os casos do ambiente e, além disso, é uma simplificação do ambiente.

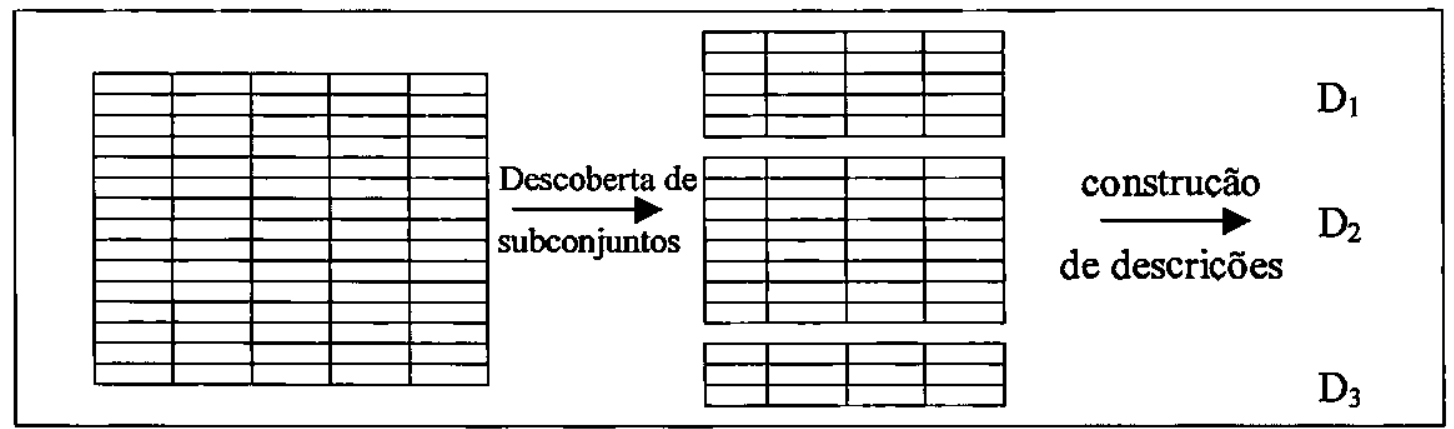

Figura 3.2: Descobrindo clusters e descrições em um conjunto de dados.

Para ilustrar a complexidade do aprendizado não supervisionado, o especialista do domínio dá o número de possíveis clusters de uma base de dados com $N$ registros. Se existem $m$ clusters na base de dados, dividi-se o conjunto de $N$ registros em $m$ subconjuntos disjuntos não vazios. Pod'e-se denotar por $P(N, m)$ o número de formas nas quais isso pode ser feito. Em geral, o número de formas para dividir $N$ elementos em $m$ subconjuntos está determinado por [Duran 74]:

$$
P(N, m)=\frac{1}{m !} \sum_{j=0}^{m}\left(\begin{array}{c}
m \\
j
\end{array}\right)(-1)^{j}(m-j)^{N}
$$

$P(N, m)$ é uma função exponencial que cresce rapidamente em $N$, de fato, para grandes $N$, se tem $P(N, m) \approx m^{N} / m ! \approx m^{N-m} e^{m} \sqrt{2 \pi m}$. O número total de formas em que o conjunto de dados de $N$ registros pode ser agrupada (clustered), denotado por $C(N)$, é:

$$
C(N)=\sum_{m=1}^{N} P(N, m)=\sum_{m=1}^{N} \frac{1}{m !} \sum_{j=0}^{m}\left(\begin{array}{c}
m \\
j
\end{array}\right)(-1)^{j}(m-j)^{N}
$$

Por exemplo, para $\mathrm{N}=8$, tem-se: 


\begin{tabular}{|c|c|c|c|c|c|c|c|c|}
\hline $\mathrm{M}$ & 1 & 2 & 3 & 4 & 5 & 6 & 7 & 8 \\
\hline $\mathrm{P}(8, \mathrm{~m})$ & 1 & 127 & 966 & 1701 & 1050 & 266 & 28 & 1 \\
\hline
\end{tabular}

Conseqüentemente, $C(N)=\sum_{m=1}^{8} P(8, m)=4140$.

Claramente, o processo de AM só tem êxito se o número de classes no conjunto de dados é pequeno. Porém, mesmo que seja assumido que o número de classes que se espera do conjunto de dados é pequeno comparado ao tamanho da base de dados, por exemplo 10 , o número de possíveis clusters, $\sum_{m=1}^{10} P(N, m)$, ainda é enorme.

\subsubsection{Por Tipo de Paradigma}

Dentro da área de $\mathrm{AM}$ foram propostos vários paradigmas diferentes. Um requisito básico para todos os paradigmas de classificação, que são discutidos a seguir, é que todo o conhecimento a ser aprendido esteja na forma de exemplos e que cada exemplo esteja relacionado a uma classe corretamente classificada. Os paradigmas de AM mais conhecidos são brevemente discutidos a seguir [Batista 97]:

Paradigma Simb6lico: os sistemas de aprendizado simbólico buscam aprender construindo representações simbólicas de um conceito através da análise de exemplos e contra-exemplos desse conceito. As representações simbólicas estão tipicamente na forma de alguma expressão lógica, árvore de decisão, regras de produção, rede semântica, etc. Os métodos de aprendizado simbólico podem ser tratados como:

- Proposicionais: estes métodos lidam apenas com enunciados declarativos, chamados proposições (ou sentenças). Os enunciados exclamativos, imperativos e interrogativos são exclúdos. Só usam sentenças que têm valores verdadeiro ou falso. É possível construir proposições compostas através do uso de conectivos do tipo $e(\wedge)$, ou $(\vee)$, não $(\neg)$, condicional $(\rightarrow)$, etc. Por exemplo, "(cor $=$ vermelho $v$ cor $=v e r d e) \wedge$ forma $=$ círculo" é uma fórmula expressa na Forma Normal Conjuntiva (FNC), como poderia ser uma conjunção de cláusulas, na qual as cláusulas são disjunções das condições do valor do atributo. $\mathrm{O}$ conhecimento pode ser representado como um conjunto de descrições, que são de fato uma formula na FNC. Por exemplo, o exemplo anterior poderia ser representado como um conjunto de descrições "cor $\in$ \{vermelho, verde $\wedge$ forma $\in\{$ círculo\}".

Uma alternativa é a Forma Normal Disjuntiva (FND), uma disjunção de condiçães, na qual os termos são conjunções das condições do valor do atributo. Porém, como foi demonstrado em [Mooney 92], a FNC executa surpreendentemente bem, isto é, as descriçбes geradas são menores que as representações FND para as mesmas tarefas de aprendizado.

De fato, ambas representações realmente não são proposicionais, porque elas envolvem uma variável - o caso por si mesmo. Por exemplo, quando no exemplo anterior usa uma regra de produção, ela é uma condição sobre um caso $X$, declarando " $P(X)=(X . c o r=$ vermelho $\vee$ $X . c o r=$ verde) $\wedge X$.forma $=$ círculo". Por esta razão, estas representações são chamadas também de "quase proposicionais".

- Relacionais: estes métodos estão representados pela Programação Lógica Indutiva (PLI) orientada a construir programas lógicos - restritos às cláusulas de Horn - a partir de exemplos positivos e negativos da relação a ser aprendida usando informação prévia 
fornecida pela teoria de domínio, como aprendizado. De maneira geral, a PLI pode ser definida como o uso da lógica simbólica para a representação explícita de problemas e de suas bases de conhecimento associadas, bem como o uso de inferência lógica controlada para a solução efetiva desses problemas.

Paradigma Estatístico: as técnicas estatísticas, em geral, tendem a focar tarefas em que todos os atributos têm valores contínuos ou ordinais. Muitos deles também são paramétricos, assumindo alguma forma de modelo, e então encontrando valores apropriados para os parâmetros do modelo a partir de dados. Os classificadores estatísticos freqüentemente assumem que valores de atributos estão normalmente distribuídos, e então usam os dados fornecidos para determinar média, variância e co-variância da distribuição.

Paradigma Instance-based: uma forma de classificar um caso é lembrar de um caso similar cuja classe é conhecida e assumir que o novo caso terá a mesma classe. Essa filosofia exemplifica os sistemas instance-based, que classificam casos nunca vistos através de casos similares conhecidos [Quinlan 88].

Paradigma Conexionista: as redes neurais são construções matemáticas relativamente simples que utilizam o mecanismo de paralelismo, conectando um grande número de pequenas unidades de processamento ligadas em rede. Essas unidades são modeladas como os neurônios e foram inspirados no modelo biológico do sistema nervoso. Sua representação envolve unidades altamente interconectadas, no qual o nome "conexionismo" é utilizado para descrever a área de estudo.

Paradigma Genético: este paradigma é derivado do modelo evolucionário de aprendizado [Holland 86]. Um classificador genético consiste de uma população de elementos de classificação que competem para fazer uma previsão. Elementos que possuem um desempenho fraco são descartados, enquanto que os elementos mais fortes proliferam, produzindo variações de si mesmos. Este paradigma possui uma analogia direta com a teoria de Darwin, na qual sobrevivem os mais bem adaptados ao ambiente.

\subsubsection{Por Tipo de Linguagens de Descrição}

Em um sistema de aprendizado é necessário utilizar linguagens para representar exemplos ou instâncias, conceitos induzidos e dependendo do caso, a teoria de domínio previamente conhecida. Estas linguagens são comumente referenciadas como "linguagens de descrição" e estão divididas em: linguagem de descrição de exemplos ou instâncias, linguagem de descrição de hipóteses ou conceitos aprendidos e linguagem de descrição da teoria de domínio ou conhecimento de fundo, todas elas são explicadas a seguir:

Linguagem de descrição de exemplos ou instâncias: descreve os exemplos utilizados pelo algoritmo de AM para aprender conceitos, estabelecendo limites sobre os tipos de padrões que o sistema pode aprender.

Linguagem de descrição de hipóteses ou conceitos aprendidos: descreve o estado interno de um algoritmo de AM, correspondente a teoria dos conceitos ou padrões que existem nos dados, estabelecendo limites sobre o que pode ou não pode ser aprendido. 
Linguagem de descrição da teoria de domínio ou conhecimento de fundo: descreve todo o conhecimento prévio que o sistema de AM possui a respeito do domínio.

\subsubsection{Por Tipo de Formalismos para Descrever Casos}

Alguns dos formalismos para descrever casos, relações entre eles, conceitos e a teoria de domínio utilizada podem ser: árvores de decisão, regras de produção, listas ou tabelas de decisão, redes semânticas, frames e scripts.

Árvores de decisão para representar conceitos: uma árvore de decisão é uma representação de conhecimento simples que tem sido usada com êxito em sistemas de Aprendizado de Máquina supervisionados, como por exemplo, o sistema ID3 de Quinlan [Quinlan 86b].

Uma árvore de decisão é uma estrutura que consiste de nós e ramos. O nó inicial é frequientemente chamado de nó raiz. Cada nó representa um atributo, os ramos representam os possíveis valores para cada atributo e os últimos nós (nós terminais) representam as diferentes classes. Um caso é classificado seguindo um caminho descendente da árvore, isto é, indo da raiz até o nó terminal correspondente aos valores dos atributos do caso.

Um exemplo, retirado de [Quinlan 86b], consiste em um conjunto de treinamento pequeno, armazenando casos que descrevem o tempo em um determinado momento. Os casos contêm informações sobre o clima (ensolarado, nublado ou chuvoso), a umidade (alta ou normal) e algumas outras propriedades. Alguns casos são exemplos positivos de uma classe $P$ e outros são exemplos negativos $N$. A tarefa de classificação consiste em construir uma árvore simples que classifique corretamente todos os casos do conjunto de treinamento. A árvore construída pode ser vista na Figura 3.3:

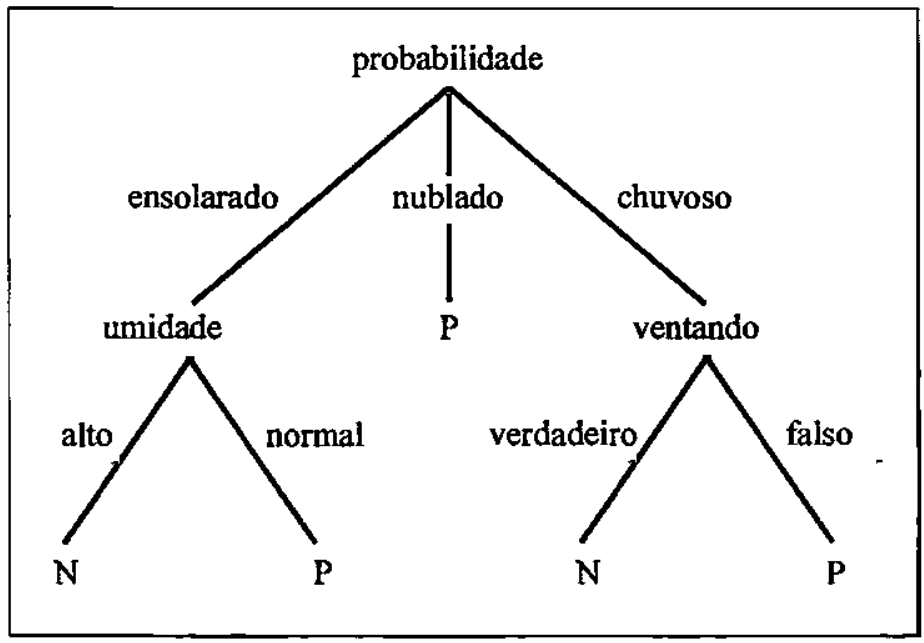

Figura 3.3: Uma simples árvore de decisão.

Regras de produção para representar conceitos: uma desvantagem das árvores de decisão é que em aplicações reais elas tendem a crescer em demasia, dificultando a sua interpretação. Consequientemente, alguns pesquisadores transformaram as árvores de decisão em outras representações mais compreensíveis. Quinlan [Quinlan 87b] descreve uma técnica para gerar 
regras de produção a partir de árvores de decisão. Esta transformação é útil principalmente considerando que:

1. as regras de produção são extensamente usadas para representar conhecimento, por exemplo, em sistemas especialistas;

2. elas podem ser interpretadas facilmente por especialistas, por causa da sua extrema modularidade, por exemplo, uma única regra pode ser entendida sem fazer referência a outras regras;

3. a precisão de classificação de uma árvore de decisão pode ser melhorada transformando-a em um conjunto de regras de produção, assim eliminando testes que são atribuíveis a peculiaridades do conjunto de treinamento.

Em alguns casos, as regras de produção proposicionais são consideradas simples, por exemplo, em regras "se-então" (if-then), a parte condicional consiste em uma expressão proposicional, por exemplo, uma expressão em FNC, ou simplesmente um termo. A conseqüência é a classe.

Por exemplo, cada caminho em uma árvore de decisão corresponde a um termo: uma conjunção de condições sobre os atributos. A árvore acima é equivalente ao seguinte conjunto de regras de produção:

$$
\begin{aligned}
& \text { se clima }=\text { ensolarado e umidade }=\text { alta então classe }=N \\
& \text { se clima }=\text { chuva e ventando }=\text { verdadeiro entäo classe }=N \\
& \text { classe default }=P
\end{aligned}
$$

A descrição $D$ para uma classe $C$ está correta se ela cobre todos os exemplos positivos e nenhum dos exemplos negativos, por exemplo, $\sigma_{D}(S)=C$.

Durante o processo iterativo para construir uma descrição correta, o sistema encontrará muitas descrições que não estão corretas. Para poder selecionar a descrição mais promissora fora de um conjunto de descrições incorretas é preciso estender a noção de exatidão, permitindo-a ser de um valor contínuo, em lugar de um número booleano. Com cada descrição $D$ para uma classe $C$, é possível associar os seguintes valores: precisão da classificação e cobertura de uma descrição.

- Precisão da classificação: está definida como a probabilidade de que uma regra classifique corretamente um conjunto de exemplos, portanto representa a probabilidade que um caso coberto pela descrição atual pertença a uma classe [Holsheimer 94]. A precisão de classificação é a porção relativa de $\sigma_{D}(S)$ que é também coberta por $C$ :

$$
\text { precisão da classificação }=\frac{\left|\sigma_{D}(S) \cap C\right|}{\left|\sigma_{D}(S)\right|}
$$

- Cobertura de uma descrição: está definida como a probabilidade que um caso arbitrário pertença à classe $C$ e seja coberto pela descrição $D$ :

$$
\text { cobertura }=\frac{\left|\sigma_{D}(S) \cap C\right|}{|C|}
$$

Baseado nesses valores pode-se distinguir os seguintes tipos de regras: 
- Regras completas: se a cobertura é igual a 1 , a regra está completa, isto é, qualquer caso que pertence à classe é coberto pela descrição para essa classe, por exemplo, $C \subseteq \sigma_{D}(S)$. Em outras palavras, a descrição é uma condição necessária para a classe.

- Regras determinísticas: se a precisão da classificação é 1, a regra é determinística, por exemplo, sempre classifica corretamente. Qualquer caso coberto pela descrição pertence à classe $C \supseteq \sigma_{D}(S)$. Conseqüentemente, a descrição é uma condição suficiente para a classe.

- Regras corretas: se a precisão da classificação e a cobertura são l, a regra está correta como foi definido anteriormente. A descrição é uma condição necessária e suficiente.

Listas ou tabelas de decisão: outra representação quase proposicional, proposta em [Rivest 87], é a representação de listas ou tabelas de decisão. Esta representação estritamente generaliza ambas representações nas árvores de decisão, FND e FNC. Por exemplo, qualquer estrutura de conhecimento nessas representações pode ser transformada a uma lista ou tabela de decisão. Uma lista ou tabela de decisão é uma lista de pares:

$$
\left(\varnothing_{1}, C_{l}\right),\left(\varnothing_{2}, C_{2}\right), \ldots,\left(\varnothing_{r}, C_{r}\right)
$$

na qual cada $\varnothing_{i}$ é uma descrição elementar e cada $C_{i}$ é a classe, de tal forma que a última descrição $\varnothing_{r}$ é a constante verdadeira. A classe de um caso $o$ é $C_{j}$ se $j$ é o menor índice da descrição $\varnothing_{j}$ que cobre o caso $o$. Um índice sempre existe, desde que o último termo é sempre verdadeiro, por exemplo, a classe default.

Pode-se pensar então em uma lista ou tabela de decisão como uma regra "se $\varnothing_{1}$ então $\mathrm{C}_{1}$ senão se $\varnothing_{2} ;$;.. então $C_{\mathrm{T}}$ ". Também se pode pensar em uma lista ou tabela de decisão como definindo uma classe dando o padrão geral com suas exceções. As exceções correspondem às condiçõos nos primeiros termos na lista ou tabela de decisão, considerando que os padrões mais gerais correspondem aos termos posteriores.

Redes semânticas: uma rede semântica é um grafo no qual os nós denotam conceitos, ou significados e os arcos denotam relações entre esses conceitos [Minsky 75].

Por exemplo, a rede semântica da Figura 3.4 especifica que o João é o cônjuge da Maria, e Maria tem cabelo vermelho. Além disso, o João e a Maria são instâncias do gênero humano, o que representa que são mamíferos.

Como se pode observar neste exemplo, existem duas formas de relą̧ões: relações entre conceitos ("cônjuge" e "cor_de_cabelo") e relações entre conceitos e classes (instância de isa). Como armazenar ambas relações na mesma rede pode ser confuso, as relações posteriores - "relações de subtipo" - às vezes são representadas em uma rede separada.

Uma rede semântica pode ser mapeada facilmente à Lógica de Primeira Ordem (LPO) (uma representação simples quase proposicional comumente usada em sistemas de Aprendizado de Máquina [Muggleton 92]), na qual cada arco é um predicado binário, com seus nós como condições. Esta representação também pode ser usada para relações de subtipo, mas uma representação melhor poderia ser:

cônjuge(maria, joão).

cor_de_cabelo(maria, vermelho). 


\author{
humano(joão). \\ humano(maria). \\ $\forall X$.humano $(X) \rightarrow$ mamifero $(X)$.
}

A vantagem principal das redes semânticas é que toda a informação relacionada a um caso em particular pode ser encontrada facilmente seguindo os vínculos desse caso. Quando as redes semânticas são usadas para Data Mining, cada exemplo pode ser uma rede semântica. As operações nos exemplos consistem em manipulações de grafos, tentando encontrar padrões, por exemplo, subgrafos, compartilhados por todos os exemplos da mesma classe.

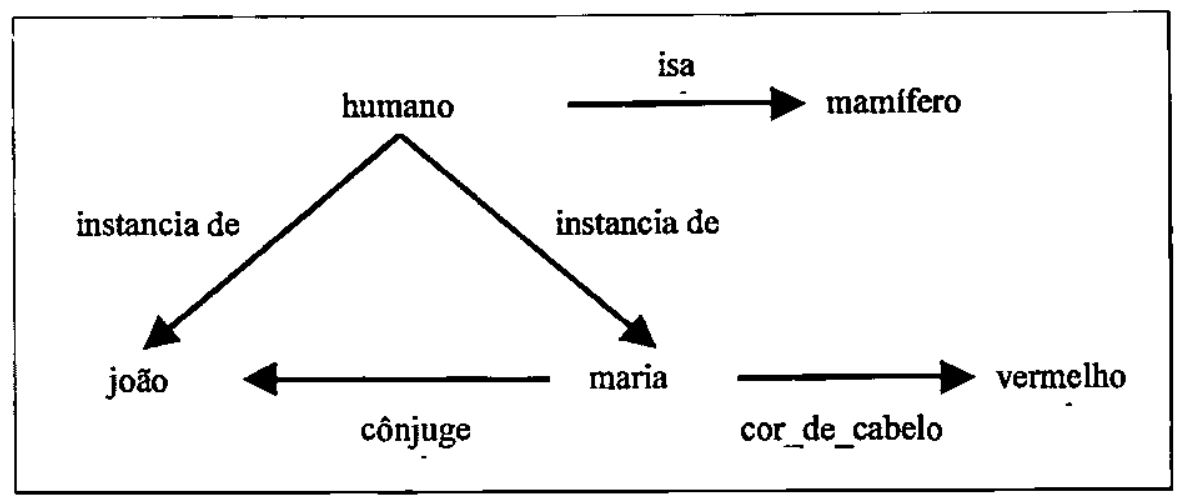

Figura 3.4: Representação de uma rede semântica.

Frames e scripts: um frame, também chamado de esquema, é um caso estruturado que consiste de um nome e vários atributos - chamados slots, preenchidos com valores de certas instâncias. Por exemplo, a informação sobre Maria, do exemplo anterior, pode ser armazenada em um frame com quatro slots, como pose ser visto na Figura 3.5:

\begin{tabular}{|c|l|}
\hline Nome do frame & \multicolumn{1}{|c|}{ Indivíduo } \\
\hline slot 1 & isa: mamífero \\
\hline slot 2 & nome: maria \\
\hline slot 3 & cônjuge: joão \\
\hline slot 4 & cor_de cabelo = vermelho \\
\hline
\end{tabular}

Figura 3.5: Representação de um frame.

Como pode ser observado, é possível incorporar informação de subtipo em frames usando slots "isa". Um slot isa faz referência a outro frame, neste caso o frame mamífero. Este frame armazena informação sobre mamíferos, por exemplo, que todos os mamíferos são vivíparos. Os slots e seus valores definem os níveis mais altos na hierarquia sendo herdada pelos níveis mais baixos. Porém, esses valores podem eventualmente ser anulados, por exemplo, em um nível alto são definidos valores padrões para os slots (todos os mamíferos são vivíparos), mas estes podem ser anulados para casos excepcionais a níveis mais baixos (um platypus é um mamífero, mas não é vivíparo).

Embora os frames possam ser representados em LPO, eles fornecem uma melhor percepção da estrutura do conhecimento do que um conjunto de - logicamente equivalentes, mas não estruturados - predicados de primeira ordem. 
Os scripts servem para representar situações e casos, sendo uma especialização de frames projetados para manipular situações além de casos, de forma tal que os nós são eventos e os conectores entre eles são simplesmente causais, isto é, um evento provoca o próximo. Um script é como um "script cinematográfico" usado para contar histórias sobre uma sequiência de eventos, responder questões em determinado ponto do nó e identificar eventos que levem a alguma tomada de decisão, sendo normalmente considerados uma subclasse dos frames.

\subsubsection{Por Modo de Integrar Novos Exemplos}

Os algoritmos de aprendizado indutivo podem ser classificados de duas formas segundo o modo em que podem ser integrados novos exemplos: incremental e não incremental, ambos são explicados a seguir.

Incremental: revê a definição do conceito atual, se necessário, em resposta a cada nova instância de treinamento observada. Os exemplos observados são considerados um a um pelo sistema, isto é, o sistema considera o primeiro exemplo e, de acordo com esse exemplo, constrói uma determinada hipótese; a seguir considera um segundo exemplo, que pode ou não modificar a primeira hipótese, baseando-se em como esta classifica o segundo exemplo. A medida que mais exemplos são apresentados, o sistema continua modificando o conceito.

Não Incremental: necessita de que todos os exemplos de treinamento, simultaneamente, estejam disponíveis para que seja induzido um conceito. É vantajoso usar esses algoritmos para problemas de aprendizado onde todos os exemplos estão disponíveis e, provavelmente, não irão ocorrer mudanças.

Data Mining é um tipo especial de Aprendizado de Máquina, que faz uso dos algoritmos de AM, em algumas de suas descobertas. A seguir serão abordados os principais aspectos relacionados a Data Mining.

\subsection{DATA MINING}

A etapa do processo de Extração de Conheçimento de Bases de Dados que busca descrições no "conjunto de dados" selecionado a partir de uma base de dados é chamada de Data Mining (DM). Essa base de dados quase sempre é grande e contém dados que foram gerados e armazenados para propósitos diferentes aos processos de aprendizado. Esses dados contém "ruídos" e alguns dos valores dos atributos estão ausentes ou são desconhecidos. Além disso, são usadas técnicas estatísticas para lidar com esse ruído ou dados ausentes. Os dados representam só um conjunto pequeno de todo o possível comportamento, de forma que é difícil para o sistema manipular seu ambiente para gerar exemplos interessantes, como no Aprendizado de Máquina. Conseqüentemente, é mais difícil descobrir descrições que nas condições ideais encontradas em Aprendizado de Máquina.

A necessidade de avaliar as descrições criadas pelos sistemas de Data Mining faz que o conjunto de dados seja dividido em um conjunto de treinamento e um conjunto de teste. O primeiro é utilizado pelos algoritmos de AM para encontrar as descrições do ambiente e o segundo as avalia. Um método comumente utilizado para realizar uma boa escolha dos conjuntos de treinamento e teste que possam avaliar todo o sistema é o método de resampling crossvalidation, que será explicado neste capítulo. 
Nesta seção, são mostrados alguns aspectos que são utilizados em Data Mining, tais como a definição do conjunto de treinamento e teste, a construção de padrões e regras.

\subsubsection{O Conjunto de Treinamento e de Teste}

O conjunto de dados selecionado a partir de uma base de dados é dividido em dois conjuntos: o primeiro chamado de "conjunto de treinamento" $S$ é utilizado pelos algoritmos de AM para representar informação sobre o ambiente e o segundo, um "conjunto de teste" para avaliar essa representação. Existem várias formas de determinar o conjunto de treinamento e de teste, na Seção 3.4.3, será explicado o método de resampling cross-validation usado no Estudo de Caso 2, por ser um dos métodos mais efetivos e mais usados pela comunidade de AM.

Um conjunto de treinamento pode ser definido como $\mathcal{A}=\{\mathcal{A} 1, \ldots, A$ n $\}$ sendo um conjunto de atributos com domínios Dom, Dom2, .., Dom. Um conjunto de treinamento é uma tabela de $\mathcal{A}$. Um exemplo, ou fato, é um registro desse conjunto de treinamento. $O$ "Universo" $U$ é a relação total sobre $\mathcal{A}$, por exemplo, $U=\operatorname{Dom}_{1} \times \ldots \times$ Dom $_{2}$. Conseqüentemente, cada conjunto de treinamento é um subconjunto finito de $U$.

Por exemplo, pode-se representar o ambiente animal, descrito na Seção 3.3.1, como um conjunto de treinamento representado na Tabela 3.1. Cada fato descreve um animal, com suas propriedades. Nesse conjunto de treinamento o primeiro atributo é o nome da espécie, o segundo denota se o animal tem asas ou barbatanas e o terceiro descreve como ele se locomove. $O$

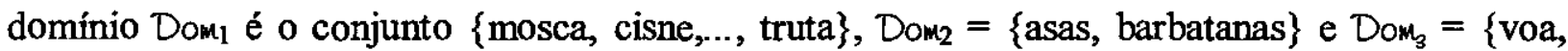
nada\}.

Tabela 3.1: Conjunto de treinamento.

\begin{tabular}{|l|l|l|}
\hline Espécie & Asas/barbatanas & Transportação \\
\hline mosca & asas & voa \\
\hline cisne & asas & voa \\
\hline pingüim & asas & nada \\
\hline tubarão & barbatana & nada \\
\hline truta & barbatana & nada \\
\hline
\end{tabular}

\subsubsection{Classes}

Quando o conjunto de dados é obtido a partir da base de dados, ele passa ser o ambiente a partir do qual os algoritmos usados por DM vão tentar inferir um modelo. No caso de aprendizado supervisionado, isto requer que o especialista do domínio defina uma ou mais classes, também conhecidas como "conceitos" [Michalski 83c], dentro de um "atributo-classe" no conjunto de dados. Sem perda de generalidade, pode-se assumir que o conjunto de dados contém um ou mais atributos que definem a classe de um registro, esses atributos são chamados de "atributos de decisão", como foi explicado no Capítulo 2, existindo uma forte correlação entre eles e a classe pré-definida. Os atributos restantes são chamados de "atributos sem valor".

A combinação de valores dos atributos de decisão definem uma classe, ou de uma forma mais geral, uma classe é definida através da condição dos atributos de decisão. 
A classe $C_{i}$ é um subconjunto de um conjunto de treinamento $S$, consistindo de todos os casos que satisfazem a condição da classe cond:

$$
C_{i}=\left\{o \in S \mid \operatorname{cond}_{i}(o)\right\}
$$

Os casos que satisfazem a condição cond ${ }_{i}$ são exemplos "positivos" ou "instâncias" da classe $C_{i}$. Os exemplos fora desse subconjunto do conjunto de treinamento são exemplos "negativos".

Criar regras de classificação significa que o sistema tem que encontrar as regras que prevejam a classe a partir dos atributos de condição, como é mostrado na Figura 3.6. Primeiro, o especialista do domínio deve definir as condições para cada classe e assim criar partições de $S$ em subconjuntos $C_{l}, \ldots, C_{n}$. Então, o sistema de DM deve construir descrições $D_{l, \ldots, D_{n}}$ para essas classes.

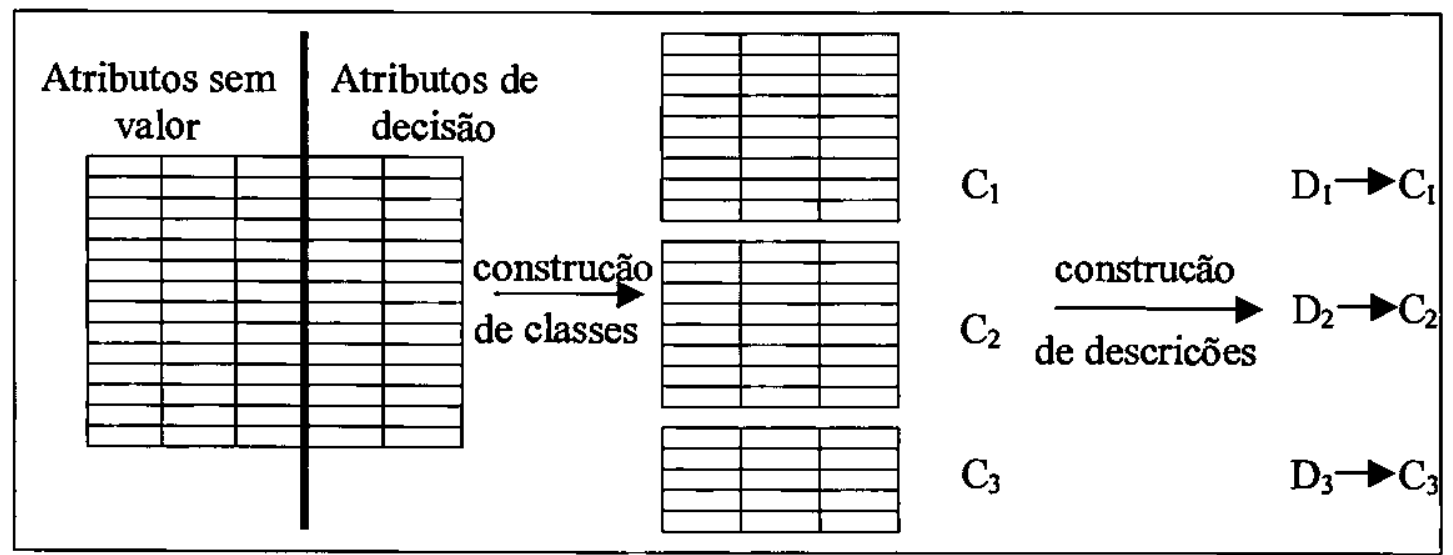

Figura 3.6: Regras de classificação de aprendizado a partir de um conjunto de dados.

Por outro lado, é possível definir uma classe diretamente em termos dos atributos de decisão. Por exemplo, em uma base de dados médica, pode-se definir uma classe "câncer" como a condição "diagnose = câncer", na qual a diagnose é um atributo de decisão. Conseqüentemente, qualquer exemplo no conjunto de treinamento para o qual o atributo "diagnose" tem um valor igual a "câncer" pertencerá a classe "câncer".

As classes também podem ser definidas incorporando informação que não é representada explicitamente na própria base de dados, por exemplo: múltiplas bases de dados e bases de dados temporais. Ambas são explicadas a seguir:

Múltiplas bases de dados: o conjunto de treinamento pode ser composto de múltiplas bases de dados. Por exemplo, pode-se procurar diferenças entre clientes do Rio de Janeiro e do São Paulo. Toda a informação dos clientes, originalmente armazenada em uma base de dados local no Rio de Janeiro pertencem à classe "Rio de Janeiro" e todos os clientes de São Paulo pertencem à classe "São Paulo".

Bases de dados temporais: pode-se procurar por "regularidades na evolução dos dados", ou seja, a descoberta de mudanças globais em uma base de dados em um período de tempo [Han 92]. Então, pode-se construir um conjunto de treinamento, composto de dois conjuntos $S_{i}$ e $S_{j}$, 
tomados da mesma base de dados em momentos diferentes. Todos os exemplos de $S_{i}$ pertencem à classe "momento $=\vec{i}$ " e os exemplos em $S_{j}$ pertencem à classe "momento $=j$ ".

Se ambos conjuntos $S_{i}$ e $S_{j}$ representam os mesmos casos (mas em momentos diferentes), pode-se usar $S_{i}$ como o conjunto de treinamento e definir uma classe em termos de $S_{i}$ e $S_{j}$, Por exemplo, a classe "lucros dobrados", contém todas as companhias que dobraram seus lucros em um determinado período, no qual o lucro é um atributo.

Note que a descrição para uma classe não é definida exclusivamente. Podem ser construídas muitas descrições diferentes que são corretas com respeito ao conjunto de treinamento. Infelizmente, nem todas essas descrições classificarão corretamente os exemplos não vistos. $O$ problema é que nem todo o conhecimento derivado das observações é válido. Uma vez determinadas as regras de classificação do modelo, o próximo passo é avaliá-las. Um método para realizar essa avaliação será explicado na próxima seção.

\subsubsection{Método de Resampling Cross-Validation}

Todos os sistemas de Aprendizado de Máquina e Data Mining devem ser avaliados para determinar a taxa de erro do classificador, chamada "taxa de erro do conjunto de teste". Se o conjunto de teste do classificador for "escondido" e mostrado somente depois do treinamento, então se tem uma correspondência procedural direta à tarefa de determinar a taxa de erro em novos casos. Tanto o conjunto de treinamento quanto o de teste devem ser amostras aleatórias do conjunto de dados. Um método aceito amplamente, pois todos os casos da amostra de exemplos são usados para testar e todos os casos são usados para treinar o sistema, é o método de resampling cross-validation, também conhecido como $k$-fold cross-validation, no qual $k$ representa o número de partições geradas aleatoriamente no conjunto de dados para treinar e testar o sistema. Neste método, a amostra de exemplos é dividida em $k$ partições mutuamente exclusivas. A cada iteração, uma partição diferente é usada para testar o sistema de aprendizado e todas as outras $k-1$ partições são utilizadas para treinar o sistema. A taxa de erro é a média das taxas de erro calculadas para as diversas partições. Por exemplo, no caso do 10-fold crossvalidation todo o conjunto de exemplos é dividido em 10 partições diferentes, aleatórias e mutuamente exclusivas. São realizadas 10 iterações, a cada iteração uma partição diferente é utilizada para testar e as outras 9 partições restantes são utilizadas para treinar o sistema. A taxa de erro é resultado das médias das taxas de erro das 10 iterações [Batista 97].

\subsubsection{Aprendizado de Máquina versus Data Mining}

Nesta seção são abordadas as diferenças existentes entre Aprendizado de Máquina e Data Mining. Na Figura 3.7 é descrita a estrutura geral para AM. O ambiente $E$ representa o mundo real, o ambiente a aprender. $E$ representa um número finito de observações, ou casos, que são codificados em algum formato legível para o computador pelo codificador $C$. $O$ conjunto de observações codificadas é o conjunto de treinamento para o algoritmo de AM.

A estrutura geral para DM, mostrado na Figura 3.8, é uma variação da estrutura AM. O codificador $C$ é substituído pela base de dados $B D$ que modela o ambiente $E$. Cada estado da base de dados reflete um estado de $E$ e cada transição de estado da $B D$ reflete uma transição de estado no ambiente $E$. 


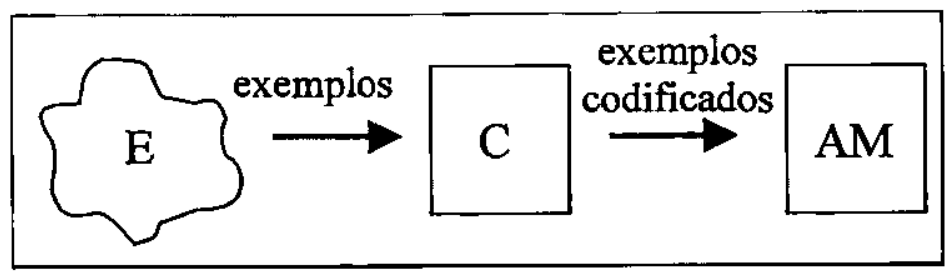

Figura 3.7: Diagrama de Aprendizado de Máquina.

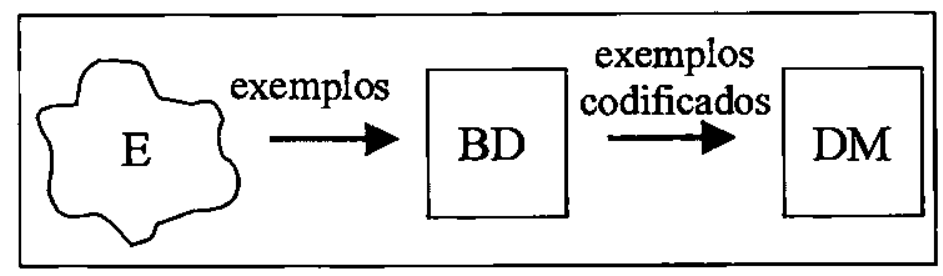

Figura 3.8: Diagrama de Data Mining.

O algoritmo de aprendizado constrói um modelo a partir da $B D$, enquanto as classes forem interessantes, isto significa que $o$ algoritmo tem que inferir as regras que governam a classificação de casos na $B D$. Deveram ser inferidas as regras que governam as transições entre as classes a partir das transições da base de dados.

Embora as estruturas para DM e AM em geral possam parecer muito semelhantes, há distinções importantes. Primeiramente, a base de dados é projetada freqüentemente para propósitos diferentes a DM. Isto é, a representação dos casos no mundo real na base de dados foi escolhida para satisfazer necessidades de aplicaçðes (por exemplo, comerciais) e não das necessidades de DM. Conseqüentemente, as propriedades e/ou os atributos que simplificariam a tarefa de aprendizado não estão necessariamente presentes. Além disso, pode não ser possível obter essas propriedades do mundo real.

A segunda diferença importante é que as bases de dados invariavelmente estão contaminadas por erros. Considerando que em AM o algoritmo é fornecido freqüentemente com exemplos de laboratório escolhidos, em DM o algoritmo tem que trabalhar com ruídos e, às vezes, até com dados contraditórios.

Uma terceira diferença existe, pois AM é um campo amplo que inclui não só aprendizado por exemplos, como também aprendizado reforçado, aprendizado dirigido, etc.

Uma outra diferença relevante é a interação com o especialista de domínio. A presença do especialista do domínio em DM é fundamental para definir e avaliar a maioria dos seus processos. AM nem sempre necessita da presença do especialista do domínio para trabalhar.

Finalmente, uma última distinção é nas metas que cada um possui: DM busca um conhecimento compreensível e AM preocupa-se mais com melhorias no desempenho de um agente. 


\subsection{ALGUNS PROBLEMAS RELACIONADOS A DATA MINING}

Vários problemas ocorrem quando se usa uma base de dados como conjunto de treinamento. Nesta seção serão mostrados alguns desses problemas e algumas possíveis soluções.

\subsubsection{Valores Desconhecidos}

No aprendizado supervisionado, tenta-se encontrar uma relação entre as variáveis de decisão e uma classe. Pode-se enfrentar isto como algum processo $T$, na qual a entrada consiste das "variáveis de decisão" e a saída é a "classe", como é descrito na Figura 3.9.

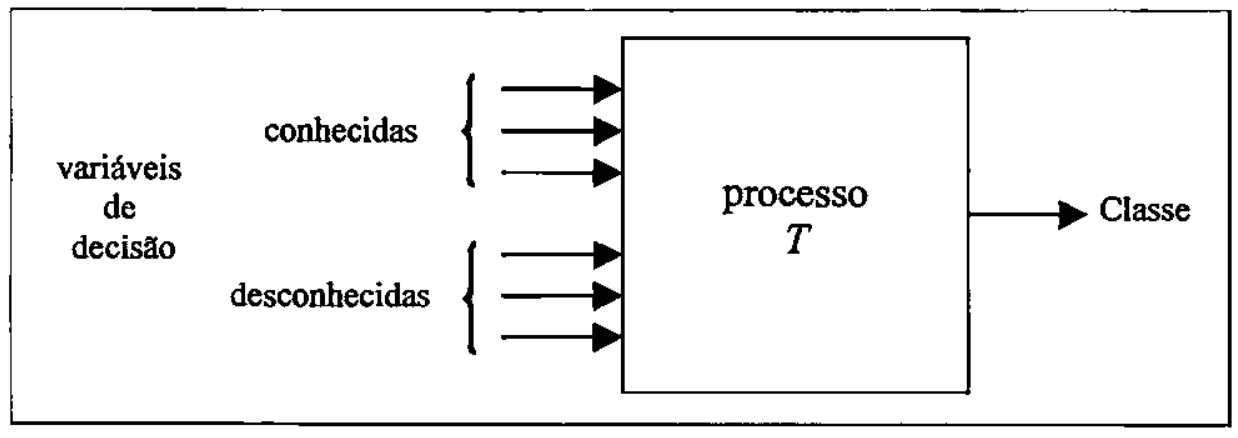

Figura 3.9: O processo ambiental $T$.

Este processo é determinístico porque a classe está exclusivamente determinada pelas variáveis de decisão, mas freqüentemente nem todas as variáveis são conhecidas. Em alguns casos o conjunto de variáveis desconhecidas são relevantes para a classificação. Logo nem sempre é possível construir uma regra que classifique cada exemplo corretamente em termos das variáveis de decisão conhecidas.

Basicamente, as duas maneiras de abordar o problema das variáveis desconhecidas são através de regras determinísticas e de regras probabilísticas.

Regras determinísticas: um especialista do domínio pode restringir as "regras determinísticas", ou seja, só construir regras usando variáveis conhecidas à classificação. Esta é a "descoberta de regras poderosas", discutidas em [Piatetsky-Shapiro 91]. Uma desvantagem é que muita informação valiosa presente no conjunto de dados não será encontrada.

Nesta abordagem, os exemplos com atributos ausentes podem ser descartados, ou alternativamente, substituir o valor desconhecido por algum valor "muito provável". Quinlan [Quinlan 86a] sugere construir regras que prevejam o valor de um atributo ausente, baseado no valor de outros atributos e da informação da classe. Estas regras são usadas para "preencher" os valores dos atributos desconhecidos e o conjunto resultante é usado para construir as descrições.

Outra forma é tratar os valores desconhecidos como valores por separado, por exemplo, adicionando o valor "desconhecido" ao domínio de cada atributo e usar esse valor nas descrições.

Regras probabilísticas: o sistema pode encontrar regras que não necessariamente classificam corretamente os exemplos, mas indicam a probabilidade de que um caso coberto pela descrição pertença a uma classe. Estas "regras probabilísticas" provêem informações importantes sobre as 
relações no ambiente, por exemplo, a relação (causal) entre fumar cigarros e câncer não é uma relação correta, pois, fumar não é uma condição suficiente nem necessária para câncer, mas esta relação é considerada muito importante.

Uma técnica para validar uma regra é calcular a sua "probabilidade". Esta probabilidade é definida como o produto das probabilidades de que cada valor do atributo desconhecido é o valor requerido na condição da regra. Assim, dado um conjunto de regras de classificação, é possível calcular para cada regra a probabilidade que o exemplo seja consistente com esta regra. Logo, somando as probabilidades para cada classe, o resultado da classificação é a classe com o valor mais alto.

Se nenhuma das variáveis de condição conhecidas são relevantes para a classificação, as variáveis e a classe são "sem conexão" e nenhuma das regras probabilísticas podem ser encontradas.

\subsubsection{Amostras}

O conjunto de treinamento $S$ pode ser visto como uma amostra do conjunto de todos os dados - "Universo" U. Um sistema de Data Mining busca conhecimento nesse conjunto de treinamento. Esse conhecimento pode ser representado através de regras, sendo que uma regra consiste de uma descri̧̧ão $D$ e uma classe $C$ e esta descrição cobre um subconjunto $\sigma_{D}(S)$. Por sua vez, este subconjunto $\sigma_{D}(S)$ pode ser visto novamente como uma amostra:

Assume-se que um caso arbitrário em $\mathrm{S}$ pertence à classe $C$ com probabilidade $p$ e que um caso no subconjunto $\sigma_{D}(S)$ pertence a essa classe com a probabilidade $p^{\prime}$ e $p \neq p^{\prime}$. A pergunta principal é: a diferença entre $p$ e $p^{\prime}$ é estatisticamente significante? Em outras palavras, foi localizada uma relação probabilística ou a diferença observada é só devida a uma coincidência? Os sistemas de Data Mining devem confiar nas técnicas estatísticas para conferir a validade das relações descobertas.

\subsubsection{Exclusão de Dados}

Os métodos clássicos estatísticos partem, em alguns casos, de amostras aleatórias, que ignoram como os dados foram "selecionados" e podem levar a conclusões errôneas.

Para ilustrar este fato, considere o acidente com o ônibus espacial Challenger. A Comissão Rogers concluiu que uma falha no anel- $O$ em um dos propulsores de combustível sólido levou ao colapso estrutural e à perda do Challenger. Na reconstrução dos eventos, que levaram à decisão do lançamento, a Comissão observou um erro nas análises de dados de esgotamento térmico, com os quais vôos sem nenhum incidente de dano do anel- $O$ foram excluídos do quadro crítico de danos do anel- $O$, assim como a temperatura ambiente na hora do lançamento, considerando que isso não contribuía com qualquer informação sobre o efeito da temperatura. Este truncamento dos dados levou à conclusão de que não existia nenhuma relação entre o dano do anel-O e a temperatura na hora do lançamento. Dalal [Dalal 89] esclarece o assunto da estatística, ao demonstrar a forte correlação entre o dano do anel e a temperatura e a quantidade de riscos (de falha catastrófica) a $31^{\circ} \mathrm{F}$. Se a análise original tivesse utilizado "todos" os dados, teria indicado que a decisão de lançamento era, na melhor das hipóteses, uma tarefa arriscada. 
Neste caso, o problema que influenciou na seleção foi o "erro humano" e poderia ter sido facilmente evitado. Na maioria dos problemas, a influência humana na seleção de dados é uma característica inerente aos dados viáveis, e os métodos de análise necessitam lidar com isso. A experiência dos pesquisadores é que cada conjunto de dados tem potencial para influenciar na seleção de inferências inválidas. Vale lembrar que:

- Qualquer técnica usada para analisar dados truncados como se fossem uma amostra aleatória, pode ser falsa, independentemente de como o truncamento foi induzido.

- Os dados por si só são raramente capazes de alertar o especialista do KDD que um mecanismo de seleção foi realizado - a informação externa dos dados fornecida por um especialista do domínio é crucial para entender a natureza e o alcance de influências potenciais.

\subsubsection{Tamanho das Bases de Dados}

As bases de dados diferem em alguns aspectos dos conjuntos de treinamento usados em AM, já que os sistemas de Aprendizado de Máquina usam conjuntos de treinamento. Os problemas tratados por Data Mining são geralmente relacionados tanto a quantidade de informação por caso, quanto ao número de casos contidos:

Informação por caso: a maioria das bases de dados contém muitos atributos. Por exemplo, a base de dados do projeto RADIX/RX [Blum 82, Walker 87, Wiederhold 86], que possui a base ARAMIS (Sistema de Informação Médica da Associação Americana de Reumatismo) com informação sobre visitas clínicas de pacientes. Cada visita é armazenada em um registro com 400 atributos e para cada paciente são armazenadas entre 50 a 100 visitas. Assim, no total são registrados de 20 a 40000 atributos para cada paciente.

Por outro lado, deve-se notar que quanto mais informação (por caso) seja dada, é mais provável que existam melhores relações. Porém, mais informação também aumenta o número de descrições construíveis e a compreensão delas.

O número de descrições depende do tamanho dos domínios, por exemplo, usando o conjunto de descrições, o número de descrições construíveis é aproximadamente $2^{l}$ no qual $l$ é a soma dos atributos segundo o tamanho do domínio. Então, para qualquer base de dados real (no qual $l \gg$ 1000), o espaço de descrição é muito grande. É possível usar constrangimento e heurística para buscar o melhor espaço para ótimas soluções aproximadas.

Número de casos: durante o processo de busca, a qualidade de cada descrição gerada tem que ser verificada. Como se discutiu antes, é preciso fazer testes estatísticos para checar se a descrição atual descreve alguma regularidade nos dados. Esses testes precisam de informação sobre o conjunto de exemplos, como o número de exemplos cobertos pela descrição, ou a distribuição de valores neste conjunto.

As bases de dados usadas em Data Mining normalmente são grandes (tipicamente $>100.000$ casos), consequientemente, examinar a base de dados por inteiro resulta em um processo caro e, principalmente, essa quantidade não é suportada pela maioria dos algoritmos de AM. Para superar esse problema, pode-se usar as seguintes técnicas: 
1. Descrições múltiplas: elas podem ser construídas em uma única iteração do processo de busca e sua qualidade pode ser calculada simultaneamente, isto é, por um único (mas complexo) acesso à base de dados. Executando a base de dados inteira no qual para cada caso atualiza a informação de cada descrição.

2. Janelas: pode-se calcular a qualidade de uma descrição usando uma amostra representativa da base de dados, chamada "janela". Um subconjunto é usado para construir descrições. As melhores descrições são então testadas na base de dados inteira. Contanto que a probabilidade atual das regras não seja igual à probabilidade prevista, adicionando alguns dos exemplos incorretamente classificados para a janela, as regras que usam esta janela são modificadas.

\subsubsection{Atualizações Constantes das Bases de Dados}

As bases de dados são atualizadas com frequiência: informação é adicionada, modificada ou removida. Qualquer conhecimento extraído previamente dessa base de dados pode então ficar inconsistente. É óbvio que um sistema de aprendizado deveria "adaptar-se" a tais mudanças. Além disso, a confiabilidade das regras é incrementada quando o tamanho da amostra é incrementada, assim se as regras são aprendidas de uma pequena base de dados e esta base de dados é dependente do tempo, faz sentido manter regras consistentes [Holsheimer 94].

Um sistema de Data Mining está correto se a probabilidade atual de cada regra não difere significativamente da probabilidade prevista dessa regra. Para os sistemas adaptáveis - sistemas dinâmicos que ajustam suas regras com o passar do tempo - pode-se usar uma janela deslizante (sliding window), por exemplo, para calcular a probabilidade atual de uma regra usando as últimas $n$ classificações [Spears 90].

É essencial manter as regras consistentes com as informações mais recentes, porque as características dos exemplos podem mudar com o passar do tempo, devido a tendências e processos no ambiente. Por esta razão, a informação mais recente deveria ser avaliada e com um peso maior antes de ser adicionada à informação mais antiga, por exemplo, deve-se usar algum "preconceito de aprendizado" (learning bias), dando pesos mais altos a recentes experiências no processo de aprendizado.

Os sistemas cognitivos ajustam suas regras quando são feitas muitas previsões incorretas [Holland 86]. Isto também poderia ativar um ajuste da regra em sistemas de Data Mining: quando a probabilidade atual de uma regra difere da probabilidade prevista em um certo período, a regra é ajustada.

Cada especialista do domínio pode reconstruir uma regra do nada, mas seria mais conveniente permitir algum tipo de "aprendizado incremental" [Utgoff 89], no qual o conhecimento previamente gerado é usado no processo de reconstrução.

\subsection{CONSIDERAÇÕES FINAIS}

Parte da própria natureza do homem é tentar explicar o comportamento do ambiente onde ele vive. Uma forma primitiva é através da observação e reconhecimento de semelhanças entre casos 
e eventos dentro desse ambiente, para poder assim, agrupar casos semelhantes em classes e construir regras que prevejam o comportamento desses casos dentro de cada classe.

Existem ambientes com uma grande quantidade de variáveis que participam do seu processo, tornando impossível para o homem, uma explicação do comportamento desse ambiente. Ante a esse problema, o homem tenta entender um ambiente complexo usando uma simplificação deste através de um "modelo". O modelo, então, é usado para prever mudanças no ambiente e permitir que o homem possa interagir e aprender com mais êxito.

Aprender consiste então, em encontrar a classe e a função de transição do modelo para uma representação interna apropriada, de forma que o modelo classifique corretamente os exemplos conhecidos, assim como os novos exemplos. Em Aprendizado de Máquina esta classificação deve ser avaliada para poder determinar sua qualidade.

A qualidade do aprendizado dos sistemas de Aprendizado de Máquina é definida por duas medidas básicas referentes a sua consistência e completeza. Consistência é uma medida de quanto uma regra é específica para o problema. Existe consistência quando não é classificado nenhum caso negativo como estando dentro dos casos positivos. Completeza é uma medida do quanto o domínio do problema é coberto pela regra. Quanto mais alta for a completeza, mais casos serão cobertos pela regra.

Vários algoritmos de AM foram desenvolvidos para criar descrições do conjunto de dados. Todos eles encontram-se limitados pelo número de registros, atributos, capacidade de memória do computador, manipulação de dados contínuos, etc. Existe uma grande variedade de algoritmos com diferentes propriedades dependendo da forma de como aprendem, do seu paradigma, da sua linguagem utilizada para descrever o aprendizado e da forma como podem ser integrados novos exemplos.

Este algoritmos de AM são utilizados por Data Mining que busca descrições em um "conjunto de dados" selecionado a partir de uma base de dados. Essa base de dados quase sempre é grande e contém dados que foram gerados e armazenados para propósitos diferentes dos processos de aprendizado. Consequientemente, é mais difícil descobrir descrições que nas condições ideais encontradas em Aprendizado de Máquina.

Bases de dados contaminadas por erros, grande dependência do especialista de domínio e busca de conhecimento compreensível a partir dessas bases de dados fazem uma das diferenças entre Data Mining e Aprendizado de Máquina.

A necessidade de avaliar as descrições criadas pelos sistemas de Data Mining faz que o conjunto de dados seja dividido em um.conjunto de treinamento e um conjunto de teste. $O$ primeiro é utilizado pelos algoritmos de AM para encontrar as descrições do ambiente e o segundo para avaliá-las. Um método comumente utilizado para realizar uma melhor determinação dos conjuntos de treinamento e teste que possam avaliar todo o sistema é o método de resampling cross-validation.

No próximo capítulo é apresentada uma breve descrição das ferramentas que foram utilizadas para auxiliar as diferentes etapas do Processo de Extração de Conhecimento de Bases de Dados. 
"What is counted does not always counts and what counts is not always counted."

- Albert Einstein

\section{FERRAMENTAS UTILIZADAS}

\subsection{CONSIDERAÇÕES INICIAS}

Várias ferramentas podem ser utilizadas para auxiliar as diferentes etapas do Processo de Extração de Conhecimento de Bases de Dados. Neste capítulo é apresentada uma breve descrição das ferramentas utilizadas neste trabalho. Primeiramente, é mostrado o software MineSet ${ }^{\mathrm{TM}}$ que foi utilizado para visualizar e discretizar os dados, bem como os utilitários para apoiar a etapa de Data Mining que o software contém. Posteriormente, será apresentada a biblioteca $\mathrm{MLC}^{++}$(Machine Learning Library in $\mathrm{C}^{++}$) usada para facilitar o trabalho. de utilização dos algoritmos de Aprendizado de Máquina CN2 e C4.5-rules, que também serão descritos neste capítulo. Finalmente, serão mostrados o software estatístico STATISTICA ${ }^{\text {TM }}$, no qual foram realizadas várias das medidas estatísticas dos conjuntos de dados e o software Excel 97, usado para apoiar o processo de seleção do conjunto de dados.

\subsection{MINESET TM}

O software MineSet ${ }^{\mathrm{TM}}$, versão 2.01 , da Silicon Graphics, incorpora um conjunto de algoritmos de Aprendizado de Máquina usando, entre outras, várias técnicas de visualização de dados em um espaço multidimensional.

O MineSet ${ }^{r M}$ suporta geração e análise de regras de associação e modelos de classificação, usados para previsão, evolução, segmentação e tendências, combinados com visualização animada e interativa. Existem outras funções adicionais dentro do software, tais como: discretização (por intervalos, por distribuição de frequiências, gerada automaticamente ou declarada pelo usuário), seleção, criação ou eliminação de coluna, filtragem de instâncias do conjunto de dados (por exemplo, selecionar só as instâncias maiores que determinado valor) e troca de tipo de dados (por exemplo, de inteiro para string).

MineSet ${ }^{\mathrm{TM}}$ provê a funcionalidade para construir e aplicar vários modelos de classificação, dando aos usuários a vantagem de isolar padrões definidos em um conjunto de dados. MineSet ${ }^{\mathrm{TM}}$ suporta quatro modelos de classificação: Regras de Associação, Árvores de Decisão, Árvores de Opção e Classificadores de Evidência. Estes, combinados com visualizadores especiais, 
permitem explorar os modelos, determinar a precisão dos algoritmos e fazer perguntas do tipo what_if. Na Figura 4.1 é apresentada a interface gráfica do MineSet ${ }^{\mathrm{TM}}$.

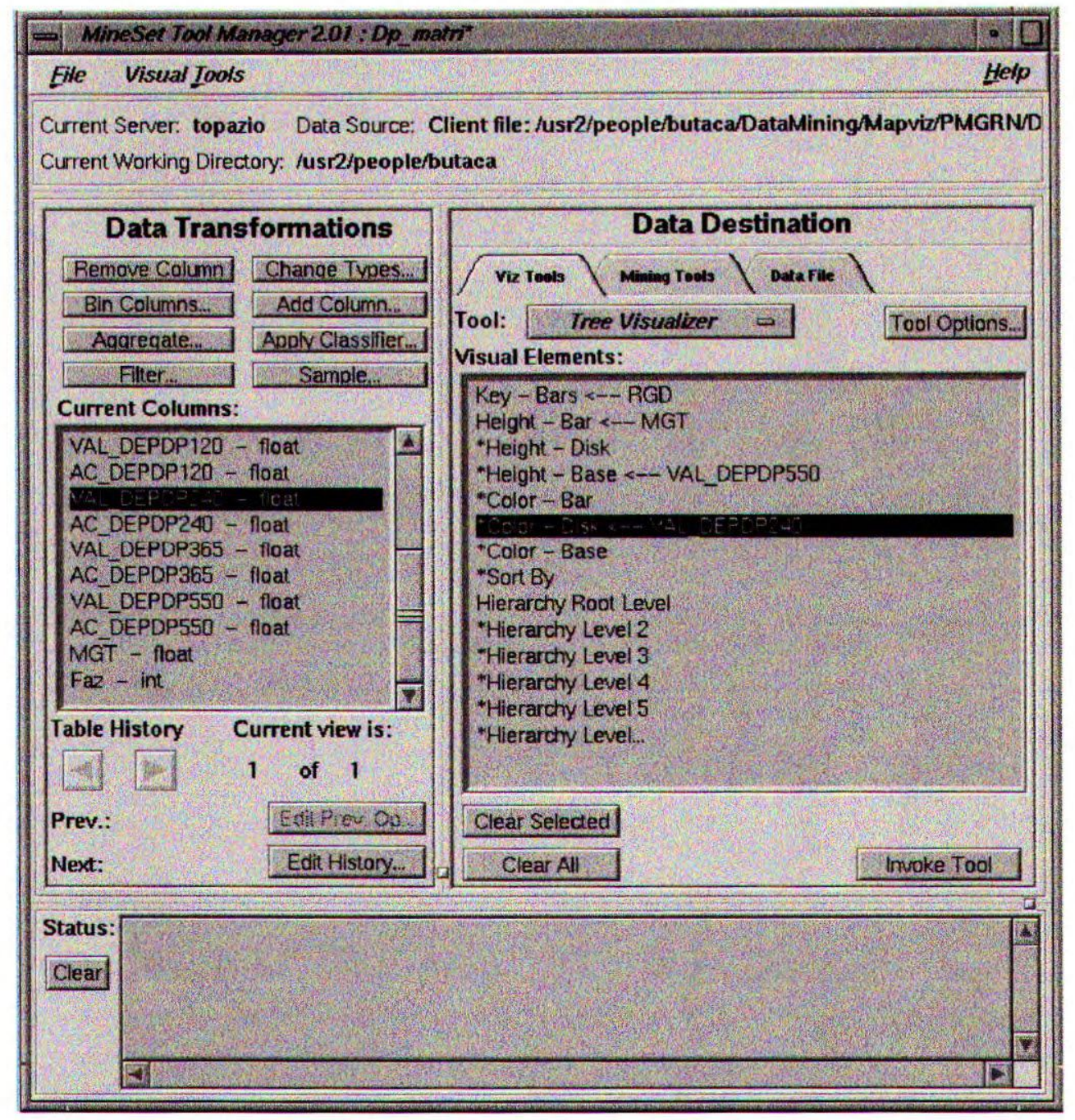

Figura 4.1: Interface gráfica do MineSet ${ }^{\mathrm{TM}}$.

O software MineSet ${ }^{\mathrm{TM}}$ constitui-se de três componentes básicos:

- Módulo de controle centralizado: consiste de uma ferramenta com interface gráfica chamada Tool Manager e um processo chamado de DataMover, que é executado no servidor sempre que o software começa operar.

- Ferramenta de Data Mining: constituída de quatro utilitários:

- Gerador de Regras de Associação.

- Classificador e Indutor de Árvore de Decisão e de Opção.

- Classificador e Indutor de Evidência.

- Importância da Coluna.

- Ferramentas de visualização: permitem a visualização dos dados utilizando diferentes visualizadores, tais como:

- Tree Visualizer: visualizador de árvores de decisão.

- Scatter Visualizer: visualizador bidimensional ou tridimensional.

- Map Visualizer: visualizador de mapas. 
- Rule Visualizer: visualizador de regras.

- Evidence Visualizer: visualizador de evidências da classe dentro de cada atributo.

- Record Visualizer: visualizador da base ou conjunto de dados.

- Statistic Visualizer: visualizador das estatísticas geradas pelo MineSet ${ }^{\mathrm{TM}}$.

- Splat Visualizer: visualizador difuso bidimensional ou tridimensional.

O MineSet ${ }^{T M}$ usa como suporte principal a biblioteca MLC $^{++}$(que será explicada na próxima seção) para trabalhar na etapa de Data Mining. O utilitário MindUtil faz a interface entre a $\mathrm{MLC}^{++}$e o MineSet ${ }^{\mathrm{TM}}$.

Para maiores informações, se encontra disponível um relatório técnico sobre visualização de gráficos, elaborado por um grupo do Laboratório de Inteligência Artificial [Oliveira 98] do ICMC-USP. Existe também um outro trabalho em andamento sobre Mineset ${ }^{\mathrm{TM}}$ [Rezende 98a], além do Guia do Usuário do próprio software.

Na Figura 4.2 é apresentado o esquema geral dos elementos que compõem o MineSet ${ }^{\mathrm{TM}}$. Na parte central, está localizada a $\mathrm{MLC}^{++}$junto com o utilitário MindUtil, para suportar todos os Algoritmos de Aprendizado de Máquina usados no software. O DataMover é o processo que roda no servidor, sempre que o software é chamado. Por fim, o ToolManager que é a interface gráfica usada pelos usuários do MineSet ${ }^{\mathrm{TM}}$ e que permite interagir com os algoritmos ou com as ferramentas de visualização existentes.

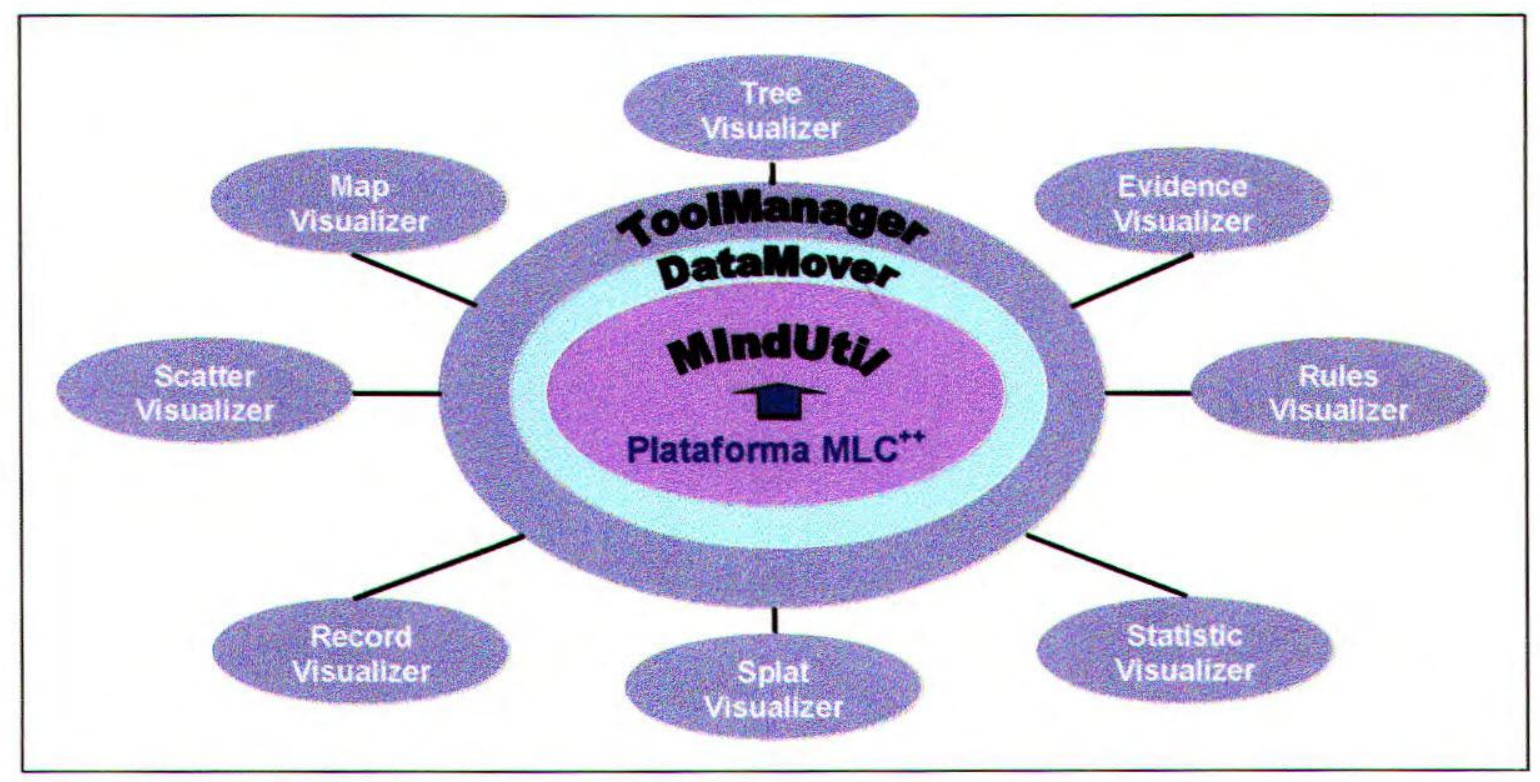

Figura 4.2: Componentes básicos do software MineSet ${ }^{\top \mathrm{M}}$.

O software MineSet ${ }^{\top \mathrm{M}}$ foi usado na fase de análise dos dados, discretização e Data Mining.

\section{3 $M L C^{++}$}

Os algoritmos de Aprendizado de Máquina utilizados neste trabalho, para obtenção de regras, estão todos contidos na $\mathrm{MLC}^{++}$(versão 2.1), que é uma biblioteca de classes em $\mathrm{C}^{++}$de Algoritmos de Aprendizado de Máquina. Essa biblioteca foi projetada para ajudar na seleção de 
algoritmos e/ou no desenvolvimento de novos algoritmos de Aprendizado de Máquina. O projeto da MLC $^{++}$começou em 1993, na Universidade de Stanford, e trata-se de um software de domínio público (inclusive os códigos fontes), sendo que desde 1995 encontra-se sob a responsabilidade da Silicon Graphics. A $\mathrm{MLC}^{++}$encontra-se disponível em http://www.sgi.com/Technology/mlc/index.html.

A biblioteca $\mathrm{MLC}^{++}$tem um papel dual: serve tanto para um sistema com usuários finais quanto para desenvolvedores de algoritmos. Essa biblioteca trabalha com mais de 30 algoritmos, alguns implementados internamente e outros externamente. Além de ser uma biblioteca de classes em $\mathrm{C}^{++}$, provê utilitários e ferramentas que podem ser usadas isoladamente, sendo o benefício principal do seu uso, a habilidade para reunir classes (que são objetos $C^{\text {t' }}$ ) e as instâncias para criar novos algoritmos ou variantes de algoritmos existentes.

$\mathrm{A} \mathrm{MLC}^{++}$está sustentada no fato de não existir um único algoritmo de Aprendizado de Máquina que possa fornecer ótimos resultados de precisão para todas as tarefas. Isto foi teoricamente provado e demonstrado experimentalmente [Kohavi 97]. Devido a este fato, recomenda-se testar vários algoritmos com o mesmo conjunto de dados, para comparar e determinar qual apresenta o melhor desempenho para cada caso.

Cada algoritmo de Aprendizado de Máquina possui um formato próprio para o conjunto de dados de entrada, sendo necessário, quase sempre, uma transformação para se usar um outro algoritmo. Uma das vantagens da biblioteca $\mathrm{MLC}^{++}$é a transformação automática do formato dos dados para os algoritmos de Aprendizado de Máquina.

Levando-se em consideração as diferentes funcionalidades (classes) da $\mathrm{MLC}^{++}$, ela pode ser dividida em quatro tipos: classes de suporte geral, classes essenciais, categorizadores e algoritmos de indução, que são explicados a seguir:

- Classes de Suporte Geral: estas classes provêem apoio para operações gerais, não específicas aos algoritmos de Aprendizado de Máquina, suportando classes para matrizes, listas encadeadas, cadeias de caracteres, números aleatórios e gráficos. Usam-se softwares de domínio público e educacional tanto quanto possível para esta funcionalidade da MLC ${ }^{++}$. Por exemplo, as manipulações gráficas são feitas usando LEDA (Library of Efficient Data Structures), desenvolvido por Stefan Näeher [Näeher 92], e dot da AT\&T [Gansner 93].

- Classes Essenciais: estas são as ferramentas básicas que são compartilhadas por muitos algoritmos de Aprendizado de Máquina supervisionado. Elas estão divididas de acordo com as suas funcionalidades:

- Input/Output: classes para ler e escrever arquivos de dados.

- Geração e Conversões: classes para gerar conjunto de dados artificiais, convertendo os tipos de atributos entre formatos (por exemplo, codificação local $\{a, b, c, d\} \rightarrow$ $\{0001,0010,0100,1000\}$, codificação binária) e normalizando valores.

- Wrappers: algoritmo que "envolve" um outro algoritmo de indução, visando gerar melhores classificações e aproveitando as vantagens de cada um deles. Algumas vezes, são usados dois algoritmos para calcular a estimativa de erro do classificador usando cross-validation (visto no Capítulo 3 ), um para gerar os $k$-folds do conjunto de dados e outro como indutor, para posteriormente calcular a média da estimativa de precisão juntando todos os $k$-folds.

- Categorizadores: os categorizadores são utilizados para prever a categoria de uma instância (na literatura são comumente chamados de classificadores, mas na $\mathrm{MLC}^{++}$, usa-se esse termo 
para evitar confusão entre classificador, classes e classes $\mathrm{C}^{++}$). Eles são as estruturas básicas geradas pelos algoritmos de indução. A biblioteca $\mathrm{MLC}^{++}$provê os categorizadores mais comuns, como: categorizador constante (que retorna a mesma categoria independente da instância), categorizador de atributo (que usa somente um atributo para prever a categoria), categorizador de disparo, categorizador do nearest-neighbor (vizinho mais próximo), categorizadores de árvores e gráficos de decisão, categorizador de perceptron e categorizador de redes neurais. Também são construídos categorizadores recursivos, por exemplo, em um categorizador de árvore de decisão, os nós ramificados são categorizados entre eles mesmos (mapeando um conjunto de instâncias no conjunto de filhos daquele nó), e o algoritmo de indução pode usar qualquer categorizador, inclusive a possibilidade de árvores de decisão recursivas. O ID3 [Quinlan 86b] usa categorizadores de atributos para atributos nominais e categorizadores de disparo para atributos reais. Para gerar árvores multivariantes [Brodley 92, Ileath 93] com perceptrons como nós, o algoritmo de indução pode colocar categorizadores de perceptron nos nós.

- Algoritmos de Indução: são os algoritmos de Aprendizado de Máquina (chamados pelos autores da biblioteca de indutores) capazes de gerar regras de produção ou árvores de decisão a partir de níveis discretos da classe do conjunto de dados. Em termos da MLC ${ }^{++}$um indutor cria um categorizador.

Na Figura 4.3 é ilustrada a interação que existe entre indutores, categorizadores, a etapa de teste e wrappers. A parte superior ilustra a indução e subseqüentes testes de um categorizador. A parte inferior mostra um wrapper cross-validation que gera os $k$-folds e calcula a média da estimativa de precisão do indutor no conjunto de dados. A separação do indutor e do categorizador representa um papel importante na decomposição global da biblioteca MLC $^{++}$para construção de vários categorizadores.

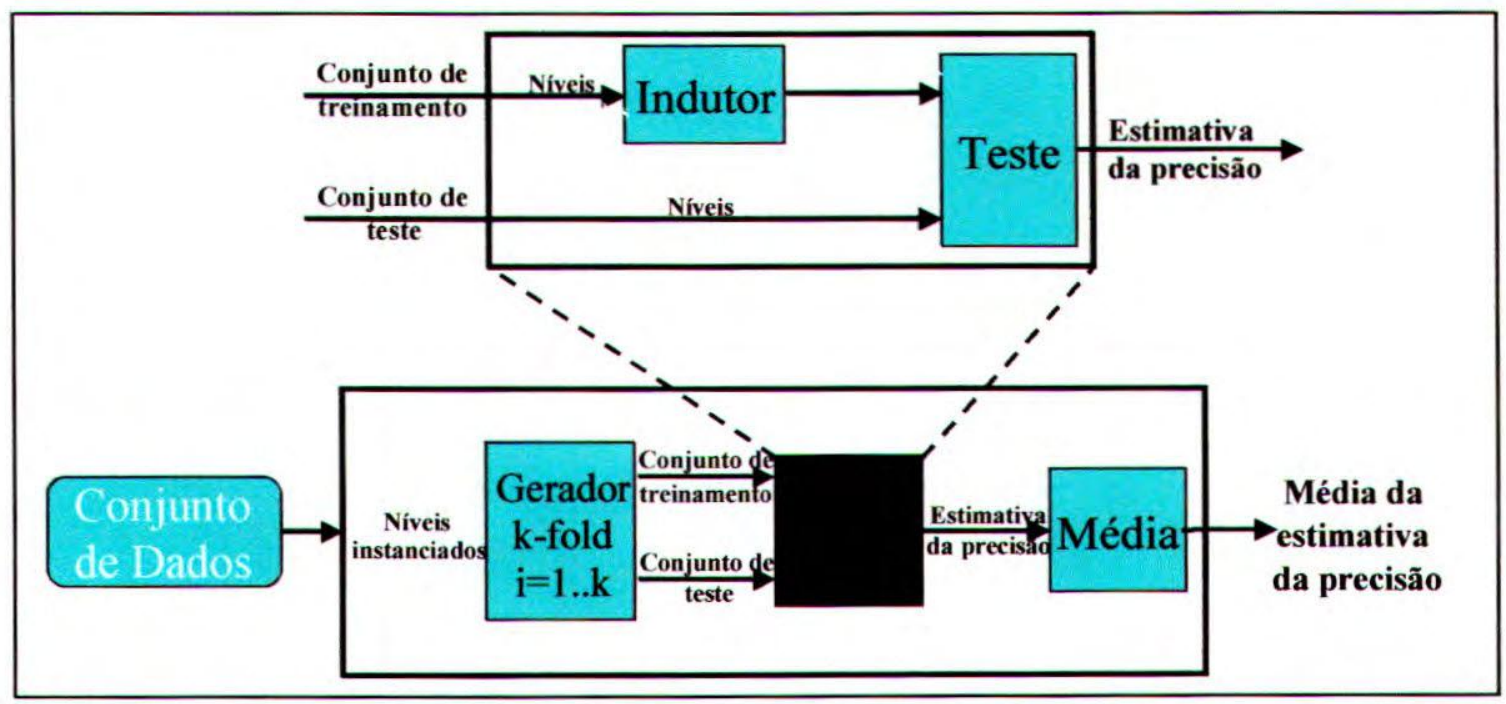

Figura 4.3: Interação entre indutor, categorizador, a etapa de teste e wrapper.

Os usuários da biblioteca $\mathrm{MLC}^{++}$devem conhecer o funcionamento básico dos indutores, uma vez que não existe um indutor ótimo para todos os conjuntos de dados. Existem indutores que têm um ótimo desempenho para alguns conjuntos de dados, mas para outros, apresentam um desempenho fraco. Isto depende de vários fatores, como: tamanho do arquivo de dados, número de registros, número de variáveis, quantidade de valores contínuos e discretos, etc. [Kohavi 97]. 
Alguns dos indutores internos implementados na $\mathrm{MLC}^{++}$são: Const [Kohavi 95], Decision Tables [Kohavi 95], ID3 [Quinlan 86b], Lazy Desicion Trees [Friedman 96], Nearest-neighbor [Dasarathy 90, Aha 91, Aha 92, Wettschereck 94], Naive-bayes [Langley 92, Domingos 96], IR [Holte 93], OODG (Oblivous read-Once Decision Graph) [Kohavi 94a], Perceptron [Hertz 91], Winnow [Littlestone 88], etc. Entre os indutores externos, que fazem interface com a MLCH, estão: C4.5 [Quinlan 93], C4.5-rules [Quinlan 87a], C4.5-unpruned [Quinlan 93], CART, CN2 [Clark 89, Clark 91], IB [Aha 92], OC1 [Murthy 94], PEBLS (Parallel Exemplar-Based Learning System) [Cost 93] e T2 [Auer 95].

Uma descrição completa sobre a biblioteca $M L C^{++}$encontra-se em [Félix 98a].

\subsection{ALGORITMOS CN2 e C4.5-rules}

Os sistemas que geram regras de indução são particularmente valiosos para aplicações nas quais a precisão e a compreensão dos modelos gerados são importantes [Langley 95]. Nos experimentos realizados neste trabalho, os algoritmos CN2 [Clark 89] e C4.5-rules [Quinlan 87a] foram usados para determinar regras e comparar as taxas de erro nos conjuntos de dados selecionados. A seguir será dada uma breve descrição desses algoritmos.

CN2: O algoritmo CN2 é um algoritmo supervisionado, pertencente ao paradigma simbólico, que utiliza regras de produção como linguagem de descrição de exemplos e não é incremental. Basicamente, o algoritmo toma um conjunto de instâncias como entrada e gera um conjunto de regras da forma "se...então" para classificar todas as instâncias.

$\mathrm{O}$ algoritmo $\mathrm{CN} 2$ gera uma lista de decisão de forma iterativa, construindo uma regra a cada iteração. Uma regra é construída procurando algum complexo (condições) que cobre um grande número de instâncias para uma classe arbitrária $C_{i}$ e poucas de outras classes (a construção de tal complexo é descrita abaixo). Tendo encontrado alguns bons complexos, o algoritmo remove do conjunto de treinamento as instâncias cobertas, e a regra "se <complexo> então prevê $C_{i}$ " é adicionada para o fim da lista de decisão. Para o conjunto restante, uma regra nova é construída, até que nenhum complexo adicional de grande importância seja encontrado.

O melhor complexo em um conjunto de treinamento é encontrado usando uma busca de viga (beam search), por exemplo, na construção de um grafo, na qual a cada iteração, o grafo é estendido até no máximo, as folhas maxstar. No momento da busca, as folhas ativas (por exemplo, os complexos) são armazenadas em um conjunto de tamanho limitado, chamado estrela. O sistema registra também os melhores complexos encontrados anteriormente.

Inicialmente, a estrela só contém a raiz do grafo e não existem condiçóes cobrindo o conjunto de treinamento inteiro. Todas as interseçôes de todos os complexos na estrela são examinadas calculando a interseção da estrela com o conjunto de todas as possíveis condições. São descartados os complexos cujo significado não exceda o threshold. Das condições restantes, a mais interessante - definidas pelo critério de qualidade - formam uma nova estrela.

O processo de busca pelo melhor complexo termina quando não pode ser encontrado nenhum complexo adicional com algum significado. O melhor complexo encontrado no grafo é retornado 
e forma a parte condicional de uma nova regra. Se nenhum complexo é encontrado, a nova regra não pode ser construída e a regra default é adicionada ao final da lista de decisão.

C4.5-rules: o.C4.5-rules é um algoritmo supervisionado, pertencente ao paradigma simbólico, que utiliza regras de produção como linguagem para descrever exemplos e não é incremental.

Um dos tipos mais extensamente usados de formalismos para descrever relações entre casos é a árvore de decisão, que emprega uma estratégia recursiva de "dividir e conquistar" para dividir as instâncias treinadas em regiões disjuntas do espaço de hipótese de acordo com as classes preestabelecidas.

Ao contrário de muitas estratégias que empregam dividir e conquistar, criando um conjunto de regras que cobrem as instâncias de treinamento, o C4.5-rules extrai regras da árvore de decisão existente.

A meta do procedimento é produzir um conjunto ordenado de regras da forma:

\section{se LHS então RHS}

no qual LHS é um conjunto de condições e RHS é a classe designada para esse conjunto de condições. Durante a classificação de uma instância, deverá existir uma regra pela qual todas as condições especificadas no $L H S$ sejam satisfeitas para aquela instância, então $R H S$ deverá concordar com a classe previamente definida, posteriormente uma nova instância, dentro do conjunto de instâncias, será analisada, até poder classificar todas as instâncias.

Em muitas ocasiões, quando o espaço de hipóteses não é coberto completamente pelo conjunto de regras, uma classe default é dada - esta é a classe definida para qualquer instância não coberta por nenhuma regra do conjunto de regras.

Os quatro passos no processo de geração de regras são:

1. Poda: primeiro, um conjunto inicial de regras é construído convertendo cada caminho da raiz até uma folha da árvore em uma regra, na qual cada condição do $L H S$ da regra corresponde a um nó interno do caminho na árvore de decisão. Uma árvore de decisão com $l$ folhas produzem um conjunto inicial de $l$ regras. Cada uma dessas regras são examinadas e as condições do $L H S$ que não parecem contribuir na estimativa da precisão da regra são removidas, resultando em uma "regra podada" mais geral, na qual será adicionada ao conjunto intermediário de regras, uma vez que não exista uma outra regra igual.

2. Seleção: as regras podadas, construídas no passo anterior, são agrupadas em conjuntos de regras por classe, uma em cada uma das $k$ classes do conjunto de treinamento (por exemplo, a $R H S$ de cada regra no subconjunto $i$ é a classe $C_{i}$ ). Cada um desses conjuntos de regras é analisado para selecionar um subconjunto que maximizará a precisão de previsão para a classe associada com este conjunto de regras.

3. Ordenamento: o conjunto de $k$ regras é ordenado de acordo com a frequiência de falsos erros positivos e uma classe default $́$ é estabelecida para os casos treinados que não foram cobertos por nenhuma das regras atuais: a classe mais frequiente desses casos é designada default. 
4. Avaliação: o conjunto de regras é avaliado usando o conjunto de treinamento para determinar se alguma regra afeta o erro de classificação adversamente. Nesse caso, a "pior" regra é removida e a avaliação é repetida até que nenhuma melhoria adicional seja possível.

\subsection{STATISTICA E EXCEL}

Foi utilizado o software estatístico STATISTICA ${ }^{\mathrm{TM}}$, versão 5.0, da StatSoft Inc., na etapa de compreensão dos dados, a fim de determinar algumas medidas estatísticas (valores máximos, mínimos, desvio padrão, média, mediana, etc.). No estudo de caso do Capítulo 5 foi utilizado este software tentando determinar um modelo matemático do conjunto de dados, por exemplo, modelo gaussiano ou exponencial. Finalmente, esta consideração foi descartada, porque os dados apresentavam um modelo híbrido (eram compostos de vários modelos), o que significava um estudo matemático bastante complexo.

Todos os dados utilizados nos estudos de casos foram trabalhados no formato do Excel 97, da Microsoft. Esse software trabalha com planilhas e gráficos possibilitando a apresentação dos dados de maneira mais representativa, por exemplo, uso da codificação por cores para identificação rápida dos conjuntos de dados. Uma vez que os dados foram selecionados, pelo Excel 97, eles foram exportados para a $\mathrm{MLC}^{++}$ou o MineSet ${ }^{\mathrm{TM}}$ em código ASCII separados por vírgulas ou espaços, respectivamente.

\subsection{CONSIDERAÇÕES FINAIS}

Neste capítulo foram abordadas brevemente as ferramentas utilizadas neste trabalho. Durante este trabalho foi realizada a instalação do software MineSet ${ }^{\mathrm{TM}}$ e da biblioteca $\mathrm{MLC}^{++}$, que foi de grande ajuda para um melhor entendimento sobre o funcionamento de cada um deles.

Também foram brevemente explicados os algoritmos CN2 e C4.5-rules. O primeiro é de domínio público e o segundo foi obtido com a compra do livro de Quinlan [Quinlan 87a]. Estes algoritmos foram escolhidos por serem bem conhecidos e estarem disponíveis no Laboratório de Inteligência Computacional do ICMC-USP, onde se desenvolveram todos os testes.

Os próximos dois capítulos mostram os dois estudos de casos realizados. O primeiro utilizou uma base de dados petroleira, e o segundo, uma base do Programa de Melhoramento Genético da Raça Nelore. 


\section{Capítulo 5}

"Se levou seis horas para cortar uma árvore, gastou as primeiras quatro afiando o machado"

- Abraham Lincoln

\section{ESTUDO DE CASO 1 - BASE DE DADOS PETROLEIRA}

\subsection{OBJETIVO}

Mostrar a influência da discretização no processo de aprendizado usando uma base de dados petroleira.

\subsection{DEFINIÇÃO DO DOMINIO}

Muitos algoritmos de AM que trabalham no processo de Extração de Conhecimento de Bases de Dados precisam de certos atributos discretos para trabalhar. Mas infelizmente a grande maioria das informações das bases de dados reais são descritas através de valores contínuos. A discretização passa a ser vista por alguns pesquisadores como uma etapa de pré-processamento dos dados no processo KDD. Este trabalho tem como um de seus objetivos mostrar que uma "discretização híbrida" pode-se considerar como uma sub-etapa de Data Mining e jogando um papel importante na obtenção de melhores resultados no processo de extração de conhecimento.

Em essência, um algoritmo de discretização aceita como entrada os valores de um atributo contínuo (inteiro ou real) e gera como saída uma pequena lista de intervalos ordenados. Cada intervalo é representado na forma $\left[\mathrm{V}_{\text {inferior }}: \mathrm{V}_{\text {superior }}\right]$, de tal forma que $\mathrm{V}_{\text {inferior }}$ e $\mathrm{V}_{\text {superior }}$ são os limites inferiores e superiores do intervalo. Geralmente os algoritmos de discretização trabalham em dois passos: primeiro, os valores dos atributos de entrada são ordenados, como um passo de inicialização e, em seguida, um procedimento de discretização é aplicado aos valores ordenados para produzir um conjunto de intervalos ordenados.

Este estudo de caso está baseado nos dados e critérios do artigo "Predicting Permeability from Porosity Using Artificial Networks" [Rogers 95], visando prever a permeabilidade de um poço petroleiro, usando regras de indução, a partir dos dados da profundidade, porosidade e permeabilidade de poços petroleiros vizinhos a ele. Três diferentes cenários baseados sob considerações geológicas são apresentados. Através dos métodos estatísticos e técnicas de visualização foi realizada uma análise dos dados para ter um melhor conhecimento do domínio. Subseqüentemente, foi realizada uma comparação das diversas taxas de erro obtidas pelos 
algoritmos simbólicos de Aprendizado de Máquina CN2 [Clark 89] e C4.5-rules [Quinlan 87b], considerando três métodos de discretização realizados nos valores da permeabilidade.

A discretização de valores contínuos apresenta algumas vantagens e desvantagens. Uma primeira vantagem refere-se ao espaço de armazenamento: os valores contínuos requerem, na maioria das vezes, um espaço maior, do que quando são usados valores discretizados. Uma outra vantagem refere-se a alimentação dos algoritmos de AM. O processamento de dados contínuos é normalmente muito mais demorado (algumas pesquisas citam reduções de tempo de aprendizado que alcançam uma ordem de magnitude considerável quando são usados dados discretizados [Catlett 91]). Adicionalmente, o processamento de dados contínuos produz classificadores de um tamanho maior. Uma desvantagem de discretizar um valor contínuo é a perda, em alguns casos, de informação disponível nos valores contínuos. Por exemplo, dois valores diferentes dentro do mesmo intervalo de discretização são considerados iguais, embora estejam nos dois extremos do intervalo. Tais efeitos podem reduzir a precisão dos algoritmos de AM [Ventura 95]. Uma forma de representar a iteração entre um algoritmo de discretização, os tipos de dados e o algoritmo de AM é mostrado na Figura 5.1.

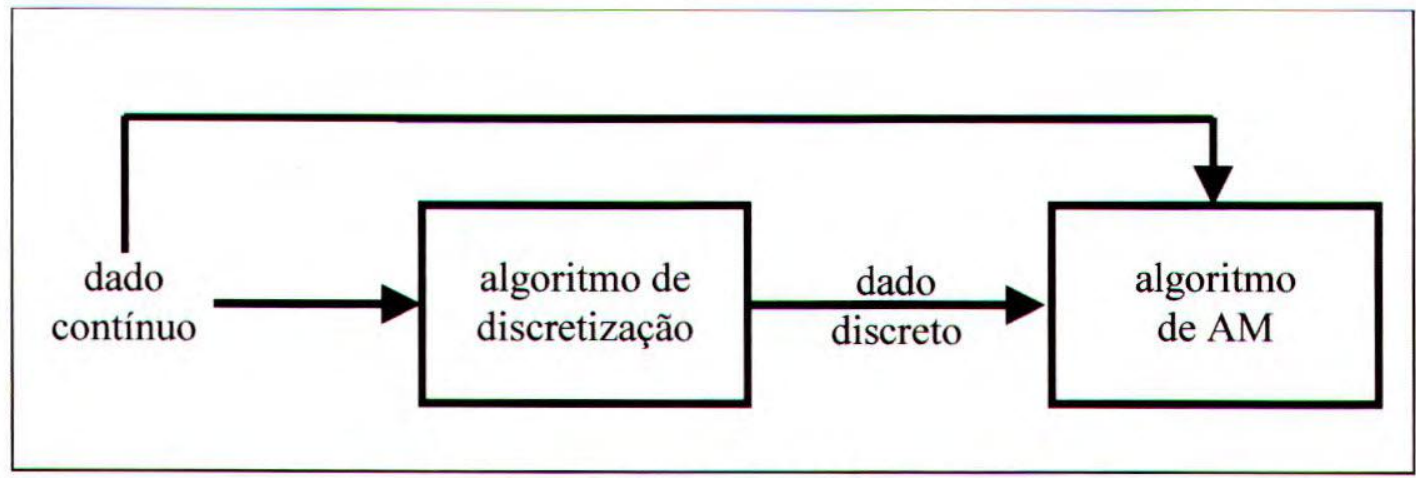

Figura 5.1: Interação entre um algoritmo de discretização, um algoritmo de AM e diversos tipos de dados.

De acordo com alguns critérios existentes as discretizações e, simultaneamente, os métodos de discretização são classificados em:

- supervisionados ou não supervisionados;

- locais ou globais;

- parametrizados ou não parametrizados.

Os métodos supervisionados levam em conta os valores das classes quando se está produzindo a discretização, os métodos não supervisionados são, por outro lado, de decisão-escondida (decision-blind) (ou classe-escondida), não fazendo uso dos níveis de instanciação. Os métodos locais discretizam somente um atributo por vez ou em certas regiões do espaço instanciado, enquanto os globais tentam uma discretização simultânea de todos os atributos. Os métodos parametrizados são aqueles para os quais o número máximo de intervalos gerados para uma determinada característica são especificados com antecedência, os métodos não parametrizados determinam esse valor automaticamente.

Vários elementos devem ser levados em conta em uma discretização como, por exemplo, técnicas estatísticas, algoritmos de discretização, especialistas do domínio, etc. Existem na literatura vários algoritmos de discretização com diferentes métodos de busca para determinar os 
"pontos de corte" mais adequados [Kerber 92, Lenarcik 92, Fayyad 93, Lenarcik 93, Ventura 94, Chmielewski 95, Dougherty 95, Lenarcik 95, Nguyen 95, Pfahringer 95, Susmaga 97]. A seguir será apresentado o contexto no qual se situa o problema.

\subsection{CONTEXTO DO PROBLEMA}

O presente estudo está baseado no trabalho "Predicting Permeability from Porosity Using Artificial Networks" [Rogers 95]. Esse trabalho mostra os resultados de uma classificação realizada por uma rede neural visando prever a permeabilidade de um poço petroleiro a partir da sua porosidade e profundidade. Os resultados obtidos são comparados com os resultados usando regressão linear e com os dados observados. O conjunto de dados está determinado pelas medidas realizadas em seis poços localizados em Big Escambia Creek, no estado de Alabama, nos Estados Unidos. Três cenários foram criados, baseados em considerações geológicas fornecidas por especialistas daquele domínio. No primeiro cenário foram utilizados os poços 1877 e 1928 como conjunto de treinamento, o poço 1802 como conjunto de validação e o poço 1930 como o poço sendo previsto. No segundo cenário foram utilizados os poços 1802 , $1877 \mathrm{e}$ 1930 como conjunto de treinamento, o poço 1928 como conjunto de validação e os poços 1704 e 1705 como os poços sendo previstos. Para o terceiro cenário foram selecionados os poços 1802 , 1877,1928 e 1930 como conjunto de treinamento, o poço 1705 como conjunto de validação e o poço 1704 como o poço sendo previsto. A maioria dos dados de porosidade e permeabilidade estão incompletos, apresentando também, a falta de seqüência na profundidade.

Fazendo uso dos algoritmos simbólicos CN2 e C4.5-rules e baseando-se nos três cenários anteriormente mostrados, foram considerados neste trabalho, os poços 1802,1877 e 1928 como conjunto de treinamento e o poço 1930 como o conjunto de teste, representando o primeiro cenário. No segundo cenário foram considerados os poços 1802, 1877, 1928 e 1930 como conjunto de treinamento, os poços 1704 e 1705 foram considerados como dois conjuntos de teste separados. Finalmente, para o terceiro cenário foram considerados os poços 1705, 1802, 1877, 1928 e 1930 como conjunto de treinamento e o poço 1704 como o conjunto de teste. Na Figura 5.2 é apresentada de forma gráfica a profundidade relativa entre os seis poços (em pés), a quantidade de casos de cada poço, assim como os três cenários formados.

Baseado no contexto anterior, este trabalho visa mostrar a influência da discretização na precisão do aprendizado, comparando várias discretizações da permeabilidade com três critérios diferentes e sendo utilizadas pelos algoritmos de indução de regras CN2 e C4.5-rules, comparando as diversas taxas de erro obtidas. A seguir será explicada a forma em que o conjunto de dados usado na etapa de Data Mining foi selecionado a partir das bases de dados originais.

\subsection{SELEÇÃO DOS DADOS}

O domínio é denotado pelo atributo-classe "permeabilidade" relacionando a "porosidade" $\mathrm{e}$ "profundidade". A permeabilidade está definida como a habilidade de um fluido em forma líquida ou gasosa penetrar pelos poros de um material quando é sujeito a uma pressão. Ela é dada em darcies. A porosidade é a propriedade que um material tem de conter poros ou interstícios (intervalos que separam as moléculas de um corpo). É definida como a relação (em porcentagem) entre o volume dos interstícios e o volume da massa do material, dependendo do número, forma e distribuição dos espaços vazios [WRRC 98]. Os dados da profundidade, 
porosidade e permeabilidade utilizados neste trabalho e descritos na Tabela 5.1 encontram-se em forma de atributos contínuos.

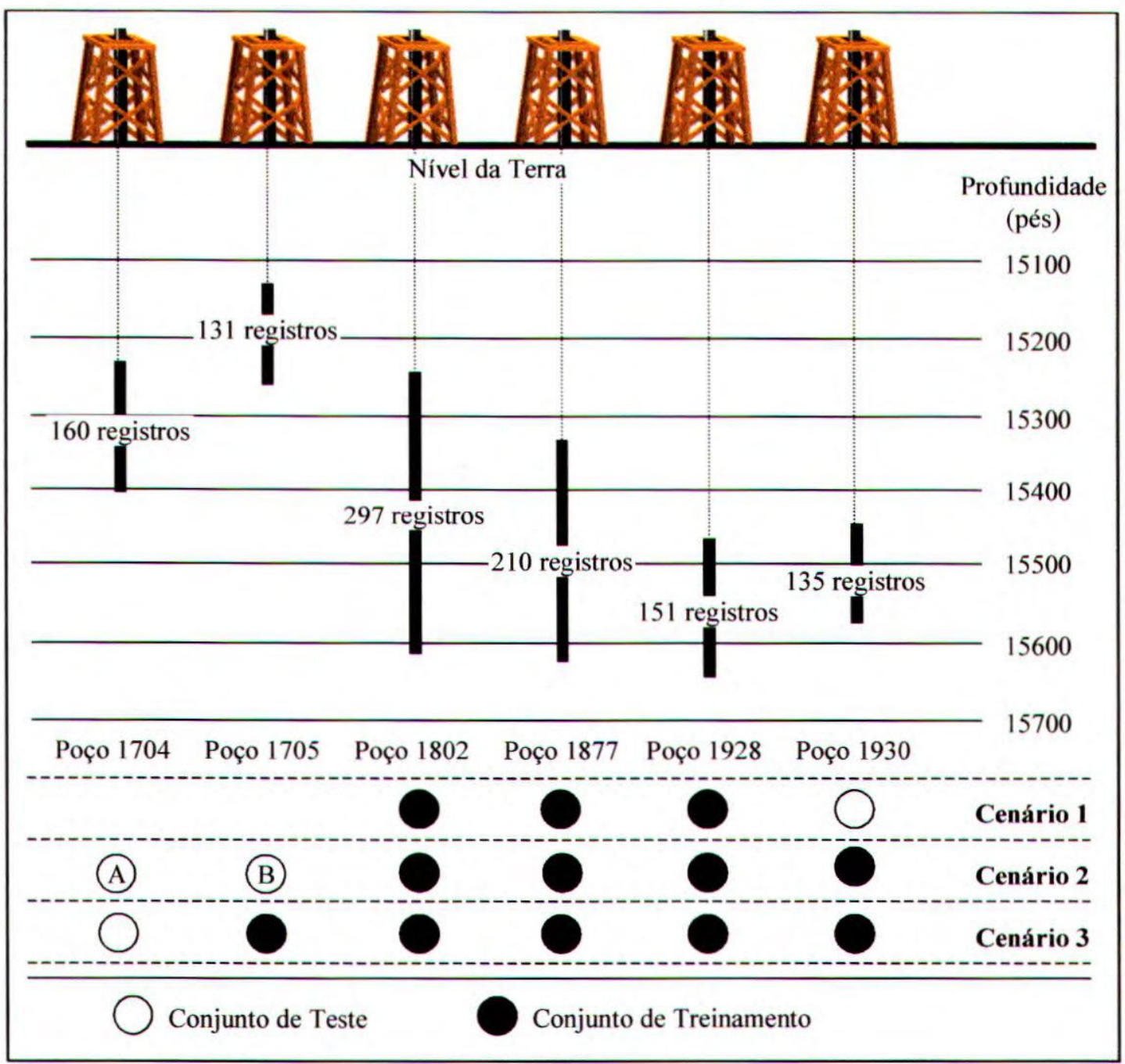

Figura 5.2: Informação dos seis poços (1084 registros em total).

A primeira fase deste estudo de caso é a análise dos dados dos poços em separado e em conjunto, para poder-se ter um melhor entendimento do domínio no qual se está trabalhando. A utilização de métodos estatísticos desempenham um papel importante nesta primeira fase; conhecer a média, o desvio padrão, a moda, os valores máximos e mínimos de cada atributo, etc. são requisitos básicos.

A ferramenta STATISTICA ${ }^{\mathrm{TM}}$ foi utilizada nesse passo para analisar a profundidade, a porosidade e a permeabilidade dos seis poços de petróleo (1084 registros) e determinar os valores máximo e mínimo, sua distribuição, a média, a mediana, o desvio padrão, o número total de valores conhecidos, o número total de valores desconhecidos, o número de valores distintos, os relacionamentos entre permeabilidade e porosidade, entre permeabilidade e profundidade, etc. Alguns desses resultados estatísticos, dos seis poços de petróleo, são mostrados na Tabela 5.1. 
Primeiramente, $96 \operatorname{casos}^{5}$ que não continham valores nem para permeabilidade e nem para porosidade foram eliminados, assim como os 6 casos que continham a legenda "LOST CORE". Esta legenda indica que o instrumento de detecção perdeu (não registrou) os valores de porosidade e permeabilidade para uma certa profundidade. Eliminados esses casos, restou um total de 982 casos.

Tabela 5.1: Resultados estatísticos dos seis poços petroleiros.

\begin{tabular}{|l|c|c|c|}
\hline & Profundidade & Porosidade & Permeabilidade \\
\hline Total de Registros & 1084 & 1084 & 1084 \\
\hline Valores Desconhecidos & 0 & 96 & 96 \\
\hline Valores “LOST CORE" & 0 & 6 & 6 \\
\hline Valores Conhecidos & 1084 & 982 & 982 \\
\hline
\end{tabular}

Em seguida observou-se que os dados originais continham muitos valores de permeabilidade da forma $<0,01$ assim como valores igual a zero, mostrados na Tabela 5.2.

Todos os valores zero assim como os valores de permeabilidade $<0,01$ foram substituídos pelo valor 0,009 . Isso significa que quaisquer valores gerados pelo algoritmo CN2 ou pelo algoritmo C4.5-rules com "permeabilidade $=0,009$ " devem ser interpretados como "permeabilidade $<0,01$ ".

A visualização prévia dos dados na maioria da vezes fornece um maior conhecimento do domínio do problema, mas por outro lado é importante ter um conhecimento prévio do domínio antes de ser aplicada a visualização dos dados para poder determinar o tipo de gráfico e a informação que ele dá dependendo dos dados considerados. Para realizar uma primeira visualização dos dados foi utilizada a ferramenta Scatter Visualizer, tanto na profundidade como na porosidade. Os valores dos atributos são representados através de quadros: um quadro pequeno indica um valor menor e um quadro grande indica um valor maior. Na Figura 5.3(a) e Figura 5.4(a) são mostrados os gráficos da análise de permeabilidade e porosidade, respectivamente.

Tabela 5.2: Distribuição da permeabilidade de valores zero e $<0,01$.

\begin{tabular}{|c|c|c|c|c|}
\hline Poço & Casos & Valores zero & Valores $<\mathbf{0 , 0 1}$ & $\%$ \\
\hline 1704 & 159 & 66 & 0 & 41,5 \\
\hline 1705 & 129 & 0 & 78 & 60,4 \\
\hline 1802 & 249 & 121 & 0 & 48,6 \\
\hline 1877 & 182 & 0 & 58 & 31,8 \\
\hline 1928 & 130 & 0 & 38 & 29,2 \\
\hline 1930 & 133 & 0 & 15 & 11,3 \\
\hline TOTAL & 982 & 187 & 189 & 38,3 \\
\hline
\end{tabular}

Foi detectado nos gráficos mostrados na Figura 5.3(a) e Figura 5.4(a), a existência de uma elevada ausência de dados no poço 1705. Posteriormente foi feito um estudo nos dados originais e se chegou a conclusão que era muito provável que existisse um erro na informação, devido à sequêencia da mesma e dos valores dos outros atributos. Na Tabela 5.3 é visto que, passando de uma profundidade de 15220 pés o valor seguinte é 15521 pés, para posteriormente voltar de

\footnotetext{
${ }^{5}$ Nesta etapa os registros passam a ser chamados de casos.
} 
15541 para 15242. Os dados foram corrigidos e em todos os resultados das figuras vistas anteriormente e posteriormente consideram essa correção.

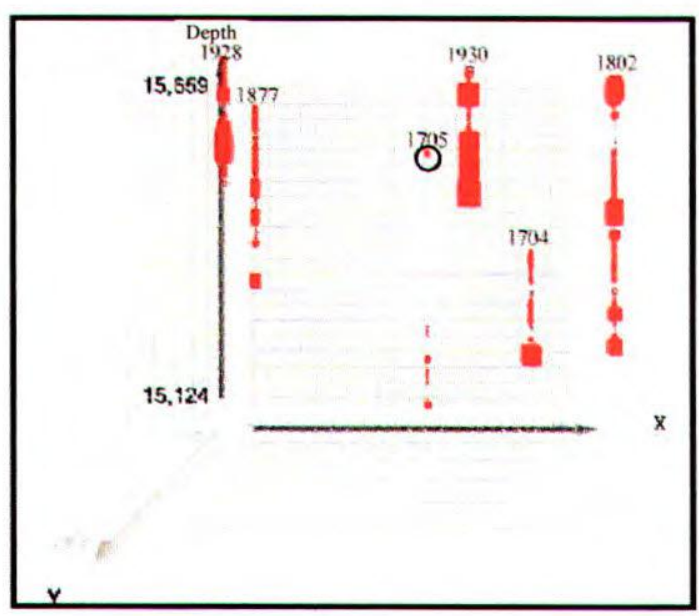

(a)

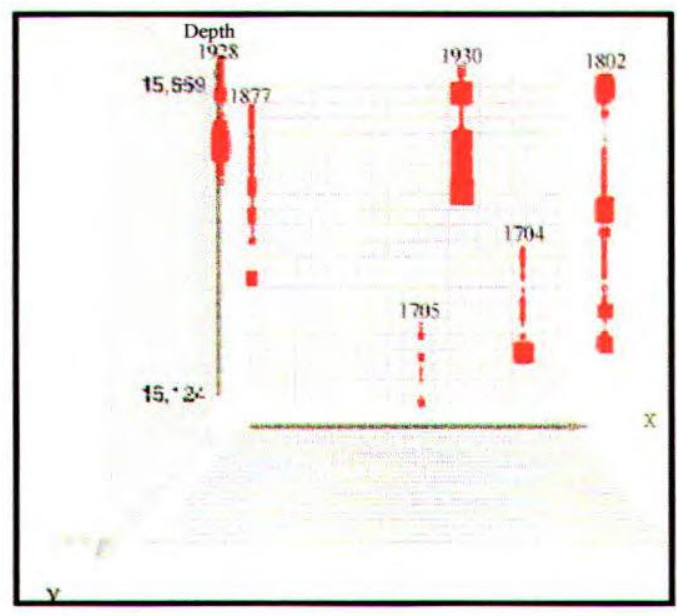

(b)

Figura 5.3: (a) Visualização da permeabilidade com um erro detectado no poço 1705;

(b) Permeabilidade após ter sido corrigida.

Analisando os gráficos da Figura 5.3(b) e Figura 5.4(b) pode-se observar uma alta heterogeneidade nos valores da permeabilidade em comparação aos valores da porosidade que apresentam um comportamento mais homogêneo. É observado também que o poço 1930 apresenta demasiada porosidade e permeabilidade em comparação aos demais poços. Também é interessante notar que os poços 1704 e 1802 apresentam pouca permeabilidade, mas muita porosidade na maioria dos seus valores em relação com os demais poços.

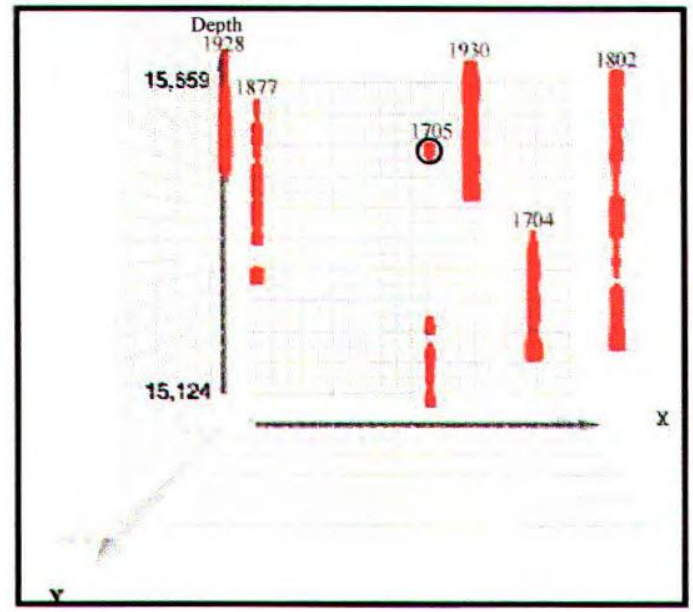

(a)

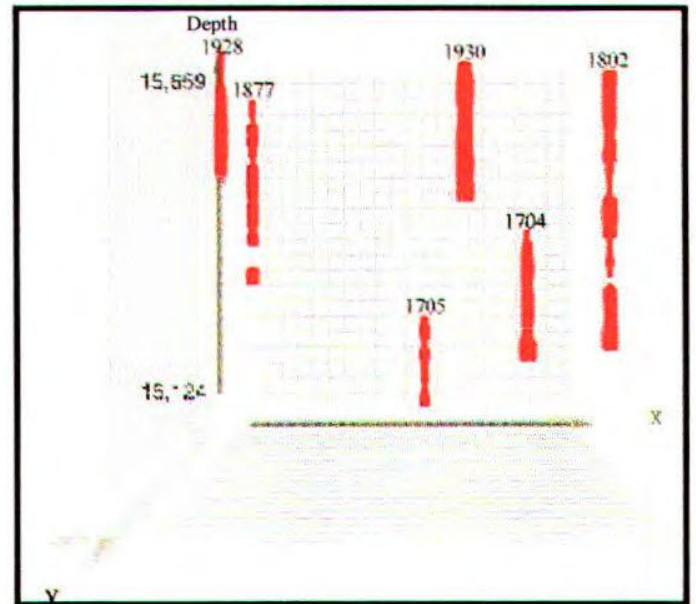

(b)

Figura 5.4: (a) Visualização da porosidade com um erro detectado no poço 1705; (b) Porosidade após ter sido corrigida.

Uma análise estatística em forma gráfica após a substituição, incluindo média, mediana, desvio padrão e histogramas é mostrada na Figura 5.5. Resultados similares são mostrados na Tabela 5.4 . 
Tabela 5.3: Erro detectado e corrigido através da visualização no poço 1705.

\begin{tabular}{|c|r|r|r|r|r|}
\hline \multicolumn{3}{|c|}{ Dado Original } & \multicolumn{3}{c|}{ Dado Corrigido } \\
\hline Profundidade & Porosidade & Permeabilidade & Profundidade & Porosidade & Permeabilidade \\
\hline & & & & & \\
15217 & 2 & $<0,01$ & 15217 & 2 & 0,009 \\
15218 & 0,7 & $<0,01$ & 15218 & 0,7 & 0,009 \\
15219 & 0,7 & $<0,01$ & 15219 & 0,7 & 0,009 \\
$\mathbf{1 5 2 2 0}$ & 0,6 & $<0,01$ & 15220 & 0,6 & 0,009 \\
$\rightarrow \mathbf{1 5 5 2 1}$ & 0,7 & $<0,01$ & 15221 & 0,7 & 0,009 \\
15522 & 0,7 & $<0,01$ & 15222 & 0,7 & 0,009 \\
15523 & 1,3 & $<0,01$ & 15223 & 1,3 & 0,009 \\
15524 & 1,1 & $<0,01$ & 15224 & 1,1 & 0,009 \\
$\ldots$ & $\ldots$ & $\ldots$. & $\ldots$. & $\ldots$ & $\ldots$ \\
$\ldots$ & $\ldots$. & $\ldots$. & $\ldots$. & $\ldots$ \\
15538 & 9,4 & 0,9 & 15238 & 9,4 & 0,9 \\
15539 & 9,8 & 0,8 & 15239 & 9,8 & 0,8 \\
$\rightarrow \mathbf{1 5 5 4 0}$ & 7,8 & 0,05 & 15240 & 7,8 & 0,05 \\
$\mathbf{1 5 5 4 1}$ & 0,8 & $<0,01$ & 15241 & 0,8 & 0,009 \\
15242 & 7,1 & 0,57 & 15242 & 7,1 & 0,57 \\
15243 & 8,3 & 0,05 & 15243 & 8,3 & 0,05 \\
15244 & 15,1 & 0,34 & 15244 & 15,1 & 0,34 \\
15245 & 11,7 & 0,29 & 15245 & 11,7 & 0,29 \\
\hline
\end{tabular}

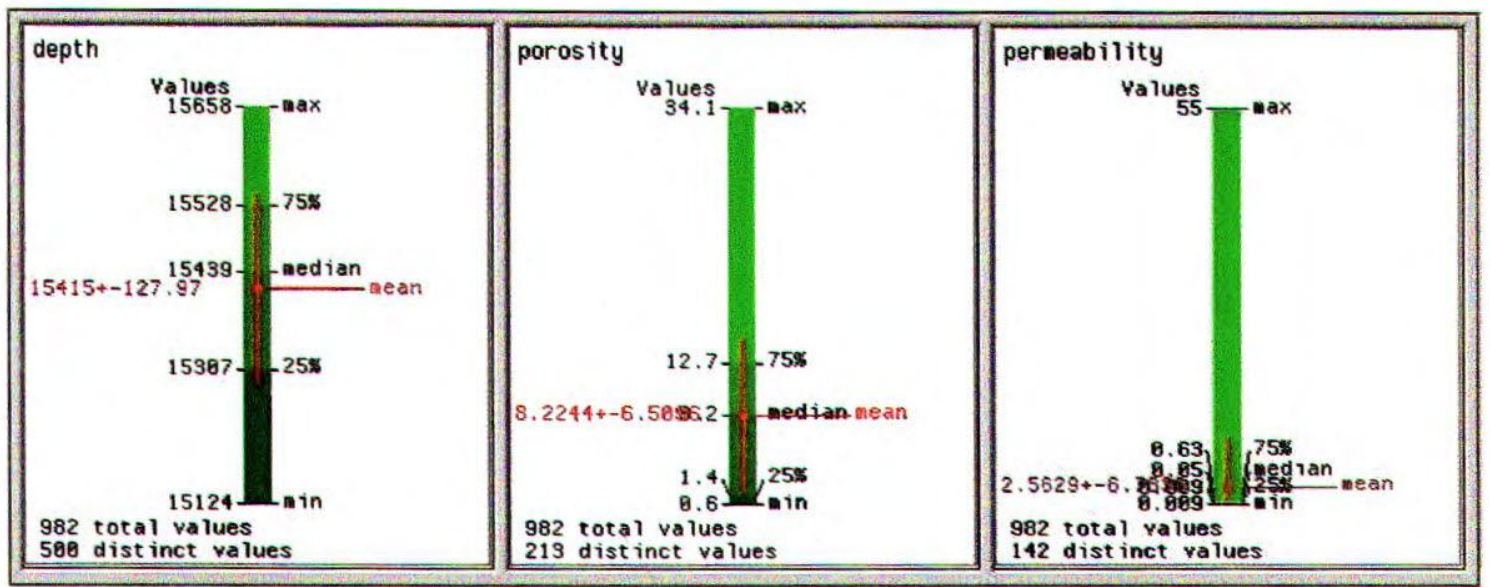

Figura 5.5: Resultados estatísticos dos seis poços usando Statistics Visualizer (982 casos).

Tabela 5.4: Descrição estatística dos seis poços (982 casos).

\begin{tabular}{|l|c|c|c|}
\hline & Profundidade & Porosidade & Permeabilidade \\
\hline Valores Distintos & 500 & 213 & 142 \\
\hline Valores [Max:Min] & {$[15568: 15124]$} & {$[34,1: 0,6]$} & {$[55: 0,009]$} \\
\hline Média & $15415 \pm 127,9$ & $8,2 \pm 6,5$ & $2,5 \pm 6,7$ \\
\hline Mediana & 15439 & 8,2 & 0,05 \\
\hline
\end{tabular}

Na Figura 5.6 é apresentada informação como à mostrada na Figura 5.2, mas com 982 casos depois da limpeza realizada nos dados dos a partir dos seis poços. 


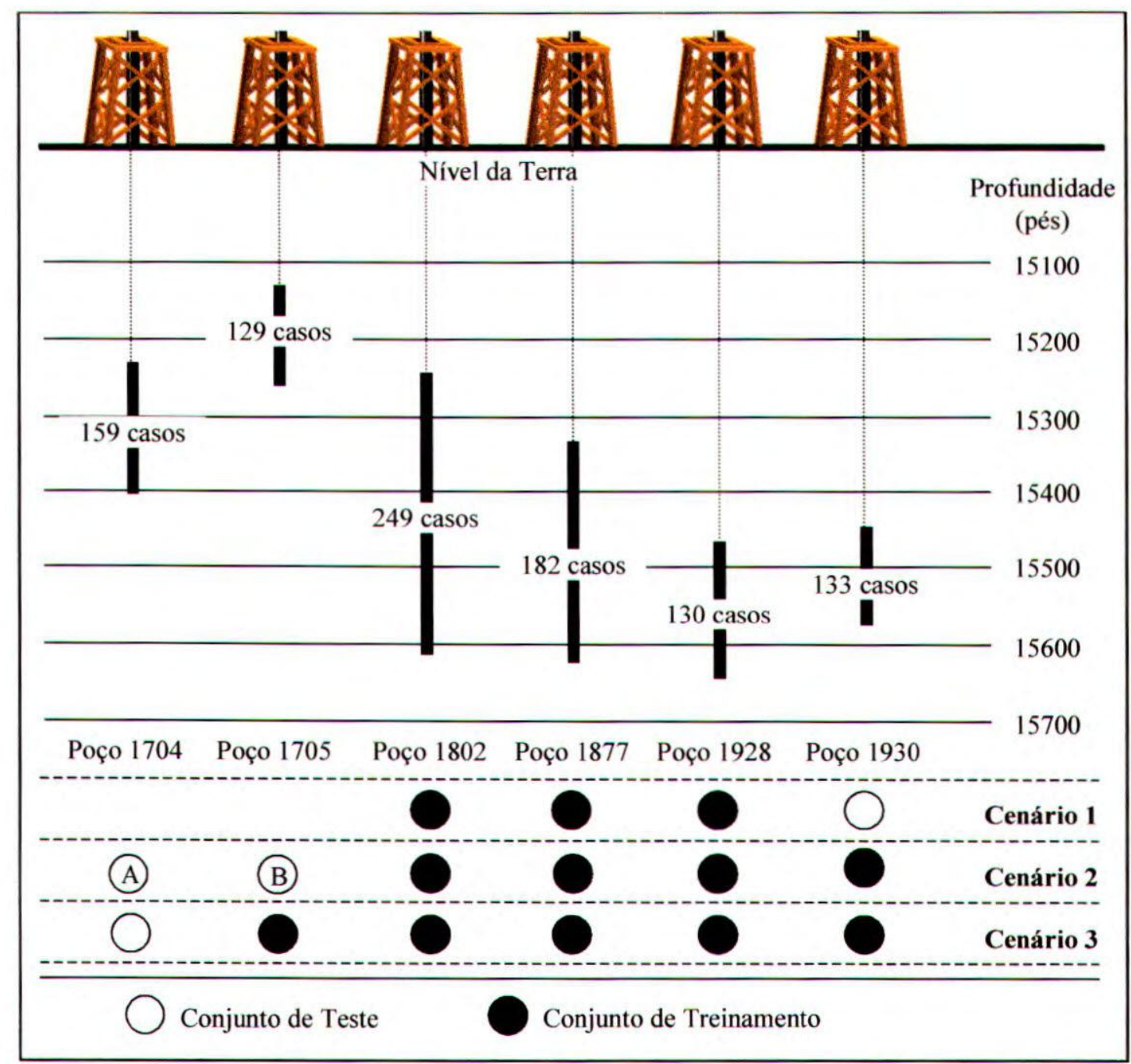

Figura 5.6: Informação dos seis poços após limpeza dos dados (982 casos em total).

\subsection{DATA MINING}

\subsubsection{Discretização no Atributo-Classe}

Após esta análise inicial e a correção dos dados, nos concentramos no processo de discretização do atributo-classe "permeabilidade" de modo que pudéssemos utilizar os algoritmos de classificação de aprendizado supervisionado CN2 e C4.5-rules.

Nesse trabalho, utilizando MineSet ${ }^{\mathrm{TM}}$, três métodos de discretização foram usados:

1. Uma discretização stand-alone do atributo-classe "permeabilidade" baseada na distribuição por freqüência.

2. Um método empírico sugerido por um especialista do domínio, para discretizar o atributo-classe "permeabilidade" considerando os valores de "porosidade". 
3. Um método híbrido que tenta melhorar a discretização sugerida pelo especialista do domínio através da precisão dos algoritmos CN2 e C4.5-rules, variando os intervalos de discretização [Félix 98b].

Existem vários critérios para fazer uma discretização, como foi visto na Seção 5.2. Depois de uma análise e de vários testes foram escolhidos, para realizar uma discretização stand-alone, os critérios supervisionado, parametrizado e local. O número de intervalos gerados para o atributoclasse "permeabilidade" é especificado com antecedência, sem tomar em consideração os demais atributos ("porosidade" e "profundidade"), tentando distribuir os valores da "permeabilidade" através dos intervalos da discretização. As discretizações foram feitas juntando todos os dados dos seis poços (982 casos), para poder fazer as comparações corretas entre os três cenários. Neste trabalho foram feitas 3 discretizações formando 2,3 e 5 grupos.

Segundo o especialista do domínio, cada terreno onde as perfurações são realizadas é único, sendo difícil determinar os intervalos da discretização para esses cenários. Um especialista do domínio que forneça a melhor discretização, em geral, será aquele que conheça esse terreno, já que os valores da permeabilidade são diferentes para cada domínio. No entanto, é importante saber, segundo ele, que na maioria dos casos, uma porosidade maior das pedras indica a possível presença de petróleo nessa área. Conseqüentemente, para determinar o critério de discretização é importante considerar a porosidade do poço. Embora o nosso especialista não tenha determinado os valores de discretização, ele forneceu um método empírico determinando as diversas discretizações da permeabilidade considerando o peso dos valores da porosidade dos poços. A tarefa foi realizada usando MineSet $^{\top M}$, que tem a capacidade de discretizar um atributo considerando o peso de um outro atributo. Os resultados das diversas discretizações usando um método stand-alone e um método sugerido pelo especialista do domínio são mostrados na Tabela 5.5 .

Tabela 5.5: Intervalos obtidos pelos dois primeiros métodos de discretização.

\begin{tabular}{||c||l||c||}
\hline \hline & $\begin{array}{c}\text { Discretização } \\
\text { stand-alone }\end{array}$ & $\begin{array}{c}\text { Discretização sugerida pelo } \\
\text { especialista do domínio }\end{array}$ \\
\hline \hline 2 intervalos & $<0,055 ;$ & $<0,445 ;$ \\
& $>0,055$ & $>0,445$ \\
\hline 3 intervalos & $<0,0095 ;$ & $<0,155 ;$ \\
& {$[0,0095: 0,235] ;$} & {$[0,155: 2,4] ;$} \\
& $>0,235$ & $>2,4$ \\
\hline 5 intervalos & $<0,0095 ;$ & $<0,055 ;$ \\
& {$[0,0095: 0,075[;$} & {$[0,055: 0,215[;$} \\
& {$[0,075: 0,245[;$} & {$[0,215: 1,05[;$} \\
& {$[0,245: 2,4] ;$} & {$[1,05: 7,85] ;$} \\
\hline
\end{tabular}

Nas Figura 5.7(a) e Figura 5.7(b), as diferentes distribuições dos valores de discretização são representadas graficamente, usando o método stand-alone e o método sugerido pelo especialista do domínio. O algoritmo de discretização escolhido para esses experimentos foi "entropia", por apresentar os melhores resultados em experimentos feitos em outros trabalhos relacionados ao assunto [Dougherty 95]. Os resultados dos dois métodos de discretização usados neste trabalho são apresentados na próxima seção. 
Deve-se notar que alguns outros critérios para discretização também foram aplicados, como o critério não-parametrizado, no qual o próprio algoritmo de discretização procura encontrar o número de intervalos de discretização automaticamente. Nesse caso, 12 intervalos de discretização foram encontrados, gerando uma grande quantidade de erro nos algoritmos de AM CN2 e C4.5-rules.

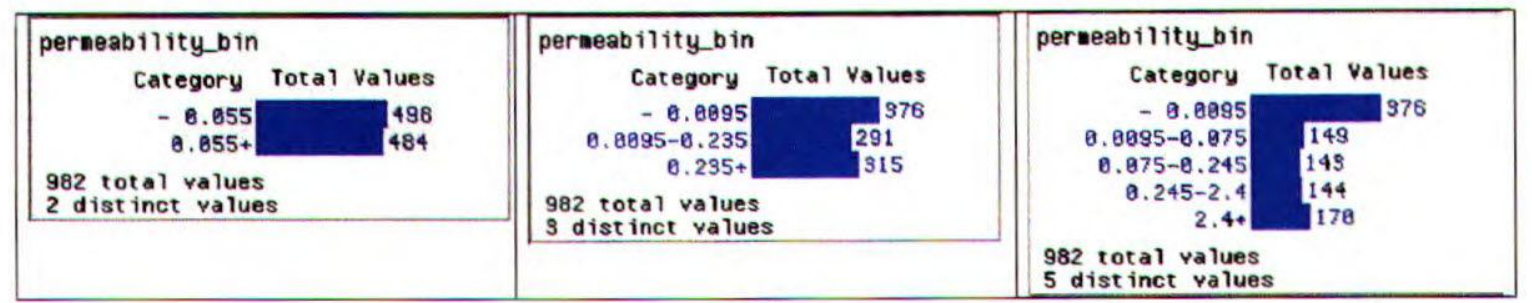

(a)

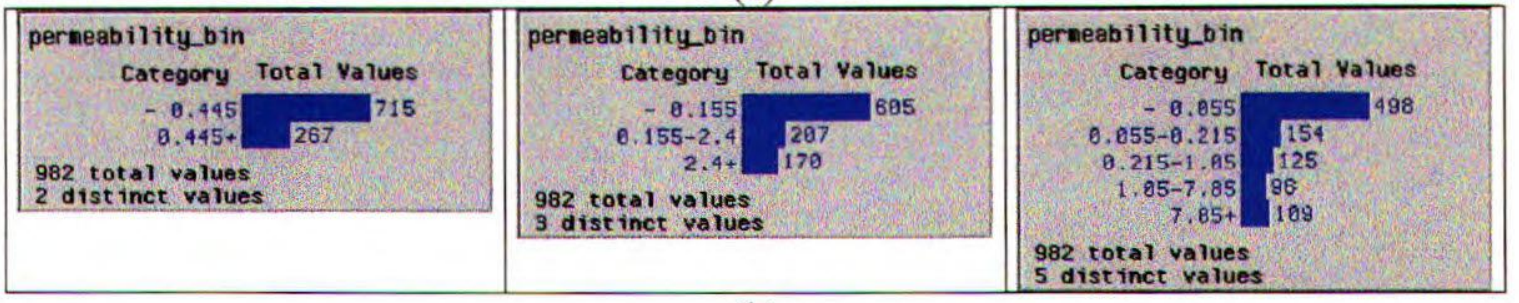

(b)

Figura 5.7: (a) Distribuição de 2, 3 e 5 discretizações usando o método stand-alone. (b) Distribuição de 2, 3 e 5 discretizações baseadas nas considerações do especialista do dominio.

\subsubsection{Comparação entre os Métodos de Discretização}

Nestes experimentos os algoritmos $\mathrm{CN} 2$ e C4.5-rules foram usados para comparar as taxas de erro utilizando as diferentes discretizações para o atributo-classe "permeabilidade". Ambos os algoritmos foram executados utilizando a biblioteca $\mathrm{MLC}^{++}$. Nos dois casos, os algoritmos foram executados com os parâmetros default da biblioteca. As taxas de erro resultantes, obtidas quando se executaram ambos algoritmos para os três cenários, além da taxa de erro da classe majoritária para o conjunto de treinamento em cada cenário, são apresentadas nas Tabelas 5.6, 5.7 e 5.8. Foi decidido apresentar as taxas de erro como uma melhor medida da precisão porque $2 \%$ de erro é duas vezes mais que um erro de $1 \%$, sendo por outro lado, é mais difícil distinguir entre uma precisão vista como $98 \%$ e outra como $99 \%$.

Tabela 5.6: Taxa de Erro para o Cenário 1.

\begin{tabular}{|c||c|c|c||c|c|c|}
\hline \multicolumn{1}{|c||}{} & \multicolumn{3}{c||}{ Discretização stand-alone } & \multicolumn{2}{c|}{$\begin{array}{c}\text { Discretização sugerida pelo } \\
\text { especialista de domínio }\end{array}$} \\
\hline \hline $\begin{array}{c}\text { No. de } \\
\text { Discretizaçeses }\end{array}$ & $\begin{array}{c}\text { CN2 } \\
\text { Taxa de } \\
\text { Erro }\end{array}$ & $\begin{array}{c}\text { C4.5-rules } \\
\text { Taxa de } \\
\text { Erro }\end{array}$ & $\begin{array}{c}\text { Taxa de Erro } \\
\text { da Classe } \\
\text { Majoritária }\end{array}$ & $\begin{array}{c}\text { CN2 } \\
\text { Taxa } \\
\text { de Erro }\end{array}$ & $\begin{array}{c}\text { C4.5-rules } \\
\text { Taxa de } \\
\text { Erro }\end{array}$ & $\begin{array}{c}\text { Taxa de Erro } \\
\text { da Classe } \\
\text { Majoritária }\end{array}$ \\
\hline \hline 2 & $12,8 \%$ & $22,6 \%$ & $47,2 \%$ & $23,3 \%$ & $13,5 \%$ & $26,7 \%$ \\
\hline 3 & $36,1 \%$ & $27,1 \%$ & $61,3 \%$ & $42,1 \%$ & $28,6 \%$ & $36,5 \%$ \\
\hline 5 & $46,6 \%$ & $41,4 \%$ & $61,3 \%$ & $67,7 \%$ & $68,4 \%$ & $47,2 \%$ \\
\hline
\end{tabular}


Tabela 5.7: Taxa de Erro para o Cenário 2.

\begin{tabular}{|c||c|c|c||r|r|r|}
\hline \multicolumn{1}{|c||}{} & \multicolumn{3}{c||}{ Discretização stand-alone } & \multicolumn{3}{c|}{$\begin{array}{c}\text { Discretização sugerida pelo } \\
\text { especialista de domínio }\end{array}$} \\
\hline \hline $\begin{array}{c}\text { No. de } \\
\text { Discretizações }\end{array}$ & $\begin{array}{c}\text { CN2 } \\
\text { Taxa de } \\
\text { Erro }\end{array}$ & $\begin{array}{c}\text { C4.5-rules } \\
\text { Taxa de } \\
\text { Erro }\end{array}$ & $\begin{array}{c}\text { Taxa de Erro } \\
\text { da Classe } \\
\text { Majoritária }\end{array}$ & $\begin{array}{c}\text { CN2 } \\
\text { Taxa } \\
\text { de Erro }\end{array}$ & $\begin{array}{c}\text { C4.5-rules } \\
\text { Taxa de } \\
\text { Erro }\end{array}$ & $\begin{array}{c}\text { Taxa de Erro } \\
\text { da Classe } \\
\text { Majoritária }\end{array}$ \\
\hline \hline 2 conjunto teste A & $13,8 \%$ & $6,9 \%$ & $47,3 \%$ & $8,8 \%$ & $10,1 \%$ & $30,8 \%$ \\
\hline 2 conjunto teste B & $13,2 \%$ & $9,3 \%$ & $47,3 \%$ & $6,2 \%$ & $5,4 \%$ & $30,8 \%$ \\
\hline 3 conjunto teste A & $17,0 \%$ & $16,4 \%$ & $64,7 \%$ & $30,2 \%$ & $17,0 \%$ & $42,2 \%$ \\
\hline 3 conjunto teste B & $7,8 \%$ & $7,8 \%$ & $64,7 \%$ & $5,4 \%$ & $7,8 \%$ & $42,2 \%$ \\
\hline 5 conjunto teste A & $28,9 \%$ & $27,7 \%$ & $66,6 \%$ & $34,0 \%$ & $32,7 \%$ & $52,7 \%$ \\
\hline 5 conjunto teste B & $22,5 \%$ & $22,5 \%$ & $66,6 \%$ & $25,6 \%$ & $19,4 \%$ & $52,7 \%$ \\
\hline
\end{tabular}

Tabela 5.8: Taxa de Erro para o Cenário 3.

\begin{tabular}{|c||c|c|c||c|c|c|}
\hline \multicolumn{1}{|c||}{} & \multicolumn{3}{c||}{ Discretização stand-alone } & \multicolumn{2}{c|}{$\begin{array}{c}\text { Discretização sugerida pelo } \\
\text { especialista de domínio }\end{array}$} \\
\hline \hline $\begin{array}{c}\text { No. de } \\
\text { Discretizações }\end{array}$ & $\begin{array}{c}\text { CN2 } \\
\text { Taxa de } \\
\text { Erro }\end{array}$ & $\begin{array}{c}\text { C4.5-rules } \\
\text { Taxa de } \\
\text { Erro }\end{array}$ & $\begin{array}{c}\text { Taxa de Erro } \\
\text { da Classe } \\
\text { Majoritária }\end{array}$ & $\begin{array}{c}\text { CN2 } \\
\text { Taxa } \\
\text { de Erro }\end{array}$ & $\begin{array}{c}\text { C4.5-rules } \\
\text { Taxa de } \\
\text { Erro }\end{array}$ & $\begin{array}{c}\text { Taxa de Erro } \\
\text { da Classe } \\
\text { Majoritária }\end{array}$ \\
\hline \hline 2 & $14,5 \%$ & $6,9 \%$ & $48,8 \%$ & $8,8 \%$ & $10,1 \%$ & $27,2 \%$ \\
\hline 3 & $21,4 \%$ & $15,7 \%$ & $62,3 \%$ & $29,6 \%$ & $18,2 \%$ & $37,8 \%$ \\
\hline 5 & $27,7 \%$ & $25,2 \%$ & $62,3 \%$ & $28,9 \%$ & $32,1 \%$ & $48,8 \%$ \\
\hline
\end{tabular}

Os resultados mostram que somente em alguns poucos casos a taxa de erro é relativamente pequena para ambos os algoritmos, CN2 e C4.5-rules. Além disso, pode ser observado que há uma alta variação nas taxas de erro. Tanto no Cenário 1 usando 3 e 5 discretizações quanto no Cenário 2 usando 3 discretizações sugeridas pelo especialista, a taxa de erro é mais alta que a taxa de erro da classe majoritária. Isto não é aceitável.

Para tentar dar solução ao problema anterior foi proposto um método híbrido que tenta melhorar a discretização sugerida pelo especialista do domínio através da precisão dos algoritmos CN2 e C4.5-rules, variando os intervalos de discretização. A seguir estudamos um cenário particular. Baseado nas considerações anteriores, o Cenário 2 com 3 discretizações sugeridas pelo especialista do domínio utilizando o conjunto de teste A, foi escolhido para este estudo. A matriz de confusão para esse caso é apresentada na Tabela 5.9.

Tabela 5.9: Matriz de confusão para o Cenário 2 usando conjunto de teste A com 3 discretizações baseado no método sugerido pelo especialista de domínio.

\begin{tabular}{|c|c|c|c|c|c|c|c|c|c|c|}
\hline Discretização & \multicolumn{5}{|c|}{ CN2 } & \multicolumn{5}{|c|}{ C4.5-rules } \\
\hline & & (a) & (b) & (c) & Erro & & (a) & (b) & (c) & Erro \\
\hline$<0,155$ & (a) & 90 & 3 & 0 & $3,2 \%$ & (a) & 92 & 1 & 0 & $1,0 \%$ \\
\hline$[0,155: 2,4]$ & (b) & 41 & 9 & 14 & $83,3 \%$ & (b) & 25 & 28 & 1 & $48,1 \%$ \\
\hline$>2,4$ & (c) & 0 & 0 & 12 & $0 \%$ & (c) & 0 & 0 & 12 & $0 \%$ \\
\hline
\end{tabular}

A distribuição de freqüências para os valores de permeabilidade do poço de petróleo 1704, utilizado como conjunto de teste nesse cenário, é apresentada na Figura 5.8. O valor "0,009" contém 66 elementos que não são mostrados nesse gráfico. 


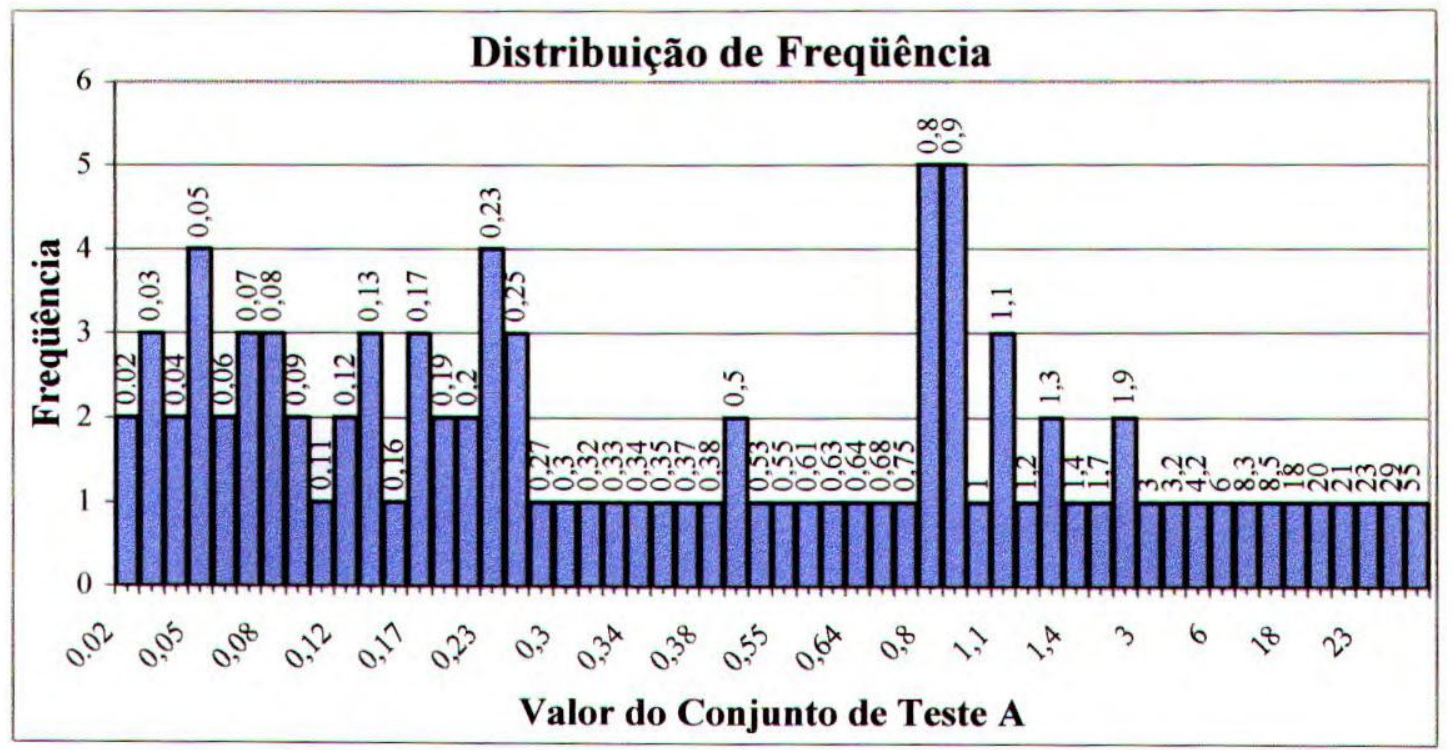

Figura 5.8: Distribuição de freqüência para os valores de "permeabilidade" no poço 1702.

Para tentar melhorar a precisão dos resultados dos algoritmos CN2 e C4.5-rules, fixou-se um limite do intervalo e variou-se o outro limite colocando valores mais altos e mais baixos. Para cada variação, as taxas de erro para ambos algoritmos foram comparadas. Inicialmente fixou-se o limite superior em 2,4 e variou-se o limite inferior $(0,155)$. Os resultados dos experimentos são apresentados na Figura 5.9.

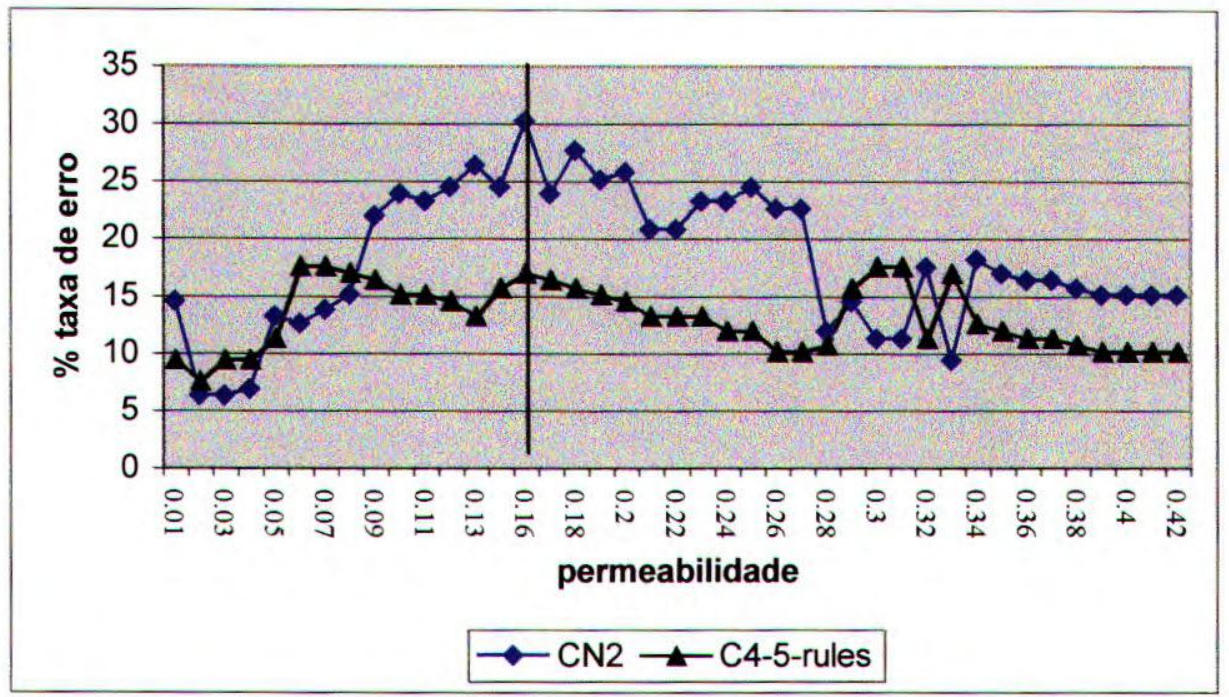

Figura 5.9: Taxa de erro apresentada pelos algoritmos CN2 e C4.5-rules fixando o limite superior em 2,4 e variando o limite inferior 0,155.

Para ambos algoritmos, as menores taxas de erro foram encontradas com o limite inferior fixado em $0,015,0,025$ e 0,035 .

Em seguida o limite inferior 0,155 foi fixado e o limite superior 2,4 foi variado usando valores mais altos e mais baixos. Os resultados dos experimentos são mostrados na Figura 5.10. Os 
valores 0,65 e 0,75 obtiveram as menores taxas de erro para o algoritmo CN2 e os valores 1,75 e 1,85 obtiveram as menores taxas de erro para o algoritmo C4.5-rules. É importante notar que somente o valor 1,75 foi utilizado nos experimentos por haver apresentado resultados semelhantes usando 1,85 .

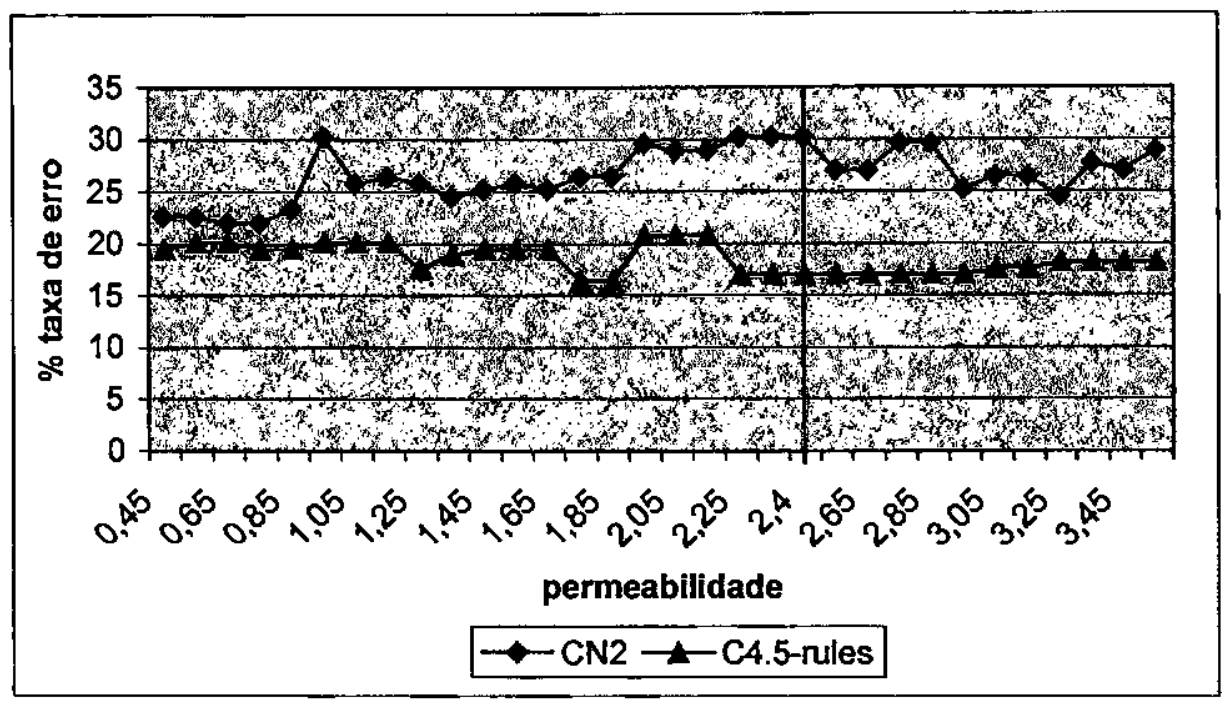

Figura 5.10: Taxa de erro apresentada pelos algoritmos CN2 e C4.5-rules fixando o limite inferior em 0,155 e variando o limite superior 2,4.

Tomando como base as menores taxas de erro apresentadas pelos algoritmos, os melhores limites inferiores próximos de 0,015 e os melhores limites superiores próximos de 2,4 foram escolhidos. Feito isso, as matrizes de confusão foram geradas para cada caso, para tentar determinar o intervalo com a menor taxa de erro considerando a distribuição dos conjuntos de dados. Nesse cenário 694 exemplos foram empregados como conjunto de treinamento e 159 exemplos como conjunto de teste. Os resultados das matrizes de confusão para os algoritmos CN2 e C4.5-rules, considerando as menores taxas de erro obtidas para esses algoritmos, são apresentadas no Apêndice A.

Com base nesses resultados, as discretizações com a menor taxa de erro e uma distribuição relativa em seus dados foram: " 0,015 e 0,75 " e " 0,015 e 1,75". Considerando que estes pontos funcionaram bem para esse cenário, foram colocados em outros cenários para determinar suas taxas de erro. As matrizes de confusão utilizando esses dois novos intervalos de discretização são apresentados no Apêndice B.

\subsubsection{Resultados Usando os Algoritmos Simbólicos de Aprendizado de Máquina}

Na Tabela 5.10 é apresentada uma comparação das taxas de erro nos três cenários, utilizando o método sugerido pelo especialista de domínio, com os pontos de corte 0,155 e 2,4, e o método híbrido proposto neste trabalho usando os pontos de corte 0,015 e 1,75 , por serem estes últimos os melhores resultados obtidos baseados nos testes realizados. 
Tabela 5.10: Comparação entre a discretização sugerida pelo especialista de domínio e a discretização híbrida.

\begin{tabular}{|c||c|c|c|c|c|c|}
\hline \multicolumn{1}{|c||}{} & \multicolumn{3}{c|}{$\begin{array}{c}\text { Discretization sugerida pelo } \\
\text { especialista de domínio 0,155 e 2,4 }\end{array}$} & \multicolumn{2}{c|}{$\begin{array}{c}\text { Discretização usando o método } \\
\text { híbrido 0,015 e 1,75 }\end{array}$} \\
\hline \hline Cenário & $\begin{array}{c}\text { CN2 } \\
\text { Taxa de } \\
\text { Erro }\end{array}$ & $\begin{array}{c}\text { C4.5-rules } \\
\text { Taxa de } \\
\text { Erro }\end{array}$ & $\begin{array}{c}\text { Taxa de Erro } \\
\text { da Classe } \\
\text { Majoritária }\end{array}$ & $\begin{array}{c}\text { CN2 } \\
\text { Taxa } \\
\text { de Erro }\end{array}$ & $\begin{array}{c}\text { C4.5-rules } \\
\text { Taxa de } \\
\text { Erro }\end{array}$ & $\begin{array}{c}\text { Taxa de Erro } \\
\text { da Classe } \\
\text { Majoritária }\end{array}$ \\
\hline \hline 1 & $42,1 \%$ & $28,6 \%$ & $36,5 \%$ & $38,3 \%$ & $39,8 \%$ & $64,4 \%$ \\
\hline 2 conjunto de teste A & $30,2 \%$ & $17,0 \%$ & $42,2 \%$ & $13,8 \%$ & $6,9 \%$ & $59,9 \%$ \\
\hline 2 conjunto de teste B & $5,4 \%$ & $7,8 \%$ & $42,2 \%$ & $3,9 \%$ & $3,1 \%$ & $59,9 \%$ \\
\hline 3 & $29,6 \%$ & $18,2 \%$ & $37,8 \%$ & $8,2 \%$ & $5,7 \%$ & $56,7 \%$ \\
\hline
\end{tabular}

Pode ser observado que, exceto para o cenário 1, a discretização híbrida melhora a precisão dos algoritmos de AM consideravelmente.

Usando o método híbrido, o algoritmo C4.5-rules induziu 10 regras de aprendizado para o conjunto de treinamento para o Cenário 2 (694 casos) que são mostradas no Apêndice C). As regras geradas classificaram erroneamente 99 casos (14,3\%), não cobrindo $2(0,2 \%)$ dos 694 casos. Das 10 regras geradas, o conjunto de teste (159 casos) só utilizou três delas, classificando erroneamente 11 casos (6,9\%) e não cobrindo $2(1,2 \%)$ dos 159 casos.

A seguir serão mostradas as três regras aplicadas no conjunto de teste que mostra a classe, o erro da classificação [AA\%] e os números de casos classificados correta e erroneamente [BB CC] no conjunto de treinamento, o erro da classificação [DD\%] e os números de casos classificados correta e erroneamente $[\mathrm{EE} \mathrm{FF}]$ no conjunto de teste:

Regra 20:

porosidade $>15.7$

-> classe $>1,75 \quad[11,1 \%]\left[\begin{array}{lll}1 & 12 & 14]\end{array}\right][14,3 \%][122]$

Regra 1:

porosidade $<=2.9$

$\rightarrow$ classe $<0,015 \quad[0,0 \%]\left[\begin{array}{lll}203 & 0] & {[1,6 \%}\end{array}\right]\left[\begin{array}{ll}60 & 1\end{array}\right]$

Regra 19:

porosidade $>3.9$

porosidade $<=15.7$

$\rightarrow$ classe $[0,015: 1,75] \quad[17,5 \%][18840] \quad[7,3 \%][766]$

Para o mesmo cenário e conjunto de treinamento (694 casos), CN2 gerou 120 regras que classificam erroneamente 18 casos (2.6\%). No entanto, mais de $50 \%$ dessas 120 regras estão especializadas para cobrir 1, 2 ou 3 exemplos.

\subsection{ANÁLISE DOS RESULTADOS}

O objetivo dos experimentos foi obter regras de previsão mais precisas, observando a influência da discretização, para determinar o comportamento da permeabilidade em um poço petroleiro observando profundidade, porosidade e permeabilidade dos poços vizinhos. Uma comparação 
empírica foi realizada entre, primeiramente, um método stand-alone, determinado pela distribuição estatística dos exemplos, um segundo método sugerido por um especialista de domínio e um terceiro método chamado "híbrido" que tentou, a partir dos valores de discretização obtidos através do especialista do domínio, melhorar a precisão dos algoritmos de AM variando os intervalos de discretização. Este "método híbrido" foi considerado como dentro da etapa de Data Mining por ser um processo iterativo constante com os algoritmos de AM.

Os resultados dos experimentos mostram que a escolha da discretização afeta diretamente a precisão dos algoritmos $\mathrm{CN} 2$ e C4.5-rules. Com uma discretização stand-alone, o algoritmo C4.5-rules apresenta melhor precisão que o algoritmo $\mathrm{CN} 2$ em $75 \%$ dos cenários e em $16,6 \%$ deles apresenta os mesmos resultados. $\mathrm{Na}$ discretização realizada com a ajuda de um especialista do domínio, o algoritmo C4.5-rules apresenta um resultado melhor em comparação ao algoritmo CN2 em 58,3\% dos cenários. Usando 3 discretizações e o método híbrido, o algoritmo C4.5rules apresenta melhor precisão que o algoritmo CN2 em $75 \%$ dos cenários.

Outro ponto importante na realização de uma discretização é que além de determinar a precisão de cada conjunto na matriz de confusão, deve-se considerar a distribuição dos elementos também. As matrizes de confusão apresentada no Apêndice B mostram que os algoritmos CN2 e C4.5-rules apresentam uma taxa de erro muito baixa para o Cenário 2 com o conjunto de teste $\mathrm{B}$ ( $3,9 \%$ e $3,1 \%$ respectivamente), utilizando os pontos de corte 0,015 e 1.75 , mas pode-se observar que existem só 3 casos formando parte de um intervalo e 78 casos formando parte do outro intervalo.

Este estudo de caso pode ser visto também como uma forma de transformar um problema de regressão em um problema de classificação, embora o objetivo tenha sido obter regras mais precisas através dos algoritmos CN2 e C4.5-rules, visando expressar, através do conhecimento simbólico, conceitos aprendidos pelo sistema de uma forma mais simples (em comparação, por exemplo, com as árvores de decisão). O poder de expressão das regras pode levar a melhores tomadas de decisão considerando só um número pequeno de regras e atributos, por exemplo.

Pode ser observado que, exceto para o Cenário 1, a discretização híbrida melhorou consideravelmente a precisão dos algoritmos de AM. Uma das alternativas propostas para tentar melhorar a precisão dos algoritmos é aplicar o método hibrido em forma local para esse cenário. O problema de discretizar cada cenário de uma forma local surge no momento de avaliar os três cenários entre si, devido ao fato de cada cenário apresentar intervalos diferentes. Também foi observado que os dados não se mostram apropriados para uma classificação, principalmente pela quantidade de valores não detectados (38,3\% do conjunto total), além disso, uma enorme falta de homogeneidade entre todos eles. Portanto, o problema deve ser tratado mais como um problema de regressão, usando Redes Neurais, do que como um problema de classificação.

Foi observado que, embora o método híbrido tenha sido consideravelmente melhor na obtenção de melhores precisões dos algoritmos de AM, o papel do especialista de domínio na definição da discretização é fundamental. Ao mesmo tempo, obtendo discretizações usando métodos standalone oferece uma importante ajuda ao especialista de domínio na determinação dos intervalos. Também cabe ressaltar que o número de intervalos influencia consideravelmente os resultados de precisão dos algoritmos de AM e que o método hibrido proposto aumenta de complexidade tendo mais intervalos. 
Finalmente, este estudo de caso é considerado como um problema de Aprendizado de Máquina (mas a mesma problemática ocorre também em problemas de Data Mining), devido ao fato de não se contou com a avaliação do conhecimento por parte do especialista do domínio, já que o especialista, neste caso geólogo, será aquele que conheça o terreno onde ficam os poços petroleiros. 


\section{Capítulo 6}

"Justamente quando consegui encontrar todas as respostas, mudaram todas as perguntas."

- Paulo Coelho em "Maktub"

\section{ESTUDO DE CASO 2 - BASE DE DADOS DO GADO NELORE}

\subsection{OBJETIVO}

Prever as características dos touros da raça Nelore a partir do acasalamento entre um reprodutor e uma matriz (vaca com finalidade de reprodução), usando o processo de Extração de Conhecimento de Bases de Dados.

\subsection{DEFINIÇÃO DO DOMÍNIO}

A originalidade dos seres vivos reside em sua capacidade de funcionar como um sistema termodinâmico aberto do qual se obtém energia do ambiente e a utiliza para manter uma série ordenada de características chamada "vida". A singularidade de uma espécie ou um indivíduo depende de sua capacidade para manter certos limites que o distinguem de todas as outras espécies ou animais. Assim, a evolução da vida, tanto nas plantas como nos animais requer a possibilidade de manter uma constância básica de organização e funcionamento das estruturas biológicas. A constância básica do meio interno é o fator que permitiu aos animais independerem, em alto grau, do meio externo [Reis 91].

A adaptação dos animais refere-se às mudanças genéticas e fisiológicas que ocorrem como resposta a estímulos internos e externos. A adaptação genética refere-se às características herdáveis que favorecem a sobrevivência de uma população em um determinado meio, enquanto a adaptação fisiológica compreende as mudanças que se produzem dentro do indivíduo (ou sistemas) em períodos mais curtos ou longos referindo-se, portanto, à capacidade e ao processo de ajuste de um animal a si mesmo, a outra matéria viva e a seu ambiente físico externo [Reis 83].

Dentre os animais existentes, se encontra o animal bovino que é considerado um sistema constituído de vários sub-sistemas perfeitamente integrados para responder tanto às alterações do meio externo quanto às do meio interno, mediante respostas rápidas (de conduta, cardiovasculares, respiratórias) e respostas lentas (endócrinas, enzimáticas, metabólicas). Essas respostas têm grande importância para a interação "genótipo-ambiente", pois a intensidade destas dependerá de como o animal responderá às alterações do meio, tanto interno como 
externo, como pode ser observado na Figura 6.1. Muitas vezes, porém, o sistema animal não tem patrimônio genético que garanta o perfeito restabelecimento do equilíbrio mostrando assim uma resposta característica.

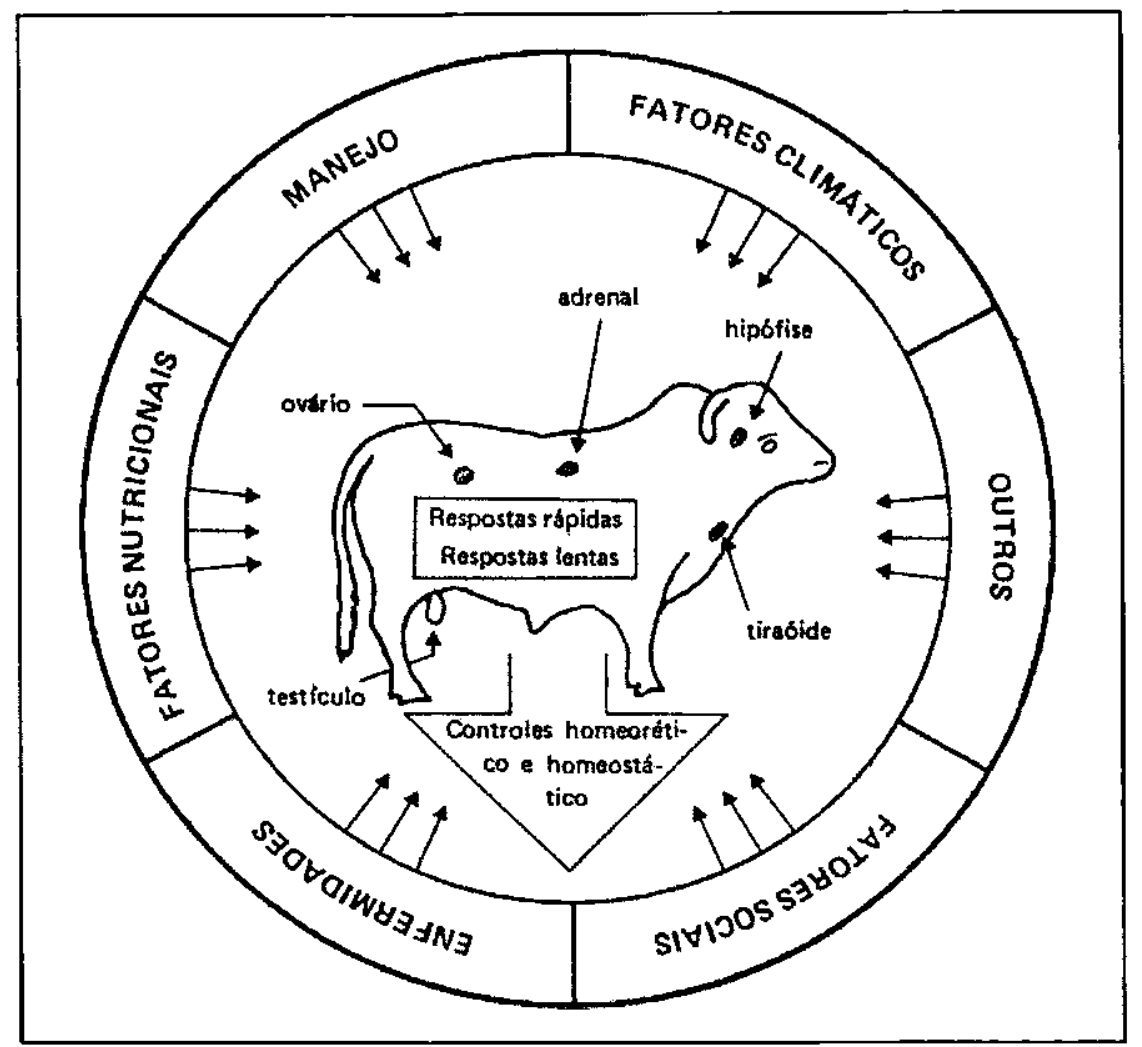

Figura 6.1: Diagrama das interrelaçōes entre o meio ambiente e o animal.

A criação de bovinos no Brasil coincide, praticamente, com a sua colonização. Nos primórdios da era colonial, o gado existente no país era todo de origem européia, proveniente da Península Ibérica, enquanto que os zebus foram introduzidos no início de século XIX [PROZEBU 84].

Os touros da raça Nelore foram trazidos da Índia e são bovinos de pelagem branca ou cinza com chifres curtos, de acordo com a classificação de Joshi e Philhips, citadas por Santiago [Santiago 87]. A população Nelore brasileira é oriunda das importações de 1930 e notadamente das de 1960 e 1962. Atualmente, o gado Nelore está tendendo a uma uniformização dentro do tipo Ongole indiano.

Apesar do Brasil ser um país de grande extensão territorial, e com uma população bovina estimada em 148,1 milhões de cabeças [ANUALPEC 95], ele possui um dos menores índices de produtividade do mundo no setor, considerando-se as baixas taxas de natalidade, altas taxas de mortalidade, longos intervalos de partos e idades elevadas para o abate e primeiro parto, resultando numa taxa de desfrute (expressa em toneladas produzidas sobre o total de toneladas do rebanho) igual a 23,2\% em 1994 [ANUALPEC 95].

As causas dessa baixa produtividade são inúmeras, e vão desde uma alta ignorância, até a falta de planejamento estratégico para o setor agropecuário. A pecuária de corte brasileira precisa utilizar, o mais rápido possível, novas tecnologias no sentido de produzir animais geneticamente superiores, que transmitam precocidade, maior eficiência reprodutiva e velocidade de ganho de 
peso, contribuindo ao aumento da taxa de desfrute do rebanho brasileiro e melhora da qualidade da carne, possibilitando, assim, a reversão deste quadro. Isto se torna ainda mais importante, principalmente, ao se aproximar o século XXI, quando as necessidades de proteínas de origem animal serão maiores, pois se espera para o ano 2020 a duplicação da população mundial que, atualmente, é da ordem de 4,85 bilhões de habitantes [Lobô 96]. A necessidade de contar com novas tecnologias para melhorar o rebanho brasileiro é de vital importância.

Ante este problema, em junho de 1988 teve início o Programa de Melhoramento Genético da Raça Nelore (PMGRN) a partir da parceria entre criadores e pesquisadores do Departamento de Genética da Faculdade de Medicina (DGFM), da Universidade de São Paulo (USP), campus de Ribeirão Preto, em busca de tecnologias modernas e de fácil aplicação na pecuária e definição de metas para viabilizar o aumento da produtividade do rebanho de corte nacional.

Este programa utiliza a metodologia do "Modelo Animal" para avaliação de touros, matrizes e animais jovens, que permite obter as Diferenças Esperadas nas Progênies (DEPs) tais como, peso e perímetro escrotal, padronizados para diferentes idades. $O$ modelo geral inclui os efeitos fixos de grupo contemporâneo e idade da vaca ao parto, e como efeitos aleatórios, os genéticos maternal e direto, e o do ambiente permanente. Os grupos contemporâneos foram definidos 'como animais do mesmo sexo, nascidos no mesmo rebanho, ano e trimestre e submetidos ao mesmo sistema de manejo e alimentação. A idade da vaca ao parto foi agrupada em 6 classes: menor que 36 meses, de 36 a 47, 48 a 59, 60 a 71, 72 a 119 e maior que 119 meses de idade. .Todos estas características, junto com o número de registro do animal, do pai e da mãe foram armazenadas em uma base de dados.

O PMGRN é formado por 60 rebanhos com criadores dos estados da Bahia, Goiás, Maranhão, Mato Grosso do Sul, Minas Gerais, São Paulo e Tocantins, totalizando cerca de 85.000 animais em controle [Lobô 97].

Os animais participantes do PMGRN são submetidos a um controle periódico criterioso de características produtivas e reprodutivas, e as informações colhidas pelos criadores são transmitidas ao Setor Administrativo do PMGRN por meio de disquetes com arquivos texto gerados em uma estrutura apropriada (dada pelo Programa) fornecida por softwares de gerenciamento de rebanhos, como o CENSUS - sistema desenvolvido pelo Setor de Desenvolvimento e Processamento de Dados do PMGRN.

A Diferença Esperada na Progênie (DEP) é usada, em todo o mundo, para comparar o mérito genético de animais para várias características e prever a habilidade de transmissão genética de um animal avaliado como progenitor com respeito a sua descendência. A DEP é calculada pelo peso dos animais aos $120,240,365$ e 550 dias e é expressa na unidade da característica, por exemplo, quilogramas para peso e centímetros para perímetro escrotal, com sinal positivo ou negativo.

As definições das DEPs, bem como das siglas usadas no decorrer deste estudo de caso são apresentadas a seguir:

- DMPP120: diferença esperada na progênie para efeito maternal no peso aos 120 dias de idade $\rightarrow$ prevê a diferença esperada em peso dos produtos das filhas do animal avaliado, devida às diferenças na habilidade maternal apresentadas por elas. 
- DDPP120 (240): diferença esperada na progênie para efeito direto no peso aos 120 (240) dias de idade - indica a diferença em quilogramas esperada, como média da progênie, com relação à base genética de referência, devido aos genes para crescimento passados pelos seus pais.

- DDPP365 (550): diferença esperada na progênie para efeito direto no peso aos 365 (550) dias de idade - prevê a habilidade de um animal em transmitir genes para crescimento pósdesmame; para estas características, o componente mais importante é o efeito genético direto.

- DDPE365 (550): diferença esperada na progênie para efeito direto no perímetro escrotal aos 365 (550) dias de idade - prevê a habilidade de um animal em transmitir genes para crescimento testicular à sua progênie; são características extremamente importantes na seleção de bovinos de corte, pela correlação favorável que apresentam com a fertilidade e a precocidade sexual.

- AC Acurácia: confiabilidade na previsão da DEP. Quanto maior for a mesma, menor será a mudança esperada no valor da DEP em uma futura avaliação, em decorrência do acréscimo de um maior número de informações sobre o animal. A acurácia pode variar de 0 a 1 , sendo assim, um indicador do risco que se corre ao tomar decisões de seleção baseadas nas DEPs.

Finalmente, cabe destacar que a DEP que expressa o valor genético dos animais, minimiza os possiveis erros que possam ser cometidos no processo de escolha dos reprodutores.

Para obter as previsões das DEPs, o software MTDFREML necessita que sejam fornecidos parâmetros genéticos com os componentes de co-variâncias apropriados, estimados em análises prévias sobre a base de dados disponível.

Estes componentes determinam as estimativas dos parâmetros genéticos das características analisadas, entre os quais hereditariedade e correlações genéticas são a base do melhoramento por meio da seleção.

O coeficiente de hereditariedade refere-se à proporção da variância fenotípica em uma população que é determinada pelos efeitos médios dos genes. Em termos práticos, expressa que parte do valor fenotípico (por exemplo, peso) observado nos pais é transmitida à sua progênie. Este coeficiente é um parâmetro fundamental para orientar o criador e o "melhorista" na escolha adequada do método de melhoramento genético.

\subsection{CONTEXTO DO PROBLEMA}

Em 1997, o DGFM em parceria como o Laboratório de Inteligência Computacional (LABIC) do Instituto de Ciências Matemáticas e de Computação (ICMC) da USP - São Carlos começaram a trabalhar em um projeto de pesquisa para fazer uma análise das informações do PMGRN usando a tecnologia de Extração de Conhecimento de Bases de Dados com a finalidade de encontrar situações interessantes.

Ante uma grande quantidade de situações analisadas, foi selecionado o problema da previsão das características dos touros da raça Nelore a partir da informação das DEPs de um reprodutor (pai) e uma matriz (mãe). Este problema é de suma importância para os criadores de gado, porque embora exista certo conhecimento ou suspeitas por parte dos pesquisadores do DGFM, ainda não é possivel afirmar com certeza, quais características genéticas são transmitidas diretamente ao 
touro pelo reprodutor e quais pela matriz. A solução para este problema visa prever a DEP de um touro a partir de suas outras DEPs e as de seus pais.

Segundo os pesquisadores do PMGRN (especialistas do domínio), a DDPE550 (Diferença esperada na progênie para efeito Direto no Perímetro Escrotal aos 550 dias) é a DEP a ser prevista, pelo fato que o perímetro escrotal representa um fator extremamente importante na seleção de reprodutores. Ter um bom reprodutor significa que sua progênie pode dar touros com um bom peso para o abatimento, touros com uma idade curta ao abatimento, touros reprodutores, vacas com boa prọução de leite, vacas com alta precocidade, etc.

\subsection{SELEÇÃO DOS DADOS}

Nesta seção é explicada a forma como o problema foi definido, após uma análise na base de dados do PMGRN, bem como as diversas etapas realizadas para selecionar o conjunto de dados.

\subsubsection{Descrição da Base de Dados}

A descrição geral da base de dados do PMGRN enviada pelos pesquisadores do DGFM, no formato Excel 97, é apresentada na Tabela 6.1.

Tabela 6.1: Descrição da base de dados do PMGRN.

\begin{tabular}{|c|c|c|c|c|c|c|c|c|c|c|}
\hline $\begin{array}{c}\text { Tamanbo } \\
\text { do Arquivo }\end{array}$ & Registros & $\begin{array}{c}\text { Total de } \\
\text { Atributos }\end{array}$ & $\begin{array}{c}\text { Atributos } \\
\text { Inteiros }\end{array}$ & $\begin{array}{c}\text { Atributos } \\
\text { Reais }\end{array}$ & $\begin{array}{c}\text { Atribatos } \\
\text { String }\end{array}$ & $\begin{array}{c}\text { Atribatos } \\
\text { Data }\end{array}$ & Machos & Fêmeas & $\begin{array}{c}\text { Rafa } \\
\text { Tipo 1 }\end{array}$ & $\begin{array}{c}\text { Raca } \\
\text { Tipo 5 }\end{array}$ \\
\hline $18280 \mathrm{~KB}$ & 65535 & 35 & 11 & 18 & 5 & 1 & 18406 & 47129 & 52377 & 13158 \\
\hline
\end{tabular}

A descrição de cada um dos atributos que compõe a base de dados é mostrada na Tabela 6.2.

\subsubsection{Criação da Base de Dados para Definir o Grupo Contemporâneo}

Depois de uma análise da descrição dos atributos da base de dados do PGMRN, foi sugerido ao especialista do domínio a criação de uma nova base de dados que adicionasse, além das características do animal, as características dos pais, para posteriormente selecionar, a partir dessa nova base de dados, um grupo contemporâneo de animais com as mesmas características (por exemplo, touros ou vacas).

Na Figura 6.2 é mostrada de uma forma geral a estratégia sugerida para poder anexar as características do pais do touro. A idéia básica era que a partir de um animal com uma $G \_A N I M$ $G G G G$, por exemplo, buscar na mesma base de dados, o pai $A A A A$ e a mãe $D D D D$ (passo la e 1b), para posteriormente criar uma base de dados com todos os dados do animal, do pai e da mãe (passos 2a, $2 b$ e $2 c$, respectivamente).

Para efetuar a construção desse novo conjunto de dados foi elaborado um programa em C++ Builder, cuja função é construir uma nova base de dados contendo em cada registro todos os novos atributos do animal (105 atributos). O programa tem como entrada um arquivo em formato ASCII que possui os atributos dos registros separados por vírgulas, gerado através do Excel 97, no formato .csv. Ao ser iniciado, o programa gera um índice com a identificação de cada animal e a sua posição no arquivo de dados, usado como chave para busca o atributo G_ANIM do 
registro. O programa cria um arquivo temporário que possui todos os registros do arquivo de entrada, mas com uma leitura que possibilita busca aleatória de cada registro no arquivo. Para cada registro desse arquivo, é realizada uma busca no vetor de índices para encontrar os registros do pai e da mãe (G_PAI e G_MAE, respectivamente). Com esses índices, os registros são lidos do arquivo temporário criado anteriormente. Caso o registro do pai ou da mãe não seja encontrado, ele fica em branco. Os registros do touro, do pai e da mãe são escritos no arquivo de saída como um único registro. O programa gera um arquivo de saída que possui o mesmo formato do arquivo de entrada. Uma descrição das informações dessa nova base pode ser observada na Tabela 6.3 .

Tabela 6.2: Descrição dos atributos da base de dados do PMGRN.

\begin{tabular}{|c|c|c|}
\hline Nome do Atributo & Descriçăo do Atributo & Atributo \\
\hline G ANIM & Registro Genealógico Definitivo do Animal & Inteiro \\
\hline G.PAI & Registro Genealógico Definitivo do Pai & Inteiro \\
\hline G MAE & Registro Genealógico Definitivo da Mãe & Inteiro \\
\hline CNI & Número de Controle Interno Exclusivo & Inteiro \\
\hline NFA & Número da Fazenda & Inteiro \\
\hline SERIE & Série fornecida pela $\mathrm{ABCZ}$, identificadora dos animais & Inteiro \\
\hline RGN & Registro Genealógico de Nascimento do Animal & String \\
\hline RGD & Registro Genealógico Definitivo do Animal & String \\
\hline RC & Raça & Inteiro \\
\hline $\mathbf{S X}$ & Sexo do Animal & Inteiro \\
\hline DT_NASC & Data de Nascimento do Animal & Data \\
\hline PAI_SER & Série fornecida pela $A B C Z$, relativa ao pai & Inteiro \\
\hline PAIRG & Registro Genealógico Definitivo do Pai fomecido pela $\mathrm{ABCZ}$ & String \\
\hline MAE_SER & Série fornecida pela $\mathrm{ABCZ}$, relativa a Mãe & Inteiro \\
\hline MAE_RG & Registro Genealógico Definitivo da Mãe fomecido pela $\mathrm{ABCZ}$ & String \\
\hline NOME & Nome do Animal & String \\
\hline ANIMAL & Código intemo para identificar o animal & Inteiro \\
\hline $\mathbf{F}$ & Coeficiente de consangüinidade do animal & Real \\
\hline DDPP120 & Valor da DEP direta para peso aos 120 dias & Real \\
\hline ADPP120 & Acurácia da DEP direta para peso aos 120 dias & Real \\
\hline DMPP120 & Valor da DEP materna para peso aos 120 dias & Real \\
\hline AMPP120 & Acurácia da DEP materna para peso aos 120 dias & Real \\
\hline DDPP240 & Valor da DEP direta para peso aos 240 dias & Real \\
\hline ADPP240 & Acurácia da DEP direta para peso aos 240 dias & Real \\
\hline DMPP240 & Valor da DEP matema para peso aos 240 dias & Real \\
\hline AMPP240 & Acurácia da DEP matema para peso aos 240 dias & Real \\
\hline DDPP365 & Valor da DEP direta para peso aos 365 dias & Real \\
\hline ADPP365 & Acurácia da DEP direta para peso aos 365 dias & Real \\
\hline DDPP550 & Valor da DEP direta para peso aos 550 dias & Real \\
\hline ADPP550 & Acurácia da DEP direta para peso aos 550 dias & Real \\
\hline DDPE365 & Valor da DEP direta para perímetro escrotal aos 365 dias & Real \\
\hline ADPE365 & Acurácia da DEP direta para perímetro escrotal aos 365 dias & Real \\
\hline DDPE550 & Valor da DEP direta para perímetro escrotal aos 550 dias & Real \\
\hline ADPE550 & Acurácia da DEP direta para perímetro escrotal aos 550 dias & Real \\
\hline MGT & Mérito Genético Total & Real \\
\hline
\end{tabular}




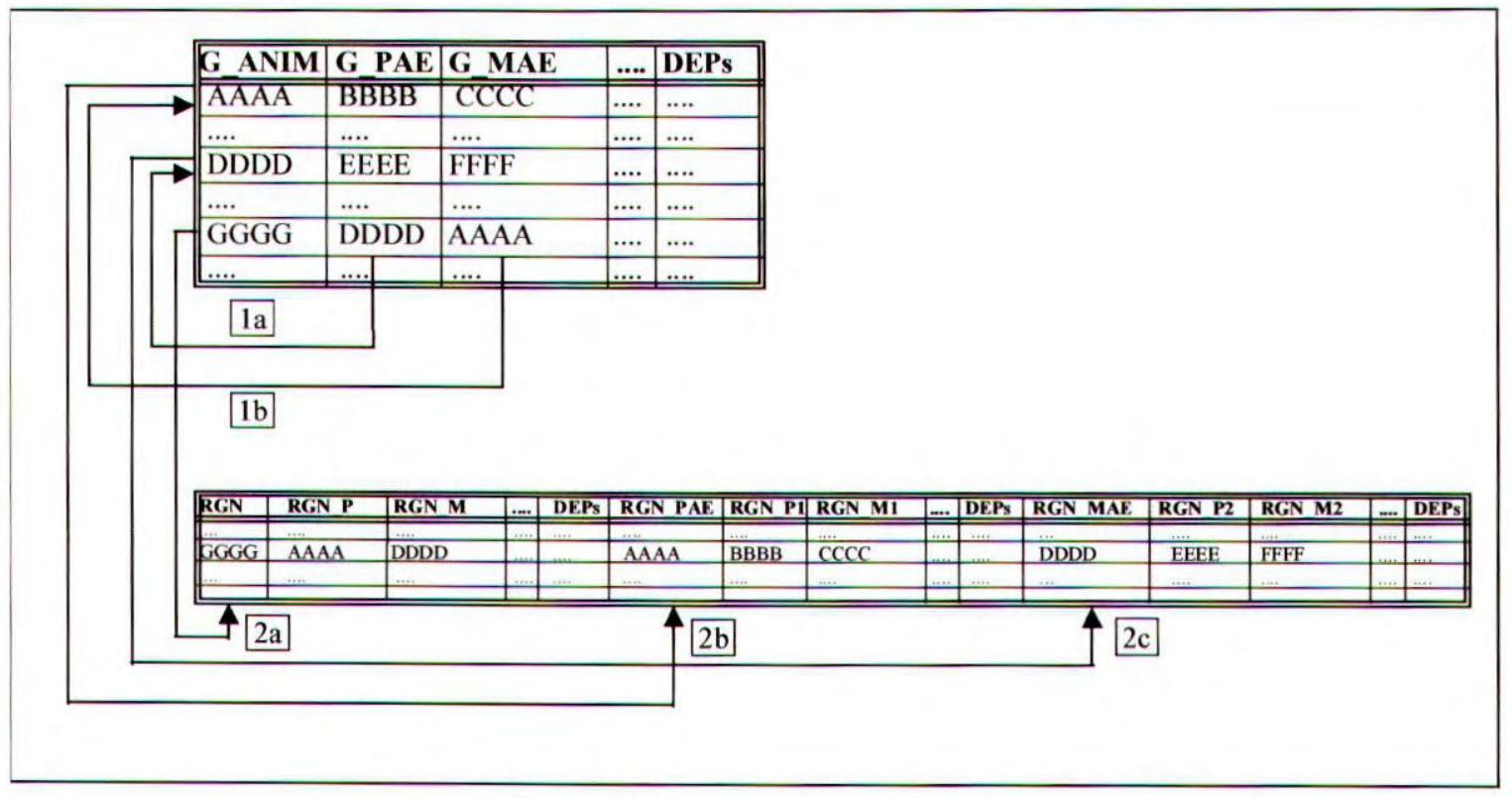

Figura 6.2: Estratégia para criar uma nova base de dados.

Tabela 6.3: Descrição das informações da nova base de dados.

\begin{tabular}{|l|r|}
\hline Descrição & Número de Registros \\
\hline \hline Animal com pai e mãe & 49444 \\
\hline Animal só com pai cadastrado & 329 \\
\hline Animal só com mãe cadastrada & 1948 \\
\hline Animal sem pai e mãe cadastrado & 13814 \\
\hline
\end{tabular}

Para efeito do estudo de caso foi considerado o grupo contemporâneo de machos nascidos no ano de 1994. As características do conjunto de dados gerado após a filtragem, usando o Excel 97, considerando apenas os 49444 animais com pai e mãe, é apresentada na Tabela 6.4.

Tabela 6.4: Descrição do arquivo gerado considerando o grupo contemporâneo nascidos em 1994.

\begin{tabular}{|c|c|c|c|c|}
\hline $\begin{array}{c}\text { Tamanho do arquivo } \\
\text { KB }\end{array}$ & Sexo & $\begin{array}{c}\text { Ano de } \\
\text { Nascimento }\end{array}$ & Registros & Total de Atributos \\
\hline 376 & 1 (Touro) & 1994 & 4078 & 105 \\
\hline
\end{tabular}

Cabe ressaltar que o atributo-classe DDPE550 foi colocado no final de todos os atributos, na etapa de preparação dos dados, já que os algoritmos de Aprendizado de Máquina precisam que o atributo-classe fique sempre na final de todos os atributos. O conjunto de dados selecionado foi exportado, usando Excel 97, para um formato ASCII separado por espaços, para poder ser utilizado pelo Mineset ${ }^{\mathrm{TM}}$.

\subsubsection{Seleção dos Atributos}

Em seguida, o conjunto de dados obtido foi submetido a uma seleção de atributos, utilizando a opção Remove Column do MineSet ${ }^{\mathrm{TM}}$, para considerar somente os atributos relativos às DEPs, 
baseados nas considerações do especialista do domínio. Dessa forma, foram considerados os seguintes 22 atributos: DDPP120, DMPP120, DDPP240, DMPP240, DDPP365, DDPP550, DDPE365, DDPP120_P, DMPP120_P, DDPP240_P, DMPP240_P, DDPP365_P, DDPP550_P, DDPE365_P, DDPE550_P, DDPP120_M, DMPP120_M, DDPP240_M, DMPP240_M, DDPP365_M, DDPP550_M e o atributo-classe DDPE550. Os atributos que terminam com _P e _ M fazem referência aos atributos do pai e da mãe, respectivamente. Na Tabela 6.5 é mostrada detalhes desse conjunto de dados.

Tabela 6.5: Descrição do conjunto de dados utilizados no MineSet ${ }^{\mathrm{TM}}$.

\begin{tabular}{|c|c|c|c|}
\hline Casos & $\begin{array}{c}\text { Total de } \\
\text { Atributos }\end{array}$ & $\begin{array}{c}\text { Atributos } \\
\text { Contínuos }\end{array}$ & $\begin{array}{c}\text { Atributos } \\
\text { Discretos }\end{array}$ \\
\hline 4078 & 22 & 22 & 0 \\
\hline
\end{tabular}

Os atributos DDPE365_M e DDPE550_M não foram considerados, pois as matrizes não possuem perímetro escrotal.

Usando a ferramenta Statistic Visualizer do MineSet $^{\mathrm{TM}}$ foram realizados alguns cálculos estatísticos, apresentados na Tabela 6.6, a fim de se obter uma melhor idéia do domínio, a partir dos 22 atributos e 4078 registros selecionados.

\subsection{DATA MINING}

Nesta etapa, inicialmente são explicadas as três discretizações realizadas no atributo-classe DDPE550, tentando melhorar a precisão dos algoritmos de Aprendizado de Máquina CN2 e C4.5-rules. Posteriormente serão mostrados os resultados obtidos, usando essas três discretizações, através do utilitário Column Importance do MineSet ${ }^{\mathrm{TM}}$, para determinar os atributos mais relevantes para o atributo-classe. Da mesma forma, foi utilizado a ferramenta Tree Visualizer do MineSet ${ }^{\mathrm{TM}}$ para gerar árvores de decisão e identificar alguns nós importantes da árvore. Finalmente, são apresentados os resultados das regras geradas pelos algoritmos.

Cabe ressaltar que todos os resultados obtidos foram comparados com os resultados obtidos usando redes bayesianas, que formam parte de outro trabalho de mestrado. Essas comparações foram realizadas visando ter uma melhor confiança no conhecimento obtido. Porém essas comparações não serão aqui apresentadas, por não serem objetos de estudo deste trabalho.

\subsubsection{Discretizações no Atributo-Classe}

O atributo-classe DDPE550, inicialmente contínuo, foi discretizado para atender aos padrões dos algoritmos simbólicos de Aprendizado de Máquina utilizados na etapa de Data Mining. Foram consideradas três discretizações para esse atributo, cujos valores e a forma como foram realizadas podem ser vistos na Tabela 6.7. 
Tabela 6.6: Resumo dos cálculos estatísticos do conjunto de dados selecionado.

\begin{tabular}{|l|c|l|l|r|}
\hline & $\begin{array}{c}\text { Valores } \\
\text { Distintos }\end{array}$ & $\begin{array}{c}\text { Valores } \\
\text { [Max:Min] }\end{array}$ & $\begin{array}{c}\text { Média } \pm \\
\text { Variância }\end{array}$ & Mediana \\
\hline DDPP120 & 132 & {$[8,9:-6,3]$} & $1,1 \pm 2,0$ & 1,2 \\
\hline DMPP120 & 70 & {$[4,3:-3]$} & $0,1 \pm 1,0$ & 0,1 \\
\hline DDPP240 & 206 & {$[15,1:-10,2]$} & $2,2 \pm 3,3$ & 2,3 \\
\hline DMPP240 & 100 & {$[6,2:-4,4]$} & $0,2 \pm 1,5$ & 0,2 \\
\hline DDPP365 & 297 & {$[27,3:-14,4]$} & $3,4 \pm 5,1$ & 3,4 \\
\hline DDPP550 & 368 & {$[32,4:-18,2]$} & $3,9 \pm 6,5$ & 3,7 \\
\hline DDPE365 & 22 & {$[1,4:-0,8]$} & $0,0 \pm 0,2$ & 0 \\
\hline DDPP120_P & 114 & {$[9,1:-9,1]$} & $2,1 \pm 2,9$ & 2 \\
\hline DMPP120_P & 66 & {$[4,8:-4,6]$} & $0,1 \pm 1,7$ & 0,1 \\
\hline DDPP240_P & 158 & {$[15,8:-14]$} & $3,9 \pm 4,9$ & 3,7 \\
\hline DMPP240_P & 88 & {$[7,0:-6,8]$} & $0,1 \pm 2,5$ & 0,1 \\
\hline DDPP365_P & 196 & {$[23,5:-14,8]$} & $5,6 \pm 6,6$ & 5,4 \\
\hline DDPP550_P & 217 & {$[29,4:-17,4]$} & $6,6 \pm 8,4$ & 6 \\
\hline DDPE365_P & 22 & {$[1,4:-0,9]$} & $0,1 \pm 0,4$ & 0,1 \\
\hline DDPE550_P & 31 & {$[1,6:-1,6]$} & $0,0 \pm 0,6$ & 0 \\
\hline DDPP120_M & 108 & {$[6,5:-5,5]$} & $0,2 \pm 1,5$ & 0,1 \\
\hline DMPP120_M & 74 & {$[4,0:-4,1]$} & $0,1 \pm 1,0$ & 0,1 \\
\hline DDPP240_M & 165 & {$[10,5:-9,3]$} & $0,5 \pm 2,6$ & 0,5 \\
\hline DMPP240_M & 105 & {$[5,8:-5,9]$} & $0,2 \pm 1,5$ & 0,2 \\
\hline DDPP365_M & 244 & {$[17,7:-12,5]$} & $1,1 \pm 4,0$ & 1 \\
\hline DDPP550_M & 306 & {$[21,3:-17,3]$} & $1,2 \pm 5,2$ & 0,9 \\
\hline DDPE550 & 34 & {$[2,2:-1,6]$} & $-0,0 \pm 0,4$ & 0 \\
\hline
\end{tabular}

Tabela 6.7: Descrição das Discretizações do atributo-classe DDPE550.

\begin{tabular}{|c|c|c|c|}
\hline $\begin{array}{c}\text { Forma de } \\
\text { discretização }\end{array}$ & $\begin{array}{c}\text { Intervalo de } \\
\text { Valores }\end{array}$ & $\begin{array}{l}\text { Número } \\
\text { de Casos }\end{array}$ & Metodologia \\
\hline 1 & $\begin{array}{c}<-0,15 \\
{[-0,15: 0,001[} \\
{[0,001: 0,25[} \\
{[0,25: 0,45]} \\
>0,45\end{array}$ & $\begin{array}{r}1296 \\
1331 \\
552 \\
404 \\
495\end{array}$ & $\begin{array}{l}\text { Os valores do atributo-classe DDPE550 foram } \\
\text { divididos em casos negativos e positivos, baseados em } \\
\text { considerações do especialista do domínio. Em seguida } \\
\text { foram efetuadas } 3 \text { discretizações, no conjunto de dados } \\
\text { positivos e } 2 \text { discretizações no conjunto de dados } \\
\text { negativos usando, em ambos casos, discretização por } \\
\text { freqüência. }\end{array}$ \\
\hline 2 & $\begin{array}{c}<-0,45 \\
{[-0,45: 0,001[} \\
{[0,001: 0,15[} \\
{[0,15: 0,35]} \\
>0,35\end{array}$ & $\begin{array}{r}603 \\
2024 \\
290 \\
482 \\
679\end{array}$ & $\begin{array}{l}\text { A partir das discretizações realizadas anteriormente } \\
\text { tentou-se melhorar a discretização com base na } \\
\text { precisão do algoritmo C4.5-rules, baseado na } \\
\text { experiência do Estudo de Caso } 1 \text {. }\end{array}$ \\
\hline 3 & $\begin{array}{c}<-0,35 \\
{[-0,35:-0,05[} \\
{[-0,05: 0,05[} \\
{[0,05: 0,35]} \\
>0,35\end{array}$ & $\begin{array}{r}831 \\
755 \\
1041 \\
772 \\
679\end{array}$ & $\begin{array}{l}\text { Os valores do atributo-classe DDPE550 foram } \\
\text { discretizados por freqüência sem distinguir casos } \\
\text { positivos e negativos. }\end{array}$ \\
\hline
\end{tabular}


Na Figura 6.3 são mostradas as distribuições de valores para cada intervalo em cada discretização realizada. Estes gráficos foram gerados usando o Statistic Visualizer do MineSet ${ }^{\mathrm{TM}}$.

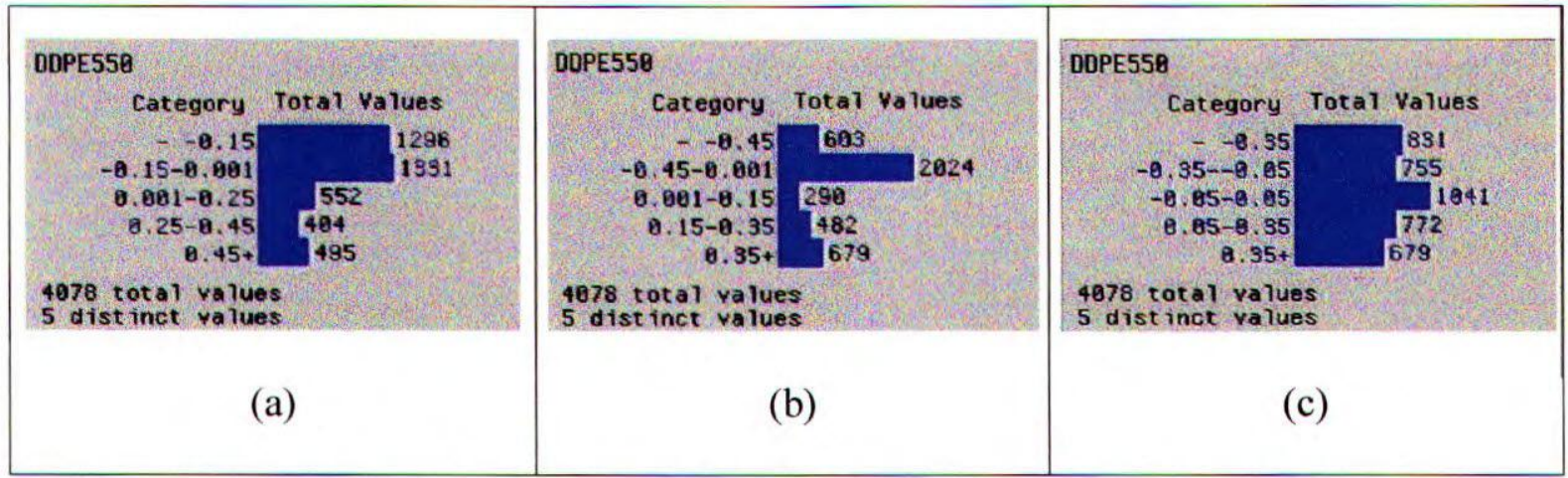

Figura 6.3: Distribuição dos valores da DDPE550 na (a) discretização 1; (b) discretização 2; (c) discretização 3.

Uma vez determinadas as três formas de discretização, foi usado o método 10-fold crossvalidation no conjunto de dados, para determinar a precisão dos algoritmos usados. Na Tabela 6.8 são mostrados os resultados obtidos.

Tabela 6.8: Precisão dos algoritmos nas três formas de discretização usando 10-fold crossvalidation.

\begin{tabular}{|c|c|c|}
\hline $\begin{array}{c}\text { Forma de } \\
\text { Discretização }\end{array}$ & Precisão do Algoritmo CN2 & Precisão do Algoritmo C4.5-rules \\
\hline 1 & $54,1 \% \pm 0,7 \%(51,0 \%-59,1 \%)$ & $60,5 \% \pm 0,6 \%(57,8 \%-63,9 \%)$ \\
\hline 2 & $57,3 \% \pm 0,7 \%(52,2 \%-59,8 \%)$ & $64,1 \% \pm 1,1 \%(59,9 \%-70,3 \%)$ \\
\hline 3 & $49,2 \% \pm 0,7 \%(45,9 \%-52,1 \%)$ & $57,4 \% \pm 1,1 \%(52,7 \%-63,7 \%)$ \\
\hline
\end{tabular}

\subsubsection{Resultados da Seleção de Atributos Relevantes}

A seleção dos atributos relevantes para o atributo-classe DDPE550 foi obtida usando a opção Column Importance do MineSet ${ }^{\mathrm{TM}}$, que determina os atributos mais importantes para o atributoclasse, baseados nas correlações com ele. Um medida chamada "pureza" (número incremental de 0 a 100) informa quão bem os atributos separam as diferentes classes. Adicionando mais atributos (valor default=3) é possível incrementar a pureza. Em todos os testes, o valor declarado para determinar os atributos que tinham que ser levados em conta foi 12 , por motivos de desempenho do servidor, já que para determinar o atributo 13 o cálculo demorava mais que 10 horas.

A seguir, na Tabela 6.9 serão mostrados os resultados obtidos na seleção dos atributos relevantes observados a partir do conjunto de dados, usando as três formas de discretização mostradas na Tabela 6.7 .

Os resultados obtidos na Tabela 6.9 foram divididos em três grupos a partir da sua pureza: um grupo com os dois primeiros atributos altamente relevantes (DDPE365, DDPE550_P), um 
segundo grupo com os 4 atributos posteriores medianamente relevantes (DMPP120_P, DDPP240_P, DDPP365_P, DDPP550, DDPP365, DMPP240_P e DDPP365) ${ }^{6}$ e um terceiro grupo com o restante dos atributos, considerados não tão relevantes.

Cada discretização apresentou uma seleção de atributos relevantes diferente. Isto é devido ao fato que a pureza é definida pelo quão bem os atributos separam as diferentes classes, porém se as classes são diferentes, a seleção de atributos também será. Por exemplo, na discretização 2 , considerando os pontos de corte $[-0,45 ; 0,001 ; 0,15 ; 0,35]$, a seleção dos atributos relevantes é exclusiva para aqueles pontos de corte. Nesse caso, o valor 0,35 representa os touros que tem 0,35 centímetros a mais de perímetro escrotal em relação ao pai.

Por apresentar melhores resultados na precisão dos algoritmos CN2 e C4.5-rules, como é observado na Tabela 6.8 , os próximos experimentos foram realizados considerando apenas a discretização 2 .

Tabela 6.9: Resultados obtidos da seleção dos atributos relevantes usando as três formas de discretização.

\begin{tabular}{|c|c|c|c|}
\hline Vivel & Discretização 1 & Discretização 2 & Discretização 3 \\
\hline 1 & $\begin{array}{l}\text { DDPE365: } \\
\text { pureza }=31,0\end{array}$ & $\begin{array}{l}\text { DDPE365: } \\
\text { pureza }=35,4\end{array}$ & $\begin{array}{l}\text { DDPE365: } \\
\text { Pureza }=26,1\end{array}$ \\
\hline 2 & $\begin{array}{l}\text { DDPE550_P: } \\
\text { pureza }=40,3\end{array}$ & $\begin{array}{l}\text { DDPE550_P: } \\
\text { pureza }=44,3\end{array}$ & $\begin{array}{l}\text { DDPE550_P: } \\
\text { pureza }=37,6\end{array}$ \\
\hline 3 & $\begin{array}{l}\text { DMPP120_P : } \\
\text { pureza }=4 \overline{7}, 0\end{array}$ & $\begin{array}{l}\text { DDPP240_P : } \\
\text { pureza }=50,6\end{array}$ & $\begin{array}{l}\text { DDPP365_P : } \\
\text { Pureza }=49,8\end{array}$ \\
\hline 4 & $\begin{array}{l}\text { DDPP550: } \\
\text { pureza }=56,4\end{array}$ & $\begin{array}{l}\text { DDPP550: } \\
\text { pureza }=57,8\end{array}$ & $\begin{array}{l}\text { DDPP550: } \\
\text { pureza }=59,6\end{array}$ \\
\hline 5 & $\begin{array}{l}\text { DDPP365: } \\
\text { pureza }=64,9\end{array}$ & $\begin{array}{l}\text { DMPP240_P : } \\
\text { pureza }=6 \overline{5}, 8\end{array}$ & $\begin{array}{l}\text { DDPP365 : } \\
\text { pureza }=67,8\end{array}$ \\
\hline 6 & $\begin{array}{l}\text { DDPP365_P : } \\
\text { pureza }=72,1\end{array}$ & $\begin{array}{l}\text { DDPP365: } \\
\text { pureza }=73,5\end{array}$ & $\begin{array}{l}\text { DMPP240_P : } \\
\text { pureza }=74,8\end{array}$ \\
\hline 7 & $\begin{array}{l}\text { DDPP120: } \\
\text { pureza }=78,1\end{array}$ & $\begin{array}{l}\text { DDPP550_M: } \\
\text { pureza }=79,4\end{array}$ & $\begin{array}{l}\text { DMPP120_M : } \\
\text { pureza }=80,6\end{array}$ \\
\hline 8 & $\begin{array}{l}\text { DMPP240_M : } \\
\text { pureza }=83,2\end{array}$ & $\begin{array}{l}\text { DDPP120: } \\
\text { pureza }=84,2\end{array}$ & $\begin{array}{l}\text { DDPP120: } \\
\text { pureza }=84,9\end{array}$ \\
\hline 9 & $\begin{array}{l}\text { DDPP240_M: } \\
\text { pureza }=86,8\end{array}$ & $\begin{array}{l}\text { DMPP240_M: } \\
\text { pureza }=8 \overline{7}, 9\end{array}$ & $\begin{array}{l}\text { DDPP240_M: } \\
\text { pureza = } 88,3\end{array}$ \\
\hline 10 & $\begin{array}{l}\text { DDPP240: } \\
\text { Pureza }=89,0\end{array}$ & $\begin{array}{l}\text { DDPP240: } \\
\text { pureza }=90,6\end{array}$ & $\begin{array}{l}\text { DDPP240: } \\
\text { pureza }=90,4\end{array}$ \\
\hline 11 & $\begin{array}{l}\text { DDPP365_M: } \\
\text { pureza =90,6 }\end{array}$ & $\begin{array}{l}\text { DDPP240_M: } \\
\text { pureza }=92,3\end{array}$ & $\begin{array}{l}\text { DMPP240: } \\
\text { pureza }=92,0\end{array}$ \\
\hline 12 & $\begin{array}{l}\text { DDPE365_P : } \\
\text { pureza }=92,3\end{array}$ & $\begin{array}{l}\text { DMPP240: } \\
\text { pureza }=93,6\end{array}$ & $\begin{array}{l}\text { DDPP365_M: } \\
\text { pureza }=93,2\end{array}$ \\
\hline
\end{tabular}

\footnotetext{
${ }^{6}$ Atributos considerados nas três discretizações.
} 


\subsubsection{Uso da Ferramenta Tree Visualizer}

Com o uso da ferramenta Tree Visualizer do MineSet ${ }^{\mathrm{TM}}$ foi possível determinar alguns casos interessantes baseados na precisão dos nós gerados na árvore de decisão mostrada na Figura 6.4. Alguns desses resultados obtidos foram:

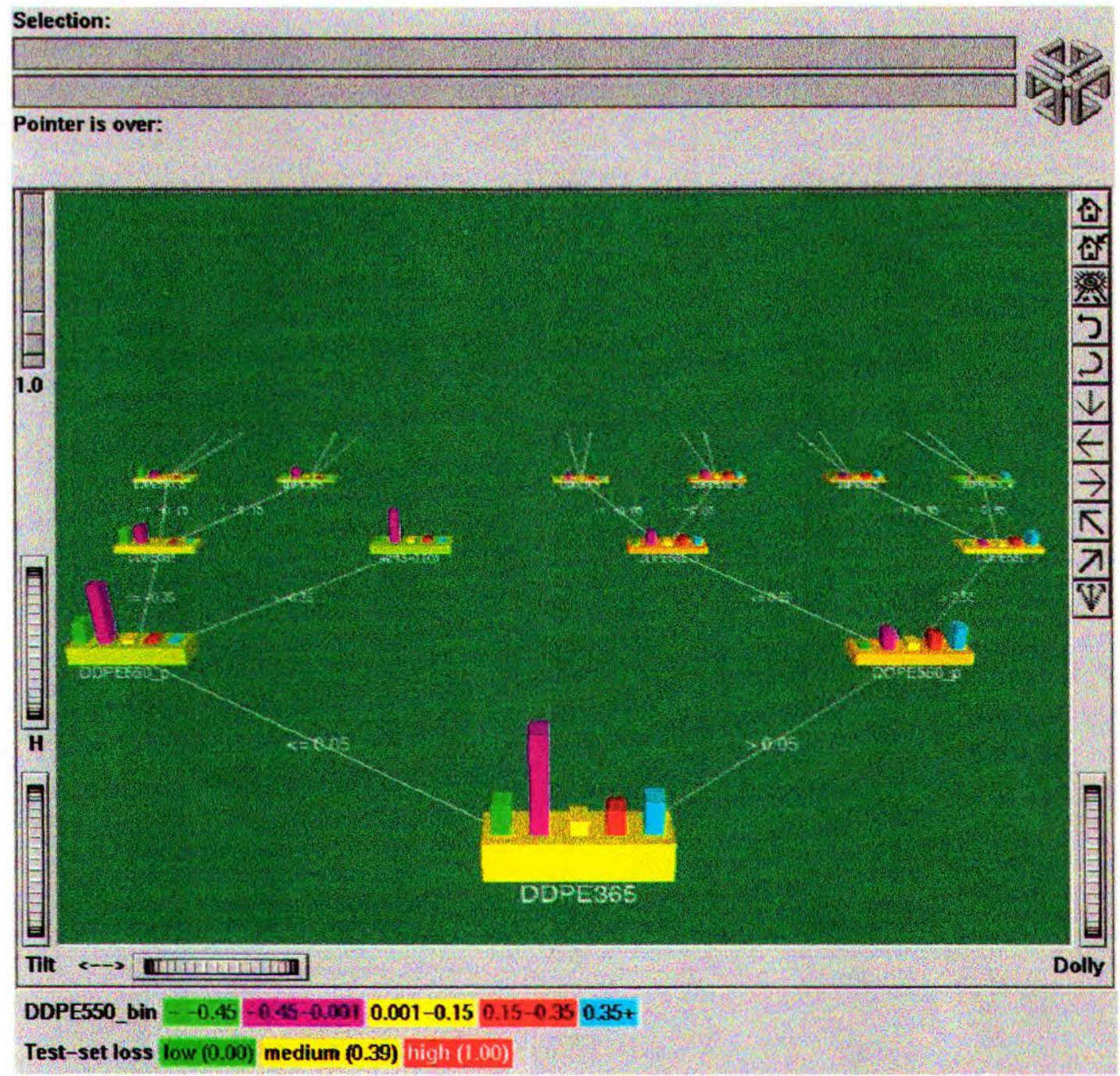

Figura 6.4: Árvore de decisão gerada através de Tree Visualizer.

- Dos 603 casos (14,7\% do total do conjunto de dados) com uma DDPE550 menor que -0,45, 147 casos (24,3\% pertencentes a essa classe) tinham as seguintes condições na árvore:

IF DDPE365 $<=0,05$

AND DDPE550_P $<=-0,35$

AND DDPE365 $<=-0,15$

AND DDPE550_P $<=-0,95$

$->-0,45$ (Taxa de erro: $27 \% \pm 6 \%$ )

- Dos 679 casos (16,6\% do total do conjunto de dados) com uma DDPE550 maior que 0,35, 168 casos $(24,7 \%$ dessa classe $)$ tinham as seguintes condições na árvore: 
IF DDPE365>0,05

AND DDPE550_p $>0,55$

AND DDPE550_p $>0,95$

AND DDPP365 $\mathrm{m}>-1,6$

$->0,35+$ (Taxa de erro: $9 \% \pm 4 \%$ )

- Dos 2024 casos (49,6\% do total do conjunto de dados) com uma DDPE550 entre -0.45 e $0.001,1052$ casos ( $51,9 \%$ dessa classe) tinham as seguintes condições na árvore:

IF DDPE365< $<=0,05$

AND DDPE550_p $>-0,35$

$\rightarrow[-0,45: 0,001[+($ Taxa de erro: $21 \% \pm 2 \%)$

\subsubsection{Resultados Usando os Algoritmos Simbólicos de Aprendizado de Máquina}

Mediante o uso de algoritmos simbólicos de Aprendizado de Máquina é possível obter uma classificação do conjunto de dados. Futuros casos podem ser previstos uma vez que foi realizada essa classificação, partindo das condições das regras geradas pelos algoritmos. A seguir serão apresentadas as regras obtidas utilizando os algoritmos $\mathrm{CN} 2$ e C4.5-rules.

$\mathbf{C N 2}^{7}$ : Algumas das principais regras geradas no conjunto de dados usando a discretização 2, para DDPE550 > 0,35, com 679 casos, mostrando a precisão da regra [AA\%] e os casos classificados correta e erroneamente [BB CC] são:

IF DDPP365 $>3.00$

AND DDPE365 $>0.05$

AND DDPE550_P $>1.50$

THEN class $=0 . \overline{35}+[100 \%]\left[\begin{array}{ll}60 & 0\end{array}\right]$

IF DDPE365 $>0.55$

AND DDPE550_P $>0.65$

AND DDPP550 $\mathrm{M}>-5.00$

THEN class $=0 . \overline{3} 5+[98,3 \%]\left[\begin{array}{ll}60 & 1\end{array}\right]$

IF DDPP365 $>2.60$

AND DDPE365_P $<0.75$

AND DDPE550_P $>0.95$

AND DDPP 120_M $<1.70$

AND DDPP365_M $>-1.35$

THEN class $=0 . \overline{3} 5+[100 \%][500]$

IF $\quad 0.35<$ DDPE $365<0.65$

AND DDPE550_P $>1.05$

AND DDPP550_M $>0.25$

THEN class $=0 . \overline{35}+[100 \%][600]$

${ }^{7}$ É importante ressaltar que várias regras geradas pelo algoritmo $\mathrm{CN} 2$ podem cobrir o mesmo caso. 
IF DDPP365 $<11.20$

AND DDPE $365>0.35$

AND DDPE365_P $<0.85$

AND DDPE550 $\mathrm{P}>0.65$

AND DMPP120_M $>-0.05$

AND DDPP240_M $>1.25$

THEN class $=0 . \overline{3} 5+[100 \%]\left[\begin{array}{ll}53 & 0\end{array}\right]$

IF DDPP240 $>4.00$

AND DDPE3 $65>0.55$

AND DMPP $1202<15.05$

THEN class $=0.35+[100 \%]\left[\begin{array}{ll}43 & 0\end{array}\right]$

IF DDPE365 $>0.25$

AND DDPP240 P $<8.75$

AND DMPP1201 $>4.80$

AND DDPE550_P $>0.65$

AND DDPP365_M $>4.95$

THEN class $=0 . \overline{3} 5+[100 \%]\left[\begin{array}{ll}40 & 0\end{array}\right]$

C4.5-rules: Algumas das principais regras geradas no conjunto de dados usando a discretização 2 para DDPE550 > 0,35, com 679 casos, mostrando a precisão da regra [AA\%] e os casos classificados correta e erroneamente. [BB CC] são:

Rule 298:

$$
\begin{aligned}
& \text { DDPE550_P }>1.4 \\
& \text { DDPP365_M }>0.6 \\
& \rightarrow \text { class } 0.35+[97.3 \%]\left[\begin{array}{ll}
50 & 0
\end{array}\right]
\end{aligned}
$$

Rule 486:

$$
\begin{aligned}
& \text { DDPP550 }>11.8 \\
& \text { DDPE365 }>0.2 \\
& \text { DDPP120_P }<=3.5 \\
& \text { DDPE550_P }>-0.1 \\
& \text { DMPP120_M }>-0.2 \\
& \rightarrow \text { class } 0.35+[92.7 \%]\left[\begin{array}{ll}
25 & 1
\end{array}\right]
\end{aligned}
$$

Rule 594:

$$
\begin{aligned}
& \text { DDPE365 }>0.4 \\
& \text { DDPE550_P }>0.7 \\
& \rightarrow \text { class } 0.35+[91.4 \%]\left[\begin{array}{ll}
77 & 6
\end{array}\right]
\end{aligned}
$$

Rule 652:

$$
\begin{aligned}
& \text { DDPP550 }>-0.6 \\
& \text { DDPE365 }>0 \\
& \text { DDPE550_P }>0.9 \\
& \rightarrow \text { class } 0.35+[89.6 \%]\left[\begin{array}{ll}
90 & 15
\end{array}\right]
\end{aligned}
$$

Rule 605:

$$
\begin{aligned}
& \text { DDPP240 }<=4.2 \\
& \text { DDPE365 }>0.1 \\
& \text { DDPP365 }>5.2 \\
& \text { DDPE365_P }<=0.5 \\
& \text { DDPE550-P }>0.5 \\
& \text { DDPP120_M }<=1.6 \\
& \text { DMPP120 M }>-0.2 \\
& \rightarrow \text { class } 0.35+[85.6 \%]\left[\begin{array}{ll}
18 & 2
\end{array}\right]
\end{aligned}
$$




\subsection{ANÁLISE DOS RESULTADOS}

Alguns dos resultados obtidos na etapa de Data Mining são apresentados a seguir:

- Existe uma alta dependência da DDPE365 do touro e da DDPE550_P, para a obtenção de melhores DDPE550.

- É importante ter um pai reprodutor com altas DEPs, mas não necessariamente mães com DEPs elevadas, como foi visto nas regras geradas pelos algoritmos, que consideram que as DEPs da mãe, na maioria das regras, são dadas a partir de valores negativos para uma DDPE550 maior que 0,35 .

- A existência de relevantes DEPs para um melhor desenvolvimento do perímetro escrotal, tais como: DMPP120_P, DDPP240_P, DDPP365_P, DDPP365_M, DDPP550, DDPP365, DMPP240_P e DDPP365.

Vale ressaltar que todos esses resultados já foram dados ao especialista do domínio, e encontram-se em fase de avaliação. 
Capítulo 7

"Na teoria, não existe diferença entre teoria e prática; na prática, existe."

- Chuck Reid

\section{CONCLUSÕES}

Este trabalho visou compreender e delimitar as etapas do processo de Extração de Conhecimento de Base de Dados, analisando especialmente a etapa de Data Mining.

A primeira grande conclusão deste trabalho foi a existência de técnicas e/ou métodos que fazem parte de duas ou mais etapas do processo KDD, dificultando a delimitação dessas etapas. Esse problema foi observado no estudo de caso 1 ao usar o método proposto de discretização híbrida, considerado como fazendo parte da etapa de Data Mining (por interagir diretamente com os algoritmos de Aprendizado de Máquina), mas, por outro lado, os métodos de discretização não supervisionados e não parametrizados podem ser considerados como fazendo parte da etapa de preparação do conjunto de dados.

Perante este problema é proposto um modelo que integra as etapas do processo de KDD, observado na Figura 7.1, em vez de delimitá-las como no modelo clássico proposto por Fayyad [Fayyad 96c], observado na Figura 7.2.

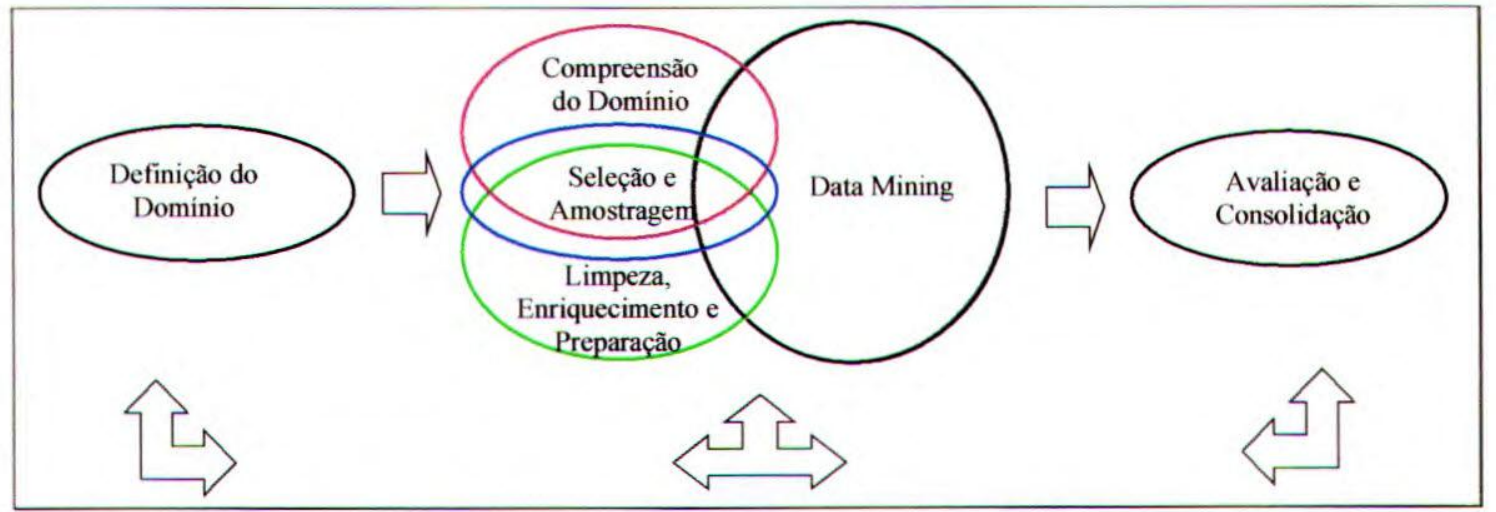

Figura 7.1: Modelo proposto para o processo de Extração de Conhecimento de Bases de Dados. 


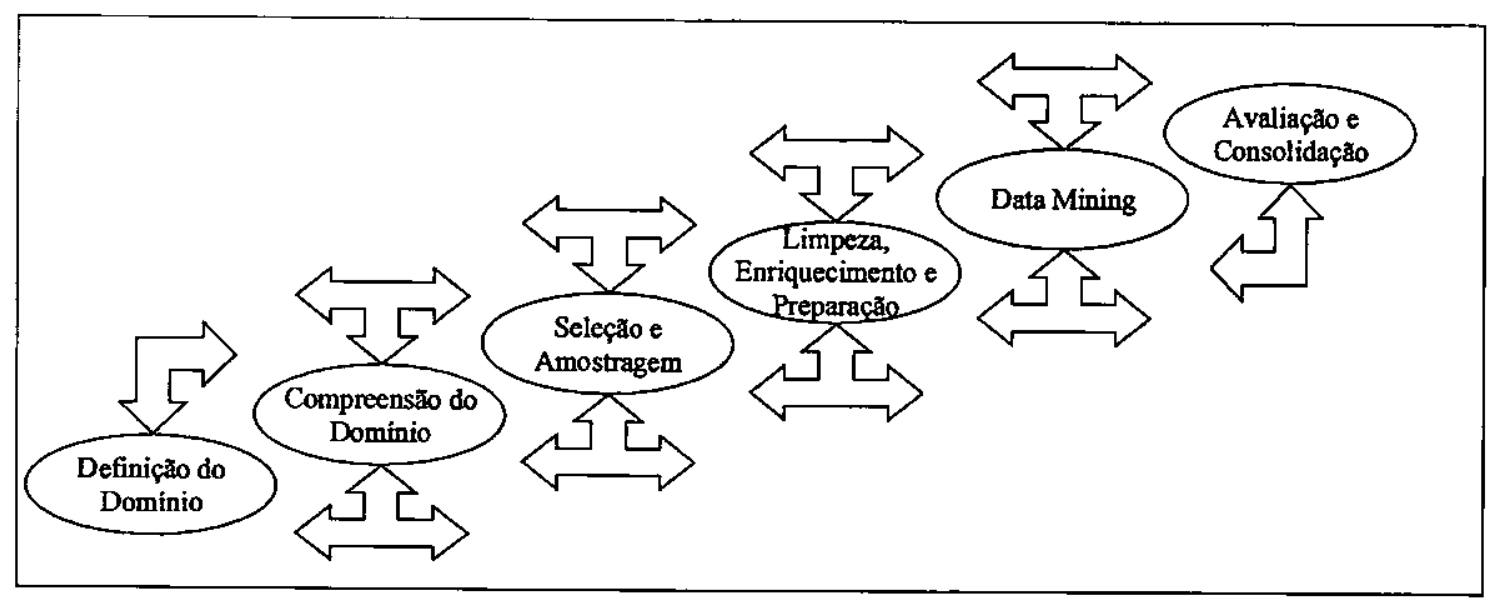

Figura 7.2: Modelo clássico para o processo de Extração de Conhecimento de Bases de Dados [Fayyad 96c].

Em ambos modelos, todas essas etapas são recursivas, isto é, quando é detectado um problema em alguma etapa, pode-se voltar a etapas anteriores para uma redefinição do mesmo. No modelo proposto, as etapas de Compreensão do Domínio, Seleção e Amostragem, Limpeza, Enriquecimento e Preparação, e Data Mining estão interagindo constantemente na procura de conhecimento.

O modelo proposto aborda o problema de delimitação das etapas em situações complexas, como por exemplo, em uma base de dados de mais de 400 atributos, a região na Figura 7.1 entre a Seleção e Amostragem, e Compreensão do Domínio auxilia o especialista do processo KDD a selecionar apenas os atributos relevantes a fim de reduzir e conseqüentemente tornar mais compreensível o domínio da aplicação.

A região na Figura 7.1 de interseção entre Compreensão do Domínio, Seleção e Amostragem, Limpeza, Enriquecimento e Preparação, e Data Mining representa a situação em que uma base de dados é colocada em sua totalidade como sendo o conjunto de dados utilizado pelos algoritmos de Aprendizado de Máquina, visando obter algum possível conhecimento prévio. Esta situação não pode ser observada no modelo clássico.

Vale ressaltar que nem sempre é necessário passar por todas as etapas do processo, as vezes, as bases de dados não precisam realizar um processo de limpeza e/ou enriquecimento. Esta observação não é aplicável à Definição do Domínio, Data Mining e à Avaliação e Consolidação do conhecimento, por ser etapas importantes que trabalham na parte analítica e na descoberta de padrões.

A segunda grande conclusão foi a delimitação da etapa de Data Mining em três sub-etapas:

- Redução de instâncias e/ou atributos (features).

- Descoberta de padrões.

- Pré-avaliação do conhecimento obtido por parte do especialista do processo KDD.

A primeira sub-etapa se refere ao fato de que não necessariamente devem ser utilizados todas as instâncias ou atributos do conjunto de dados pelos algoritmos de Aprendizado de Máquina, a não ser que o especialista do domínio determine o contrário. A segunda sub-etapa visa, geralmente 
através de técnicas de Aprendizado de Máquina, encontrar padrões, modelos ou classificações dentro do conjunto de dados. Finalmente a terceira sub-etapa se refere à pré-avaliação do conhecimento por parte do especialista do processo $\mathrm{KDD}$, objetivando eliminar o conhecimento espúrio que não representa valor nenhum e/ou situações óbvias guiadas pelo senso comum.

Outras contribuições de caráter mais específico trazidas por este trabalho foram:

- Proposta de um método de discretização híbrido na etapa de Data Mining visando a obtenção de conhecimento mais "confiável".

- Síntese dos métodos de classificação de algoritmos de Aprendizado de Máquina utilizados na etapa de Data Mining.

Recomendação para trabalhos futuros:

- Em geral:

- Utilizar diferentes bases de dados para poder avaliar o modelo proposto do processo KDD, mostrado na Figura 7.1.

- Avaliar/Delimitar as três sub-etapas pertencentes à etapa de Data Mining em diversos tipos de bases de dados.

- No tocante ao estudo de caso 1:

- Investigar diferentes métodos de discretização aplicados a diversas bases de dados petroleiras, com o propósito de obter um conhecimento "confiável" das perfurações realizadas nas diversas regiões petroleiras, com o objetivo de mostrar o comportamento das diferentes camadas da terra através de regras de indução.

- Aplicar o método de discretização híbrida nessas bases de dados petroleiras para poder observar seu desempenho no momento de gerar regras mais precisas.

- No tocante ao estudo de caso 2:

- Realizar os mesmos experimentos utilizando os touros nascidos em 1993 comparando os resultados obtidos com os deste trabalho.

- Analisar as características do touro "Ludy" (RGN C-6740), um dos melhores reprodutores do PMGRN, com mais de 1200 filhos cadastrados.

- Prever outras DEPs aplicando a mesma metodologia usada na DDPE550. 


\section{APÊNDICE A}

\section{TAXAS DE ERRO DO ESTUDO DE CASO 1}

Taxas de erro combinando os melhores limites inferiores próximos de $0,015 \mathrm{e}$ melhores limites superiores próximos de 2,4 usando os algoritmos CN2 e C4.5rules.

Taxas de erro combinando os melhores limites inferiores próximos de $0,015(0,015,0,025$ e $0,035)$ e melhores limites superiores próximos de $2,4(0,65$ e 0,75$)$ usando o algoritmo $\mathrm{CN} 2$.

\begin{tabular}{|c|c|c|c|c|c|c|c|c|c|c|c|}
\hline Intervalo & \multicolumn{5}{|c|}{ CN2 } & \multicolumn{6}{|c|}{ C4.5-rules } \\
\hline \multirow{4}{*}{$\begin{array}{c}<0,015 \\
{[0,015: 0,65]} \\
>0,65\end{array}$} & & (a) & (b) & (c) & $\begin{array}{c}\text { Erro } \\
\%\end{array}$ & & (a) & (b) & (c) & $\begin{array}{l}\text { Erro } \\
\%\end{array}$ & $\begin{array}{c}\text { Taxa de Erro da } \\
\text { Classe Majoritária \% }\end{array}$ \\
\hline & (a) & 61 & 5 & 0 & 7,5 & (a) & 60 & 6 & 0 & 9,1 & \\
\hline & (b) & 11 & 41 & 5 & 28 & (b) & 1 & 50 & 6 & 12,2 & \\
\hline & (c) & 4 & 4 & 28 & 22,2 & (c) & 0 & 7 & 29 & 19,4 & \\
\hline TOTAL & & & & & 18,2 & & & & & 12,6 & 59,9 \\
\hline
\end{tabular}

\begin{tabular}{|c|c|c|c|c|c|c|c|c|c|c|c|}
\hline Intervalo & \multicolumn{5}{|c|}{ CN2 } & \multicolumn{6}{|c|}{ C4.5-rules } \\
\hline \multirow{4}{*}{$\begin{array}{c}<0,015 \\
{[0,015: 0,75]} \\
>0,75\end{array}$} & & (a) & (b) & (c) & $\begin{array}{c}\text { Erro } \\
\%\end{array}$ & & (a) & (b) & (c) & $\begin{array}{c}\text { Erro } \\
\%\end{array}$ & $\begin{array}{c}\text { Taxa de Erro da Classe } \\
\text { Majoritária \% }\end{array}$ \\
\hline & (a) & 63 & 3 & 0 & 4,5 & (a) & 60 & 6 & 0 & 9,1 & \\
\hline & (b) & 2 & 58 & 0 & 3,3 & (b) & 1 & 54 & 5 & 10 & \\
\hline & (c) & 0 & 18 & 15 & 54,5 & (c) & 0 & 7 & 26 & 21,2 & \\
\hline TOTAL & & & & & 14,5 & & & & & 11,9 & 59,9 \\
\hline
\end{tabular}

\begin{tabular}{|c|c|c|c|c|c|c|c|c|c|c|c|}
\hline Intervalo & \multicolumn{5}{|c|}{ CN2 } & \multicolumn{6}{|c|}{ C4.5-rules } \\
\hline \multirow{4}{*}{$\begin{array}{c}<0,025 \\
{[0,025: 0,65]} \\
>0,65\end{array}$} & & (a) & (b) & (c) & $\begin{array}{c}\text { Erro } \\
\%\end{array}$ & & (a) & (b) & (c) & $\begin{array}{c}\text { Erro } \\
\%\end{array}$ & $\begin{array}{c}\text { Taxa de Erro da Classe } \\
\text { Majoritária \% }\end{array}$ \\
\hline & (a) & 64 & 4 & 0 & 5,8 & (a) & 61 & 7 & 0 & 10,2 & \\
\hline & (b) & 15 & 35 & 5 & 36,3 & (b) & 0 & 49 & 6 & 10,9 & \\
\hline & (c) & 2 & 6 & 28 & 22,2 & (c) & 0 & 7 & 29 & 19,4 & \\
\hline TOTAL & & & & & 20,1 & & & & & 12,6 & 57,8 \\
\hline
\end{tabular}

\begin{tabular}{|c|c|c|c|c|c|c|c|c|c|c|c|}
\hline Intervalo & \multicolumn{5}{|c|}{$\mathrm{CN} 2$} & \multicolumn{6}{|c|}{ C4.5-rules } \\
\hline \multirow{4}{*}{$\begin{array}{c}<0,025 \\
{[0,025: 0,75]} \\
>0,75\end{array}$} & & (a) & (b) & (c) & $\begin{array}{c}\text { Erro } \\
\%\end{array}$ & & (a) & (b) & (c) & $\begin{array}{c}\text { Erro } \\
\%\end{array}$ & $\begin{array}{c}\text { Taxa de Erro da } \\
\text { Classe Majoritária \% }\end{array}$ \\
\hline & (a) & 62 & 6 & 0 & 8,8 & (a) & 61 & 7 & 0 & 10,2 & \\
\hline & (b) & 8 & 44 & 6 & 24,1 & (b) & 0 & 53 & 5 & 8,6 & \\
\hline & (c) & 0 & 7 & 26 & 21,2 & (c) & 0 & 7 & 26 & 21,2 & \\
\hline TOTAL & & & & & 17 & & & & & 11,9 & 57,8 \\
\hline
\end{tabular}




\begin{tabular}{|c|c|c|c|c|c|c|c|c|c|c|c|}
\hline Intervalo & \multicolumn{5}{|c|}{ CN2 } & \multicolumn{6}{|c|}{ C4.5-rules } \\
\hline \multirow{4}{*}{$\begin{array}{c}<0,035 \\
{[0,035: 0,65]} \\
>0,65\end{array}$} & & (a) & (b) & (c). & $\begin{array}{c}\text { Erro } \\
\%\end{array}$ & & (a) & (b) & (c) & $\begin{array}{c}\text { Erro } \\
\%\end{array}$ & $\begin{array}{c}\text { Taxa de Erro da } \\
\text { Classe Majoritária \% }\end{array}$ \\
\hline & (a) & 65 & 6 & 0 & 8,4 & (a) & 61 & 10 & 0 & 14 & \\
\hline & (b) & 7 & 40 & 5 & 23 & (b) & $\overline{0}$ & 46 & 6 & 11,5 & \\
\hline & (c) & 1 & 7 & 28 & 22,2 & (c) & 0 & 7 & 29 & 19,4 & \\
\hline TOTAL & & & & & 16,4 & & & & & 14,5 & 56,5 \\
\hline
\end{tabular}

\begin{tabular}{|c|c|c|c|c|c|c|c|c|c|c|c|}
\hline Intervalo & \multicolumn{5}{|c|}{ CN2 } & \multicolumn{6}{|c|}{ C4.5-rules } \\
\hline \multirow{4}{*}{$\begin{array}{c}<0,035 \\
{[0,035: 0,75]} \\
>0,75\end{array}$} & & (a) & (b) & (c) & $\begin{array}{c}\text { Erro } \\
\%\end{array}$ & & (a) & (b) & (c) & $\begin{array}{l}\text { Erro } \\
\%\end{array}$ & $\begin{array}{c}\text { Taxa de Erro da } \\
\text { Classe Majoritária \% }\end{array}$ \\
\hline & (a) & 65 & 6 & 0 & 8,4 & (a) & 61 & 10 & 0 & 14 & \\
\hline & (b) & 5 & 45 & 5 & 18,1 & (b) & 0 & 54 & 1 & 1,8 & \\
\hline & (c) & 0 & 7 & 26 & 21,2 & (c) & 0 & 12 & 21 & 36,3 & \\
\hline TOTAL & & & & & 14,5 & & & & & 14,5 & 56,5 \\
\hline
\end{tabular}

Taxas de erro combinando os melhores limites inferiores próximos de $0,015(0,015,0,025 \mathrm{e}$ $0,035)$ e melhor limite superior próximo de $2,4(1,75)$ usando o algoritmo C4.5-rules.

\begin{tabular}{|c|c|c|c|c|c|c|c|c|c|c|c|}
\hline Intervalo & \multicolumn{5}{|c|}{ CN2 } & \multicolumn{6}{|c|}{ C4.5-rules } \\
\hline \multirow{4}{*}{$\begin{array}{c}<0,015 \\
{[0,015: 1,75]} \\
>1,75\end{array}$} & & (a) & (b) & (c) & $\begin{array}{c}\text { Erro } \\
\%\end{array}$ & & (a) & (b) & (c) & $\begin{array}{c}\text { Erro } \\
\%\end{array}$ & $\begin{array}{c}\text { Taxa de Emo da } \\
\text { Classe Majoritária \% }\end{array}$ \\
\hline & (a) & 62 & 4 & 0 & 6 & (a) & 60 & 6 & 0 & 9 & \\
\hline & (b) & 11 & 63 & 5 & 20,2 & (b) & 1 & 76 & 2 & 3,7 & \\
\hline & (c) & 1 & 1 & 12 & 14,2 & (c) & 0 & 2 & 12 & 14,2 & \\
\hline TOTAL & & & & & 13,8 & & & & & 6,9 & 59,9 \\
\hline
\end{tabular}

\begin{tabular}{|c|c|c|c|c|c|c|c|c|c|c|c|}
\hline Intervalo & \multicolumn{5}{|c|}{ CN2 } & \multicolumn{6}{|c|}{ C4.5-rules } \\
\hline \multirow{4}{*}{$\begin{array}{c}<0,025 \\
{[0,025: 1,75]} \\
>1,75\end{array}$} & & (a) & (b) & (c) & $\begin{array}{c}\text { Erro } \\
\%\end{array}$ & & (a) & (b) & (c) & $\begin{array}{c}\text { Erro } \\
\%\end{array}$ & $\begin{array}{c}\text { Taxa de Erro da Classe } \\
\text { Majoritária \% } \\
\end{array}$ \\
\hline & (a) & 62 & 6 & 0 & 8,8 & (a) & 61 & 7 & 0 & 10,2 & \\
\hline & (b) & 17 & 54 & 6 & 29,8 & (b) & $\overline{0}$ & 75 & 2 & 2,5 & \\
\hline & (c) & 1 & 1 & 12 & 14,2 & (c) & 0 & 2 & 12 & 14,2 & \\
\hline TOTAL & & & & & 19,5 & & & & & 6,9 & 57,8 \\
\hline
\end{tabular}

\begin{tabular}{|c|c|c|c|c|c|c|c|c|c|c|c|}
\hline Intervalo & \multicolumn{5}{|c|}{$\overline{C N 2}$} & \multicolumn{6}{|c|}{ C4.5-rules } \\
\hline \multirow{4}{*}{$\begin{array}{c}<0,035 \\
{[0,035: 1,75]} \\
>1,75\end{array}$} & & (a) & (b) & (c) & $\begin{array}{c}\text { Erro } \\
\%\end{array}$ & & (a) & (b) & (c) & $\begin{array}{l}\text { Erro } \\
\%\end{array}$ & $\begin{array}{l}\text { Taxa de Emo da Classe } \\
\text { Majoritária \% }\end{array}$ \\
\hline & (a) & $\overline{63}$ & 8 & 0 & 11,2 & (a) & 61 & 10 & 0 & 14 & \\
\hline & (b) & 16 & 52 & 6 & 29,7 & (b) & 0 & 72 & 2 & 2,7 & \\
\hline & (c) & 0 & 2 & 12 & 14,2 & (c) & 0 & 2 & 12 & 14,2 & \\
\hline TOTAL & & & & & 20,1 & & & & & 8,8 & 56,5 \\
\hline
\end{tabular}




\section{APÊNDICE B}

\section{MATRIZES DE CONFUSÃO DO ESTUDO DE CASO 1}

Matrizes de confusão usando os pontos de corte " 0,015 e 0,75 " e "0,015 e 1,75".

Matrizes de confusão usando os pontos de corte 0,015 e 0,75 .

\begin{tabular}{|c|c|c|c|c|c|c|c|c|c|c|c|}
\hline Cenário & \multicolumn{5}{|c|}{$\mathrm{CN} 2$} & \multicolumn{6}{|c|}{ C4.5-rules } \\
\hline \multirow{4}{*}{1} & & (a) & (b) & (c) & $\begin{array}{c}\text { Erro } \\
\%\end{array}$ & & (a) & (b) & (c) & $\begin{array}{c}\text { Erro } \\
\%\end{array}$ & $\begin{array}{c}\text { Taxa de Erro da } \\
\text { Classe Majoritária \% }\end{array}$ \\
\hline & (a) & 15 & 5 & 2 & 31,8 & (a) & 14 & 7 & 1 & 36,3 & \\
\hline & (b) & 10 & 23 & 18 & 54,9 & (b) & $\overline{2}$ & 32 & 17 & 37,2 & \\
\hline & (c) & 4 & 10 & 46 & 23,3 & (c) & 0 & 14 & 46 & 23,3 & \\
\hline TOTAL & & & & & 36,8 & & & & & 30,8 & 54,4 \\
\hline
\end{tabular}

\begin{tabular}{|c|c|c|c|c|c|c|c|c|c|c|c|}
\hline Cenário & \multicolumn{9}{|c|}{ CN2 } & \multicolumn{1}{c|}{ C4.5-rules } \\
\hline \multirow{3}{*}{2 B } & & (a) & (b) & (c) & $\begin{array}{c}\text { Erro } \\
\%\end{array}$ & & (a) & (b) & (c) & $\begin{array}{c}\text { Erro } \\
\%\end{array}$ & $\begin{array}{c}\text { Taxa de Erro da } \\
\text { Classe Majoritária \% }\end{array}$ \\
\cline { 2 - 15 } & (a) & 78 & 0 & 0 & 0 & (a) & 77 & 1 & 0 & 1,2 & \\
& (b) & 5 & 35 & 4 & 20,4 & (b) & 1 & 39 & 4 & 11,3 & \\
\cline { 2 - 13 } & (c) & 2 & 2 & 3 & 57,1 & (c) & 0 & 5 & 2 & 71,4 & \\
\hline TOTAL & \multicolumn{1}{|c|}{} & & 10,1 & & & & & 8,5 & 59,9 \\
\hline
\end{tabular}

\begin{tabular}{|c|c|c|c|c|c|c|c|c|c|c|c|}
\hline Cenário & \multicolumn{9}{|c|}{ CN2 } & \multicolumn{6}{|c|}{ C4.5-rules } \\
\hline \multirow{3}{*}{3} & & (a) & (b) & (c) & $\begin{array}{c}\text { Erro } \\
\%\end{array}$ & & (a) & (b) & (c) & $\begin{array}{c}\text { Erro } \\
\%\end{array}$ & $\begin{array}{c}\text { Taxa de Erro da } \\
\text { Classe Majoritaria \% }\end{array}$ \\
\cline { 2 - 14 } & (a) & 62 & 4 & 0 & 6 & (a) & 62 & 4 & 0 & 6 & \\
& (b) & 7 & 46 & 7 & 23,3 & (b) & 1 & 58 & 1 & 3,3 & \\
& (c) & 0 & 7 & 26 & 21,2 & (c) & 0 & 12 & 21 & 36,3 & \\
\hline TOTAL & \multicolumn{1}{|c|}{} & & 15,7 & & & & & 11,3 & 56,7 \\
\hline
\end{tabular}

Matrizes de confusão usando os pontos de corte 0,015 e 1,75.

\begin{tabular}{|c|c|c|c|c|c|c|c|c|c|c|c|}
\hline Cenário & \multicolumn{5}{|c|}{ CN2 } & \multicolumn{6}{|c|}{ C4.5-rules } \\
\hline \multirow{4}{*}{1} & & (a) & (b) & (c) & $\begin{array}{c}\text { Erro } \\
\%\end{array}$ & & (a) & (b) & (c) & $\begin{array}{l}\text { Erro } \\
\%\end{array}$ & $\begin{array}{c}\text { Taxa de Erro da } \\
\text { Classe Majoritária \% }\end{array}$ \\
\hline & (a) & 17 & 4 & 1 & 22,7 & (a) & 16 & 2 & 4 & 27,2 & \\
\hline & (b) & 14 & 30 & 16 & 50 & (b) & 8 & 21 & 31 & 65 & \\
\hline & (c) & 1 & 15 & 35 & 31,3 & (c) & 0 & 8 & $\overline{43}$ & 15,6 & \\
\hline TOTAL & & & & & 38,3 & & & & & 39,8 & 54,4 \\
\hline
\end{tabular}




\begin{tabular}{|c|c|c|c|c|c|c|c|c|c|c|c|}
\hline Cenário & \multicolumn{5}{|c|}{ CN2 } & \multicolumn{6}{|c|}{ C4.5-rules } \\
\hline \multirow{4}{*}{$2 \mathrm{~B}$} & & (a) & (b) & (c) & $\begin{array}{c}\text { Erro } \\
\%\end{array}$ & & (a) & (b) & (c) & $\begin{array}{l}\text { Erro } \\
\%\end{array}$ & $\begin{array}{c}\text { Taxa de Eño da } \\
\text { Classe Majoritária \% }\end{array}$ \\
\hline & (a) & 77 & 1 & 0 & 1,2 & (a) & 77 & 1 & 0 & 1,2 & \\
\hline & (b) & 1 & 47 & 0 & 2 & (b) & 1 & 47 & 0 & 2 & \\
\hline & (c) & 1 & 2 & 0 & 0 & (c) & 0 & 2 & 1 & 66,6 & \\
\hline TOTAL & & & & & 3,9 & & & & & 3,1 & 59,9 \\
\hline
\end{tabular}

\begin{tabular}{|c|c|c|c|c|c|c|c|c|c|c|c|}
\hline Cenário & \multicolumn{5}{|c|}{ CN2 } & \multicolumn{6}{|c|}{ C4.5-rules } \\
\hline \multirow{4}{*}{3} & & (a) & (b) & (c) & $\begin{array}{c}\text { Erro } \\
\%\end{array}$ & & (a) & (b) & (c) & $\begin{array}{l}\text { Erro } \\
\%\end{array}$ & $\begin{array}{c}\text { Taxa de Erro da } \\
\text { Classe Majoritária \% }\end{array}$ \\
\hline & (a) & 62 & 4 & 0 & 6 & (a) & 62 & 4 & 0 & 6 & \\
\hline & (b) & 6 & 72 & 1 & 8,8 & (b) & 1 & 76 & 2 & 3,7 & \\
\hline & (c) & 0 & 2 & 12 & 14,2 & (c) & 0 & 2 & 12 & 14,2 & \\
\hline TOTAL & & & & & 8,2 & & & & & 5,7 & 56,7 \\
\hline
\end{tabular}




\section{SAIDA GERADA PELO ALGORITMO C4.5-rules NO ESTUDO DE CASO 1}

Saída gerada pelo algoritmo C4.5-rules usando os pontos de corte $[0,015 ; 1,75]$ no Estudo de Caso 1.

Rules generated by the C4.5-rules.

C4.5 [release 8] rule generator Thu Jul 9 19:13:38 1998

\section{Options:}

Rulesets evaluated on unseen cases

File stem $</$ var/tmp/AAAa000ox $>$

Read 694 cases (2 attributes) from /var/tmp/AAAa000ox

Processing tree 0

Final rules from tree 0:

Rule 20:

porosidade $>15.7$

$\rightarrow$ class $1.75+[86.4 \%]$

Rule 18:

profundidade $>15599$

porosidade $>3.9$

$\rightarrow$ class $1.75+$ [79.4\%]

Rule 12:

profundidade $>15426$

profundidade $<=15496$

porosidade $>10,8$

$->$ class $1.75+[78.7 \%]$

Rule 17:

profundidade $>15582$

porosidade $>11.1$ 
Rule 1:

porosidade $<=2.9$

$\rightarrow$ class - 0,015 [99.3\%]

Rule 4:

profundidade $>15412$

porosidade $<=3.9$

$\rightarrow$ class - 0,015 [96.3\%]

Rule 16:

profundidade $>15582$

profundidade $<=15599$

porosidade $<=11.1$

-> class - 0,015 [86.7\%]

Rule 14:

profundidade $>15515$

porosidade $<=10,3$

$\rightarrow$ class - 0,015 [77.2\%]

Rule 19:

porosidade $>3.9$

porosidade $<=15.7$

$\rightarrow$ class 0,015-1.75 [65.3\%]

Rule 3:

$$
\begin{aligned}
& \text { porosidade }>2.9 \\
& \text { porosidade }<=3.2 \\
& ->\text { class } 0.015-1.75[54.6 \%]
\end{aligned}
$$

Default class: $0.015-1.75$

Evaluation on training data (694 items):

\begin{tabular}{|c|c|c|c|c|c|c|}
\hline Rule & Size & Erro & Used & Wrong & Advantage & Class \\
\hline 20 & 1 & $13,6 \%$ & 126 & $14(11,1 \%)$ & $53(64 \mid 11)$ & $>1,75+$ \\
\hline 18 & 2 & $20,6 \%$ & 4 & $0(0,0 \%)$ & $4(4 \mid 0)$ & $>1,75+$ \\
\hline 12 & 3 & $21,3 \%$ & 33 & $11(33,3 \%)$ & $11(22 \mid 11)$ & $>1,75+$ \\
\hline 17 & 2 & $35,5 \%$ & 6 & $2(33,3 \%)$ & $3(4 \mid 1)$ & $>1,75+$ \\
\hline 1 & 1 & $0,7 \%$ & 203 & $0(0,0 \%)$ & $56(56 \mid 0)$ & $<0,015$ \\
\hline 4 & 2 & $3,7 \%$ & 22 & $4(18,2 \%)$ & $1(4 \mid 3)$ & $<0,015$ \\
\hline 16 & 3 & $13,3 \%$ & 8 & $1(12,5 \%)$ & $3(3 \mid 0)$ & $<0,015$ \\
\hline 14 & 2 & $22,8 \%$ & 60 & $27(45,0 \%)$ & $6(33 \mid 27)$ & $<0,015$ \\
\hline 19 & 2 & $34,7 \%$ & 228 & $40(17,5 \%)$ & $0(0 \mid 0)$ & {$[0,015: 1,75]$} \\
\hline 3 & 2 & $45,4 \%$ & 2 & $0(0,0 \%)$ & $0(0 \mid 0)$ & {$[0,015: 1,75]$} \\
\hline
\end{tabular}

Tested 694, errors $99(14.3 \%) \ll$ 
(a) (b) (c) <-classified as

$\begin{array}{llll}261 & 16 \quad 1 \text { (a): class }-0.015\end{array}$

$32192 \quad 26$ (b): class 0.015-1.75

$0 \quad 24142$ (c): class $1.75+$

Evaluation on test data (159 items):

\begin{tabular}{|c|c|c|c|c|c|c|}
\hline Rule & Size & Erro & Used & Wrong & Advantage & Class \\
\hline 1 & 1 & $0,7 \%$ & 61 & $1(1,6 \%)$ & $59(60 \mid 1)$ & $<0,015$ \\
\hline 19 & 2 & $34,7 \%$ & 82 & $6(7,3 \%)$ & $0(0 \mid 0)$ & {$[0,015: 1,75]$} \\
\hline 20 & 1 & $13,6 \%$ & 14 & $2(14,3 \%)$ & $10(12 \mid 2)$ & $>0,75$ \\
\hline
\end{tabular}

Tested 159, errors $11(6.9 \%)<<$
(a) (b) (c) <-classified as
$\begin{array}{llll}60 & 6 & 0 & \text { (a): } \text { class }<0.015\end{array}$
$\begin{array}{llll}1 & 76 & 2 & \text { (b): class [0.015:1.75] }\end{array}$
$\begin{array}{llll}0 & 2 & 12 & \text { (c): class }>1.75\end{array}$

No qual:

- Rule: Número de regra.

- Size: Número de atributos que participam na regra.

- Erro: Taxa de erro prevista.

- Used: Número de casos cobertos pela regra.

- Wrong: Número de casos errados.

- Advantage a(b|c): se a regra for omitida, $b$ casos classificados corretamente pela regra passariam a serem classificados incorretamente e $c$ casos classificados incorretamente passariam a ser classificados corretamente pelas subseqüentes regras e a regra default. $\mathrm{O}$ beneficio de ter a regra seria $a=b-c$. 
APÊNDICE D

\section{APRENDIZADO INDUTIVO}

\section{APRENDIZADO INDUTIVO}

Os humanos e outras criaturas inteligentes (que neste trabalho serão chamados de sistemas cognitivos) tentam entender o seu ambiente usando uma simplificação deste. Essa simplificação é chamada de "modelo" e sua criação é conhecida como "aprendizado indutivo". Durante a fase de aprendizado, o sistema cognitivo observa seu ambiente e reconhece semelhanças entre objetos e eventos deste ambiente, agrupando objetos semelhantes em classes e construindo regras que prevejam o comportamento dos habitantes de tal classe. Os modelos, então, são usados para prever mudanças no ambiente e permitir que o sistema cognitivo possa interagir nesse sistema com mais êxito nesse ambiente [Holland 86].

Existem muitos modelos possíveis que podem ser criados a partir de um número finito de observações do ambiente. Conseqüentemente, são necessários critérios como exatidão e qualidade para selecionar um modelo apropriado.

\section{O Ambiente}

O ambiente de um sistema cognitivo pode ser definido em condições locais (uma tábua de xadrez, ou todos os clientes de uma empresa), ou como a totalidade do universo, incluindo o próprio sistema.

A situação do ambiente em um determinado momento $t$ é descrita pelo estado $S_{t}$. Esse estado descreve os objetos do ambiente juntamente com suas propriedades e relações mútuas. $\mathrm{O}$ estado do ambiente muda com o passar do tempo, assim um subseqüente estado $S_{t+l}$ pode conter novos objetos e relações, ou objetos podem ter desaparecido e/ou suas propriedades podem ter mudado. Implícita a cada ambiente é a "função de transição de estado" T que especifica como o ambiente muda com o passar do tempo.

O ambiente pode ser definido como um sistema de transição de estados, por exemplo, o par $(S, \mathrm{~T})$, no qual $S$ é o conjunto de todos os possíveis estados e T é a função de transição T: $S \rightarrow$ $S_{t+1}$. T define o próximo estado $S_{t+1}$ para qualquer estado $S_{t}$. Por exemplo, assume-se que o estado consiste de um único objeto, com propriedades "cor $=$ vermelho" e "movendo-se rápido". No próximo estado, a propriedade "cor" do objeto permanece inalterada, mas a propriedade "movendo-se rápido" mudar para "parado", obedecendo a lei de que todos os objetos em movimento reduzem a sua velocidade.

Um modo direto para criar um modelo do ambiente seria fazer uma cópia interna fiel desse sistema de transição de estados e, além disso, registrar todas as transições. Para prever o próximo estado a partir do estado atual, simplesmente se compara o estado atual com todos os estados 
registrados anteriormente. Por exemplo, uma pessoa poderia aprender a jogar xadrez, observando os jogos e memorizando o próximo movimento apropriado para quaisquer das possíveis configurações de peças do tabuleiro de xadrez. Infelizmente, esta representação só é possível para ambientes simples, consistindo em uma pequena variedade de estados. Além da enorme quantidade de armazenamento, precisa-se representar todos esses estados, por isto - para ambientes reais - é pouco provável que o estado atual se iguale a qualquer um dos estados anteriores.

Assim, em lugar de fazer uma cópia fiel, pode-se usar abstrações, que utilizam um pequeno número de propriedades para caracterizar os objetos em um estado. Os objetos que satisfazem o mesmo subconjunto de propriedades são mapeados para uma mesma representação interna.

Neste ponto, é muito importante fazer uma restrição. Alguns dos sistemas de Data Mining procuram relações dentro dos objetos, por exemplo, relações entre propriedades em um único objeto. Conseqüentemente, nesta percepção do ambiente, os objetos são completamente sem conexão e então, assume-se que o efeito de T sobre um objeto em $S$ não depende de outros objetos em $S$. Note que esta suposição, embora implícita em alguns sistemas de Data Mining, é absurda, pois os objetos de um conjunto de dados estão relacionados em uma maior ou menor proporção [Holsheimer 94].

\section{Classes}

Considerando que um estado é descrito usando um conjunto limitado de propriedades, objetos distintos podem ser representados internamente como um único objeto. Em outras palavras, escolhendo um conjunto particular de propriedades que possa ser representado em um modelo que induza uma "classe equivalente" do objeto. A cada classe corresponde um único padrão de valores, a "descrição da classe".

O conjunto de todas as classes é denotado por $C$ e cada classe por $C_{i}$ correspondendo a descrição de valores $D_{i}$ para as propriedades selecionadas. Assim, usando essas descrições, pode-se construir uma "função de classificação" $P: S \rightarrow C$, que mapeie um objeto $o$ em um estado $S$ para uma classe $C_{i}$ quando $o$ satisfaz $D_{i}$. $P$ é estendida diretamente para uma função $P: S \rightarrow P(C)$, que mapeia cada estado do conjunto de classes correspondentes aos objetos em $S$. Por exemplo, se é selecionada a propriedade "velocidade", no exemplo anterior, pode-se distinguir duas classes, "movendo-se rápido" e "parado". Por outro lado, também se pode selecionar a propriedade "cor", que - na ausência de outros objetos - a classe "cor = vermelha".

\section{Função de Transição do Modelo}

Usando uma representação interna de estados, o sistema deve construir uma função de transição do modelo T', que pretenda imitar a função de transição T que opera no mundo real. A função T" descreve como as representações internas (classes) $C_{t, i}$ de um estado $S_{t}$ do ambiente conduzem às representações internas $C_{t+1, i}$ do estado subseqüente $S_{t+1}$. Por exemplo, continuando com o mesmo exemplo da "velocidade", pode-se construir uma função de transição do modelo mapeando a classe "movendo-se rápido" com "parado", determinando as diferenças existentes, e prevendo assim que qualquer objeto "movendo-se rápido" reduzirá a sua velocidade.

Este modelo é ilustrado na Figura D.1, na qual indica que um estado do ambiente $S_{t}$ no conjunto de todos os estados $S$ é transformado em um estado $S_{t+1}$, após um certo intervalo de tempo. Para simplificar a figura, assume-se que a representação interna desse estado é só uma classe $C_{t}$ e a 
aplicação da função de transição do modelo T' para esta classe resulta na classe $C_{t+1}$, que é a representação interna do estado $S_{t+1}$.

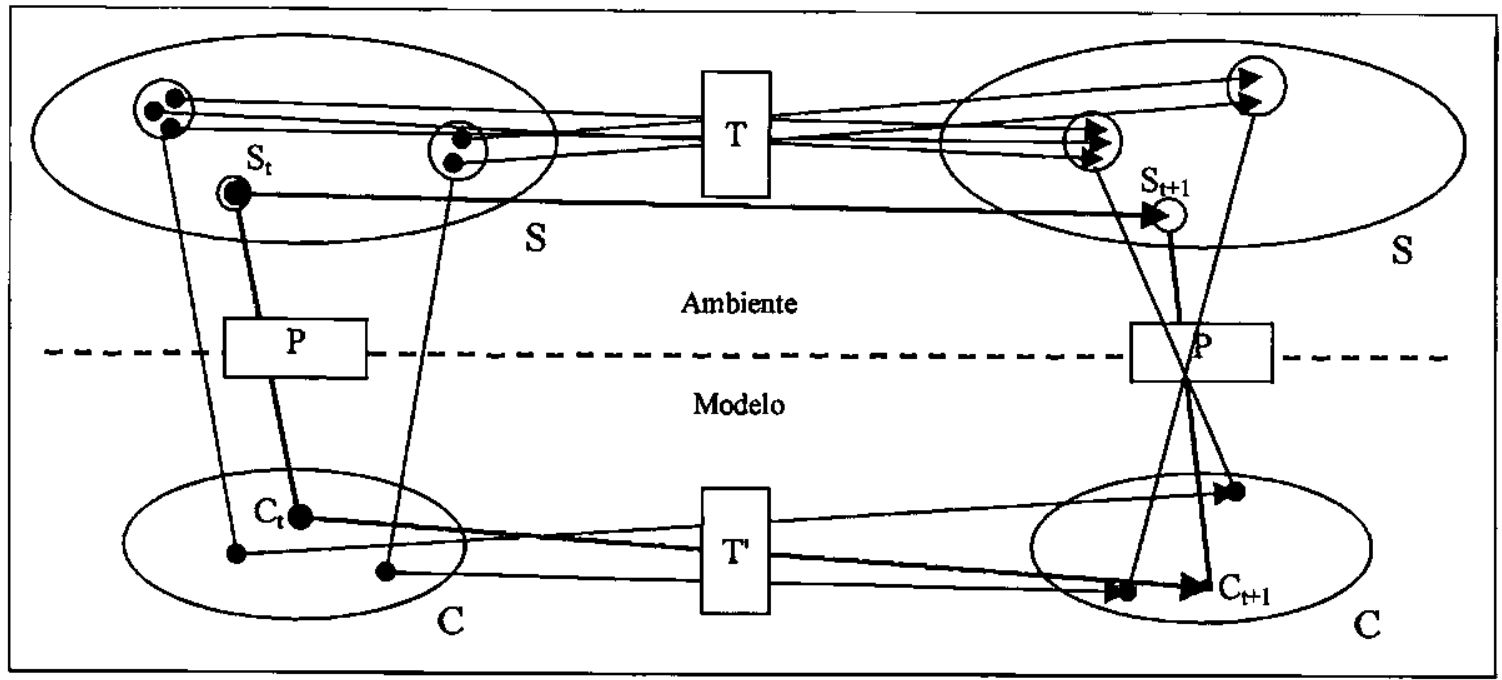

Figura D.1: Modelo interno que representa transições no ambiente.

\section{Exatidão do Modelo}

Um modelo correto é capaz de prever o próximo estado, por exemplo, em qualquer momento $t$, a representação interna do próximo estado é idêntica à representação prevista pelo modelo. Desde que o ambiente e o modelo, sejam formalizados como uma função de transição do estado, a função de classificação $P$ deverá ser idêntica entre o ambiente e o modelo. Em outras palavras, o diagrama deve ser comutativo:

$$
P\left(T^{\prime}\left(S_{\nu}\right)\right)=\mathrm{T}^{\prime}\left(P\left(S_{\Downarrow}\right)\right.
$$

Quando esta condição se cumpre, então se diz que o modelo prevê exatamente o próximo estado.

\section{Aprendizado}

No começo, o sistema cognitivo não tem nenhuma classe para representar estados ambientais internamente e não tem nenhuma função de transição do modelo. Além disso, quando o sistema já tem um modelo para representar este ambiente, este pode tornar-se inadequado porque o ambiente está mudando constantemente. Para uma operação bem sucedida em tal ambiente, o sistema tem que ser adaptável, isto é, deverá "aprender".

Aprender consiste em encontrar a classe e a função de transição do modelo em uma representação interna apropriada, de forma que o modelo classifique corretamente os exemplos conhecidos, assim como os novos exemplos.

\section{Qualidade do Modelo}

Um problema comum em aprendizado indutivo é que dado um conjunto de exemplos, o sistema passa a construir múltiplos modelos corretos em relação a esses exemplos. Em outras palavras, em modelos que corretamente prevêem o próximo estado, para todos os estados do ambiente, o sistema tem que encontrar também os estados mais distantes. Porém, se o modelo está sendo usado para prever corretamente os estados distantes, então também deve prever corretamente qualquer estado não visto que poderia acontecer. 
As descrições dos estados são construídas usando uma estratégia de busca iterativa (iterative search strategy) na qual procura o conjunto de todas as melhores descrições construídas. Primeiro, uma hipótese inicial (por exemplo, uma descrição) é formulada e verificada através do cálculo de alguma "função de qualidade". Essa função, baseada em técnicas estatísticas, calcula a exatidão da hipótese em relação ao conjunto de treinamento. Logo, a hipótese é aceitada, rejeitada ou melhorada até que a hipótese correta seja encontrada, como é mostrada na Figura D.2. Uma hipótese é melhorada mediante, por exemplo, a agregação de condições dos atributos, ou a generalização de condições. Quando existem múltiplas alternativas para uma nova hipótese, a escolha é guiada pela heurística, constrangimento e interação com o especialista do domínio.

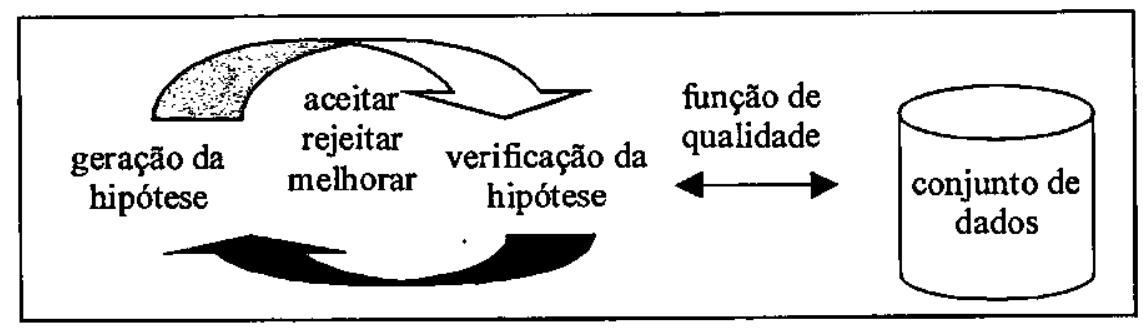

Figura D.2: A busca iterativa para determinar o melhor modelo.

Um problema - discutido por muitos filósofos - é a distinção entre as relações realmente existentes e as relações aparentes entre estados, que não são geralmente válidas, mas acontecem só por causa do número limitado de exemplos. Na maioria dos ambientes, o número de possíveis estados é infinito, de forma que a exatidão de um modelo normalmente não pode ser verificada conferindo todas as possíveis situações. Tendo múltiplos modelos, alguns desses são mais simples do que outros. Espera-se que os modelos mais simples sejam os mais prováveis de serem os corretos. A razão por trás desta regra - também conhecida como "o aparelho de barbear de Ockham" [Sills 68] (Ockham's razor) - é que se existem múltiplas descrições para um fenômeno particular, faz sentido escolher a mais simples, porque é mais provável capturar a natureza do fenômeno. 


\section{Bibliografia}

Os Gurus da navegação estimam que levaria 10.958 anos para ter acesso as 80 milhões de páginas online que existem na WEB

(para usuários que normalmente visitam 20 páginas por dia). - Annette Hamilton, ZDNet AnchorDesk

[Aha 91]

[Aha 92]

[Amaral 97]

[ANUALPEC 95]

[Auer 95]

[Babcock 94]

[Batista 97]

[Blum 82]
Aha, D.W., Kibler, D. \& Albert, M.K., Instance-Based Learning Algorithms, Machine Learning, v. 6, Kluwer Academic Publishers, The Netherlands, 1991, pp. 37-66.

Aha, D.W., Tolerating Noisy, Irrelevant and Novel Attributes in Instance-Based Learning Algorithms, International Journal of Man-Machine Studies 36(1), 1992, pp. 267-287.

Amaral, A., Desmitificando Definitivamente o Data Warehousing, Revista Developers Magazine, ISSN 1413-9154, Brasil, Fevereiro, 1997, pp. 14-17.

Consultoria \& Comércio FNP, ANUALPEC 95, Anuário Estatístico de Pecuária de Corte, FNP, São Paulo, 1995, pp. 268.

Auer, P., Holte, R. \& Maass, W., Theory and Applications of Agnostic PACLearning with Small Decision Trees, in Proc. Machine Learning: Proceedings of the $12^{\text {th }}$ International Conference, Prieditis \& S. Russell, eds., Morgan Kaufmann Publishers, Inc., 1995.

Babcock, C., Parallel Processing Mines Retail Data, Computer World, September, 1994.

Batista, G.E.A.P.A., Um Ambiente de Avaliação de Algoritmos de Aprendizado de Máquina Utilizando Exemplos, Dissertação de Mestrado, ICMC-USP, São Carlos, Brasil, 1997.

Blum, R.L., Discovery and Representation of Causal Relationships from a Large Time-Oriented Clinical Database: The RX Project, volume 19 of Lecture Notes 
in Medical Informatics, Spinger-Verlag, 1982.

[Brodley 92]

Brodley, C.E. \& Utgoff, P., Multivariate Decision Trees, Technical Report MASSCS 92-93, University of Massachusetts, Amherst, 1992.

[Brooks 97]

Brooks, P.L., Visualizando os Dados, Revista DBMS, n. 5 v. 1, Setembro, 1997, pp. 35-43.

[Cabena 97] Cabena, P., Hadjinian, P., Stadler, R., Verhees, J. \& Zanasi, A., Discovering Data Mining From Concept to Implemetation, ISBN 0-13-743980-6, PrenticeHall, USA, 1997.

[Carbonell 87] Carbonell, J.G. \& Langley, P., Machine Learning. Encyclopedia of Artificial Intelligence, Ed. John Wiley \& Sons, USA, 1987, pp. 464-488.

[Catlett 91]

Catlett, J., Megainduction: Machine Learning on Very Large Databases, Ph.D. Thesis, University of Sydney, 1991.

[Chmielewski 95] Chmielewski, M. \& Grzymala-Busse, J., Global Discretization of Continuous Attributes as Preprocessing for Machine Learning, in Lin, T.Y. and Wildberger, A.M., (eds.), Soft Computing, Society for Computer Simulation, San Diego, 1995, pp. 294-301.

[Clark 89]

Clark, P. \& Niblett, T., The CN2 Induction Algorithm, Machine Learning 3(4), 1989, pp. 261-283.

[Clark 89]

[Clark 91]

Clark, P. \& Niblett, T., The CN2 Induction Algorithm, Machine Learning, v. 3, 1989, pp. 261-283.

Clark, P. \& Boswell, R., Rule Induction with CN2: Some Recent Improvements, in Proc. $5^{\text {th }}$ European Conference (EWSL 91), Y. Kodratoff, ed., Springer Verlag, 1991, pp. 151-163.

[Cost 93]

Cost, S. \& Salzberg, S., A Weighted Nearest Neighbor Algorithm for Learning with Symbolic Features, Machine Learning 10(1), 1993, pp. 57-78.

[Dalal 89] Dalal, S.R., Fowlkes, E.B. \& Hoadley, B., Risk Analysis of the Space Shuttle: Pre-Challenger Prediction of Failure, Journal of the American Statistical Association, 1989, pp. 945-957.

[Dasarathy 90] Dasarathy, B.V., Nearest Neighbor (NN) Norms: NN Pattern Classification Techniques, IEEE Computer Society Press, Los Alamitos, California, 1990.

[DeJesus 95]

DeJesus, E., Mineração de Dados, Revista Byte, Outubro, Brasil, 1995, pp. 96.

[Dietterich 83] Dietterich, T.G. \& Michalski, R.S., A Comparative Review of Selected Methods for Learning from Examples, in [Michalski 83b], pp. 41-81.

[Dilly 95]

[Domingos 96]

Dilly, R., Data Mining. an Introduction Student Notes, 1997, [Online] Available. URL: http://www.qub.ac.uk/courses/datamining/stu_notes /dm_book_1.html

Domingos, P. \& Pazzani, M., Beyond Independence: Conditions for the Optimality of the Simple Bayesian Classifier, in Proc. Machine Learning: Proceedings of the $13^{\text {th }}$ International Conference, L. Saitta ed., Morgan 
Kaufmann Publishers Inc., 1996, pp. 105-112.

[Dougherty 95]

Dougherty, J., Kohavi, R. \& Sahami, M., Supervised and Unsupervised Discretizations of Continuous Features, in Proc. of the 12th International Conference on Machine Learning, Morgan Kaufmann Publishers, 1995, pp. 194202.

[Draper 95]

Draper, D., Assessment and Propagation of Model Uncertainty (with Discussion), Journal Of The Royal Statistical Society (Series B), 1995, pp. 4597.

[Duran 74] Duran, B.S. \& Odel, P.L., Cluster Analysis: a Survey, v. 100 of Lecture Notes in Economics and Mathematical Systems, Springer-Verlag, 1974.

[EMF 82]

[Fayyad 93]

Energy Modeling Forum, World Oil: Summary Report, EMF Report 6, Energy Modeling Forum, Stanford University, Stanford, CA, 1982.

Fayyad, U.M. \& Irani, K.B., Multi-interval Discretization of Continuous-Valued Attributes for Classification Learning, in Proc. of the 13th International Conference on Machine Learning, Morgan Kaufmann Publishers, 1993, pp. 1022-1027.

[Fayyad 96a] Fayyad, U.M., Piatesky-Shapiro, G., Smyth, P. \& Uthurusamy, R., Advanced in Knowledge and Data Mining, AAAI/MIT Press, 1996.

[Fayyad 96b] Fayyad, U.M., Piatesky-Shapiro, G. \& Smyth, P., The KDD Process for Extracting Useful Knowledge from Volumes of Data, Communications of the ACM, v. 39, n. 11, November 1996, pp. 27-34.

[Fayyad 96c] Fayyad, U.M., Data Mining and Knowledge Discovery: Making Sense Out of Data, IEEE EXPERT, October 1996, pp. 20-25.

[Fayyad 97]

[Félix 98a]

Fayyad, U.M. \& Simoudis, E., DATA MINING and Knowledge Discovery, in Proc. $15^{\mathrm{TH}}$ International Joint Conference on Artificial Intelligence, Nagoya, Japan, 1997, pp. A-7.

Félix, L.C.M., Rezende, S.O, Doi, C.Y., Paula, M.F. \& Romanato, M.J., $M L C++$ Biblioteca de Aprendizado de Máquina em $C++$, Relatório Técnico No. 72, ISSN-0103-2569, ICMC-USP, São Carlos, SP, Brasil, 1998.

[Félix 98b]

Félix, L.C.M., Rezende, S.O, Monard, M.C. \& Calkins, C.W., Transforming a Regression Problem into a Classification Problem Observing the Discretization Process: A Case Study, Relatório Técnico No. 76, ISSN-0103-2569, ICMCUSP, São Carlos, SP, Brasil, 1998.

[Friedman 96] Friedman, J., Kohavi, R. \& Yun, Y., Lazy Decision Trees, in Proc. $13^{\text {th }}$ National Conference on Artificial Intelligence, AAAI Press and the MIT Press., 1996.

[Gansner 93]

Gansner, E. R., Koutsofios, E., North, S.C., \& Vo K.P., A Technique for Drawing Directed Graphs, IEEE Transactions on Software Engineering, 1993, pp. 214-230.

[Glymour 97]

Glymour, C., Madigan, D., Pregibon, D. \& Padhraic, S., Statistical Themes and Lessons for Data Mining, Data Mining and Knowledge Discovery v. 1, Kluwer 
[Guzmán 96]

[Han 92]

[Harrison 93]

[Heckerman 97]

[Hertz 91]

[Holland 86]

[Holsheimer 94]

[Holte 93]

[Ileath 93]

[Inmon 96]

[Karsten 95]

[Kerber 92]

[Kohavi 94a]

[Kohavi 94b]

[Kohavi 95]
Guzmán, A.A., Uso y Diseño de Mineros de Datos, Revista Soluciones Avanzadas, a. 4, n. 34, México, Junio 1996, pp. 67-72.

Han, J., Cai, Y. \& Cercone, N., Knowledge Discovery in Databases: An Attribute-Oriented Approach, in Proc. of the $18^{\text {th }}$ VLDB Conference, Vancouver, British Columbia, Canada, 1992, pp. 547-559.

Harrison, D., Backing Up, Network Computing, October, 1993, pp. 98-104.

Heckerman, D., Approach for Learning Causal Networks, in Proc. $11^{\text {th }}$ Conference on Uncertainly in Artificial Intelligence, Ed. Morgan Kaufmann, Montreal, Canada, 1995.

Hertz, J., Krogh, A. \& Palmer, R.G., Introduction to the Theory of Neural Computation, Addison Wesley, 1991.

Holland, J.H., Holyoak, K.J., Nisbett, R.E. \& Thagard, P.R., Induction: Processes of Inference, Learning and Discovery. Computational Models of Cognition and Perception, MIT Press, Cambridge, 1986.

Holsheimer, M. \& Siebes, A, Data Mining. The Search for Knowledge in Databases, Technical Report CS-R9406, ISSN 0169-118X, Centrum voor Wiskunde en Informatica, Amsterdam, The Netherlands, 1994.

Holte, R.C., Very Simple Classification Rules Perform Well on most Commonly Used Datasets, Machine Learning 11, 1993, pp. 63-90.

Ileath, D., Kasif,'S. \& Salzberg, S., Induction of Oblique Decision Trees, in $13^{\text {th }}$ International Joint Conference on Artificial Intelligenge, Morgan Kaufmann, 1993, pp. 1002-1007.

Inmon, W.H., Bulding the Operationsl Data Store, Ed. John Wiley \& Sons, 1996.

Karsten, M.D. \& Focardi, S., Technology Overview: A Report on Data Mining, France-Swiss CSCS TR-9502, Swiss Scientific Computing Center, May, 1995.

Kerber, R., ChiMerge: Discretization of Numeric Attributes, in Proc. of the $10^{\text {th }}$ National Conference on Artificial Intelligence, 1992, pp. 123-127.

Kohavi, R., Bottom-Up Induction of Oblivious, Read-Once Decision Graphs, in F. Bergadano \& L. D. Raedt, eds, Proceedings of the European Conference on Machine Learning, 1994, pp. 154-169.

Kohavi, R., John, G., Long, R., Manley, D. \& Pfleger, K., MLC++: A Machine Learning Library in $C++$, in Tool with Artificial Intelligence, IEEE Computer Society Press, 1994, pp. 740-743.

Kohavi, R., The Power of Decision Tables, in N. Lavrac \& S. Wrobel, eds, Proceedings of the European Conference on Machine Learning, Lecture Notes in Artificial Intelligence, Springer Verlag, Berlin, Heidelberg, New York, v. 914, 1995, pp. 174-189. 
[Kohavi 97]

[Langley 92]

[Langley 95]

[Lenarcik 92]

[Lenarcik 93]

[Lenarcik 95]

[Littlestone 88]

[Lobô 96]

[Lobô 97]

[Mannila 97]

[Michalski 83a]

[Michalski 83b]

[Michalski 83c]

[Michalski 86a]
Kohavi, R. \& Kunz, C., Option Decision Trees with Majority Votes, in Proc. of the Fourteenth International Conference of Machine Learning, D. Fisher ed., Morgan Kaufmann, 1997.

Langley, P., Iba, W. \& Thompson, K., An Analysis of Bayesian Classifiers, in Proc. $10^{\text {th }}$ National Conference on Artificial Intelligence, AAAI Press and MTT Press, 1992, pp. 223-228.

Langley, P. \& Simmon, H.A., Applications of Machine Learning and Rule Induction, Communications of the ACM 38 (11), 1995, pp. 55-64.

Lenarcik, A. \& Piasta, Z., Discretization of Condition Attribute Space, in: Slowinski R., (ed.), Intelligence Decision Support. Handbook of Applications and Advances of the Rough Set Theory, Kluwer Academic Publishers, Dordrecht, 1992, pp. 373-389.

Lenarcik, A. \& Piasta, Z., Probabilistic Approach to Decision Algorithm Generation in the Case of Continuous Condition Attributes, Foundations of Computing and Decision Sciences, v. 18, n. 3-4, Poznan, Poland, 1993, pp. 213224.

Lenarcik, A. \& Piasta, Z., Minimizing the Number of Rules in Deterministic Rough Classifiers, in Lin, T.Y. \& Wildberger, A.M., (eds.), Soft Computing, Society for Computer Simulation, San Diego, 1995, pp. 32-35.

Littlestone, N., Learning Quickly when Irrelevant Attributes Abound: A new Linear-threshold Algorithm, Machine Learning 2, 1988, pp. 285-318.

Lobô, R.B., Programa de Melhoramento Genético da Raça Nelore, Faculdade de Medicina de Ribeirão Preto, Universidade de São Paulo, Ribeirão Preto, 1996, pp. 7-8.

Lobô, R.B. \& Bezerra, L.A.F., Avaliação Genética de Animais Jovens, Touros e Matrizes, Faculdade de Medicina de Ribeirão Preto, Universidade de São Paulo, Ribeirão Preto, 1997, pp. 1-2.

Mannila, H., Methods and Problems in Data Mining, in Proc. International Conference on Database Theory, Ed. Springer-Verlag, Delphi, Greece, 1997.

Michalski, R.S. \& Stepp, R.E., Learning from Observation: Conceptual Clustering, [Michalski 83b], pp. 331-363.

Michalski, R.S., Carbonell, J.G. \& Mitchell, T.M., (eds.), Machine Learning: An Artificial Intelligence Approach, v. 1, Morgan Kaufmann, San Mateo, California, 1983.

Michalski, R.S., A Theory and Methodology of Inductive Learning, in [Michalski 83b], pp. 83-134.

Michalski, R.S., Carbonell, J.G. \& Mitchell, T.M., (eds.), Machine Learning: An Artificial Intelligence Approach, v. 2, Morgan Kaufmann, San Mateo, California, 1986. 
[Minsky 75]

[Mooney 92]

[Muggleton 92]

[Murthy 94]

[Näeher 92]

[Nguyen 95]

[Nilsson 82]

[Oliveira 98]

[Pfahringer 95]

[Piatetsky-Shapiro 91]

[PROZEBU 84]

[Quinlan 86a]

[Quinlan 86b]

$\times$ [Quinlan 87a]

[Quinlan 87b]
Minsky, M., A Framework for Representating Knowledge, in Patrick Henry Winston, editor, The Psychology of Computer Vision, McGraw-Hill, New York, 1975, pp. $211-277$.

Mooney, R.J., Encouraging Experimental Results on Learning CNF, Technical Report, University of Texas, October 1992.

Muggleton, S., Inductive Logic Programming, volume 38 of A.P.I.C. series, Academic Press Ltd., London, 1992.

Murthy, S.K., Kasif, S. \& Salzberg, S., A System for the Induction of Oblique Decision Trees, Journal of Artificial Intelligence Research 2, 1994, pp. 1-33.

Naeher, S., LEDA: A Library of Efficient Data Types and Algorithms, MaxPlanck-Institut fuer Informatik, IM Stadtwald, D-66123 Saarbruecken, FRG, 3.0 edition, 1992.

Nguyen, S.H. \& Skowron, A., Quantization of Real Value Attributes: Rough Set and Boolean Reasoning Approach, in Proc. of the Second Joint Annual Conference on Information Sciences, Wrightsville Beach, North Carolina, 1995, pp. 34-37.

Nilsson, N.J., Principles of Artificial Intelligence, Symbolic Computation, Springer-Verlag, 1982.

Oliveira, R.B.T \& Rezende, S.O., Ferramentas de Visualização de Dados do MineSet, Relatório Técnico No. 71, ISSN 0103-2569, ICMC-USP, São Carlos, SP, Brasil, 1998.

Pfahringer, B., Compression-based Discretization of Continuous Attributes, in Prieditis A. and Russel S., (eds.), Proceedings of the Twelfth International Conference on Machine Learning, Morgan Kaufmann Publishers, 1995.

Piatetsky-Shapiro, G., Discovery, Analysis, and Presentation of Strong Rules, in Piatetsky-Shapiro, G. \& Frawley, W.J., editors, Knowledge Discovery in Databases, AAAI Press, Menlo Park, California, 1991, pp. 229-248.

Ministério da Agricultura - Secretaria Nacional de Produção Agropecuária, Projeto de Melhoramento Genético de Zabuinocultura: PROZEBU, 1984/1988, Brasília, 1984, pp. 168.

Quinlan, J.R., The Effect of Noise on Concept Learning, in [Michalski 86a], pp. 149-166.

Quinlan, J.R., Induction of Decision Trees, Machine Learning 1, Reprinted in Shavlik and Dietterich (eds.) Readings in Machine Learning, 1986, pp. 81-106.

Quinlan, J.R., Simplifying Decision Trees, International Journal of Man-Machine Studies, n. 27, 1987, pp. 221-234.

Quinlan, J.R., Generating Production Rules from Decision Trees, in Proc. of Fourth International Machine Learning Workshop, Morgan Kaufmann, San Mateo, CA., 1987, pp. 304-307. 
[Quinlan 88]

[Quinlan 93]

[Reis 83]

[Reis 91]

[Rezende 98a]

[Rezende 98b]

[Rivest 87]

[Rogers 95]

[Sammut 86]

[Santiago 87]

[Sills 68]

[Simpson 51]

[Spears 90]

[Susmaga 97]

[Utgoff 89]

[Ventura 94]

[Ventura 95]
Quinlan, J.R., C4.5 Programs for Machine Leaning, Morgan Kaufmann Publishers, CA, 1988.

Quinlan, J.R., C4.5: Programs for Machine Learning, Morgan Kaufmann Publishers, Inc., Los Altos, California, USA, 1993.

Reis, J.C., Interações Genótipo-Ambientes em Bovinos, Exame de qualificação de doutoramento, Ribeirão Preto FMRP-USP, 1983, pp. 16.

Reis, J.C. \& Lobô, R.B., Interações Genótipo-Ambientes nos Animais Domésticos, Brasil, 1991, pp. 19-22.

Rezende, S.O., Paula, M.F. \& Figueiredo, L.F., MineSet, Ferramenta de Data Mining, Relatório Técnico No. 77, ISSN 0103-2569, ICMC-USP, São Carlos, SP, Brasil, 1998.

Rezende, S.O., Oliveira, R.B.T., Félix, L.C.M. \& Rocha, C.A.J., Visualization for Knowledge Discovery in Database, in Proc. of International Conference on Data Mining, Rio de Janeiro, Brazil, Setember, 1998.

Rivest, R.L., Learning Decision Lists, Machine Learning, 1987, pp. 229-246.

Rogers, S.J., Chen, H.C., Kopaska-Merkel, D.C. \& Fang, J.H., Predicting Permeability from Porosity Using Artificial Neural Networks, American Association of Petroleum Geologists Bulletin, v. 79, December 1995, pp. 17861797.

Sammut, C. \& Banerji, R.B., Learning Concepts by Asking Questions, in [Michalski 86a], pp. 167-191.

Santiago, A.A., A Raça Nelore, in Gado Nelore: 100 anos de seleção, São Paulo, Ed. Dos Criadores, 1987, pp. 153-154.

Sills, D.C., William of Ockham, in International Encyclopedia of the Social Sciences, Macmillan Company \& The Free Press, New York, 1968, pp. 269-270.

Simpson, C.H., The Interpretation of Interaction in Contingency Tables, Journal of the Royal Statistical Society (Series B)13, 1951, pp. 238-241.

Spears, W.M. \& De Jong, K., Using Genetic Algorithms for Supervised Concept Learning, in Proc. of tools for AI, 1990.

Susmaga, R, Analyzing Discretizations of Continuos Attributes Given a Monotonic Discrimination Function, Intelligent Data Analysis, Elsevier Science Inc., 1997.

Utgoff, P.E, Incremental Induction of Decision Trees, Machine Learning, 1989, pp. 161-186.

Ventura, D. \& Martinez, T.R., BRACE: A Paradigm for the Discretization of Continuously Valued Data, in Proc. of the Seventh Florida Artificial Intelligence Research Symposium, 1994, pp. 117-121.

Ventura, D. \& Martinez, T.R., An Empirical Comparison of Discretization 
Methods, in Proc. of the Tenth International Symposium on Computer and Information Sciences, 1995, pp. 443-450.

[Walker 87] Walker, M.G, How Feasible is Automated Discovery, IEEE Expert, Spring 1987, pp. $69-82$.

[Way 91]

Way, J. \& Smith, B.A., The Evolution of Synthetic Aperture Raaar systems and their Progression to the EOS SAR, IEEE Transactions on Geoscience and Remote Sensing 29(6), 1991, pp. 962-985.

[Wen 95]

Wen, S.W., Hernandez, R. \& Naylor, C.D., Pitfalls in Nonrandomized Studies: The Case of Incidental Appendectomy with Open Cholecystectomy, Journal of the American Medical Association 274, 1995, pp. 1687-1691.

[Wettschereck 94] Wettschereck, D., A Study of Distance-Based Machine Learning Algorithms, $\mathrm{PhD}$ thesis, Oregon State University, 1994.

[Wiederhold 86] Wiederhold, G.C.M., Walker, M.G., Blum, R.L. \& Downs, S.M., Acquisition of Knowledge from Data, in ACM SIGART International Symposium on Methodologies for Intelligent Systems, Knoxville, Tennessee, 1986, pp. 74-84.

[WRRC 98] Water Resource Research Center, Glossary of Organizations and Acronyms, College of Agriculture, The University of Arizona, 1998, [Online] Available. URL: http://Ag.Arizona.Edu/Azwater/Gloss.html 